\title{
UNESP- Universidade Estadual Paulista "Júlio de Mesquita Filho"

Influência do tempo de exposição à obesidade sobre a expressão gênica e protéica do sistema regulador do trânsito de cálcio miocárdico

Ana Paula Lima Leopoldo 


\title{
UNESP- Universidade Estadual Paulista \\ "Júlio de Mesquita Filho" \\ unesp

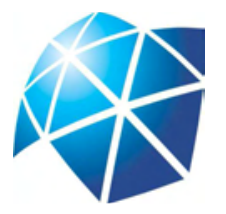 \\ Faculdade de Medicina de Botucatu \\ Departamento de Clínica Médica \\ Laboratório Experimental da Clínica Médica
}

\section{Influêncía do tempo de exposição à obesidade}

sobre a expressão gênica e protéica do sistema

regulador do trânsito de cálcio miocárdico

\author{
Ana Paula Lima Leopoldo
}

Tese apresentada à Faculdade de Medicina, Universidade Estadual Paulista "Julio de Mesquita Filho"

Campus de Botucatu, para obtenção do título de Doutor em Fisiopatologia em Clínica Médica "Ciências da Saúde"

ORIENTADOR: Prof. Dr. Antonio Carlos Cicogna

CO-ORIENTADORA: Profa. Dra. Patrícia Chakur Brum 
FICHA CATALOGRÁFICA ELABORADA PELA SEÇÃO DE AQUIS. E TRAT. DA INFORMAÇÃO DIVISÃO TÉCNICA DE BIBLIOTECA E DOCUMENTAÇÃO - CAMPUS DE BOTUCATU - UNESP BIBLIOTECÁRIA RESPONSÁVEL: ROSEMEIRE APARECIDA VICENTE

Leopoldo, Ana Paula Lima.

Influência do tempo de exposição à obesidade sobre a expressão gênica e protéica do sistema regulador do trânsito de cálcio miocárdico / Ana

Paula Lima Leopoldo. - Botucatu, 2010

Tese (doutorado) - Faculdade de Medicina de Botucatu, Universidade Estadual Paulista, 2010.

Orientador: Prof. Dr. Antonio Carlos Cicogna

Co-orientador: Prof ${ }^{\mathrm{a}}$. Dra ${ }^{\mathrm{a}}$. Patrícia Chakur Brum

Assunto CAPES: 40101002

1. Coração - Fisiopatologia. 2. Obesidade - Fisiopatologia. 3. Hormônios tireoidianos.

Palavras-chave: coração; dieta hiperlipídica; hormônio tireoidiano; obesidade; trânsito de $\mathrm{Ca}^{+2}$ 
Dedico este trabalho às pessoas mais importantes da minha vida,

\section{À toda minha família}

Que soube compreender todos os momentos em que estive ausente, obrigada pelos constantes incentivos e torcida pelo meu futuro. Vocês são essenciais!

\section{Aos meus Pais}

Significado de devoção e coragem, com o exemplo deles, aprendi que tudo é possível com força de vontade e pensamento positivo, e, sobretudo, a importância da dignidade e do caráter. Amor eterno!

\section{Ao meu marido, André,}

Pelo privilégio de ter você ao meu lado, sempre carinhoso, otimista e compreensivo até nos momentos mais difíceis. Pelos momentos de esperança que pensa, junto comigo, no nosso futuro. Amo você!

Há três coisas fundamentais para a felicidade:

alguma coisa para fazer, alguém para amare algo para esperar. 


\section{AGRADECIMENTIOS ESPECIAIS}

Ao meu orientador, Prof. Dr. Antonio Carlos Cicogna, pela oportunidade, credibilidade e por ter me ensinado que ciência não se faz em poucas horas, mas sim em investigação científica baseada na observação e experimentação, com perseverança e muita dedicação.

Minha eterna gratidão!

Ao Prof. Dr. Carlos Roberto Padovani, por compartilhar de forma exemplar seus conhecimentos. Obrigada por sempre acreditar em nosso aprendizado e por estimular a busca de oportunidades científicas e de vida.

À Profa. Dra. Célia Regina Nogueira, por ter estruturado e disponibilizado o laboratório de biologia molecular acreditando, sempre, no trabalho baseado em cooperação. Obrigada pela sua compreensão, acessibilidade e, principalmente, amizade.

À Profa. Dra. Maeli Dal Pai Silva, pela constante prontidão em nos receber em seu laboratório, tanto para utilização quanto para o esclarecimento das dúvidas. Obrigada pela sua estima e consideração.

À Profa. Dra. Patrícia Chakur Brum, por sempre me receber com carinho e atenção em seu laboratório. Obrigada pela oportunidade de aprendizagem e pelo privilégio de sua coorientação.

À Profa. Dra. Alessandra Medeiros, por todo auxílio e paciência no meu aprendizado de Western Blot. Obrigada pela amizade e por ter partilhado comigo seus conhecimentos.

Ao amigo, Prof Dr. Mario Mateus Sugizaki, por todo apoio, amizade e incentivo durante todos esses anos de pós-graduação. Você é co-responsável por essa conquista.

Muito obrigada!

O saber é uma atitude de espírito que se forma lentamente ao contato dos que sabem. 


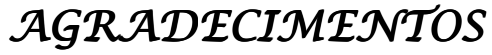

Esta pesquisa é resultado do trabalho em conjunto, cooperação e amizade de muitas pessoas. Muito obrigada a todos aqueles cujo apoio e amizade fizeram a diferença. O trabalho foi grande, mas, pela presença de pessoas inestimáveis como vocês, foi permeado de alegrias e muitas risadas.

Ter amigos é não estar só.

Ter amigos é poder partilhar

segredos, lágrimas e sorrisos.

Aos amigos do grupo do Professor Cicogna, que compartilharam das mesmas dificuldades e expectativas: André Nascimento, Dijon, Silvio, Danielle, Carlos, Paulinha, Adriana, Albano, Carolina, Loreta e Olga. Obrigada por toda colaboração no desenvolvimento deste trabalho, convivência e amizade.

Aos amigos do laboratório e da pós-graduação: Renata (Fia), Lidiane (Suflê), Fabiana (Fafa), Francieli (Paina), Marcelo (Russo), Ricardo (Clone), Paula (Tata), Aline (Morango), Cristiana, Sandro (BG), Maria Tereza (T3), Marcos (Meleca), Paula Schmidt, Rosangela, Juliana (Ju), Paulo (Chucky), Camila Bonomo, Daniele, Camila, Natasha, Fernanda, Miriane e Regiane. Obrigada pela fundamental contribuição de me fazerem rir, mesmo quando a vontade era de chorar.

Um agradecimento especial e carinhoso aos amigos e funcionários do Laboratório Experimental da Clínica Médica, José Carlos Georgete, Mário Bruno, Elenize, Camila, Corina, Sueli Clara, Sueli Garcia, Vitor, José Aparecido, De Lalla, Rogério e Ângelo. Obrigada pela convivência, cooperação e apoio imensuráveis durante esta etapa da minha vida.

À Sandra Fábio, pelo companheirismo, pelos constantes ensinamentos das fórmulas e cálculos e pela importante contribuição na dosagem bioquímica deste trabalho. Obrigada por tornar o dia-a-dia do laboratório mais descontraído. 
Aos professores Dr Katashi Okoshi e Dra Marina Politi Okoshi por toda colaboração, atenção e estima nestes anos de pós-graduação.

Aos professores Dra Célia Regina Nogueira e Dr. Leonardo Antonio Mamede Zornoff pelas críticas e sugestões durante o exame de qualificação, que contribuíram para o aprimoramento deste trabalho.

Aos atenciosos e prestativos amigos e funcionários da pós-graduação: Regina Célia Spadin, Nathanael Pinheiro Salles, Janete Aparecida Herculano Nunes Silva, Andrea Paula Longo Devidé, e Lílian Cristina Nadal Bianchi Nunes. Obrigada pelo carinho com que vocês nos recebem e auxiliam em todos os momentos.

Aos atenciosos e prestativos amigos e funcionários do departamento de Clínica Médica: Ana Maria Mengue, Alexandre Luís Loureiro, Renato Borges Pereira, Elisangela Aparecida da Silva, Laura Andrade Câmara e Bruno José Fajiolli. Obrigada pelo auxílio, disponibilidade e atenção durante estes anos de pós-graduação.

A todos meus $A M I G O S$ de longe, porém nunca distantes, que sempre estiveram na torcida, e aos amigos de Botucatu, obrigada por compreenderem esta fase da minha vida. Muitas vezes fui ausente, mas sempre com vocês em meu coração.

À FAPESP pelo auxílio financeiro. 


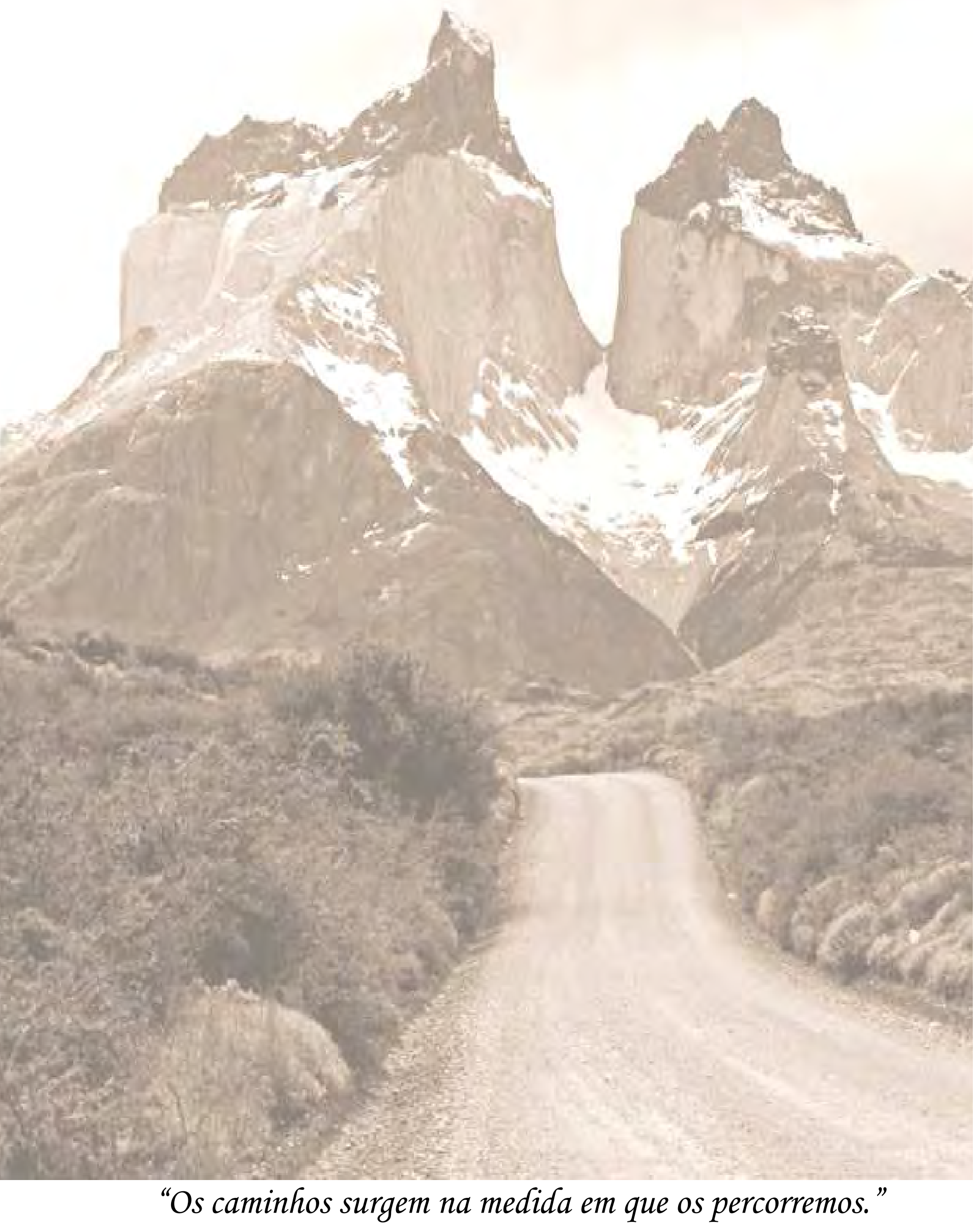

Werner Sprenger 


\section{RESUMO}

Atualmente mais de um bilhão de pessoas apresentam sobrepeso, sendo que, mais de 30\% desta população é obesa. Diversas alterações estruturais e funcionais do coração em humanos tem sido frequentemente associadas com a obesidade. Modelos experimentais, por dieta hiperlipídica, têm sido utilizados para estudar a relação obesidade e coração. O trânsito de cálcio miocárdico tem sido extensivamente estudado em diversos modelos experimentais e frequentemente relacionado com disfunção cardíaca. Entretanto, a literatura mostra escassez de estudos que avaliaram a relação entre o tempo de exposição à obesidade por dieta hiperlipídica, o RNAm e as proteínas envolvidas na homeostase de $\mathrm{Ca}^{+2}$ miocárdico. Além disso, pesquisas relatam a influência dos hormônios tireoidianos nestas proteínas, podendo acarretar alterações na contração e relaxamento cardíaco. O objetivo principal desse estudo foi testar a hipótese que o aumento no tempo de exposição à obesidade acarreta diminuição na expressão e/ou fosforilação das proteínas e dos respectivos níveis de RNAm relacionados com o trânsito de $\mathrm{Ca}^{+2}$ miocárdico. Este estudo teve como objetivo secundário constatar se a diminuição na expressão gênica foi acompanhada de redução dos níveis hormonais tireoidianos. Os períodos de dieta hiperlipídica, utilizados nesse estudo, foram eficientes em promover obesidade, desde que o índice de adiposidade utilizado para caracterizar os animais como obesos foi 79,5\%, 82\% e 69,5\% maior do que os respectivos controles, após 15, 30 e 45 semanas. O tempo de exposição à dieta hiperlipídica não promoveu alterações na gordura corporal total entre os grupos obesos; este resultado indica que, neste trabalho, não houve aumento na intensidade da obesidade ao longo do tempo. Neste estudo foram visualizadas algumas comorbidades frequentemente associadas com a obesidade experimental, como intolerância à glicose, resistência à insulina, hiperinsulinemia, hiperleptinemia e dislipidemia; entretanto, não houve alterações no comportamento da pressão arterial sistólica final. A obesidade promoveu aumento nos níveis séricos de TSH ao longo do tempo e diminuição dos níveis de T4 acompanhado de elevação das concentrações séricas de T3. Os resultados da estrutura do coração post mortem mostraram que a obesidade acarretou aumento do coração, VD e do AT nos três momentos, apesar da não significância estatística no peso do coração na $45^{\mathrm{a}}$ semana ( $\left.\mathrm{p}=0,052\right)$; além disso, houve remodelação do VE nos momentos 15 e 30 semanas. Contudo, a análise da área seccional transversa do miócito mostrou aumento apenas na $30^{\mathrm{a}}$ semana de obesidade. Embora a obesidade tenha alterado os níveis de RNAm do CANAL L e RyR, entre os grupos controle e obeso e ao longo do tempo, este comportamento não foi visualizado na expressão protéica de CANAL L. Neste estudo, enquanto a obesidade 
na $15^{\mathrm{a}}$ e $45^{\mathrm{a}}$ semana, acarretou diminuição dos níveis de RNAm da SERCA, do NCX e da CSQ em relação aos respectivos controles, na $30^{\mathrm{a}}$ semana de obesidade ocorreu elevação dos níveis de SERCA, NCX e da CSQ em relação ao $\mathrm{C}_{30}$. Entretanto, esta alteração no RNAm não foi acompanhada de alterações na expressão protéica de SERCA e CSQ. Os níveis de RNAm de PLB foram diminuídos após 15 semanas de obesidade e elevados na 30 a semana entre os grupos. Os níveis protéicos de PLB, PLB thr17 e a razão PLB thr17/PLB não sofreram alterações decorrente da obesidade. O principal achado deste estudo é que a obesidade, após 15 e 30 semanas, acarretou diminuição nos níveis de pPLB ser16. A análise de correlação mostrou que não ocorreu associação significativa entre os níveis de T3 e o RNAm das proteínas do trânsito de $\mathrm{Ca}^{+2}$. Um fato importante, visualizado neste estudo, foi a divergência de comportamento entre os níveis de RNAm e a expressão protéica. Enquanto os RNAm variaram na dependência do tratamento e tempo experimental, as proteínas mostraram comportamento igual entre os grupos e os momentos. Diante destes resultados podemos concluir, que o tempo de exposição à obesidade promove diferentes respostas na expressão de RNAm e modifica apenas a proteína PLB fosforilada na serina 16. Os níveis hormonais tireoidianos não influenciam a expressão gênica das proteínas do trânsito de $\mathrm{Ca}^{2+}$ miocárdico.

Palavras-chave: obesidade, dieta hiperlipídica, coração, hormônio tireoidiano, trânsito de $\mathrm{Ca}^{2+}$ 


\section{ABSTRACT}

Currently, greater than one billion people are overweight and $30 \%$ of the population is obese. Several structural and functional changes of the heart have often been associated with human obesity. Experimental models for high-fat diets have been used to study the relationship between obesity and the heart. Myocardial calcium $\left(\mathrm{Ca}^{2+}\right)$ handling has been extensively studied in several experimental models and has often been shown to be related to cardiac dysfunction. However, few studies have evaluated the relationship between the duration of exposure to obesity and a high-fat diet, and mRNA and proteins involved in homeostasis of myocardial $\mathrm{Ca}^{2+}$. Some studies have reported the influence of thyroid hormones on these proteins, which may cause changes in cardiac contraction and relaxation. The main objective of the current study was to test the hypothesis that the increased duration of exposure to obesity leads to a reduction in the expression and/or phosphorylation of proteins and mRNA levels related to myocardial $\mathrm{Ca}^{2+}$ handling. This study had, as additional objective, to verify if the decrease in mRNA expression was accompanied by a reduction in thyroid hormone levels. The periods of exposure to a high-fat diet used in this study were effective in promoting obesity since the adiposity index used to characterize animals as obese was $79.5 \%, 82 \%$, and $69.5 \%$ higher than controls after 15, 30, and 45 weeks, respectively. The duration of exposure to a high-fat diet did not change the total body fat between the obese groups. This result indicates that there was not an increase in the intensity of obesity over time. In this study, some co-morbidities often associated with experimental obesity existed, such as glucose intolerance, insulin resistance, hyperinsulinemia, hyperleptinemia, and dyslipidemia; however, the co-morbidities were not associated with changes in systolic blood pressure. Obesity promoted an increase in serum TSH over time and a decrease in T4 levels accompanied by elevated serum concentrations of T3. The cardiac structure results post-death showed that obesity caused an increase in the heart, and right ventricular and atrium weights at the 3 evaluation times, although the change in heart weight at 45 weeks was not statistically significant $(\mathrm{p}=0.052)$. In addition, there was left ventricular remodeling at 15 and 30 weeks. However, the analysis of the cross-sectional area of myocytes showed an increase in obesity at 30 weeks. Although obesity altered the mRNA levels of the ryanodine receptor (RyR) and L-type $\mathrm{Ca}^{2+}$ channels between obese and control groups over time, this change was not shown in the protein expression of L-type $\mathrm{Ca}^{2+}$ channels. While obesity at the $15^{\text {th }}$ and $45^{\text {th }}$ weeks resulted in a reduction of mRNA levels of $\mathrm{Ca}^{2+}$ ATP-ase of sarcoplasmic reticulum (SERCA), $\mathrm{Na}^{+} / \mathrm{Ca}^{2+}$ exchanger (NCX), and calsequestrin (CSQ) in relation to respective controls, in the 
$30^{\text {th }}$ week of obesity the mRNA levels of SERCA, NCX, and CSQ were higher than $\mathrm{C}_{30}$. However, the change in mRNA was not accompanied by changes in SERCA and CSQ protein expression. The mRNA levels of phospholamban (PLB) were decreased after 15 weeks of obesity and elevated at 30 weeks between the groups. The protein levels of PLB, PLB phosphorylation at threonine-17 (pPLB thr17), and the ratio between pPLB thr17 and PLB was not changed due to obesity. The main finding of this study was that obesity, after 15 and 30 weeks, resulted in decreased levels of PLB phosphorylation at serine-16 (pPPLB ser16). The correlation analysis showed that there was no significant association between the levels of T3 mRNA and protein of myocardial $\mathrm{Ca}^{2+}$ handling. An important fact observed in this study was the difference in behavior between the levels of mRNA and protein expression. While the mRNA varied depending on the experimental treatment and time of exposure, the proteins were equal among the groups and times of exposure of obesity. In conclusion, the time of exposure to obesity promotes different responses in mRNA expression and modifies only the pPPLB ser16. Thyroid hormone levels do not influence the expression of mRNA and proteins of myocardial $\mathrm{Ca}^{2+}$ handling.

Keywords: obesity, high-fat diet, heart, thyroid hormone, $\mathrm{Ca}^{2+}$ handling 


\section{LISTA DE QUADROS}

Quadro 1- Composição dos macro e micronutrientes das rações $(\%)$.................................. 29

Quadro 2- Ensaios utilizados na PCR em tempo real................................................... 40

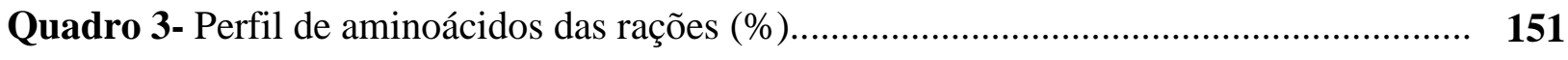

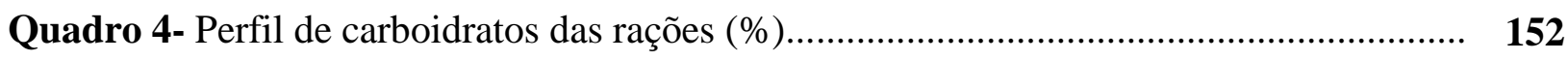

Quadro 5- Perfil de ácidos graxos saturados e insaturados das rações $(\%)$.......................... 153 


\section{LISTA DE FIGURAS}

Figura 1. Evolução semanal do peso corporal dos animais controle e obeso.

Figura 2. Pressão arterial sistólica final dos animais controle e obeso submetidos à 15 semanas de tratamento.

Figura 3. Teste de tolerância à glicose dos animais controle e obeso submetidos à 15 semanas de tratamento

Figura 4. Área glicêmica, obtida no teste de tolerância à glicose, dos animais controle e obeso obeso submetidos à 15 semanas de tratamento.

Figura 5. Índice HOMA-IR dos animais controle e obeso submetidos à 15 semanas de tratamento.

Figura 6. Níveis séricos de insulina e leptina dos animais controle e obeso submetidos à 15 semanas de tratamento

Figura 7. Níveis séricos de TSH dos animais controle e obeso submetidos à 15 semanas de tratamento

Figura 8. Níveis séricos de T4 dos animais controle e obeso submetidos à 15 semanas de tratamento

Figura 9. Níveis séricos de T3 dos animais controle e obeso submetidos à 15 semanas de tratamento.

Figura 10. Secções transversas de fragmentos do VE dos grupos controle e obeso submetidos à 15 semanas de tratamento

Figura 11. Secções transversas subendocárdicas do ventrículo esquerdo (VE) dos grupos controle e obeso submetidos à 15 semanas de tratamento.

Figura 12. Expressão gênica de CANAL L e RyR no miocárdio dos animais controle e obeso submetidos à 15 semanas de tratamento.

Figura 13. Expressão gênica de SERCA, PLB, NCX e CSQ no miocárdio dos animais controle e obeso submetidos à 15 semanas de tratamento

Figura 14. Expressão protéica de SERCA, PLB, CSQ, CANAL L e a razão SERCA/PLB no miocárdio dos animais controle e obeso submetidos à 15 semanas de tratamento..

Figura 15. Expressão protéica de pPLB thr 17, pPLB ser16 e as razões pPLB thr17/PLB e pPLB ser16/PLB no miocárdio dos animais controle e obeso submetidos à 15 semanas de tratamento. 
Figura 16. Pressão arterial sistólica final dos animais controle e obeso submetidos à 30 semanas de tratamento

Figura 17. Teste de tolerância à glicose dos animais controle e obeso submetidos à 30 semanas de tratamento.

Figura 18. Área glicêmica, obtida no teste de tolerância à glicose, dos animais controle e obeso submetidos à 30 semanas de tratamento

Figura 19. Índice HOMA-IR dos animais controle e obeso submetidos à 30 semanas de tratamento

Figura 20. Níveis séricos de insulina e leptina dos animais controle e obeso submetidos à 30 semanas de tratamento.

Figura 21. Níveis séricos de TSH dos animais controle e obeso submetidos à 30 semanas de tratamento.

Figura 22. Níveis séricos de T4 dos animais controle e obeso submetidos à 30 semanas de tratamento

Figura 23. Níveis séricos de $\mathrm{T} 3$ dos animais controle e obeso submetidos à 30 semanas de tratamento

Figura 24. Secções transversas de fragmentos do VE dos grupos controle e obeso submetidos à 30 semanas de tratamento.

Figura 25. Secções transversas subendocárdicas do ventrículo esquerdo (VE) dos grupos controle e obeso submetidos à 30 semanas de tratamento.

Figura 26. Expressão gênica de CANAL L e RyR no miocárdio dos animais controle e obeso submetidos à 30 semanas de tratamento.

Figura 27. Expressão gênica de SERCA, PLB, NCX e CSQ no miocárdio dos animais controle e obeso submetidos à 30 semanas de tratamento.

Figura 28. Expressão protéica de SERCA, PLB, CSQ, CANAL L e a razão SERCA/PLB no miocárdio dos animais controle e obeso submetidos à 30 semanas de tratamento..

Figura 29. Expressão protéica de pPLB thr 17, pPLB ser16 e as razões pPLB thr17/PLB e pPLB ser16/PLB no miocárdio dos animais controle e obeso submetidos à 30 semanas de tratamento

Figura 30. Pressão arterial sistólica final dos animais controle e obeso submetidos à 45 semanas de tratamento

Figura 31. Teste de tolerância à glicose dos animais controle e obeso submetidos à 45 semanas de tratamento 
Figura 32. Área glicêmica, obtida no teste de tolerância à glicose, dos animais controle e obeso submetidos à 45 semanas de tratamento

Figura 33. Índice HOMA-IR dos animais controle e obeso submetidos à 45 semanas de tratamento.

Figura 34. Níveis séricos de insulina e leptina dos animais controle e obeso submetidos à 45 semanas de tratamento.

Figura 35. Níveis séricos de TSH dos animais controle e obeso submetidos à 45 semanas de tratamento.

Figura 36. Níveis séricos de $\mathrm{T} 4$ dos animais controle e obeso submetidos à 45 semanas de tratamento.

Figura 37. Níveis séricos de $\mathrm{T} 3$ dos animais controle e obeso submetidos à 45 semanas de tratamento.

Figura 38. Secções transversas de fragmentos do VE dos grupos controle e obeso submetidos à 45 semanas de tratamento.

Figura 39. Secções transversas subendocárdicas do ventrículo esquerdo (VE) dos grupos controle e obeso submetidos à 45 semanas de tratamento.

Figura 40. Expressão gênica de CANAL L e RyR no miocárdio dos animais controle e obeso submetidos à 45 semanas de tratamento.

Figura 41. Expressão gênica de SERCA, PLB, NCX e CSQ no miocárdio dos animais controle e obeso submetidos à 45 semanas de tratamento

Figura 42. Expressão protéica de SERCA, PLB, CSQ, CANAL L e a razão SERCA/PLB no miocárdio dos animais controle e obeso submetidos à 45 semanas de tratamento..

Figura 43. Expressão protéica de pPLB thr 17, pPLB ser16 e as razões pPLB thr17/PLB e pPLB ser16/PLB no miocárdio dos animais animais controle e obeso submetidos à 45 semanas de tratamento.

Figura 44. Pressão arterial sistólica final dos animais controle e obeso submetidos à 15, 30 e 45 semanas de tratamento.

Figura 45. Área glicêmica, obtida no teste de tolerância à glicose, dos animais controle e obeso submetidos à 15,30 e 45 semanas de tratamento.

Figura 46. Índice HOMA-IR dos animais controle e obeso submetidos à 15, 30 e 45 semanas de tratamento.

Figura 47. Níveis séricos de insulina dos animais controle e obeso submetidos à 15,30 e 45 semanas de tratamento. 
Figura 48. Níveis séricos de leptina dos animais controle e obeso submetidos à 15,30 e 45 semanas de tratamento

Figura 49. Níveis séricos de TSH dos animais controle e obeso submetidos à 15,30 e 45 semanas de tratamento

Figura 50. Níveis séricos de $\mathrm{T} 4$ dos animais controle e obeso submetidos à 15,30 e 45 semanas de tratamento

Figura 51. Níveis séricos de $\mathrm{T} 3$ dos animais controle e obeso submetidos à 15,30 e 45 semanas de tratamento

Figura 52. Área seccional transversa dos miócitos (AST) realizada em fragmentos do ventrículo esquerdo de animais controle e obeso submetidos a 15, 30 e 45 semanas de tratamento

Figura 53. Expressão gênica de SERCA, PLB, RyR, CANAL L, NCX e CSQ normalizados pela $\beta$-actina no miocárdio dos animais controles e obeso submetidos à $15,30 \mathrm{e}$ 45 semanas de tratamento

Figura 54. Expressão protéica de SERCA, PLB, CSQ CANAL L e razão SERCA/PLB normalizados pela $\beta$-actina no miocárdio dos animais controles e obeso submetidos à 15,30 e 45 semanas de tratamento.

Figura 55. Expressão protéica de pPLB Ser16, pPLB Thr17 e as razões pPLB Ser16/PLB e pPLB Thr17/PLB normalizados pela $\beta$-actina no miocárdio dos animais controles e obeso submetidos à 15, 30 e 45 semanas de tratamento.

Figura 56. Resumo das vias de sinalização da insulina

Figura 57. Resumo da via de atuação da leptina.

Figura 58. Resumo das vias de sinalização hipertrófica em cardiomiócitos.

Figura 59. Resumo da cascata de ativação $\beta$-adrenérgica em cardiomiócitos.

Figura 60. Fatores envolvidos na sinalização transcricional. 


\section{LISTA DE TABELAS}

Tabela 1. Perfil nutricional no momento inicial de obesidade.............................................. 47

Tabela 2. Perfil nutricional após 15 semanas...................................................................... 49

Tabela 3. Estrutura macroscópica cardíaca post mortem após 15 semanas............................... $\quad 55$

Tabela 4. Teor de água nos tecidos cardíaco, pulmonar e hepático após 15 semanas................ $\quad 60$

Tabela 5. Perfil nutricional após 30 semanas..................................................................... 62

Tabela 6. Estrutura macroscópica cardíaca post mortem após 30 semanas.............................. $\quad 69$

Tabela 7. Teor de água nos tecidos cardíaco, pulmonar e hepático após 30 semanas............... 74

Tabela 8. Perfil nutricional após 45 semanas ............................................................. $\quad \mathbf{7 6}$

Tabela 9. Estrutura macroscópica cardíaca post mortem após 45 semanas............................. $\quad 83$

Tabela 10. Teor de água nos tecidos cardíaco, pulmonar e hepático após 45 semanas ............. $\quad \mathbf{8 8}$

Tabela 11. Perfil nutricional após 15,30 e 45 semanas ....................................................... 91

Tabela 12. Estrutura macroscópica cardíaca post mortem após 15, 30 e 45 semanas.................. 101

Tabela 13. Medida de associação linear de Pearson entre os níveis de T3 e expressão gênica após 15,30 e 45 semanas........................................................................... $\mathbf{1 0 5}$

Tabela 14. Teor de água nos tecidos cardíacos, pulmonar e hepático após 15, 30 e 45 semanas. 109 


\section{SUMÁRIO}

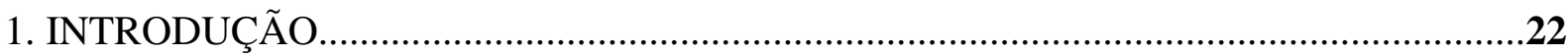

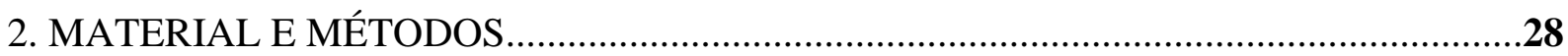

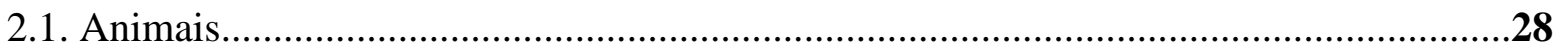

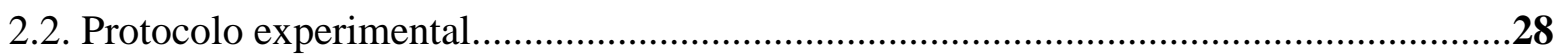

2.2.1. Composição das rações padrão e hiperlipídica...................................................29

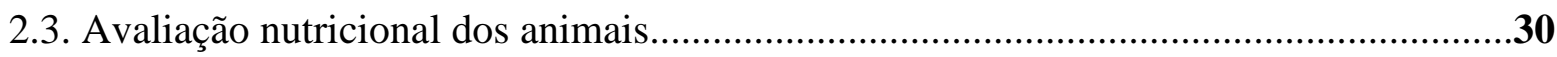

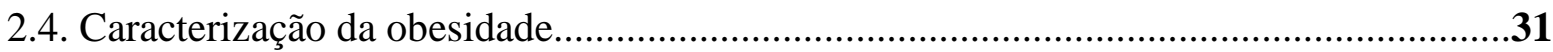

2.5. Determinação do momento inicial de obesidade.........................................................31

2.6. Constituição dos grupos controle e obeso................................................................31

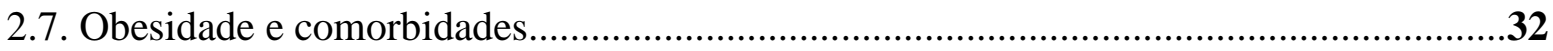

2.7.1. Hipertensão arterial sistêmica..........................................................................32

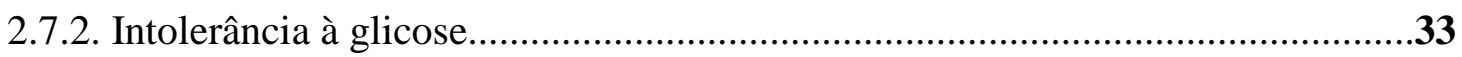

2.7.3. Resistência sistêmica à insulina.......................................................................33

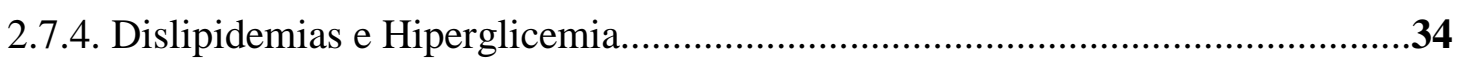

2.7.5. Hiperinsulinemia e Hiperleptinemia..............................................................34

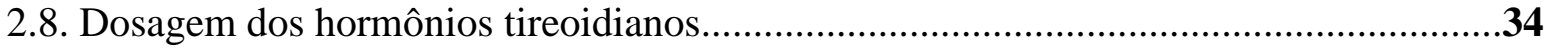

2.9. Caracterização da remodelação cardíaca...................................................................35

2.9.1. Estrutura do coração post mortem......................................................................35

2.9.2. Área seccional transversa do miócito.............................................................35

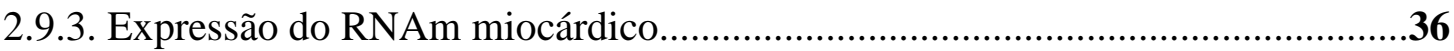

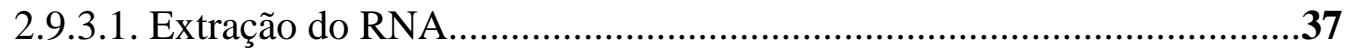

2.9.3.2. Transcrição reversa do RNA (RT).................................................38 
2.9.3.3. PCR em tempo real.

2.9.4. Expressão de proteínas miocárdicas.

2.9.4.1. Extração das proteínas miocárdicas.....................................................41

2.9.4.2. Eletroforese em gel...............................................................41

2.9.4.3. Transferência e identificação das proteínas.........................................42

2.9.4.3.1. Anticorpos primários utilizados..........................................43

2.9.4.3.2. Anticorpo de normalização...............................................43

2.9.4.3.3. Anticorpos secundários utilizados........................................44

2.9.4.4. Quantificação das proteínas...............................................................44

2.10. Determinação do teor de água nos tecidos cardíaco, pulmonar e hepático...................44

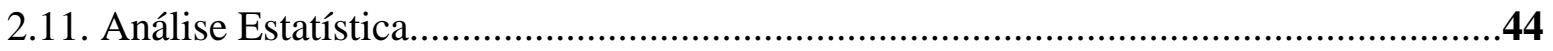

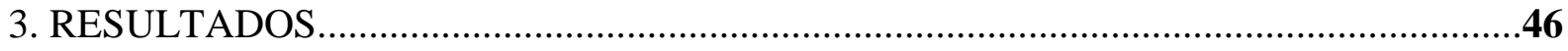

3.1. Caracterização do momento inicial de obesidade ....................................................46

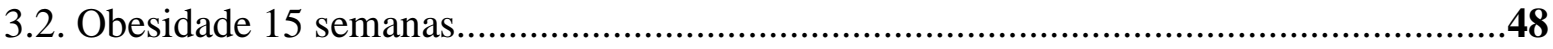

3.2.1. Composição dos grupos controle e obeso........................................................48

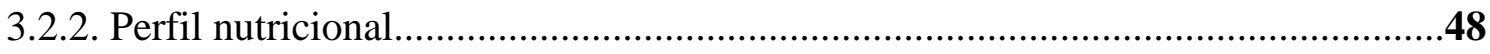

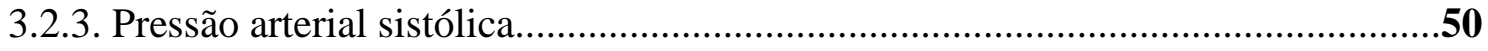

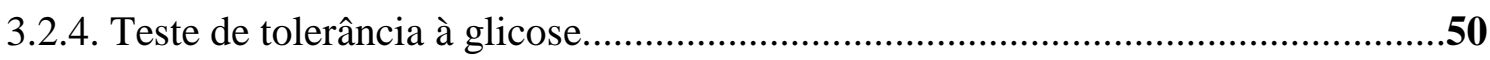

3.2.5. Índice de resistência à insulina...........................................................................51

3.2.6. Análise sérica dos hormônios insulina e leptina..................................................52

3.2.7. Análise sérica dos hormônios tireoidianos.....................................................53

3.2.8. Estrutura do coração post mortem.....................................................................54

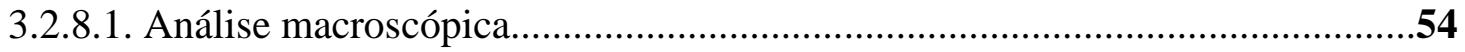


3.2.9. Expressão de RNAm miocárdico..............................................................57

3.2.10. Expressão das proteínas miocárdicas............................................................58

3.2.11. Determinação do teor de água nos tecido cardíaco, pulmonar e hepático.............59

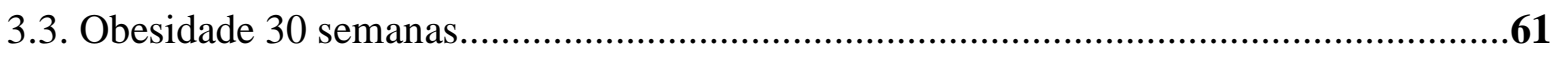

3.3.1. Composição dos grupos controle e obeso.......................................................61

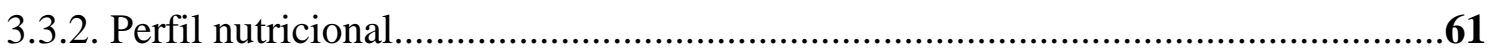

3.3.3. Pressão arterial sistólica............................................................................63

3.3.4. Teste de tolerância à glicose.......................................................................63

3.3.5. Índice de resistência à insulina......................................................................64

3.3.6. Análise sérica dos hormônios insulina e leptina.................................................64

3.3.7. Análise sérica dos hormônios tireoidianos...........................................................66

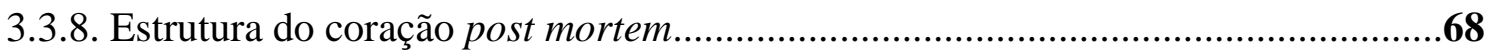

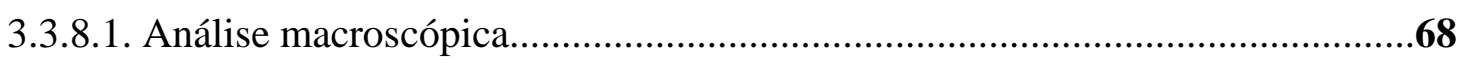

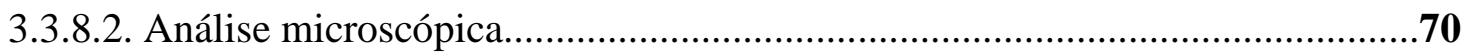

3.3.9. Expressão de RNAm miocárdico................................................................

3.3.10. Expressão das proteínas miocárdicas...........................................................72

3.3.11. Determinação do teor de água nos tecido cardíaco, pulmonar e hepático.............73

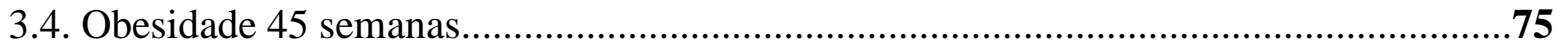

3.4.1. Composição dos grupos controle e obeso........................................................75

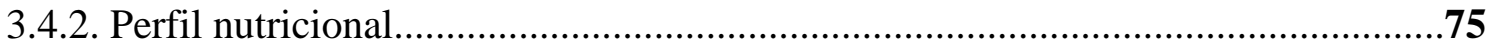

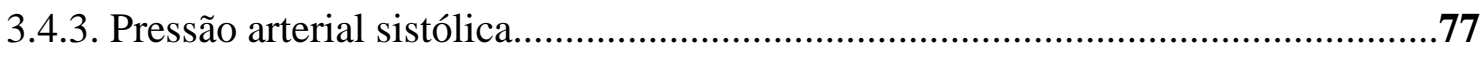

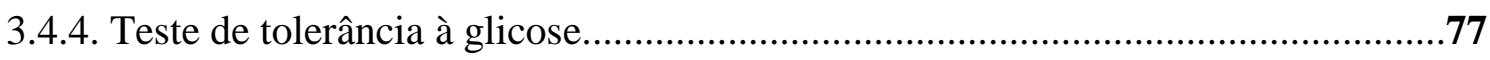


3.4.6. Análise sérica dos hormônios insulina e leptina...................................................79

3.4.7. Análise sérica dos hormônios tireoidianos.........................................................80

3.4.8. Estrutura do coração post mortem.......................................................................82

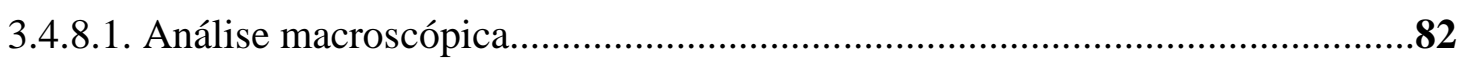

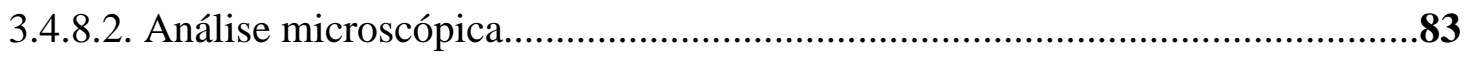

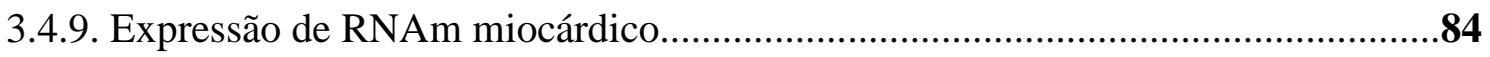

3.4.10. Expressão das proteínas miocárdicas..........................................................86

3.4.11. Determinação do teor de água nos tecido cardíaco, pulmonar e hepático............87

3.5. Comparação entre os grupos controles e obesos após 15, 30 e 45 semanas.....................89

3.5.1. Composição dos grupos controle e obeso.........................................................89

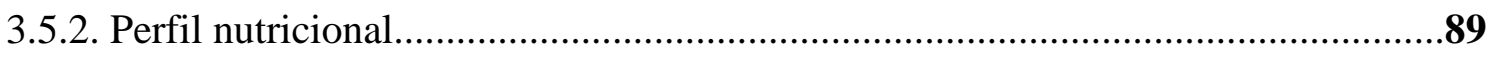

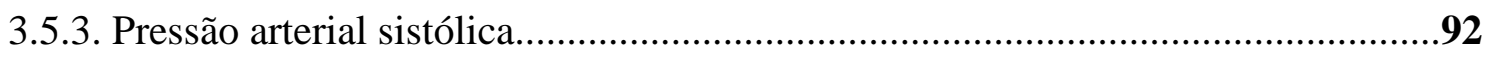

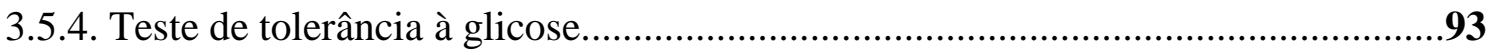

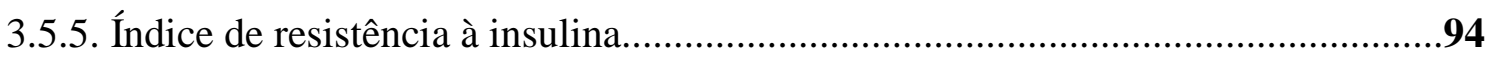

3.5.6. Análise sérica dos hormônios insulina e leptina..................................................95

3.5.7. Análise sérica dos hormônios tireoidianos.............................................................97

3.5.8. Estrutura do coração post mortem.................................................................99

3.5.8.1. Análise macroscópica...............................................................................99

3.5.8.2. Análise microscópica...........................................................................102

3.5.9. Expressão de RNAm miocárdico...............................................................103

3.5.10. Expressão das proteínas miocárdicas...........................................................105

3.5.11. Determinação do teor de água nos tecido cardíaco, pulmonar e hepático...........108 


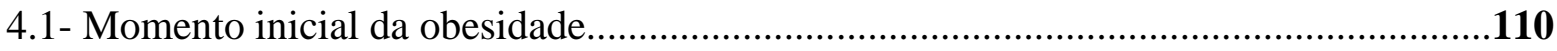

4.2. Constituição dos grupos controle e obeso................................................................110

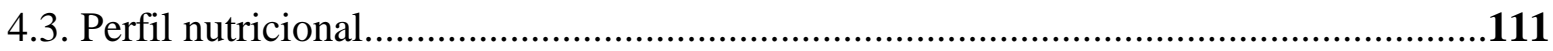

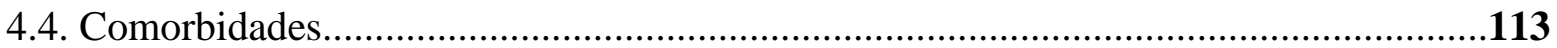

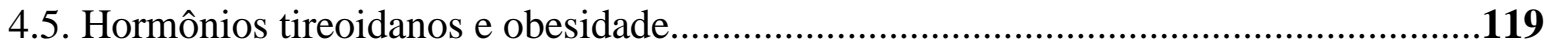

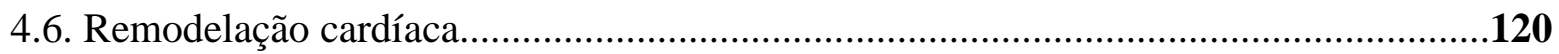

4.6.1. Estrutura do coração post mortem.................................................................120

4.6.2. Expressão de RNAm e proteínas miocárdicas..................................................123

5. CONCLUSÃO

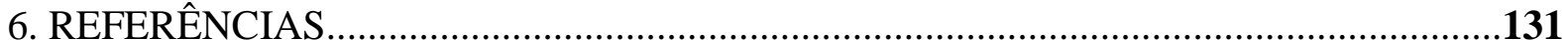

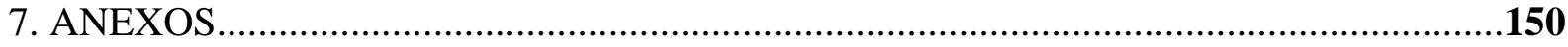

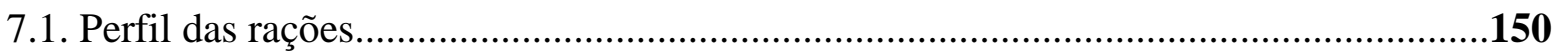

7.2. Curvas das dosagens dos hormônios tireoidianos.....................................................154

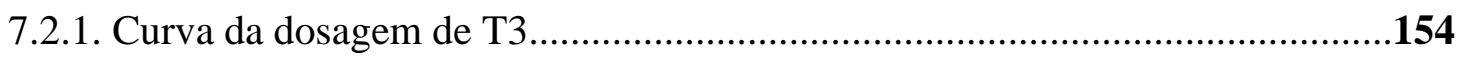

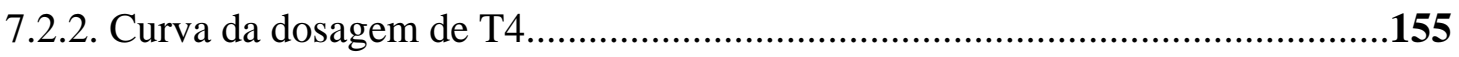

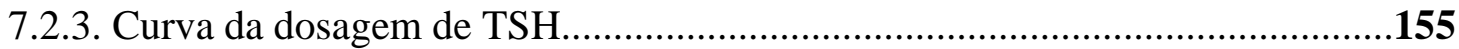

7.3. Amplificação de PCR em tempo real....................................................................156

7.3.1. Curvas de amplificação dos grupos controle e obeso 15 semanas ....................156

7.3.2. Curvas de amplificação dos grupos controle e obeso 30 semanas.....................157

7.3.3. Curvas de amplificação dos grupos controle e obeso 45 semanas.....................158

7.4. Dificuldades na técnica de Western Blot................................................................159 


\section{1- INTRODUÇÃO}

A obesidade é caracterizada pelo acúmulo excessivo de gordura corporal, ${ }^{(1)}$ representando um problema de abrangência mundial que afeta principalmente países industrializados. ${ }^{(2-4)}$ Atualmente mais de um bilhão de pessoas apresentam sobrepeso, sendo que, mais de $30 \%$ desta população é obesa. ${ }^{(5)}$ No Brasil, segundo a Pesquisa de Orçamentos Familiares do Instituto Brasileiro de Geografia e Estatística, ${ }^{(6)}$ aproximadamente 40 milhões de pessoas têm sobrepeso e, deste grupo, 10,5 milhões são obesos. A pesquisa relata ainda, que $35 \%$ da população adulta brasileira se tornará obesa em 2025, refletindo-se em conseqüências econômicas para a saúde pública. Esta prevalência coloca o Brasil com número de internações hospitalares, devido ao excesso de peso, semelhante a dos países desenvolvidos, sendo $6,8 \%$ do total dos casos referente a homens e 9,3\% a mulheres, o que equivale a $3,02 \%$ e $5,83 \%$, respectivamente, dos custos totais de hospitalização. ${ }^{(7)}$

A etiologia da obesidade é multifatorial, sendo que a associação dos fatores genéticos, metabólicos, comportamentais e ambientais contribui para o aumento do peso corporal. $\mathrm{O}$ comportamento adquirido pela moderna sociedade industrializada, envolvendo o sedentarismo, os hábitos alimentares inadequados ou a combinação de ambos têm levado ao aumento da prevalência da obesidade. ${ }^{(8-10)}$

A obesidade é fator de risco para muitas comorbidades, como diabetes mellitus tipo 2, dislipidemias, doenças cardiovasculares, respiratórias, digestivas, osteoarticulares, renais crônicas, inflamatórias e psicológicas, ${ }^{(5,11,12)}$ as quais, estão associadas com prejuízo da qualidade de vida e mortalidade.

O tecido adiposo deixou de ser conceituado apenas como depósito passivo dos estoques de triacilglicerol, sendo atualmente considerado um órgão com múltiplas funções, secretando elevado número de mediadores que participam de diversos processos, como a 
oxidação dos lipídeos e glicose, regulação da ingestão alimentar, controle do balanço energético e ação da insulina, entre outros. ${ }^{(13-15)}$

A obesidade frequentemente tem sido associada com alterações estruturais e funcionais do coração em humanos. ${ }^{(12,16-26)}$ As diversas alterações cardíacas comumente observadas na obesidade, como remodelação excêntrica ${ }^{(12,16-19)}$ ou concêntrica do ventrículo esquerdo, ${ }^{(20)}$ modificações hemodinâmicas, como aumento da frequiência cardíaca, do volume total sanguíneo, do débito cardíaco e da resistência vascular periférica ${ }^{(12,16-22)}$ e funcionais sistólica e diastólica, ${ }^{(23-26)}$ podem ser precursoras da insuficiência cardíaca. Pesquisas recentes mostram que a hipertrofia cardíaca está diretamente relacionada com o aumento do índice de massa corporal (IMC) e das gorduras visceral e epicárdica. ${ }^{(16,27)}$ Desta forma, assumi-se que um longo estado de obesidade eventualmente levará à insuficiência cardíaca. ${ }^{(19)}$

Diversos modelos experimentais têm sido utilizados para estudar a relação obesidade e coração. Modelos genéticos, como ratos Zucker e camundongos deficientes de leptina Lep/Lep (ob/ob) geralmente apresentam disfunção cardíaca. ${ }^{(28-34)}$ Entretanto, estes animais podem não apresentar algumas anormalidades exibidas em humanos obesos, como hiperinsulinemia, hiperglicemia, hipertensão arterial e hipertrofia cardíaca. $^{(35,36)}$ A administração de uma dieta rica em gordura para roedores representa uma alternativa em modelos experimentais, uma vez que, reproduz muitas características da obesidade humana. ${ }^{(37,38)}$ Desta forma, a obesidade induzida por dieta hiperlipídica torna-se uma ferramenta fundamental na avaliação das possíveis alterações cardíacas resultantes do excesso de tecido adiposo. Trabalhos mostram que a obesidade, induzida por dietas hiperlipídicas, apresentam resultados discordantes em relação à disfunção cardíaca. Enquanto pesquisas mostraram que ratos obesos por dieta hiperlípidica, durante 12 e 15 semanas, apresentaram disfunção contrátil, ${ }^{(39-41)}$ outros investigadores têm mostrado que a obesidade, por dieta hiperlipídica, durante um período de 11 e 12 semanas, não apresenta alterações na função 
cardíaca. ${ }^{(38,42)}$ A discrepância nos resultados encontrados poderia ser devido às diferentes técnicas utilizadas, assim como, o fato de que estes autores não avaliaram a intensidade e a duração da obesidade. Embora as alterações na função cardíaca, experimental e humana, ocorram com elevação do tecido adiposo, os mecanismos responsáveis por estas modificações não estão estabelecidos. Muitos fatores têm sido sugeridos como responsáveis pelas possíveis anormalidades cardíacas em modelos de obesidade, entre eles, as proteínas reguladoras do trânsito de cálcio $\left(\mathrm{Ca}^{+2}\right)$ miocárdico. ${ }^{(39)}$

$\mathrm{O}$ trânsito de $\mathrm{Ca}^{+2}$ representa um dos principais mecanismos reguladores do ciclo de contração e relaxamento cardíaco. ${ }^{(43)}$ Enquanto a rápida elevação da concentração de $\mathrm{Ca}^{+2}$ citosólico induz a contração, sua diminuição provoca o relaxamento. A contração cardíaca inicia-se com a despolarização das células cardíacas pelo potencial de ação, abertura dos canais de $\mathrm{Ca}^{+2}$ do tipo L (CANAL L) e influxo de $\mathrm{Ca}^{+2}$ através destes canais. ${ }^{(44)} \mathrm{O}$ conseqüente influxo de $\mathrm{Ca}^{+2}$ desencadeia liberação de grande quantidade de $\mathrm{Ca}^{+2}$ do retículo sarcoplasmático (RS) pelos receptores rianodina (RyR). ${ }^{(42)} \mathrm{O}$ aumento do $\mathrm{Ca}^{+2}$ citosólico possibilita a ligação desse íon com a troponina $\mathrm{C}(\mathrm{TnC})$ e, a consequente interação actinamiosina. A intensidade da contração depende da quantidade e da responsividade dos miofilamentos ao $\mathrm{Ca}^{+2}$. O relaxamento inicia-se quando a concentração intracelular de $\mathrm{Ca}^{+2}$ é reduzida, principalmente, pela recaptação do $\mathrm{Ca}^{+2}$ pela ATPase de $\mathrm{Ca}^{+2}$ do $\mathrm{RS}$ (SERCA). A função da SERCA é regulada pela fosfolambam (PLB) que, em seu estado fosforilado, na serina 16 (pPLB ser16) via adenosina monofosfato cíclico (AMPc), ou na treonina 17 (pPLB thr17) via quinase dependente de cálcio, calmodulina, permite a recaptura do $\mathrm{Ca}^{+2}$ pela SERCA para dentro do RS. ${ }^{(44-47)}$ A calsequestrina (CSQ) proteína do lúmen do RS tem a função de estoque de $\mathrm{Ca}^{+2}$. Assim, o $\mathrm{Ca}^{+2}$ recapturado pela SERCA para dentro do RS é armazenado pela CSQ, devido à sua capacidade de ligação aos íons $\mathrm{Ca}^{+2}$, tornando-o disponível para a próxima liberação pelos RyR. Outra proteína, importante na regulação do 
efluxo de $\mathrm{Ca}^{+2}$ celular é o trocador $\mathrm{Na}^{+} / \mathrm{Ca}^{+2}(\mathrm{NCX})$, que, utiliza o gradiente de $\mathrm{Na}^{+}$ transmembrana para catalisar a extrusão do $\mathrm{Ca}^{+2}$. Desta forma, a quantidade e/ou atividade de diferentes proteínas, localizadas no sarcolema e no RS, regulam o trânsito de $\mathrm{Ca}^{+2}$ celular, modulando a contração e o relaxamento do miocárdio. ${ }^{(43,44)}$ As alterações no trânsito de $\mathrm{Ca}^{+2}$ intracelular podem ser decorrentes de prejuízo na expressão, função ou regulação das proteínas, ocasionados por modificações nos mecanismos de transcrição, tradução e/ou póstraducional.

$\mathrm{O}$ trânsito de $\mathrm{Ca}^{+2}$ miocárdico tem sido extensivamente estudado em diversos modelos experimentais e frequentemente relacionado com disfunção cardíaca. ${ }^{(48-50)}$ Em modelos com desenvolvimento de insuficiência cardíaca, a redução da expressão da SERCA foi observada por diversos autores; ${ }^{(51-53)}$ em contrapartida, há relatos do aumento compensatório dos níveis de NCX. ${ }^{(53,54)}$ A expressão de PLB tem resultados controversos, sendo encontrado preservada, diminuída ou aumentada na insuficiência cardíaca experimental. ${ }^{(51,52,54,55)}$ Entretanto, a literatura mostra escassez de estudos que avaliaram a relação entre a obesidade por dieta hiperlipídica, o RNAm e as proteínas envolvidas na homeostase de $\mathrm{Ca}^{+2}$ miocárdico. Pesquisa com cães, ${ }^{(56)}$ alimentados com dieta hiperlipídica por 6 semanas, verificou níveis semelhantes de RNAm e protéicos da RyR; contudo, a expressão protéica de RyR fosforilada foi elevada no grupo alimentado com dieta rica em gordura. Outros investigadores, ${ }^{(57)}$ também utilizando cães, alimentados por 9 semanas com dieta hiperlipídica, observaram diminuição da expressão de RNAm da SERCA e do PLB no miocárdio. Relling et $a l^{(39)}$ utilizando ratos submetidos à dieta hiperlipídica, por 12 semanas, mostraram que a obesidade, não acompanhada de comorbidades, promoveu aumento da expressão protéica da SERCA e da PLB e diminuição dos níveis de PLB fosforilado. Em pesquisa recente em nosso laboratório, Lima-Leopoldo et $a l^{(58)}$ observaram que a obesidade, induzida por um ciclo de dietas hiperlipídicas em ratos Wistar durante 15 semanas, acrescida de solução de água com açúcar, aumentou os níveis de 
RNAm da SERCA, da RyR e da PLB. A divergência nos resultados acima pode ser atribuída aos diferentes períodos, dietas e unidades experimentais.

Diversos trabalhos têm indicado a participação dos hormônios tireoidianos como moduladores da transcrição gênica das proteínas reguladoras do trânsito de $\mathrm{Ca}^{+2}$ no miocárdio. ${ }^{(59-61)}$ A ação genômica do triiodotironina (T3) é mediada pela ligação aos seus receptores nucleares, regulando a expressão de genes por meio de interações com seqüências especificas do DNA. Os receptores ligados ao T3, em combinação com o recrutamento de proteínas coativadoras, levam à ativação da transcrição. ${ }^{(62)}$ A literatura relata que os hormônios tireoidianos podem atuar positivamente na expressão protéica da SERCA, RyR e canal L; e, negativamente, no PLB e NCX. ${ }^{(61)}$ Assim, a influência dos hormônios tireoidianos nas proteínas responsáveis pela homeostase de $\mathrm{Ca}^{+2}$ pode acarretar alterações na contração e relaxamento cardíaco. ${ }^{(63)}$ No entanto, os estudos da função tireoidiana na obesidade apresentam resultados inconsistentes sendo descritos variavelmente, como normal, elevada, ou diminuída em indivíduos obesos. ${ }^{(64-70)}$

Além da carência de estudos que relacionam obesidade, RNAm e as respectivas proteínas reguladoras do trânsito de $\mathrm{Ca}^{+2}$ intracelular, não foram encontrados na literatura pesquisas que avaliaram a influência do tempo de exposição à obesidade sobre essas variáveis. Trabalhos longitudinais em humanos mostraram uma associação da duração da obesidade com as diversas anormalidades cardíacas; ${ }^{(71-73)}$ entretanto, estudos clínicos que avaliam a influência da obesidade apresentam limitações éticas. Por esta razão, a experimentação animal é essencial na avaliação da relação entre o tempo de exposição à obesidade e os fatores envolvidos na regulação cardíaca, como as proteínas do trânsito de $\mathrm{Ca}^{+2}$ miocárdico.

O objetivo principal desse estudo foi testar a hipótese que o aumento no tempo de exposição à obesidade acarreta diminuição na expressão e/ou fosforilação das proteínas 
relacionadas com o trânsito de $\mathrm{Ca}^{+2}$ miocárdico. A hipótese, que há redução das proteínas e dos respectivos níveis de RNAm, foi baseada em estudos clínicos que mostraram uma relação entre a duração da obesidade e a presença de disfunção cardíaca, ${ }^{(19,71-73)}$ que, como referido anteriormente, pode ser causada por alterações nas proteínas do trânsito de cálcio miocárdico. ${ }^{(39)}$ Além disso, este estudo teve como objetivo secundário constatar se a diminuição na expressão gênica foi acompanhada de redução dos níveis hormonais tireoidianos. 


\section{2- MATERIAL E MÉTODOS}

\section{1- Animais}

No presente estudo foram utilizados 110 ratos Wistar machos, com 30 dias de idade, provenientes do Biotério do Laboratório Experimental do Departamento da Clínica Médica, Faculdade de Medicina de Botucatu, Universidade Estadual Paulista "Júlio de Mesquita Filho" - UNESP, São Paulo, Brasil. Os animais foram mantidos no biotério de origem sob as seguintes condições: gaiolas individuais de polipropileno com tampas de arame cromado forradas com maravalha de Pinus esterilizada, temperatura ambiente $\left(24 \pm 2{ }^{\circ} \mathrm{C}\right)$, umidade controlada $\left(55 \pm 5^{\circ} \mathrm{C}\right)$ e ciclos de iluminação de 12 horas. Os procedimentos experimentais foram realizados de acordo com o "Guide for the Care and Use of Laboratory Animals" publicado pelo U.S. National Institutes of Health ${ }^{(74)}$ e aprovados pela Comissão de Ética Experimental em Pesquisa da Faculdade de Medicina de Botucatu - UNESP.

\section{2- Protocolo Experimental}

Os ratos foram randomizados em dois grupos: tratados com dietas normocalórica (DN, $\mathrm{n}=55)$ ou hipercalórica $(\mathrm{DH}, \mathrm{n}=55)$. Os ratos $\mathrm{DN}$ receberam ração padrão para roedores ( $\mathrm{RC}$ Focus 1765, Agroceres ${ }^{\circledR}$, Rio Claro, São Paulo, Brasil) e os DH um ciclo de quatro rações hiperlipídicas (RC Focus 2413, 2414, 2415 e 2416, Agroceres ${ }^{\circledR}$, Rio Claro, São Paulo, Brasil), por períodos de 15, 30 e 45 semanas. As rações hiperlipídicas foram alternadas a cada 24 horas. Os ratos DN e DH receberam 50 g de ração e após 24 horas a quantidade não ingerida foi mensurada. A oferta de água foi ad libitum.

As rações idealizadas no Laboratório Experimental de Músculo Papilar Isolado do Departamento de Clínica Médica, Faculdade de Medicina de Botucatu, Unesp, foram adaptadas a partir de modelo dietético utilizado anteriormente pelo grupo. ${ }^{(75)}$ 


\subsection{1- Composição das rações padrão e hiperlipídica}

A ração padrão RC Focus 1765 foi composta pelos seguintes ingredientes: fosfato bicálcico, óleo de soja degomado, cloreto de sódio, milho moído, aditivo antioxidante, farelo de soja, farelo de trigo, farinha de carne e ossos, farinha de peixe, suplemento mineral e vitamínico. As quatro rações hiperlipídicas RC Focus 2413, 2414, 2415 e 2416 apresentaram a mesma composição nutricional, com exceção dos aditivos flavorizantes, queijo, bacon, chocolate ou baunilha, respectivamente; as rações foram constituídas de cloreto de sódio, caseína, soro de leite em pó, concentrado protéico de soja, milho integral moído, farinha de bolacha, fosfato bicálcico, carbonato de cálcio, óleo de milho, aditivos emulsificante e antioxidante, suplemento mineral e vitamínico.

A composição de macro e micronutrientes das rações padrão e hiperlipídica, mensurada pela empresa Agroceres ${ }^{\circledR}$, Rio Claro, São Paulo, Brasil, está apresentada no Quadro 1.

Quadro 1- Composição dos macro e micronutrientes das rações (\%)

\begin{tabular}{ccc}
\hline & \multicolumn{2}{c}{ Rações } \\
\cline { 2 - 3 } Componentes & Padrão & Hiperlipídica \\
\hline Proteína & 22,0 & 20,0 \\
Carboidrato & 42,7 & 26,4 \\
Gordura & 4,0 & 20,0 \\
\hline Vitaminas e Minerais & 11,3 & 12,1 \\
Fibras & 8,0 & 9,0 \\
Umidade & 12,0 & 12,5 \\
Calorias (Kcal/g) & 2,95 & 3,65 \\
\hline \% Calorias da proteína & 29,8 & 21,9 \\
\hline Calorias do carboidrato & 57,9 & 28,9 \\
\hline \% Calorias da gordura & 12,3 & 49,2 \\
\hline
\end{tabular}




\section{3- Avaliação nutricional dos animais}

O perfil nutricional foi determinado pela análise de ingestão calórica, eficiência alimentar, peso e gordura corporal, índice de adiposidade, lipídios, glicemia e proteína sérica. A ingestão calórica foi calculada pela seguinte fórmula: ingestão alimentar semanal (g) multiplicada pelo valor energético de cada ração (kcal). Com a finalidade de analisar a capacidade do animal converter a energia consumida em peso corporal, foi calculada a eficiência alimentar (EA), dividindo-se o ganho total de peso corporal dos animais (g) pela energia total ingerida (kcal). O peso corporal dos animais foi aferido semanalmente, utilizando-se uma balança digital Mettler® modelo Spider 2 (Toledo do Brasil Indústria de Balanças Ltda, São Bernardo do Campo, SP, Brasil). A quantidade de gordura corporal total foi determinada pela somatória dos depósitos de gordura epididimal, retroperitoneal e visceral. O índice de adiposidade foi calculado dividindo-se a gordura corporal total (g) pelo peso corporal final (g), multiplicado por $100 .{ }^{(76)}$ Para análise do perfil glicêmico, lipídico e protéico, os ratos foram colocados em jejum por 12 a 15 horas, anestesiados com pentobarbital sódico $\left(50 \mathrm{mg} / \mathrm{kg} / \mathrm{IP}\right.$, Cristália ${ }^{\circledR}$ Produtos Químicos Farmacêuticos Ltda, Itapira, São Paulo, Brasil) e eutanasiados por decapitação. A seguir, as amostras de sangue foram coletadas em tubos Falcon, centrifugadas a 3000rpm por 10 minutos (Eppendorf ${ }^{\circledR}$ Centrifuge 5804-R, Hamburg, Germany) e armazenadas em freezer à $-80^{\circ} \mathrm{C}$ (Thermo Fisher Scientific LLC, Asheville, NC, USA). As concentrações séricas de glicose, triacilglicerol, colesterol total, lipoproteínas de alta e baixa densidade foram determinadas utilizando-se kits específicos $\left(\mathrm{CELM}^{\circledR}\right.$, Barueri, São Paulo, Brasil) e analisadas pelo método enzimático colorimétrico automatizado (Technicon, RA-XT ${ }^{\mathrm{TM}}$ System, Global Medical Instrumentation, Minessota, USA). Os níveis de ácidos graxos não-esterificados (NEFA) foram avaliados utilizando kit colorimétrico (WAKO NEFA-C, Wako Pure Chemical Industries, Osaka, Japan) pelo método de Johnson \& Peters. ${ }^{(77)}$ 


\section{4- Caracterização da obesidade}

A obesidade nos animais ao final dos períodos de 15, 30 e 45 semanas de tratamento foi determinada utilizando-se o índice de adiposidade. Diversos estudos têm utilizado este índice como ferramenta para avaliar a quantidade de gordura corporal em roedores. ${ }^{(38,42)}$ Este método de baixo custo é facilmente realizado, pois permite avaliar os depósitos de gordura corporal de maneira precisa e consistente.

\section{5- Determinação do momento inicial da obesidade}

O momento do início da obesidade foi determinado aferindo-se semanalmente o peso corporal dos animais. Na terceira semana de tratamento, observou-se aumento significante do peso corporal no grupo DH em relação ao DN. Com a finalidade de verificar se a diferença do peso corporal entre os grupos era resultante do maior índice de adiposidade nos ratos $\mathrm{DH}$, foram eutanasiados 19 animais de cada grupo para determinação da quantidade de gordura corporal. Como o grupo DH apresentou índice de adiposidade estatisticamente maior do que o DN, a terceira semana de tratamento foi considerada como o início da obesidade no grupo $\mathrm{DH}$.

\section{6- Constituição dos grupos controle e obeso}

Após 15, 30 e 45 semanas do início da obesidade, os grupos de animais que receberam ração padrão e hiperlipídica foram denominados como Controle (C) e Obeso (Ob), respectivamente, e alocados em seis sub-grupos: $\mathrm{C}_{15}, \mathrm{C}_{30}, \mathrm{C}_{45}, \mathrm{Ob}_{15}, \mathrm{Ob}_{30}$ e $\mathrm{Ob}_{45}$.

$\mathrm{Na}$ experimentação biológica, em especial estudos experimentais, mesmo quando mantidas as condições laboratoriais semelhantes, não está assegurada uma homogeneidade de resposta. Neste sentido, os ratos submetidos à ração padrão e hiperlipídica poderiam apresentar, em maior ou menor escala, características comuns, como, por exemplo, o índice 
de adiposidade. Estudo publicado previamente ${ }^{(78)}$ mostrou que este fato pode conduzir a um erro de classificação, ou seja, animais submetidos à ração padrão poderiam ser classificados como controle, quando na realidade, exibem características de animais obesos, ou vice versa. Por essa razão, tornou-se necessário estabelecer um critério que separasse os animais em dois grupos distintos de acordo com o índice de adiposidade. Com essa finalidade, foi construído um intervalo de $95 \%$ de confiança (IC) para a média do índice de adiposidade dos ratos controle e obeso. Foi adotado como ponto de separação (PS) entre os grupos, o ponto médio entre o limite superior do $\mathrm{C}_{15}$ e o limite inferior do $\mathrm{Ob}_{15}$; a partir deste ponto foram excluídos do grupo $\mathrm{C}_{15}$ os animais com índice de adiposidade acima do PS e do grupo $\mathrm{Ob}_{15}$ os animais com índice de adiposidade abaixo do PS. O mesmo procedimento foi realizado para os grupos $\mathrm{C}_{30} ; \mathrm{Ob}_{30} ; \mathrm{C}_{45}$ e $\mathrm{Ob}_{45}$
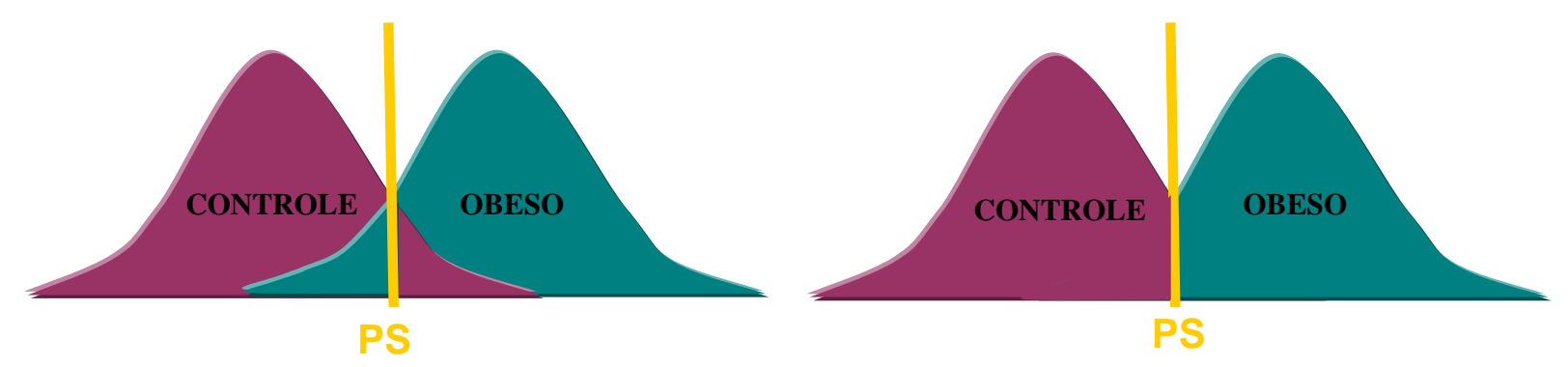

Representação esquemática do critério utilizado para composição dos grupos controle e obeso

\section{7- Obesidade e comorbidades}

As alterações no perfil cardiovascular, metabólico e hormonal, como hipertensão arterial sistêmica, intolerância à glicose, resistência sistêmica à insulina, dislipidemias, hiperglicemia, hiperinsulinemia e hiperleptinemia ${ }^{(38,39,79-84)}$ que podem estar frequentemente associadas à obesidade, foram avaliadas em todos os sub-grupos.

\subsection{1- Hipertensão arterial sistêmica}

Como os animais obesos podem apresentar hipertensão arterial sistêmica, ${ }^{(80,85,86)}$ foi mensurada a pressão arterial sistólica (PAS). A PAS foi aferida indiretamente por 
plestimografia de cauda, utilizando-se electro-sphymomanometer, Narco Bio-System ${ }^{\circledR}$, modelo 709-0610 (International Biomedical, Inc, USA); este método não permite avaliar a pressão arterial diastólica. Com a finalidade de produzir vasodilatação da artéria caudal, os ratos foram previamente aquecidos, à temperatura de $40^{\circ} \mathrm{C}$ por 5 minutos, em uma caixa de madeira $(50 \times 40 \mathrm{~cm})$ forrada com maravalha de Pinus autoclavada. Após o aquecimento foi acoplado o sensor e o manguito em torno da cauda do animal; o manguito foi insuflado até atingir pressão de $200 \mathrm{mmHg}$ e, posteriormente, desinsuflado. As pulsações arteriais foram registradas em polígrafo Gould RS 3200 (Gould Instrumenta Valley View, Ohio, USA).

\subsection{2- Intolerância à glicose}

Como os animais obesos podem apresentar níveis glicêmicos normais em condições basais, foi analisado o perfil glicêmico após uma sobrecarga de glicose. A partir deste teste é possível constatar se os ratos obesos desenvolveram intolerância à glicose, isto é, apresentaram níveis de glicemia elevados em relação ao grupo C após a sobrecarga de glicose. As coletas de sangue, na artéria caudal, foram realizadas na condição basal após um período de jejum de 6 horas e após a administração intraperitoneal de glicose 25\% (Sigma-Aldrich ${ }^{\circledR}$, St Louis, MO, USA), equivalente a $2 \mathrm{~g} / \mathrm{kg}$. As amostras sanguíneas foram coletadas nos momentos 0 , considerado condição basal, e após 15, 30, 60, 90 e 120 minutos da infusão da glicose. A mensuração dos níveis glicêmicos foi realizada com glicosímetro portátil AccuChek Go Kit (Roche Diagnostic Brazil Ltda, SP, Brasil). A intolerância à glicose foi avaliada pelo perfil da curva e área glicêmica.

\subsection{3- Resistência sistêmica à insulina}

Como os animais obesos podem apresentar resistência à ação da insulina, ${ }^{(38,39,81,83,84)}$ calculamos o índice HOMA-IR (homeostatic model assessment), que baseia-se nas 
concentrações de glicose e insulina de jejum. O cálculo foi realizado pela seguinte fórmula: concentração de insulina $(\mu \mathrm{U} / \mathrm{mL})$ multiplicada pelos níveis glicêmicos $(\mathrm{mM} / \mathrm{L})$ dividida por $22,5 .^{(87)}$

\subsection{4- Dislipidemias e Hiperglicemia}

Como os animais obesos podem apresentar alterações do perfil lipídico e glicêmico, ${ }^{(38,80,81)}$ foram avaliadas as concentrações séricas de glicose, triacilglicerol, colesterol total, lipoproteínas de alta e baixa densidade e ácidos graxos não-esterificados (NEFA). A metodologia utilizada foi descrita no item 2.3, referente à avaliação nutricional dos animais.

\subsection{5 - Hiperinsulinemia e Hiperleptinemia}

Como os animais obesos podem apresentar hiperinsulinemia e hiperleptinemia, ${ }^{(81-83,88)}$ foram analisados os níveis séricos destes hormônios. As concentrações hormonais foram determinadas pelo método de ELISA utilizando-se kits específicos (Linco Research Inc, St. Louis, MO, USA). A leitura foi realizada com auxílio de leitor de micro-placa (Spectra MAX 190, Molecular Devics, Sunnyvale, CA, USA).

\section{8- Dosagem dos hormônios tireoidianos}

Como os animais os animais obesos podem apresentar alterações hormonais tireoidianas $^{(64-70)}$ e que estas podem influenciar a expressão das proteínas reguladoras do trânsito de cálcio miocárdico ${ }^{(59-61)}$ foram dosadas as concentrações séricas totais de hormônio estimulante da tireóide (TSH), tiroxina (T4) e triiodotironina (T3). A dosagem sérica foi realizada pela empresa Genese Produtos Diagnósticos (São Paulo, SP, Brasil) com a 
tecnologia Luminex Corporation's xMAPTM, por reação de imunoensaio multiplex, Lincoplex kits (Linco Research Inc, St. Louis, MO, USA).

\section{9- Caracterização da remodelação cardíaca}

Como a obesidade pode acarretar remodelação cardíaca, ${ }^{(12,16-19)}$ o coração foi analisado por meio de estudos estruturais e moleculares. A estrutura foi avaliada post mortem por análises macroscópicas e microscópicas. A avaliação molecular do ácido ribonucléico mensageiro (RNAm) e das proteínas miocárdicas relacionadas com o trânsito de cálcio, objetivo desse trabalho, foi realizada, respectivamente, pelas técnicas de reação em cadeia da polimerase (PCR) em tempo real e Western Blot. Os métodos utilizados no estudo na para análise da remodelação cardíaca estão descritos abaixo.

\subsection{1- Estrutura do coração post mortem}

As análises estruturais, macro e microscópica post mortem, permitem identificar a presença de remodelação cardíaca a nível atrial e ventricular. A remodelação a nível macroscópico, que identifica a presença ou ausência de hipertrofia, foi determinada pela análise dos seguintes parâmetros: peso total do coração, do átrio, dos ventrículos esquerdo e direito, e das respectivas relações com o PCF e comprimento da tíbia. A remodelação do VE a nível microscópico foi avaliada pela mensuração da área seccional transversa do miócito $\left(\mathrm{AST} ; \mu \mathrm{m}^{2}\right)$, de acordo com metodologia descrita abaixo.

\subsection{2- Área seccional transversa do miócito}

A análise da área seccional transversa do miócito foi realizada utilizando amostras do ventrículo esquerdo (VE). Após toracotomia mediana, o coração foi rapidamente removido e amostras da parede anterior do VE foram retiradas a $6 \mathrm{~mm}$ do ápice. Os fragmentos foram 
colocados em solução de formol a $10 \%$ por 24 h. ${ }^{(89)}$ As amostras foram submetidas a cortes histológicos de $5 \mu \mathrm{m}$ de espessura e posteriormente processadas segundo a técnica de Reticulina de Gömori. ${ }^{(90)} \mathrm{O}$ fragmento foi imerso em permanganato de potássio $1 \%$, ácido oxálico $3 \%$, alúmen de ferro $1 \%$, prata amoniacal, formol $10 \%$, cloreto de ouro $0,2 \%$ e hiposulfito de sódio $2 \%$ e posteriormente corado pelo ácido púrico. A técnica de Reticulina de Gömori permitiu mensurar de forma mais precisa a área transversa do miócito do VE. O cálculo das áreas seccionais dos miócitos foi realizado mensurando-se 50 a 70 células por amostra. Os miócitos analisados, localizados na camada subendocárdica, apresentavam forma arredondada e núcleo centralizado. As áreas seccionais transversas dos miócitos (AST; $\mu \mathrm{m}^{2}$ ) foram utilizadas como indicador do tamanho celular, caracterizando presença ou ausência de hipertrofia cardíaca. Os cortes histológicos, realizados para a análise AST, foram ampliados 40 vezes com o auxílio de microscópio (Leica Mikroshopie \& System GmbH, Wetzlar, Germany), que acoplado a uma câmera de vídeo envia imagens digitais a um computador dotado de programa de análise de imagens (Image Pro-plus, Media Cybernetics, Silver Spring, Maryland, USA).

\subsection{3- Expressão do RNAm miocárdico}

A expressão do RNAm foi realizada pela técnica de PCR em tempo real. ${ }^{(91)} \mathrm{O}$ método compreende as seguintes etapas: extração de RNA de amostras biológicas, conversão das moléculas de RNA em ácido desoxirribonucléico complementar (cDNA), amplificação de um segmento do cDNA a partir da reação em cadeia da polimerase e quantificação dos fragmentos amplificados. A possibilidade de monitorar, ao longo da reação, os ciclos de amplificação, confere maior precisão e reprodutibilidade à PCR em tempo real quando comparado com a PCR convencional. ${ }^{(92)}$ 
Neste trabalho foi realizada expressão de RNAm das proteínas relacionadas com o trânsito de cálcio intracelular, ATPase de cálcio do retículo sarcoplasmático (SERCA), Fosfolambam (PLB), Receptor Rianodina (RyR), CANAL L, Calsequestrina (CSQ) e Trocador $\mathrm{Na}^{+} / \mathrm{Ca}^{2+}(\mathrm{NCX})$. Além disso, foi analisada a expressão do gene constitutivo, $\beta$ actina. A metodologia utilizada está descrita abaixo.

\subsubsection{1- Extração de RNA miocárdico}

Fragmentos do ventrículo esquerdo foram rapidamente congelados em nitrogênio líquido e armazenados em freezer a $-80^{\circ} \mathrm{C}$. A amostra congelada foi homogeneizada em aparelho Polytron (Ika Ultra Turrax ${ }^{\circledR}$ T25 Basic, Wilmington, NC, USA) após adição de $1 \mathrm{ml}$ de TRIzol $^{\circledR}$ (Invitrogen Brasil, São Paulo) para cada $100 \mathrm{mg}$ de tecido. O TRIzol ${ }^{\circledR}$, solução monofásica de fenol e guanidina isotiocianato, tem como finalidade manter a integridade do RNA durante a lise celular que ocorre no processo de homogeneização. ${ }^{(93)}$

A amostra homogeneizada foi transferida para um tubo de $1,5 \mathrm{~mL}$ e incubada à temperatura ambiente $\left(24^{\circ} \mathrm{C}\right)$ durante 5 minutos. Em seguida, adicionou-se clorofórmio (Merck KGaA, Damstadt, Germany) na proporção de $0,2 \mathrm{ml} / 1 \mathrm{ml}$ TRIzol ${ }^{\circledR}$; a amostra foi agitada, manualmente, com vigor por 15 segundos e incubada por 3 minutos à temperatura ambiente. Após essa segunda incubação, o material foi centrifugado (Eppendorf Centrifuge 5804R, Hamburg, Germany), a 12.000 x g durante 15 minutos a $4^{\circ} \mathrm{C}$. Este processo separou a amostra homogeneizada de VE em três fases: a) uma inferior, de fenol-clorofórmio e de coloração rosada, contendo DNA; b) uma interfase branca com proteínas; e c) uma fase superior, aquosa, incolor, contendo RNA.

A porção de RNA foi transferida para um tubo de 1,5 mL; a seguir, adicionou-se álcool isopropílico (Merck KGaA, Damstadt, Germany) na proporção de 0,5 $\mathrm{ml} / 1 \mathrm{ml}$ de TRIzol $^{\circledR}$; a amostra foi, então, agitada manualmente 10 vezes por inversão, incubada por 10 
minutos à temperatura ambiente $\left(24^{\circ} \mathrm{C}\right) \mathrm{e}$, posteriormente, centrifugada a $12.000 \mathrm{x}$ g durante 10 minutos a $4^{\circ} \mathrm{C}$. Após o descarte do sobrenadante, o precipitado de RNA foi visualizado como um gel esbranquiçado e semitransparente, denominado pellet. Este foi lavado com álcool etílico 75\% (Merck KGaA, Damstadt, Germany) na proporção de $1 \mathrm{~mL} / 1 \mathrm{~mL}$ de TRIzol $^{\circledR}$ e centrifugado a 7.500 x g por 5 minutos a $4{ }^{\circ} \mathrm{C}$. Após o álcool etílico ser descartado, o pellet foi seco por 10 minutos à temperatura ambiente. O sedimento de RNA foi diluído em $20 \mu \mathrm{L}$ de água ultrapura e incubado por 10 minutos a $60^{\circ} \mathrm{C}$ em banho-maria (Fanem 100, São Paulo, Brasil); a finalidade deste procedimento foi inativar a possível presença de RNase.

A quantificação do RNA foi realizada com auxílio de um espectrofotômetro (GeneQuant ${ }^{\mathrm{TM}}$ RNA/DNA Calculator, Amersham Pharmacia Biotech, Cambridge, England) na absorbância de 260 nm. A pureza do RNA foi constatada pela razão das absorbâncias em 260/280 nm. As amostras cujas razões foram inferiores a 1,6 foram descartadas por apresentarem contaminação por proteínas. A concentração do RNA foi quantificada de acordo com a fórmula: $[\mathrm{RNA}]=\mathrm{A}_{260} \times 40 \times 70$. Posteriormente, para verificar a integridade do RNA, $1 \mu \mathrm{L}$ do RNA das amostras quantificadas foram diluídas em $8 \mu \mathrm{L}$ de água ultrapura e $1 \mu \mathrm{L}$ de corante (Orange G, Acros Organics, New Jersey, USA), aplicadas em gel de agarose 1\% (0,3 g agarose, $30 \mathrm{~mL}$ de TAE Buffer $1 \mathrm{x}, 3 \mu \mathrm{L}$ de brometo de etídio) e submetidas a uma voltagem de $80 \mathrm{mV}$ (Power Pac Basic ${ }^{\mathrm{TM}}$ Bio-Rad, Hercules, CA, USA) por 20 minutos. A integridade do RNA foi constatada pela visualização das bandas de RNA ribossômico, $28 \mathrm{~S}$ e $18 \mathrm{~S}$, e ausência de rastros do RNA no gel. As amostras que se mostraram íntegras foram utilizadas como substrato para o processo de transcrição reversa.

\subsubsection{2- Transcrição reversa do RNA (RT)}

Transcrição reversa é um processo que converte as moléculas do RNA em ácido desoxirribonucléico complementar (cDNA). As amostras do RNA do músculo cardíaco foram 
submetidas à transcrição reversa utilizando-se o kit SuperScript II First-Strand Synthesis System for $R T-P C R^{\circledR}$ (Invitrogen, São Paulo, Brasil). As amostras utilizadas no experimento foram incubadas em um termociclador (Mastercycler ${ }^{\circledR}$ Gradient, Eppendorf, Hamburg, Germany). Inicialmente, uma mistura contendo $1000 \mathrm{ng} / \mu \mathrm{L}$ de RNA total, $1 \mu \mathrm{L}$ de $d N T P$ mix $10 \mathrm{mM}, 1 \mu \mathrm{L}$ de random hexamers $50 \mathrm{ng} / \mu \mathrm{L}$ e $7 \mu \mathrm{L}$ de $\mathrm{H}_{2} \mathrm{O}$ DEPC (dietil pirocarbonato) foi incubada durante 5 minutos a $65^{\circ} \mathrm{C}$. A seguir, após adição de $9 \mu \mathrm{L}$ de uma solução contendo, $2 \mu \mathrm{L}$ de tampão RT 10x, $4 \mu \mathrm{L}$ de $\mathrm{MgCl}_{2} 25 \mathrm{mM}, 2 \mu \mathrm{L}$ de DTT 0,1 M e $1 \mu \mathrm{L}$ de inibidor de RNase, $R$ NaseOUT ${ }^{\circledR}$, a mistura foi incubada por 2 minutos a $25^{\circ} \mathrm{C}$. Após o acréscimo de 1 $\mu \mathrm{L}$ da enzima SuperScript $I I^{\circledR}$, procedeu-se a nova incubação por 10,50 e 15 minutos a $25^{\circ} \mathrm{C}$, $42^{\circ} \mathrm{C}$ e $70^{\circ} \mathrm{C}$, respectivamente. Após adição de $1 \mu \mathrm{L}$ de $\mathrm{RNase} \mathrm{H}$, a solução foi incubada por 20 minutos a $37^{\circ} \mathrm{C}$.

Para verificar a qualidade da transcrição reversa foi realizado um controle negativo, ou seja, uma amostra de RNA foi submetida à reação de RT, porém, a enzima SuperScript II ${ }^{\circledR}$ foi substituída por $1 \mu \mathrm{L}$ de $\mathrm{H}_{2} \mathrm{O}$ DEPC. O controle negativo, utilizado nas reações de PCR, foi confirmado pela ausência de amplificação de RNAm.

\subsubsection{3- PCR em tempo real}

A PCR em tempo real foi realizada com ensaios específicos contendo sonda TaqMan MGB-FAM (Applied Biosystems, CA, USA). A identificação dos ensaios (primers) está apresentado no Quadro 2. O sistema TaqMan utiliza uma sonda fluorescente que permite a detecção de cópias do produto específico do RNAm, conforme seu acúmulo durante os ciclos da reação. A sonda é constituída por um corante reporter fluorescente na extremidade $5^{\prime}$ e um corante quencher na extremidade $3^{\prime}$. Enquanto a sonda está intacta, a proximidade do quencher reduz a fluorescência emitida pelo corante reporter através da transferência de energia por ressonância de fluorescência. A sonda se anela a seqüência e é clivada por meio 
da atividade da nuclease 5'da Taq DNA polimerase. A clivagem da sonda separa o corante reporter do corante quencher, aumentando o sinal da fluorescência emitida pelo corante reporter. A fluorescência foi monitorada em tempo real com um aparelho StepOne Plus (Applied Biosystems, CA, USA). As amostras foram normalizadas pelo controle interno $\beta$ actina e a quantificação da expressão realizada pelo método $\Delta \Delta \mathrm{CT}$, conforme manual do fabricante (Applied Biosystems, CA, USA).

Quadro 2. Ensaios utilizados na PCR em tempo real

\begin{tabular}{|c|c|}
\hline Gene & Ensaios \\
\hline SERCA & Rn00568762_m1 \\
\hline PLB & Rn01434045_m1 \\
\hline RyR & Rn01470303_m1 \\
\hline NCX & Rn00570527_m1 \\
\hline CSQ & Rn00567508_m1 \\
\hline CANAL $L$ & Rn00709287_m1 \\
\hline$\beta$-actina & Rn00667869_m1 \\
\hline
\end{tabular}

\subsection{4- Expressão de proteínas miocárdicas}

A expressão protéica foi realizada pela técnica de Western Blot, método frequentemente utilizado em pesquisas para detectar proteínas em um homogenato de tecido biológico. ${ }^{(94)} \mathrm{O}$ método compreende as seguintes etapas: extração de proteínas, eletroforese em gel, transferência das proteínas do gel para uma membrana de nitrocelulose, identificação das proteínas por anticorpos específicos e quantificação dos blots de polipetídeos. ${ }^{(95)}$ 
Neste trabalho foi realizada a expressão das proteínas relacionadas com os com o trânsito de cálcio intracelular, ATPase de $\mathrm{Ca}^{+2}$ do retículo sarcoplasmático (SERCA), Fosfolambam (PLB), PLB fosforilado Ser16 (pPLB Ser16), PLB fosforilado Thr17 (pPLB Thr17), CANAL L e Calsequestrina (CSQ). Além disso, foi analisada a expressão da proteína de normalização, $\beta$-actina. A metodologia de Western Blot está descrita abaixo.

\subsubsection{1- Extração das proteínas miocárdicas}

Fragmentos do ventrículo esquerdo foram rapidamente congelados em nitrogênio líquido e armazenados em freezer a $-80^{\circ} \mathrm{C}$. A amostra congelada foi homogeneizada em aparelho Polytron (Ika Ultra Turrax ${ }^{\mathrm{TM}}$ T25 Basic, Wilmington, USA) com tampão de lise hipotônico (fosfato de potássio $50 \mathrm{mM} \mathrm{pH} \mathrm{7,0,} \mathrm{sucrose} \mathrm{0,3} \mathrm{M,} \mathrm{DTT} \mathrm{0,5} \mathrm{mM,} \mathrm{EDTA} 1 \mathrm{mM}$ pH 8.0, PMSF 0,3 mM, NaF $10 \mathrm{mM}$ e inibidor de protease $(0,1 \mathrm{mg} / \mathrm{mL}$, Sigma, St. Louis, MO, USA). O processo foi realizado três vezes durante 10 segundos a $4^{\circ} \mathrm{C}$, com intervalos de 20 segundos. O produto da homogeneização foi centrifugado (Eppendorf 5804R, Hamburg, Germany) a $12000 \mathrm{rpm}$ por 20 minutos a $4^{\circ} \mathrm{C}$, e o sobrenadante transferido para tubos eppendorfs e armazenado em freezer $-80^{\circ} \mathrm{C}$. A concentração de proteína foi analisada pelo método de Bradford, ${ }^{(96)}$ utilizando as curvas de BSA Protein Standard (Bio-Rad, Hercules, CA, USA) como padrão.

\subsubsection{2- Eletroforese em gel}

Após a quantificação da concentração protéica, as amostras cardíacas foram diluídas em tampão Laemmli (Tris-HCL 240mM, SDS, 0,8\%, glicerol 40\%, azul de bromofenol $0,02 \%$ e $\beta$-mercaptoetanol $200 \mathrm{mM}$ ) e separadas por eletroforese utilizando sistema MiniProtean 3 Electrophoresis Cell (Bio-Rad, Hercules, CA, USA). A corrida eletroforética foi realizada em gel bifásico, de empilhamento (Tris-HCL 240mM pH 6,8, poliacrilamida 30\%, 
APS e Temed) e de resolução (Tris-HCL 240mM pH 8,8, poliacrilamida 30\%, APS e Temed). O gel de resolução apresentava uma concentração de 6 a 15\%, dependente do peso molecular da proteína analisada. No primeiro poço do gel foi aplicado um padrão de peso molecular, Kaleidoscope Prestained Standards (Bio-Rad, Hercules, CA, USA) para identificação do tamanho das bandas. A corrida eletroforética foi efetuada a 120V (Power Pac HC 3.0A, BioRad, Hercules, CA, USA), por um período variável de acordo com o tamanho da proteína, em média 1 h30 minutos, com tampão de corrida (Tris 0,25M, glicina 192 mM e SDS 1\%).

\subsubsection{3- Transferência e identificação das proteínas}

As proteínas foram transferidas para uma membrana de nitrocelulose utilizando-se sistema Mini-Trans Blot (Bio-Rad, Hercules, CA, USA) contendo tampão de transferência (Tris $25 \mathrm{mM}$, glicina $192 \mathrm{mM}$, metanol 20\% e SDS 0,1\%). Após a transferência os sítios inespecíficos de ligação do anticorpo primário à membrana foram bloqueados mediante incubação com solução bloqueadora a 0,5\% de leite em pó desnatado Molico® (Nestlé Brasil, Araçatuba, SP, Brasil), dissolvido em tampão tampão TBS-T (Tris 10mM, pH 7,6, NaCl 150 $\mathrm{mM}$ e Tween $200,1 \%)$ por 120 minutos à temperatura ambiente $\left(24^{\circ} \mathrm{C}\right)$ sob constante agitação. Em seguida, a membrana foi lavada três vezes em tampão TBS-T (Tris 10mM, pH 7,6, $\mathrm{NaCl} 150 \mathrm{mM}$ e Tween 20 0,1\%) e incubada com o anticorpo primário diluído na solução bloqueadora, sob agitação constante por 12 horas. Após a incubação com o anticorpo primário, a membrana foi lavada três vezes em tampão TBS-T e incubada com o anticorpo secundário em solução bloqueadora por 2 horas sob agitação constante. Para remover o excesso de anticorpo secundário, a membrana foi lavada três vezes em tampão TBS-T. A imuno-detecção foi realizada por meio do método de quimioluminescência de acordo com as instruções do fabricante (Enhancer Chemi-Luminescence, Amersham Biosciences, NJ-USA). 
Finalmente, as membranas de nitrocelulose foram expostas a filmes radiográficos X-Omat AR (Eastman Kodak Co., USA), nos tempos padronizados para cada proteína cardíaca em análise.

\subsubsection{1- Anticorpos primários utilizados}

- Ryanodine Receptor, mouse IgG1 (ABR, Affinity BioReagents, Golden, CO, USA). Concentração recomendada pelo fabricante, 1:5000.

- Phospho-RYR2 (ser2809), rabbit (Badrilla, Leeds, West Yorkshire, UK). Concentração recomendada pelo fabricante, 1:2000.

- Serca2 ATPase, mouse IgG1 (ABR, Affinity BioReagents, Golden, CO, USA). Concentração recomendada pelo fabricante, 1: 2500.

- Phospholamban, mouse IgG2a (ABR, Affinity BioReagents, Golden, CO, USA). Concentração recomendada pelo fabricante, $2 \mu \mathrm{g} / \mathrm{ml}$.

- Phospho-Phospholamban (ser16), rabbit (Badrilla, Leeds, West Yorkshire, UK): Concentração recomendada pelo fabricante, 1:5000.

- Phospho-Phospholamban (thr17), rabbit (Badrilla, Leeds-UK): Concentração recomendada pelo fabricante, 1:5000.

- Exchanger $\mathrm{Na}^{+} / \mathrm{Ca}^{2+}$, mouse IgG2b (Upstate, Lake Placid, NY, USA): Concentração recomendada pelo fabricante, 1:2000.

- Calcium Channel, Voltage Gated Alpha 1C, rabbit (Chemicon International, Temecula, CA, USA). Concentração recomendada pelo fabricante, 1:100.

\subsubsection{2- Anticorpo de normalização}

- $\quad \beta$-Actin, mouse IgG1 (Santa Cruz Biotechonology Inc, CA, USA): Concentração recomendada pelo fabricante, 1:200. 


\subsubsection{3- Anticorpos secundários}

Os anticorpos secundários, anti-rabbit IgG-HRP SC2004 e anti-mouse IgG-HRP SC2005 (Santa Cruz Biotechonology, Inc. Santa Cruz, CA, USA), anti-anticorpos primários foram utilizados na titulação de 1:5000-1:10000.

\subsubsection{4- Quantificação das proteínas}

As análises quantitativas das bandas protéicas (blots) foram realizadas pelo programa Scion Image (Scion Corporation, Frederick, Maryland, EUA), software livre, disponível no endereço http://www.scioncorp.com/.

\subsection{0- Determinação do teor de água nos tecidos cardíaco, pulmonar e hepático}

Em razão da obesidade poder acarretar aumento na volemia corporal dos ratos, ${ }^{(97)} \mathrm{o}$ que poderia promover acúmulo de líquido nos tecidos, foi realizada a avaliação do teor de água tecidual nas amostras de ventrículos esquerdo e direito, átrio, pulmão e fígado. Após a remoção do tecido a ser examinado, foi realizada a pesagem in natura. Em seguida, as amostras foram submetidas à secagem em estufa (Kamp Metalúrgica, Duque de Caxias, Rio de Janeiro, Brasil), sob temperatura de $55 \pm 5^{\circ} \mathrm{C}$, por um período de 48 horas. A determinação do teor de água foi expressa em valores relativos e calculada pela seguinte fórmula: [(PNPS)/PN] x 100\%, onde PN representa o peso in natura e o PS o peso seco.

\subsection{1- Análise Estatística}

O perfil nutricional, as comorbidades associadas à obesidade e as análises da remodelação cardíaca de cada período de tratamento (15, 30 e 45 semanas) foram expressas por meio de medidas descritivas de posição e variabilidade e submetidas ao teste " $t$ " de Student para amostras independentes. 
A comparação do perfil glicêmico entre os grupos, visualizado tanto pelo teste de tolerância à insulina quanto pelo teste de tolerância à glicose, foi realizada pela análise de variância (ANOVA) no modelo de medidas repetidas para esquema de dois fatores independentes e complementada com o teste de comparações múltiplas de Bonferroni. ${ }^{(98)}$

A comparação dos seis grupos experimentais $\left(\mathrm{C}_{15}, \mathrm{Ob}_{15}, \mathrm{C}_{30}, \mathrm{Ob}_{30}, \mathrm{C}_{45}\right.$ e $\left.\mathrm{Ob}_{45}\right)$ foi realizada pela técnica de análise de variância (ANOVA) two way para grupos independentes, complementada com teste de comparações múltiplas de Bonferroni. A análise de associação entre as concentrações do hormônio tireoidiano e os níveis de expressão gênica foi determinada pelo teste de correlação linear de Pearson. O nível de significância considerado para todas as variáveis foi de 5\%. Os valores de $p$ entre 0,055 e 0,15 foram evidenciados neste estudo. 


\section{RESULTADOS}

Os resultados dos grupos, isoladamente, 15,30 e 45 semanas são apresentados por capítulos apenas para facilitar a visualização dos dados; entretanto, o resultado conjunto dos três momentos de avaliação, apresentado após a exposição isolada, foi o objeto da discussão neste trabalho.

\section{1- Caracterização do momento inicial de obesidade}

O peso corporal foi semelhante nas duas primeiras semanas de tratamento em ambos os grupos $\mathrm{C}$ e $\mathrm{Ob}$; entretanto, após a $3^{\mathrm{a}}$ semana de tratamento, o peso corporal dos animais $\mathrm{Ob}$ foi significativamente maior que os C (Figura 1). Neste momento, o maior peso corporal dos Ob foi associado ao aumento do índice de adiposidade, caracterizando o momento inicial de obesidade $\left(\mathrm{C}_{0}\right.$ e $\left.\mathrm{Ob}_{0}\right)$ (Figura 1; Tabela 1$)$.

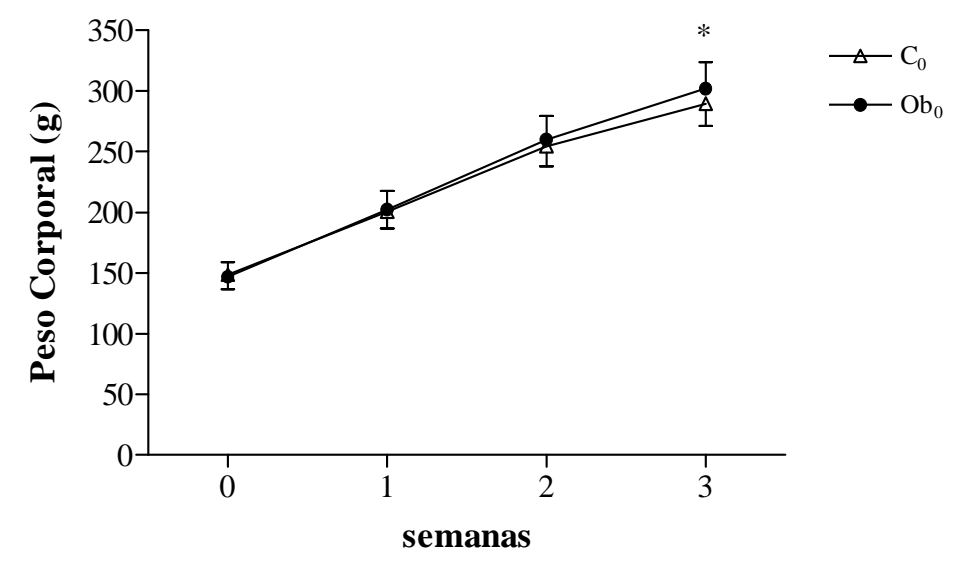

Figura 1. Evolução semanal do peso corporal dos animais controle $\left(\mathrm{C}_{0}, \mathrm{n}=19\right)$ e obeso $\left(\mathrm{Ob}_{0}, \mathrm{n}=19\right)$. Dados expressos em média \pm desvio padrão. ANOVA para o modelo de medidas repetidas em grupos independentes e complementada com o teste post-hoc de Bonferroni. * $\mathrm{p}<0,05$ vs $\mathrm{C}_{0}$.

A Tabela 1 mostra o perfil nutricional e a pressão arterial dos animais $\mathrm{C}_{0}$ e $\mathrm{Ob}_{0}$. $\mathrm{O}$ peso corporal final, o ganho de peso, os depósitos de gordura epididimal e visceral, a gordura corporal total, o índice de adiposidade foram maiores no $\mathrm{Ob}_{0}$ do que no $\mathrm{C}_{0}$. Não houve 
diferença significativa entre os grupos no depósito de gordura retroperitoneal e na pressão arterial sistólica final. Durante o período experimental, os animais $\mathrm{Ob}_{0}$ ingeriram menor quantidade de ração que os $\mathrm{C}_{0}$, porém, a eficiência alimentar foi maior nos animais $\mathrm{Ob}_{0}$ do que no $\mathrm{C}_{0}$. Não houve diferença estatística na ingestão calórica entre os grupos.

Tabela 1. Perfil nutricional no momento inicial de obesidade

\begin{tabular}{ccc}
\hline & \multicolumn{2}{c}{ Grupos } \\
\cline { 2 - 3 } Variáveis & $\mathbf{C}_{\mathbf{0}}(\mathbf{n = 1 9})$ & $\mathbf{O b}_{\mathbf{0}}(\mathbf{n}=\mathbf{1 9})$ \\
\hline PCI (g) & $148 \pm 12$ & $147 \pm 12$ \\
PCF (g) & $290 \pm 18$ & $302 \pm 22^{*}$ \\
\hline Ganho de peso (g) & $142 \pm 15$ & $155 \pm 17^{*}$ \\
\hline Epididimal (g) & $4,6 \pm 0,8$ & $5,6 \pm 1,2^{*}$ \\
\hline Retroperitoneal (g) & $5,4 \pm 1,5$ & $6,4 \pm 1,7$ \\
Visceral (g) & $4,1 \pm 1,0$ & $4,9 \pm 0,9^{*}$ \\
\hline Gordura corporal total (g) & $14 \pm 3$ & $17 \pm 3^{*}$ \\
\hline Índice de adiposidade & $4,9 \pm 1,0$ & $5,6 \pm 0,9^{*}$ \\
\hline PAS (mmHg) & $127 \pm 8$ & $131 \pm 14$ \\
\hline Ingestão alimentar (g/dia) & $26 \pm 2$ & $22 \pm 2^{*}$ \\
\hline Ingestão calórica (kcal/dia) & $77 \pm 5$ & $80 \pm 7$ \\
\hline Eficiência alimentar (\% kcal/g) & $8,7 \pm 0,6$ & $9,2 \pm 0,71^{*}$ \\
\hline & & \\
\hline
\end{tabular}

Dados expressos em média \pm desvio-padrão. PCI: peso corporal inicial; PCF: peso corporal final; PAS: pressão arterial sistólica. Dados expressos em média \pm desvio padrão. $\mathrm{C}_{0}$ : controle; $\mathrm{Ob}_{0}$ : obeso. Teste " $t$ " de Student para amostras independentes. * $\mathrm{p}<0,05$ vs $\mathrm{C}_{0}$. 


\section{2- Obesidade 15 semanas}

\subsection{1- Composição dos grupos controle e obeso}

$\mathrm{Na} 15^{\mathrm{a}}$ semana de tratamento após o início da obesidade foram sorteados 12 animais de cada grupo. Após a aplicação do critério estabelecido para a composição dos grupos, nove animais do grupo controle $\left(\mathrm{C}_{15} ; \mathrm{n}=9\right)$ e oito animais do grupo obeso $\left(\mathrm{Ob}_{15} ; \mathrm{n}=8\right)$ permaneceram no estudo.

\subsection{2- Perfil nutricional}

A Tabela 2 mostra o perfil nutricional dos animais $\mathrm{C}_{15} \mathrm{e} \mathrm{Ob}_{15}$. O peso corporal inicial e final, o ganho de peso, os depósitos de gordura epididimal, retroperitoneal e visceral, a gordura corporal total, o índice de adiposidade e os níveis séricos de triglicérides, colesterol e proteína foram maiores no $\mathrm{Ob}_{15}$ do que no $\mathrm{C}_{15}$. Não houve diferença significativa na eficiência alimentar e nas demais dosagens séricas entre os grupos. Durante o período experimental, os animais $\mathrm{Ob}_{15}$ ingeriram quantidade semelhante de ração, entretanto, a ingestão calórica foi maior nos animais $\mathrm{Ob}_{15}$ em relação ao $\mathrm{C}_{15}$. 
Tabela 2. Perfil nutricional após 15 semanas

\begin{tabular}{|c|c|c|}
\hline \multirow[b]{2}{*}{ Variáveis } & \multicolumn{2}{|c|}{ Grupos } \\
\hline & $C_{15}(n=9)$ & $\mathrm{Ob}_{15}(\mathrm{n}=8)$ \\
\hline PCI (g) & $276 \pm 18$ & $314 \pm 18^{*}$ \\
\hline PCF (g) & $459 \pm 18$ & $568 \pm 44^{*}$ \\
\hline Ganho de peso (g) & $183 \pm 21$ & $254 \pm 38^{*}$ \\
\hline Ingestão alimentar (g/dia) & $25,4 \pm 1,1$ & $25,9 \pm 2,1$ \\
\hline Ingestão calórica (kcal/dia) & $75,1 \pm 3,1$ & $94,6 \pm 7,5^{*}$ \\
\hline Eficiência alimentar (\%) & $2,32 \pm 0,24$ & $2,55 \pm 0,30$ \\
\hline Gordura Epididimal (g) & $7,1 \pm 1,4$ & $13,7 \pm 4,1^{*}$ \\
\hline Gordura Retroperitoneal (g) & $7,5 \pm 1,6$ & $19,3 \pm 8,5^{*}$ \\
\hline Gordura Visceral (g) & $5,5 \pm 0,9$ & $12,5 \pm 4,8^{*}$ \\
\hline Gordura corporal total (g) & $20 \pm 3$ & $46 \pm 17^{*}$ \\
\hline Índice de Adiposidade (\%) & $4,38 \pm 0,58$ & $7,89 \pm 2,37 *$ \\
\hline Glicose (mg/dL) & $163 \pm 22$ & $176 \pm 13$ \\
\hline Triglicérides (mg/dL) & $61 \pm 11$ & $80 \pm 18^{*}$ \\
\hline Colesterol (mg/dL) & $56 \pm 9$ & $74 \pm 11 *$ \\
\hline HDL (mg/dL) & $22 \pm 3$ & $26 \pm 5$ \\
\hline LDL (mg/dL) & $14 \pm 4$ & $15 \pm 4$ \\
\hline Proteína (g/dL) & $5,9 \pm 0,3$ & $6,3 \pm 0,2 *$ \\
\hline NEFA (mmol/L) & $0,44 \pm 0,09$ & $0,48 \pm 0,11$ \\
\hline
\end{tabular}

Dados expressos em média \pm desvio padrão. $\mathrm{C}_{15}$ : controle; $\mathrm{Ob}_{15}$ : obeso; PCI: peso corporal inicial; PCF: peso corporal final; HDL: lipoproteína de alta intensidade; LDL: lipoproteína de baixa intensidade; NEFA: ácidos graxos não-esterificados. Teste " $t$ " de Student para amostras independentes. * $p<0,05$ vs $\mathrm{C}_{15}$. 


\subsection{3- Pressão arterial sistólica}

A Figura 2 mostra o resultado da pressão arterial sistólica final realizado nos grupos $\mathrm{C}_{15}$ e $\mathrm{Ob}_{15}$. Não houve diferença significativa na pressão arterial sistólica final entre os grupos; portanto, a obesidade durante 15 semanas não acarretou hipertensão arterial.

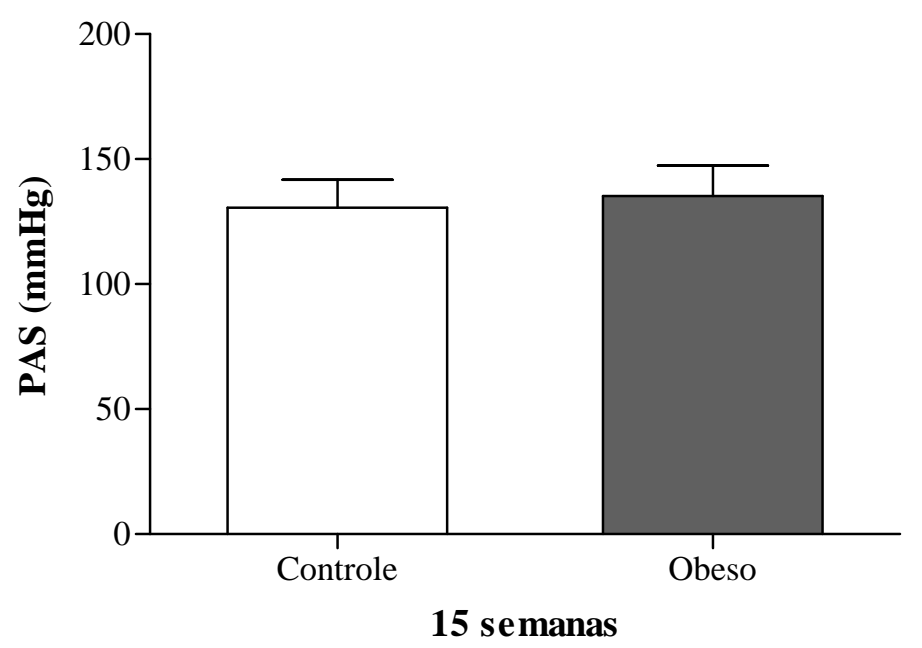

Figura 2. Pressão arterial sistólica final dos animais controle $\left(\mathrm{C}_{15}, \mathrm{n}=9\right)$ e obeso $\left(\mathrm{Ob}_{15}, \mathrm{n}=8\right)$ submetidos à 15 semanas de tratamento. Dados expressos em média \pm desvio padrão. Teste " $t$ " de Student para amostras independentes. Não houve diferença estatística entre os grupos.

\subsection{4- Teste de tolerância à glicose}

As Figuras 3 e 4 mostram o resultado do teste de tolerância à glicose realizado nos grupos $\mathrm{C}_{15}$ e $\mathrm{Ob}_{15}$. Os níveis glicêmicos foram semelhantes no momento basal entre os grupos. Após a administração intraperitoneal de glicose, a glicemia foi similar nos momentos $15(\mathrm{p}=0,07), 30(\mathrm{p}=0,07)$ e 120 minutos $(\mathrm{p}=0,15)$ entre os grupos; entretanto, o grupo $\mathrm{Ob}_{15}$ apresentou níveis glicêmicos elevados nos momentos 60 e 90 em relação ao $C_{15}$ (Figura 3). A área glicêmica foi maior no grupo $\mathrm{Ob}_{15}$ em relação ao $\mathrm{C}_{15}$ (Figura 4). 


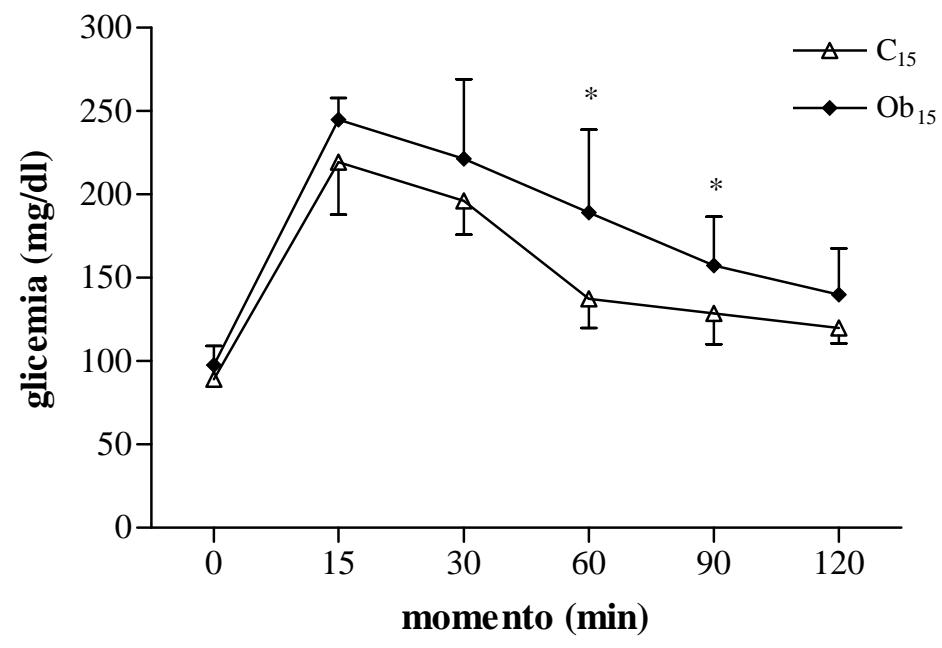

Figura 3. Teste de tolerância à glicose dos animais controle $\left(\mathrm{C}_{15}\right.$, $\mathrm{n}=8)$ e obeso $\left(\mathrm{Ob}_{15}, \mathrm{n}=8\right)$ obeso submetidos à 15 semanas de tratamento. Dados expressos em média \pm desvio padrão. Análise de variância para o modelo de medidas repetidas em grupos independentes e complementada com o teste post-hoc de Bonferroni. * $\mathrm{p}<0,05$ vs $\mathrm{C}_{15}$.

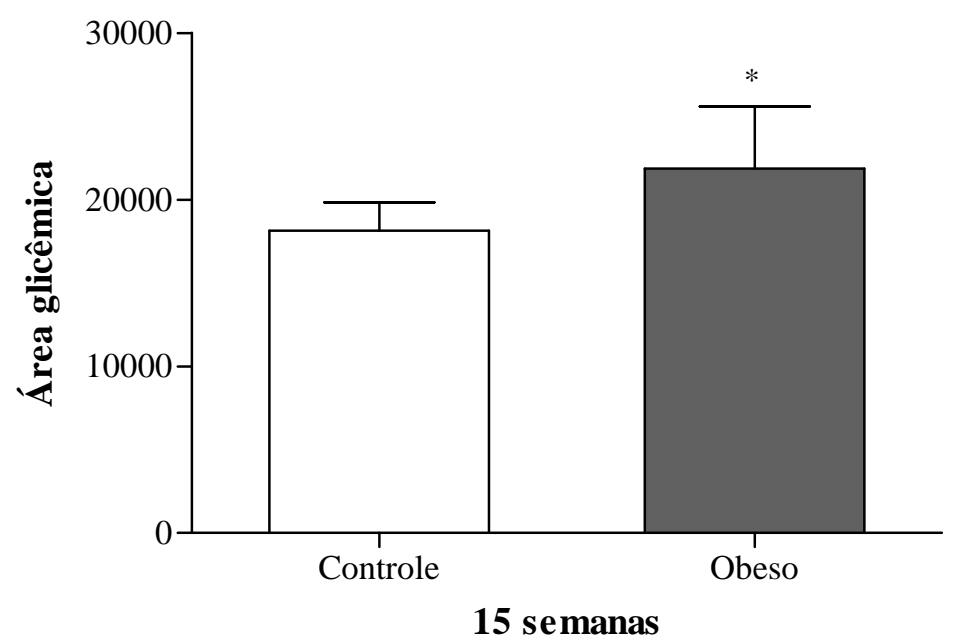

Figura 4. Área glicêmica, obtida no teste de tolerância à glicose, dos animais controle $\left(\mathrm{C}_{15}, \mathrm{n}=8\right)$ e obeso $\left(\mathrm{Ob}_{15}\right.$, $\mathrm{n}=8$ ) obeso submetidos à 15 semanas de tratamento. Dados expressos em média \pm desvio padrão. Teste " $t$ " de Student para amostras independentes. $* \mathrm{p}<0,05$ vs $\mathrm{C}_{15}$.

\subsection{5- Índice de resistência à insulina}

A Figura 5 mostra o resultado do índice HOMA-IR dos grupos $\mathrm{C}_{15}$ e $\mathrm{Ob}_{15}$. Os animais

$\mathrm{Ob}_{15}$ apresentaram maior índice HOMA-IR do que o $\mathrm{C}_{15}$. 


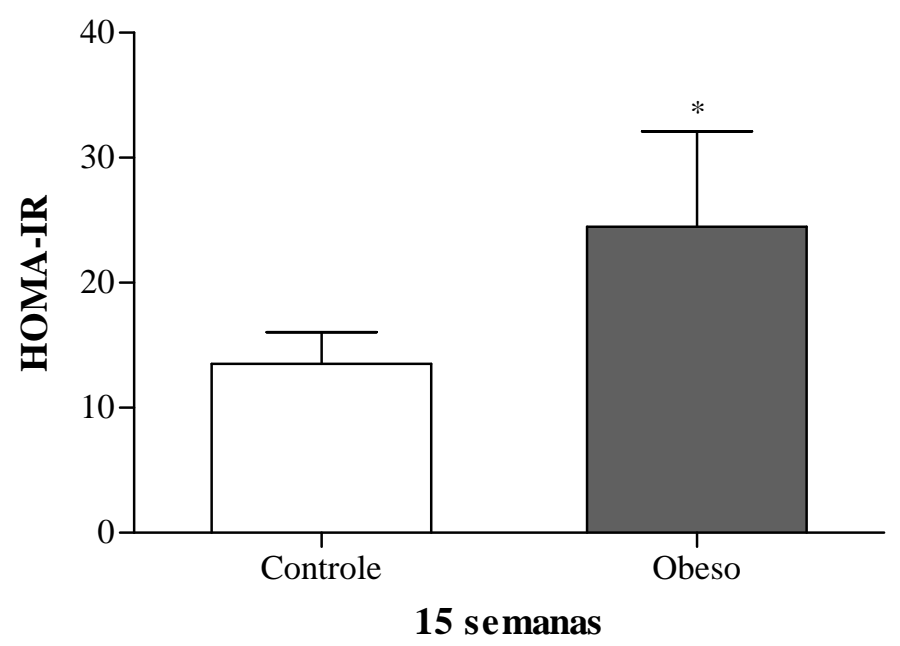

Figura 5. Índice HOMA-IR (resistência à insulina) dos animais controle $\left(\mathrm{C}_{15}, \mathrm{n}=8\right)$ e obeso $\left(\mathrm{Ob}_{15}, \mathrm{n}=8\right)$ submetidos à 15 semanas de tratamento. Dados expressos em média \pm desvio padrão. Dados expressos em média \pm desvio padrão. Teste " $t$ " de Student para amostras independentes. * $\mathrm{p}<0,05$ vs $\mathrm{C}_{15}$.

\subsection{6- Análise sérica dos hormônios insulina e leptina}

A Figura 6 mostra as dosagens de insulina e leptina dos ratos $\mathrm{C}_{15}$ e $\mathrm{Ob}_{15}$. Após quinze semanas de obesidade os animais $\mathrm{Ob}_{15}$ apresentaram níveis séricos de insulina e leptina maiores que os $\mathrm{C}_{15}$.

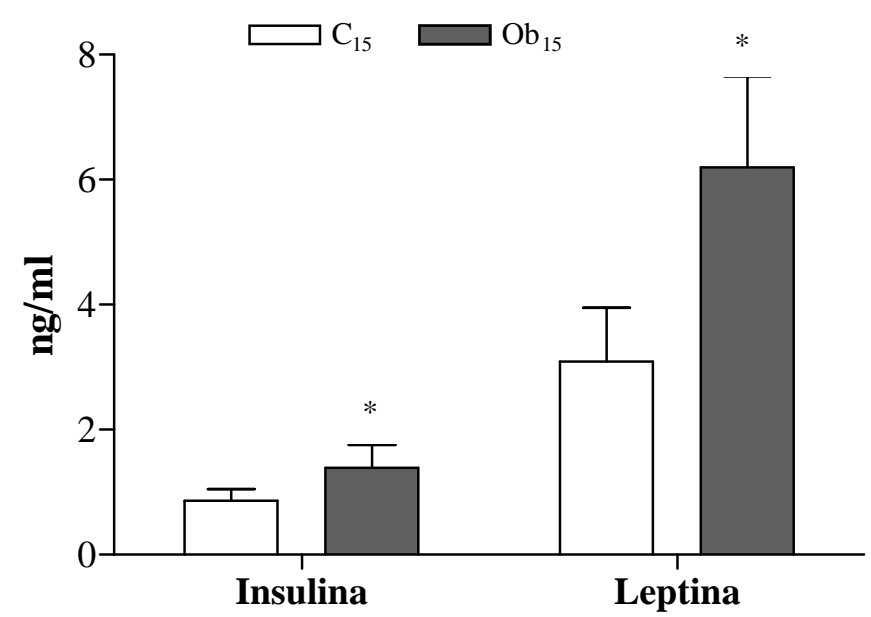

Figura 6. Níveis séricos de insulina e leptina dos animais controle $\left(\mathrm{C}_{15}, \mathrm{n}=8\right)$ e obeso $\left(\mathrm{Ob}_{15}, \mathrm{n}=8\right)$ submetidos à 15 semanas de tratamento. Dados expressos em média \pm desvio padrão. Teste " $t$ " de Student para amostras independentes. $* \mathrm{p}<0,05$ vs $\mathrm{C}_{15}$. 


\subsection{7- Análise sérica dos hormônios tireoidianos}

As Figuras 7, 8 e 9 mostram as dosagens séricas dos hormônios tireoidianos TSH, T4 e T3 dos ratos $\mathrm{C}_{15}$ e $\mathrm{Ob}_{15}$. Após quinze semanas de obesidade os animais $\mathrm{Ob}_{15}$ apresentaram níveis séricos de TSH menores que o $\mathrm{C}_{15}$. Não houve diferença significativa entre os grupos nas dosagens de T4 e T3 (T3; $\mathrm{p}=0,08)$.

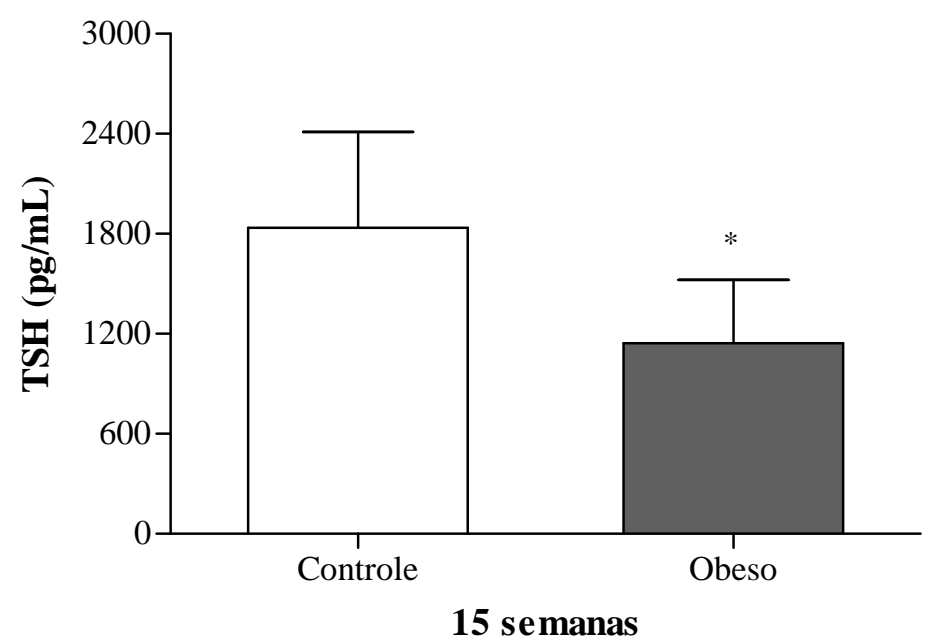

Figura 7. Níveis séricos de TSH dos animais controle $\left(\mathrm{C}_{15}\right.$, $\mathrm{n}=6)$ e obeso $\left(\mathrm{Ob}_{15}, \mathrm{n}=6\right)$ submetidos à 15 semanas de tratamento. Dados expressos em média \pm desvio padrão. Teste " $t$ " de Student para amostras independentes. * p<0,05 vs $\mathrm{C}_{15}$.

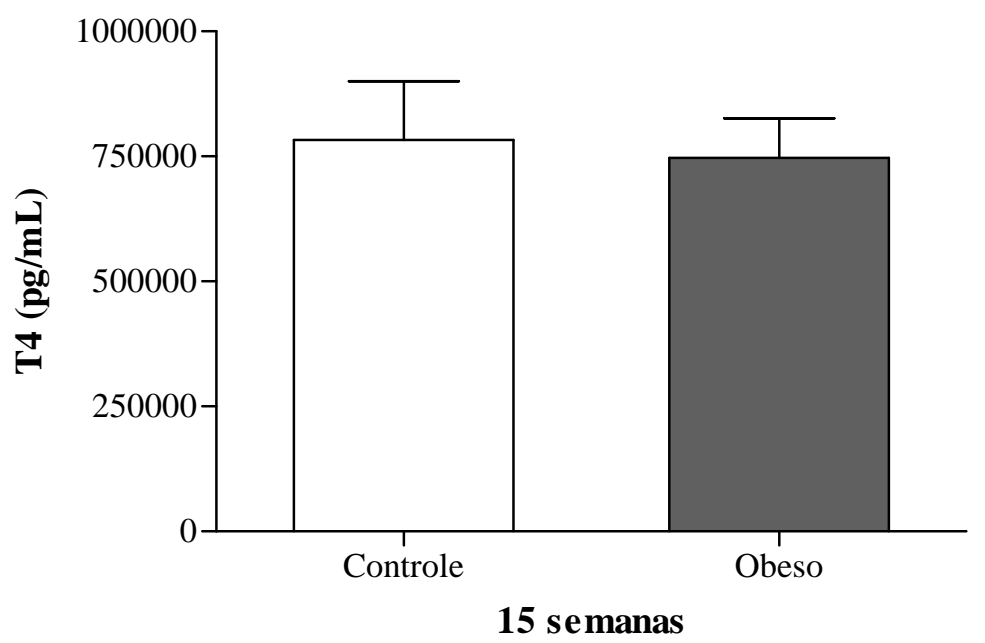

Figura 8. Níveis séricos de $\mathrm{T} 4$ dos animais controle $\left(\mathrm{C}_{15}\right.$, $\mathrm{n}=6)$ e obeso $\left(\mathrm{Ob}_{15}, \mathrm{n}=6\right)$ submetidos à 15 semanas de tratamento. Dados expressos em média \pm desvio padrão. Teste " $t$ " de Student para amostras independentes. Não houve diferença estatística entre os grupos. 


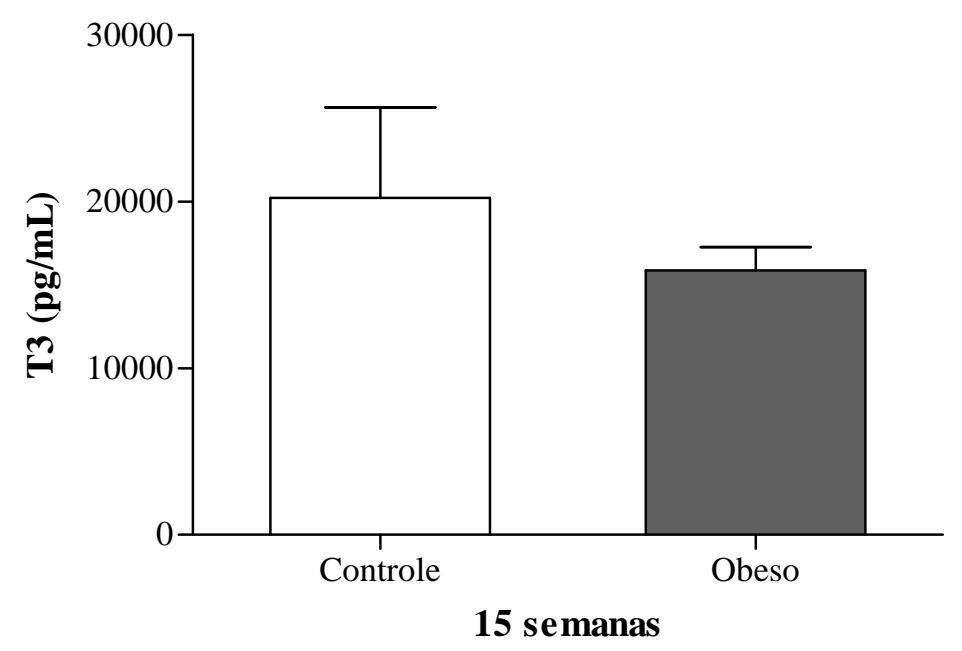

Figura 9. Níveis séricos de $\mathrm{T} 3$ dos animais controle $\left(\mathrm{C}_{15}\right.$, $\mathrm{n}=6)$ e obeso $\left(\mathrm{Ob}_{15}, \mathrm{n}=6\right)$ submetidos à 15 semanas de tratamento. Dados expressos em média \pm desvio padrão. Teste " $t$ " de Student para amostras independentes. Não houve diferença estatística entre os grupos.

\subsection{8- Estrutura do coração post mortem}

\subsubsection{1- Análise macroscópica}

A Tabela 3 mostra a estrutura macroscópica cardíaca post mortem dos ratos $\mathrm{C}_{15}$ e $\mathrm{Ob}_{15}$. Após 15 semanas de obesidade, os animais $\mathrm{Ob}_{15}$ apresentaram aumento nos pesos do coração, dos ventrículos esquerdo e direito, do átrio e nas relações coração/tíbia, VE/tíbia, VD/tíbia e AT/tíbia em relação aos animais $C_{15}$. Não houve diferença significativa nas relações coração/PCF, VE/PCF, VD/PCF e AT/PCF e no comprimento da tíbia entre os dois grupos. 
Tabela 3. Estrutura macroscópica cardíaca post mortem após 15 semanas

\begin{tabular}{|c|c|c|}
\hline \multirow[b]{2}{*}{ Variáveis } & \multicolumn{2}{|c|}{ Grupos } \\
\hline & $C_{15}(n=9)$ & $\mathrm{Ob}_{15}(\mathrm{n}=8)$ \\
\hline PCF (g) & $459 \pm 18$ & $568 \pm 44^{*}$ \\
\hline tíbia (cm) & $4,38 \pm 0,07$ & $4,42 \pm 0,07$ \\
\hline Coração (g) & $1,13 \pm 0,11$ & $1,35 \pm 0,05 *$ \\
\hline VE (g) & $0,80 \pm 0,09$ & $0,95 \pm 0,05^{*}$ \\
\hline VD $(g)$ & $0,24 \pm 0,02$ & $0,29 \pm 0,02 *$ \\
\hline $\operatorname{AT}(g)$ & $0,09 \pm 0,01$ & $0,11 \pm 0,01^{*}$ \\
\hline Coração/PCF (mg/g) & $2,46 \pm 0,19$ & $2,39 \pm 0,24$ \\
\hline VE/PCF (mg/g) & $1,74 \pm 0,17$ & $1,69 \pm 0,18$ \\
\hline VD/PCF (mg/g) & $0,52 \pm 0,06$ & $0,51 \pm 0,05$ \\
\hline AT/PCF (mg/g) & $0,20 \pm 0,02$ & $0,19 \pm 0,02$ \\
\hline Coração/tíbia (g/cm) & $0,26 \pm 0,02$ & $0,30 \pm 0,02 *$ \\
\hline VE/tíbia (g/cm) & $0,18 \pm 0,02$ & $0,22 \pm 0,01^{*}$ \\
\hline VD/tíbia (g/cm) & $0,055 \pm 0,01$ & $0,065 \pm 0,01 *$ \\
\hline AT/tíbia (g/cm) & $0,021 \pm 0,003$ & $0,025 \pm 0,002 *$ \\
\hline
\end{tabular}

Dados expressos em média \pm desvio padrão. $\mathrm{C}_{15}$ : controle; $\mathrm{Ob}_{15}$ : obeso submetidos à 15 semanas de tratamento; VE: peso do ventrículo esquerdo; VD: peso do ventrículo direito; AT: peso do átrio; VE/PCF: relação do peso do ventrículo esquerdo pelo peso corporal final; VD/PCF: relação do peso do ventrículo direito pelo peso corporal final; AT/PCF: relação do peso do átrio pelo peso corporal final. VE/tíbia: relação do peso do ventrículo esquerdo pelo comprimento da tíbia; VD/tíbia: relação do peso do ventrículo direito pelo comprimento da tíbia; AT/tíbia: relação do peso do átrio pelo comprimento da tíbia. Teste " $t$ " de Student para amostras independentes. * p<0,05 vs $\mathrm{C}_{15}$. 


\subsubsection{2- Análise microscópica}

As Figuras 10 e 11 mostram a área seccional transversa do miócito realizadas no ventrículo esquerdo dos animais $\mathrm{C}_{15}$ e $\mathrm{Ob}_{15}$. Não houve diferença significativa na área seccional dos miócitos nos fragmentos do VE entre os dois grupos (Figura 10).

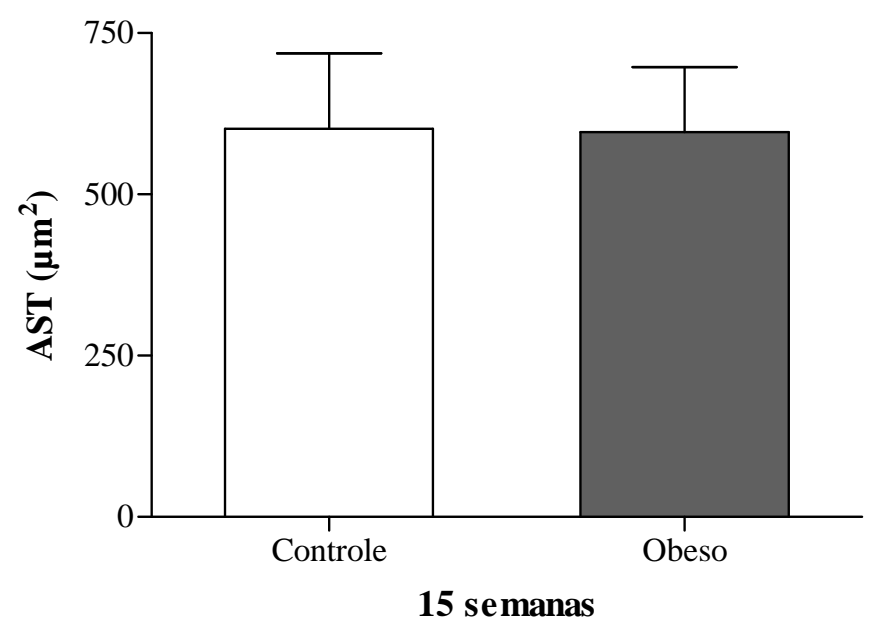

Figura 10. Secções transversas de fragmentos do VE dos grupos controle $\left(\mathrm{C}_{15}, \mathrm{n}=9\right)$ e obeso $\left(\mathrm{Ob}_{15}, \mathrm{n}=8\right)$ submetidos à 15 semanas de tratamento. Técnica de Retículina de gömori 40X. Dados expressos em média \pm desvio padrão. Teste " $t$ " de Student para amostras independentes. Não houve diferença significativa entre os grupos.
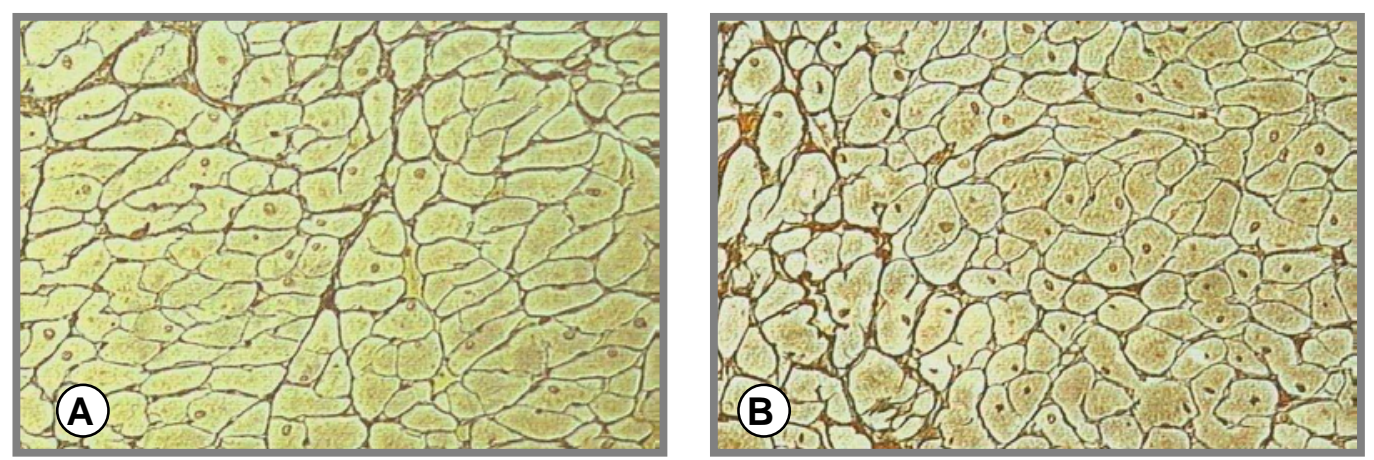

Figura 11. Secções transversas subendocárdicas do ventrículo esquerdo (VE) dos grupos controle e obeso submetidos à 15 semanas de tratamento; $\mathbf{A}$ : fragmento do $\mathrm{VE}$ do grupo $\mathrm{C}_{15} ; \mathbf{B}$ : fragmento do VE do grupo $\mathrm{Ob}_{15}$; Técnica de Reticulina de Gömori 40X. 


\subsection{9- Expressão de RNAm miocárdico}

As Figuras 12 e 13 ilustram a expressão do RNAm das proteínas relacionadas com o trânsito de cálcio miocárdico, CANAL L, RyR, SERCA, PLB, NXC e CSQ nos animais $\mathrm{C}_{15} \mathrm{e}$ $\mathrm{Ob}_{15}$. A expressão gênica do CANAL L, da SERCA, da PLB, do NCX e da CSQ foi diminuída no grupo $\mathrm{Ob}_{15}$ em relação ao $\mathrm{C}_{15}$. Entretanto, não foram observadas diferenças significativas nos níveis de RNAm de RyR entre os grupos. Os níveis de RNAm da $\beta$-actina, dados não mostrados, foram semelhantes entre os grupos.

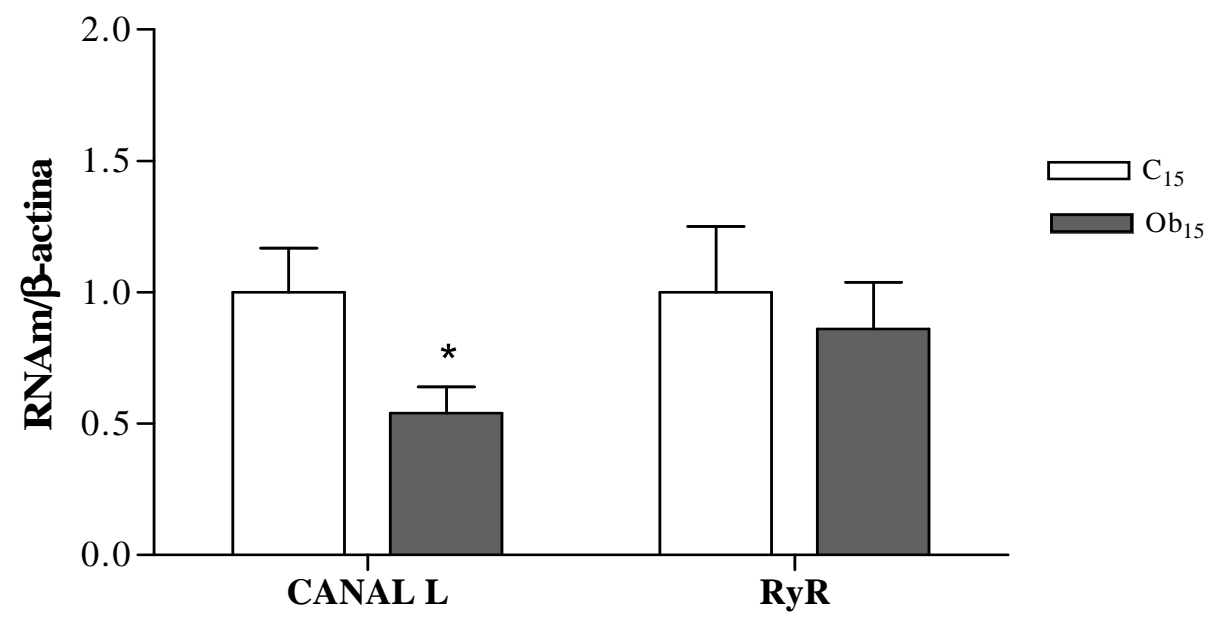

Figura 12. Expressão gênica de CANAL L e RyR no miocárdio dos animais controle $\left(\mathrm{C}_{15}, \mathrm{n}=6\right)$ e obeso $\left(\mathrm{Ob}_{15}, \mathrm{n}=6\right)$ submetidos à 15 semanas de tratamento. Dados expressos em média \pm desvio padrão Teste “ $t$ ” de Student. * $\mathrm{p}<0,05$ vs $\mathrm{C}_{15}$.

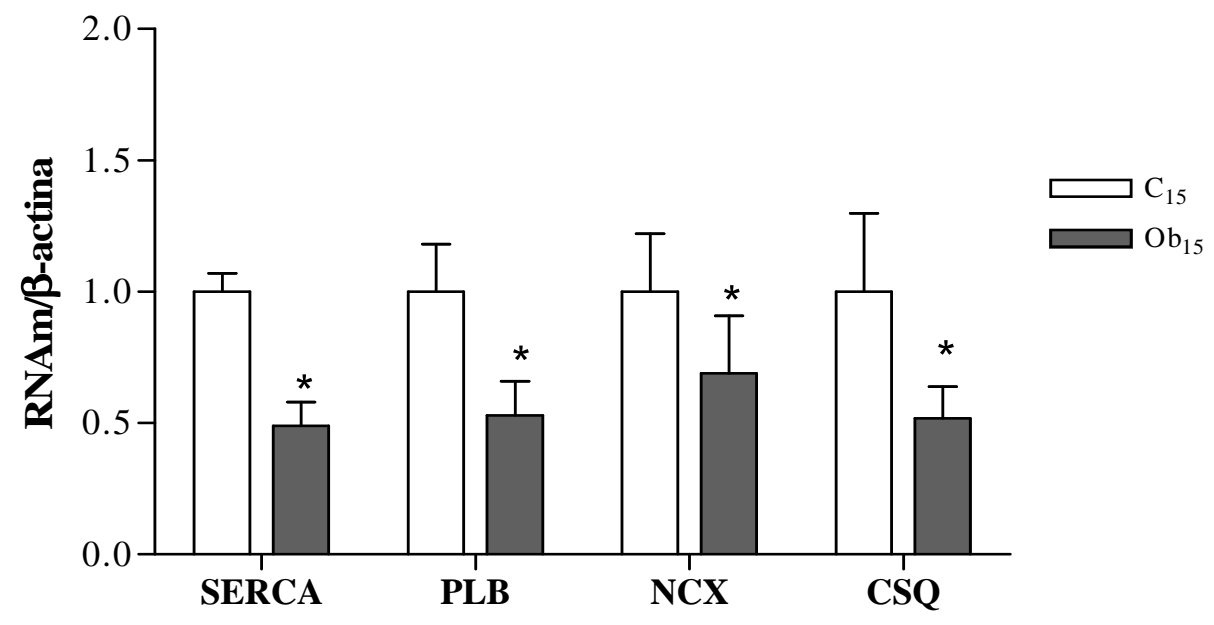

Figura 13. Expressão gênica de SERCA, PLB, NCX e CSQ no miocárdio dos animais controle $\left(\mathrm{C}_{15}, \mathrm{n}=6\right)$ e obeso $\left(\mathrm{Ob}_{15}, \mathrm{n}=6\right)$ submetidos à 15 semanas de tratamento. Dados expressos em média \pm desvio padrão. Teste " $t$ " de Student. * $\mathrm{p}<0,05$ vs $\mathrm{C}_{15}$. 


\subsubsection{0- Expressão das proteínas miocárdicas}

As Figuras 14 e 15 ilustram a expressão das proteínas relacionadas com o trânsito de cálcio intracelular nos animais $\mathrm{C}_{15} \mathrm{e} \mathrm{Ob}_{15}$. A Figura 14 mostra que os animais $\mathrm{Ob}_{15}$ apresentaram níveis protéicos menores de PLB do que o $\mathrm{C}_{15}$. Não houve diferença entre os grupos nos níveis protéicos de CANAL L, SERCA e na razão SERCA/PLB. Os animais $\mathrm{Ob}_{15}$ apresentam níveis protéicos de pPLB Ser16 diminuídos em relação ao $\mathrm{C}_{15}$. Entretanto, a obesidade promoveu aumento da razão entre pPLB Thr17 e PLB em relação ao $\mathrm{C}_{15}$ (Figura 15). Não houve diferença na expressão de pPLB Thr 17 e na razão pPLB Ser16 e PLB entre os grupos.

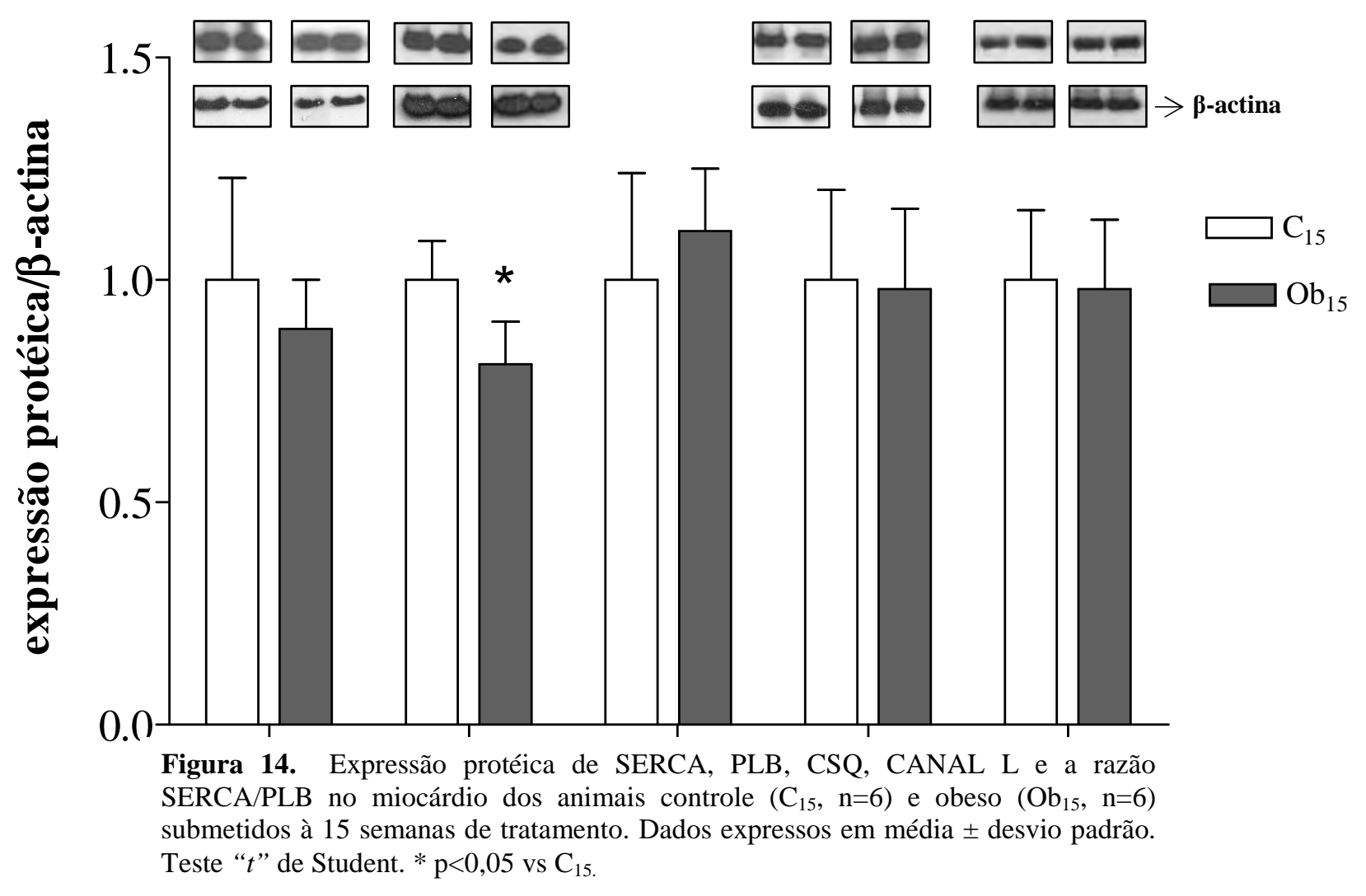




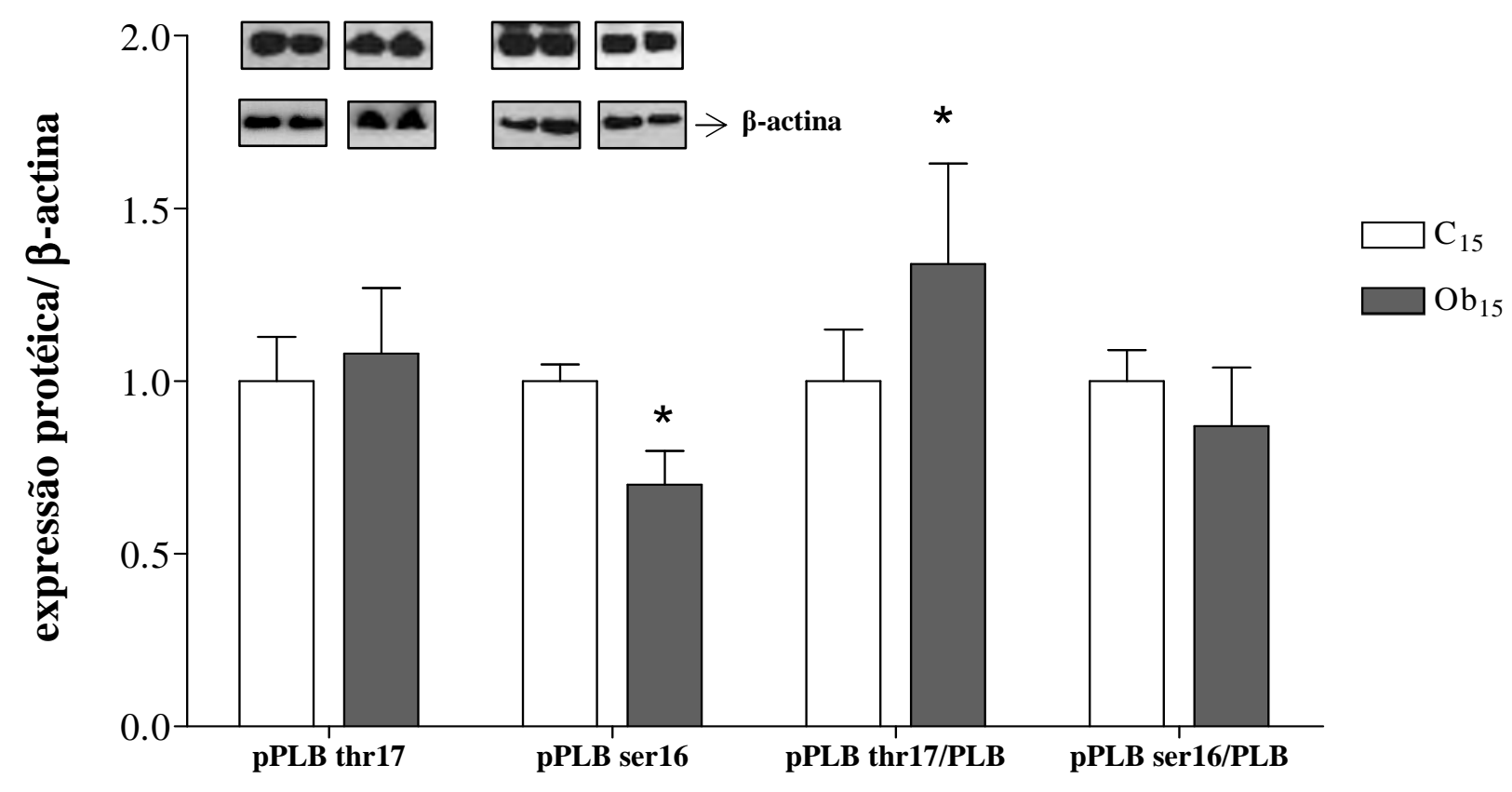

Figura 15. Expressão protéica de pPLB thr 17, pPLB ser16 e as razões pPLB thr17/PLB e pPLB ser16/PLB no miocárdio dos animais controle $\left(\mathrm{C}_{15}, \mathrm{n}=6\right)$ e obeso $\left(\mathrm{Ob}_{15}, \mathrm{n}=6\right)$ submetidos à 15 semanas de tratamento. Dados expressos em média \pm desvio padrão. * $\mathrm{p}<0,05$ vs $\mathrm{C}_{15}$. Teste “ $t$ ” de Student.

\subsubsection{1- Determinação do teor de água nos tecidos cardíaco, pulmonar e hepático}

A Tabela 4 mostra a porcentagem de umidade dos tecidos cardíaco, pulmonar e hepático dos ratos $\mathrm{C}_{15}$ e $\mathrm{Ob}_{15}$. Os animais $\mathrm{Ob}_{15}$ apresentaram menor quantidade de água no fígado que os animais $C_{15}$. Entretanto, não houve diferença significativa no teor de água do VE, VD, AT e pulmão. 
Tabela 4. Teor de água nos tecidos cardíaco, pulmonar e hepático após 15 semanas

\begin{tabular}{|c|c|c|}
\hline \multirow[b]{2}{*}{ Variáveis } & \multicolumn{2}{|c|}{ Grupos } \\
\hline & $C_{15}(n=9)$ & $O b_{15}(n=8)$ \\
\hline VE (\%) & $75,5 \pm 0,8$ & $75,2 \pm 0,6$ \\
\hline VD (\%) & $75,6 \pm 1,0$ & $75,3 \pm 1,1$ \\
\hline $\mathrm{AT}(\%)$ & $77,6 \pm 1,1$ & $77,7 \pm 1,5$ \\
\hline Pulmão (\%) & $77,4 \pm 0,7$ & $77,3 \pm 0,6$ \\
\hline Fígado (\%) & $68,0 \pm 1,0$ & $66,4 \pm 1,0^{*}$ \\
\hline $\begin{array}{l}\text { Dados expressos em média } \\
\text { semanas de tratamento; VE: } \\
\text { direito; AT: peso do átrio. } \\
\text { p }<0,05 \text { vs } \mathrm{C}_{15}\end{array}$ & $\begin{array}{l}\mathrm{C}_{15} \text { : controle } \\
\text { ulo esquerdo; } \\
\text { dent para ame }\end{array}$ & $\begin{array}{l}\text { submetidos à } 1 \\
\text { eso do ventrícul } \\
\text { independentes. }\end{array}$ \\
\hline
\end{tabular}




\section{3- Obesidade 30 semanas}

\subsection{1- Composição dos grupos controle e obeso}

$\mathrm{Na} 30^{\text {a }}$ semana de tratamento após o início da obesidade foram sorteados 12 animais de cada grupo. Após a aplicação do critério estabelecido para a composição dos grupos de 30 semanas, dez animais do grupo controle $\left(\mathrm{C}_{30} ; \mathrm{n}=10\right)$ e dez animais do grupo obeso $\left(\mathrm{Ob}_{30}\right.$; $\mathrm{n}=10)$ permaneceram no estudo.

\subsection{2- Perfil nutricional}

A Tabela 5 mostra o perfil nutricional dos animais $\mathrm{C}_{30}$ e $\mathrm{Ob}_{30}$. O peso corporal inicial e final, o ganho de peso, os depósitos de gordura epididimal, retroperitoneal e visceral, a gordura corporal total, o índice de adiposidade e os níveis de triglicérides foram maiores no $\mathrm{Ob}_{30}$ em relação ao $\mathrm{C}_{30}$. Não houve diferença significativa entre os grupos nas demais dosagens séricas. Durante o período experimental, ambos os grupos ingeriram quantidade semelhante de ração, entretanto, a ingestão calórica e a eficiência alimentar foram maiores nos animais $\mathrm{Ob}_{30}$ do que no $\mathrm{C}_{30}$. 
Tabela 5. Perfil nutricional após 30 semanas

\begin{tabular}{|c|c|c|}
\hline \multirow[b]{2}{*}{ Variáveis } & \multicolumn{2}{|c|}{ Grupos } \\
\hline & $\mathrm{C}_{30}(\mathrm{n}=10)$ & $\mathrm{Ob}_{30}(n=10)$ \\
\hline PCI (g) & $294 \pm 12$ & $315 \pm 14^{*}$ \\
\hline PCF (g) & $490 \pm 33$ & $608 \pm 22^{*}$ \\
\hline Ganho de peso (g) & $196 \pm 23$ & $293 \pm 21^{*}$ \\
\hline Epididimal (g) & $6,1 \pm 2,5$ & $12,0 \pm 3,0^{*}$ \\
\hline Retroperitoneal (g) & $8,5 \pm 2,5$ & $19,4 \pm 4,3^{*}$ \\
\hline Visceral (g) & $4,5 \pm 1,6$ & $12,0 \pm 3,0 *$ \\
\hline Gordura total (g) & $19 \pm 5$ & $43 \pm 8 *$ \\
\hline Índice de Adiposidade (\%) & $3,9 \pm 0,9$ & $7,1 \pm 1,3 *$ \\
\hline Ingestão alimentar (g/dia) & $26,1 \pm 1,7$ & $25,9 \pm 1,2$ \\
\hline Ingestão calórica (kcal/dia) & $77,0 \pm 4,9$ & $94,7 \pm 4,2^{*}$ \\
\hline Eficiência alimentar (\%) & $1,21 \pm 0,09$ & $1,47 \pm 0,12^{*}$ \\
\hline Glicose (mg/dL) & $157 \pm 15$ & $172 \pm 21$ \\
\hline Triglicérides (mg/dL) & $54 \pm 9$ & $93 \pm 19 *$ \\
\hline Colesterol (mg/dL) & $71 \pm 9$ & $73 \pm 16$ \\
\hline HDL (mg/dL) & $25 \pm 4$ & $26 \pm 4$ \\
\hline LDL (mg/dL) & $15 \pm 3$ & $14 \pm 2$ \\
\hline Proteína (g/dL) & $6,4 \pm 0,4$ & $6,7 \pm 0,5$ \\
\hline NEFA (mmol/L) & $0,42 \pm 0,10$ & $0,48 \pm 0,11$ \\
\hline
\end{tabular}

Dados expressos em média \pm desvio padrão. $\mathrm{C}_{30}$ : controle; $\mathrm{Ob}_{30}$ : obeso submetidos à 30 semanas de tratamento; PCI: peso corporal inicial; PCF: peso corporal final; HDL: lipoproteína de alta intensidade; LDL: lipoproteína de baixa intensidade; NEFA: ácidos graxos não-esterificados. Teste " $t$ " de Student para amostras independentes. * $\mathrm{p}<0,05$ vs $\mathrm{C}_{30}$. 


\subsection{3- Pressão arterial sistólica}

A Figura 16 mostra o resultado da pressão arterial sistólica final realizado nos grupos $\mathrm{C}_{30}$ e $\mathrm{Ob}_{30}$. Não houve diferença significativa na pressão arterial sistólica final entre os grupos, portanto, a obesidade durante 30 semanas não acarretou hipertensão arterial.

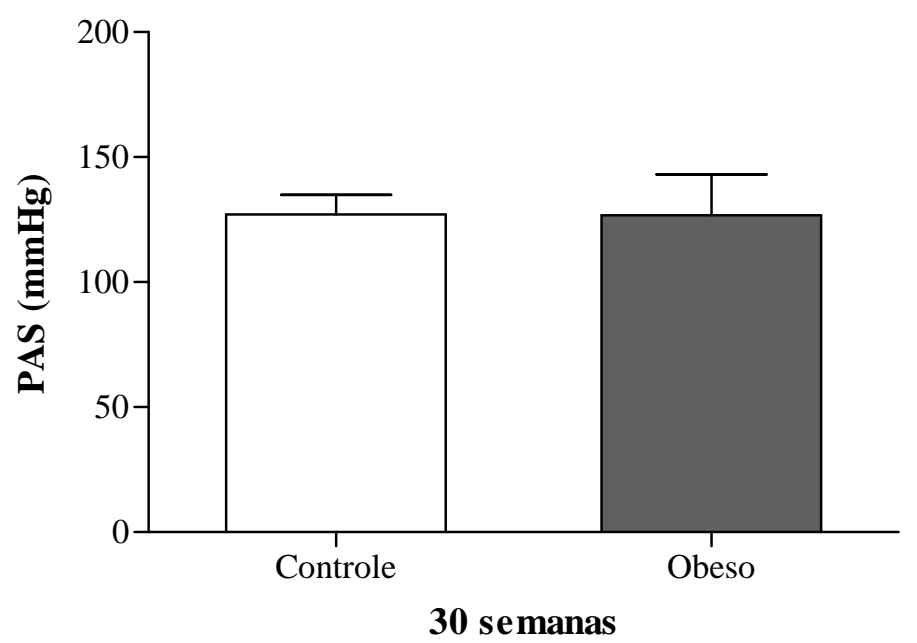

Figura 16. Pressão arterial sistólica final dos animais controle $\left(\mathrm{C}_{30}, \mathrm{n}=9\right)$ e obeso $\left(\mathrm{Ob}_{30}, \mathrm{n}=8\right)$ submetidos à 30 semanas de tratamento. Dados expressos em média \pm desvio padrão. Teste " $t$ " de Student para amostras independentes. Não houve diferença estatística entre os grupos.

\subsection{4- Teste de tolerância à glicose}

As Figuras 17 e 18 ilustram o resultado do teste de tolerância à glicose realizado nos grupos $\mathrm{C}_{30}$ e $\mathrm{Ob}_{30}$. Os níveis glicêmicos basais foram semelhantes entre os grupos. Entretanto, após a administração intraperitoneal de glicose, a glicemia foi elevada no grupo $\mathrm{Ob}_{30}$ nos momentos 15, 30, 60, 90 e 120 em relação ao grupo $C_{30}$ (Figura 17). A área glicêmica foi maior no grupo $\mathrm{Ob}_{30}$ em relação ao $\mathrm{C}_{30}$ (Figura 18). 


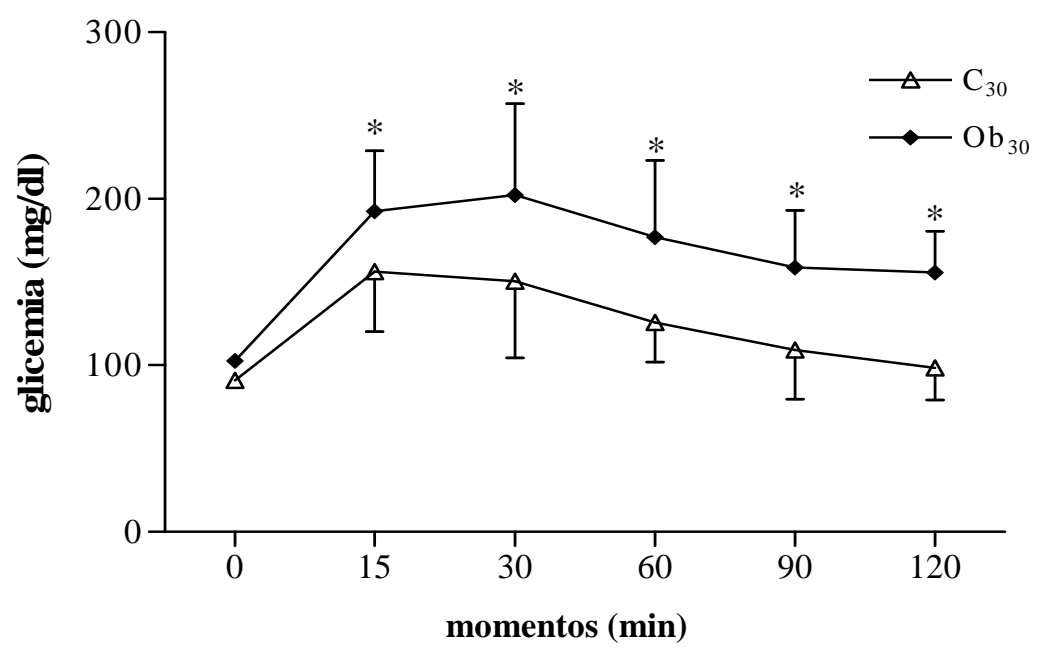

Figura 17. Teste de tolerância à glicose dos animais controle $\left(\mathrm{C}_{30}\right.$, $\mathrm{n}=9)$ e obeso $\left(\mathrm{Ob}_{30}, \mathrm{n}=9\right)$ submetidos à 30 semanas de tratamento. Dados expressos em média \pm desvio padrão. Análise de variância para o modelo de medidas repetidas em grupos independentes e teste post-hoc de Bonferroni. * $\mathrm{p}<0,05$ vs $\mathrm{C}_{30}$.

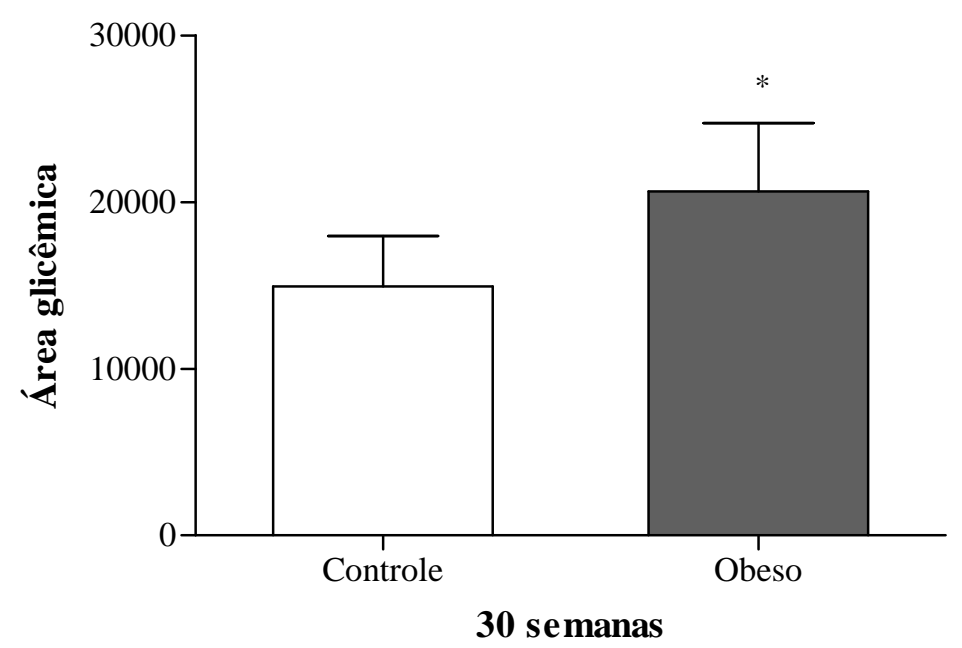

Figura 18. Área glicêmica, obtida no teste de tolerância à glicose, dos animais controle $\left(\mathrm{C}_{30}, \mathrm{n}=9\right)$ e obeso $\left(\mathrm{Ob}_{30}, \mathrm{n}=9\right)$ submetidos à 30 semanas de tratamento. Dados expressos em média \pm desvio padrão. Teste " $t$ " de Student para amostras independentes. $* \mathrm{p}<0,05$ vs $\mathrm{C}_{30}$. 


\subsection{5- Índice de resistência à insulina}

A Figura 19 mostra o resultado do índice HOMA-IR dos grupos $\mathrm{C}_{30}$ e $\mathrm{Ob}_{30}$. Os animais $\mathrm{Ob}_{30}$ apresentaram maior índice HOMA-IR do que o $\mathrm{C}_{30}$.

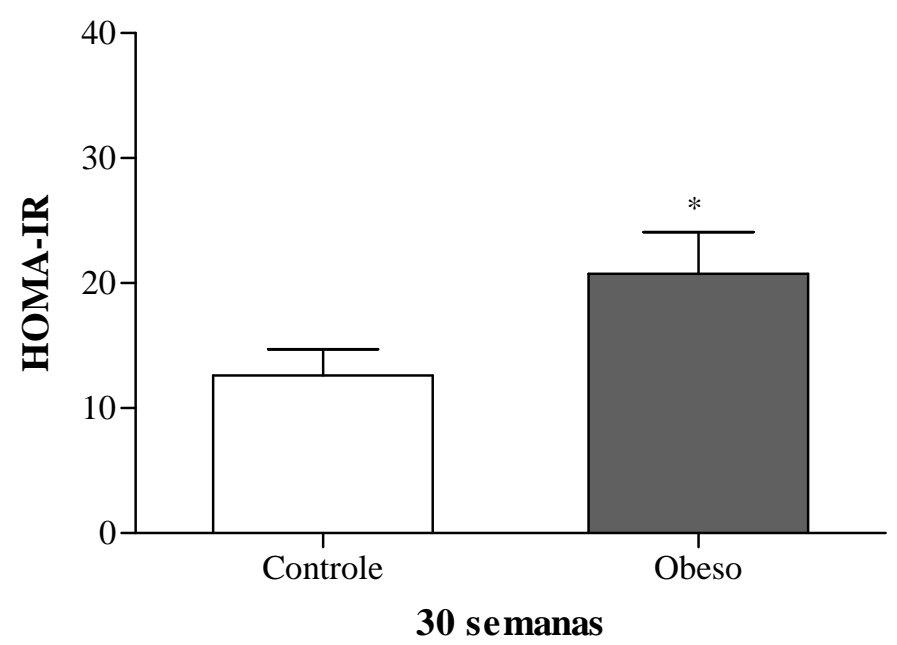

Figura 19. Índice HOMA-IR (resistência à insulina) dos animais controle $\left(\mathrm{C}_{30}, \mathrm{n}=9\right)$ e obeso $\left(\mathrm{Ob}_{30}, \mathrm{n}=9\right)$ submetidos à 30 semanas de tratamento. Dados expressos em média \pm desvio padrão. Teste " $t$ " de Student para amostras independentes. ${ }^{*} \mathrm{p}<0,05$ vs $\mathrm{C}_{30}$.

\subsection{6- Análise sérica dos hormônios insulina e leptina}

A Figura 20 ilustra as dosagens de insulina e leptina dos ratos $\mathrm{C}_{30}$ e $\mathrm{Ob}_{30}$. Após 30 semanas de obesidade os animais $\mathrm{Ob}_{30}$ apresentaram níveis séricos de insulina e leptina maiores que os $\mathrm{C}_{30}$. 


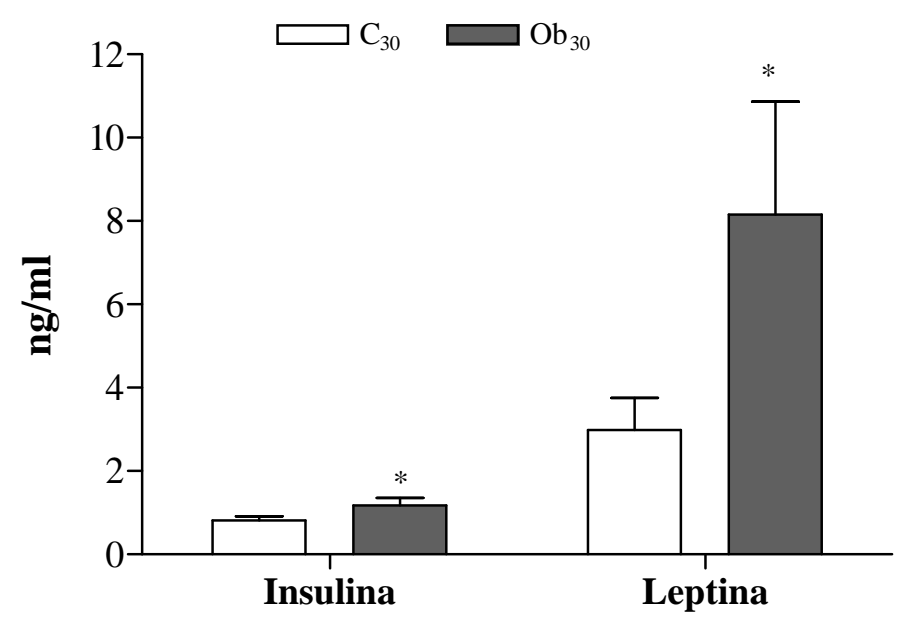

Figura 20. Níveis séricos de insulina e leptina dos animais controle $\left(\mathrm{C}_{30}, \mathrm{n}=8\right)$ e obeso $\left(\mathrm{Ob}_{30}, \mathrm{n}=8\right)$ submetidos à 30 semanas de tratamento. Dados expressos em média \pm desvio padrão. Teste " $t$ " de Student para amostras independentes. $* \mathrm{p}<0,05$ vs $\mathrm{C}_{30}$.

\subsection{7- Análise sérica dos hormônios tireoidianos}

As Figuras 21, 22 e 23 mostram as dosagens séricas dos hormônios tireoidianos TSH, T4 e T3 dos ratos $\mathrm{C}_{30}$ e $\mathrm{Ob}_{30}$. Após 30 semanas de obesidade os animais $\mathrm{Ob}_{30}$ apresentaram níveis séricos de $\mathrm{T} 4$ menores que o $\mathrm{C}_{30}$. Não houve diferença significativa entre os grupos nas dosagens de T3 $(\mathrm{p}=0,12)$ e TSH $(\mathrm{p}=0,09)$.

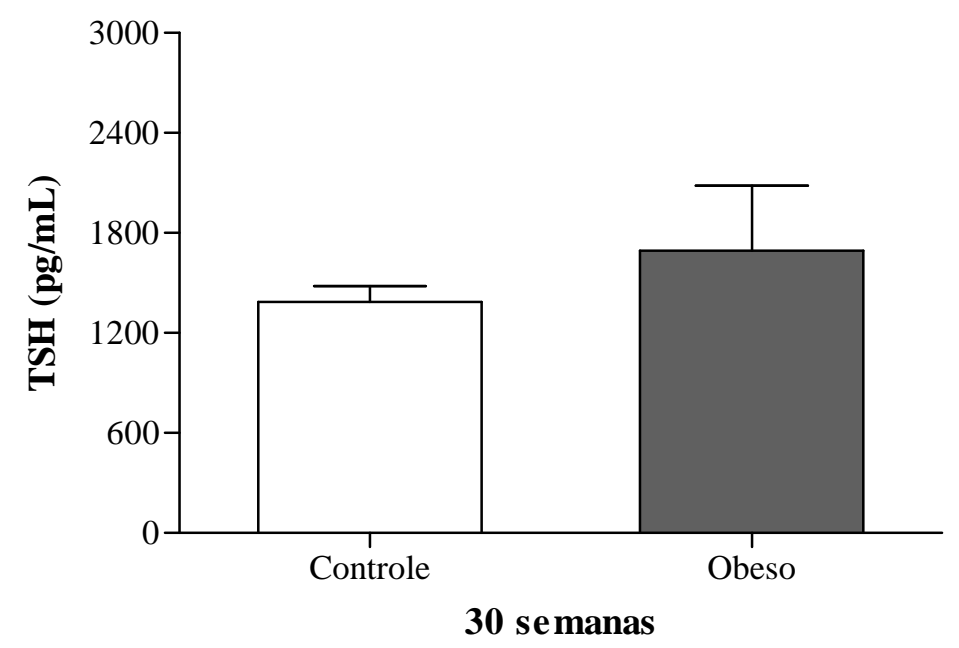

Figura 21. Níveis séricos de TSH dos animais controle $\left(\mathrm{C}_{30}\right.$, $\mathrm{n}=6)$ e obeso $\left(\mathrm{Ob}_{30}, \mathrm{n}=6\right)$ submetidos à 30 semanas de tratamento. Dados expressos em média \pm desvio padrão. Teste " $t$ " de Student para amostras independentes. Não houve diferença entre os grupos. 


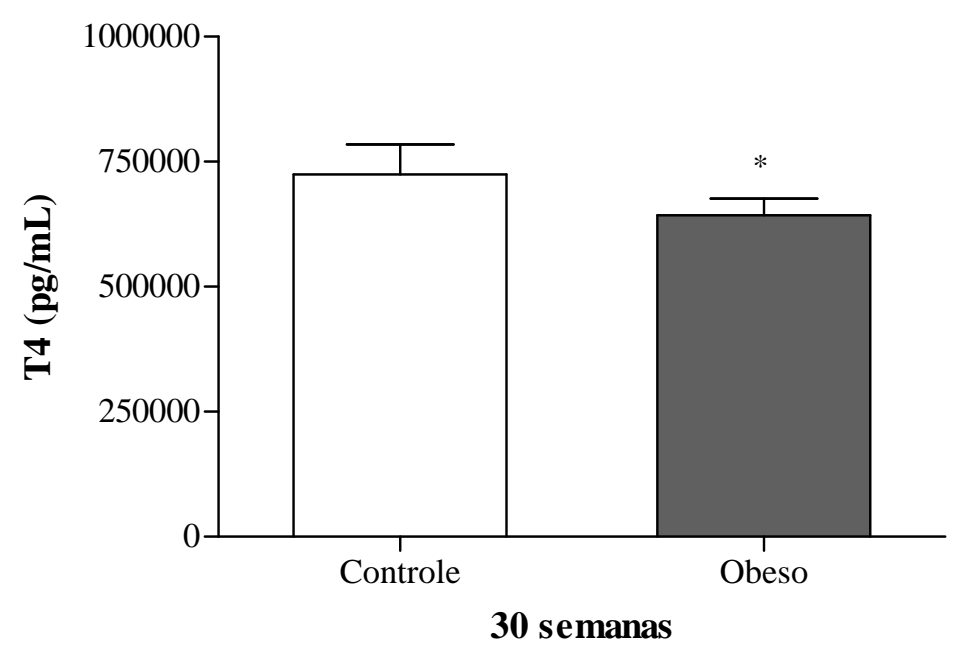

Figura 22. Níveis séricos de $\mathrm{T} 4$ dos animais controle $\left(\mathrm{C}_{30}\right.$, $\mathrm{n}=6)$ e obeso $\left(\mathrm{Ob}_{30}, \mathrm{n}=6\right)$ submetidos à 30 semanas de tratamento. Dados expressos em média \pm desvio padrão. Teste " $t$ " de Student para amostras independentes. * $\mathrm{p}<0,05$ vs $\mathrm{C}_{30}$.

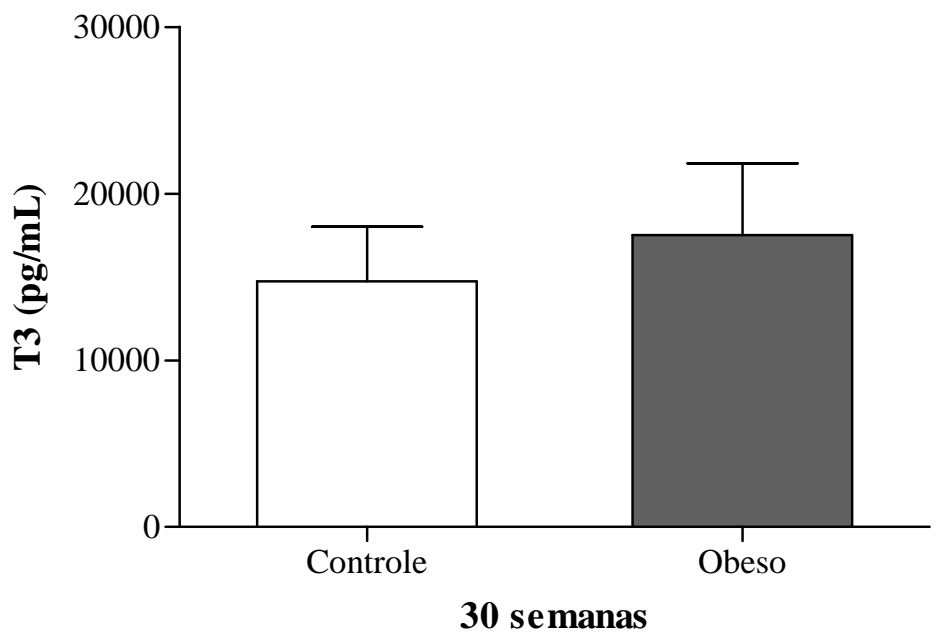

Figura 23. Níveis séricos de T3 dos animais controle $\left(\mathrm{C}_{30}\right.$, $\mathrm{n}=6)$ e obeso $\left(\mathrm{Ob}_{30}, \mathrm{n}=6\right)$ submetidos à 30 semanas de tratamento. Dados expressos em média \pm desvio padrão. Teste " $t$ " de Student para amostras independentes. Não houve diferença entre os grupos. 


\subsection{8- Estrutura do coração post mortem}

\subsubsection{1- Análise macroscópica}

A Tabela 6 mostra a estrutura macroscópica cardíaca post mortem dos ratos $\mathrm{C}_{30}$ e $\mathrm{Ob}_{30}$. Após 30 semanas de obesidade, os animais $\mathrm{Ob}_{30}$ apresentaram maiores pesos do coração, dos ventrículos esquerdo e direito, do átrio e do comprimento da tíbia do que os animais $\mathrm{C}_{30}$. As relações coração/PCF, VE/PCF e VD/PCF foram diminuídas nos animais $\mathrm{Ob}_{30}$; entretanto, as relações coração/tíbia e $\mathrm{AT} /$ tíbia foram maiores no grupo $\mathrm{Ob}_{30}$ em relação ao grupo $\mathrm{C}_{30}$. Não houve diferença significativa no peso do pulmão e nas relações AT/PCF, VE/tíbia e VD/tíbia entre os grupos. 
Tabela 6. Estrutura macroscópica cardíaca post mortem após 30 semanas

\begin{tabular}{|c|c|c|}
\hline \multirow[b]{2}{*}{ Variáveis } & \multicolumn{2}{|c|}{ Grupos } \\
\hline & $C_{30}(n=10)$ & $\mathrm{Ob}_{30}(\mathrm{n}=10)$ \\
\hline PCF (g) & $490 \pm 33$ & $608 \pm 22 *$ \\
\hline tíbia (cm) & $4,42 \pm 0,12$ & $4,55 \pm 0,11 *$ \\
\hline Coração (g) & $1,14 \pm 0,09$ & $1,28 \pm 0,11^{*}$ \\
\hline VE $(g)$ & $0,81 \pm 0,07$ & $0,90 \pm 0,09^{*}$ \\
\hline VD $(g)$ & $0,25 \pm 0,03$ & $0,28 \pm 0,03 *$ \\
\hline $\operatorname{AT}(g)$ & $0,08 \pm 0,01$ & $0,10 \pm 0,01^{*}$ \\
\hline Coração/PCF (mg/g) & $2,34 \pm 0,19$ & $2,11 \pm 0,18^{*}$ \\
\hline VE/PCF (mg/g) & $1,66 \pm 0,18$ & $1,49 \pm 0,15^{*}$ \\
\hline VD/PCF (mg/g) & $0,52 \pm 0,04$ & $0,46 \pm 0,04 *$ \\
\hline AT/PCF (mg/g) & $0,16 \pm 0,02$ & $0,16 \pm 0,02$ \\
\hline Coração/tíbia (g/cm) & $0,26 \pm 0,02$ & $0,28 \pm 0,03^{*}$ \\
\hline VE/tíbia (g/cm) & $0,18 \pm 0,02$ & $0,20 \pm 0,02$ \\
\hline VD/tíbia (g/cm) & $0,057 \pm 0,005$ & $0,062 \pm 0,006$ \\
\hline AT/tíbia (g/cm) & $0,018 \pm 0,003$ & $0,021 \pm 0,003^{*}$ \\
\hline
\end{tabular}

Dados expressos em média \pm desvio padrão. $\mathrm{C}_{30}$ : controle; $\mathrm{Ob}_{30}$ : obeso submetidos à 30 semanas de tratamento; PCF: peso corporal final; VE: peso do ventrículo esquerdo; VD: peso do ventrículo direito; AT: peso do átrio; VE/PCF: relação do peso do ventrículo esquerdo pelo peso corporal final; VD/PCF: relação do peso do ventrículo direito pelo peso corporal final; AT/PCF: relação do peso do átrio pelo peso corporal final. VE/tíbia: relação do peso do ventrículo esquerdo pelo comprimento da tíbia; VD/tíbia: relação do peso do ventrículo direito pelo comprimento da tíbia; AT/tíbia: relação do peso do átrio pelo comprimento da tíbia. Teste " $t$ " de Student para amostras independentes. $* \mathrm{p}<0,05$ vs $\mathrm{C}_{30}$. 


\subsubsection{2- Análise microscópica}

As Figuras 24 e 25 mostram a área seccional transversa do miócito realizadas no ventrículo esquerdo dos animais $\mathrm{C}_{30}$ e $\mathrm{Ob}_{30}$. Os animais $\mathrm{Ob}_{30}$ apresentaram AST dos fragmentos do VE maior que o $\mathrm{C}_{30}$. (Figura 24).

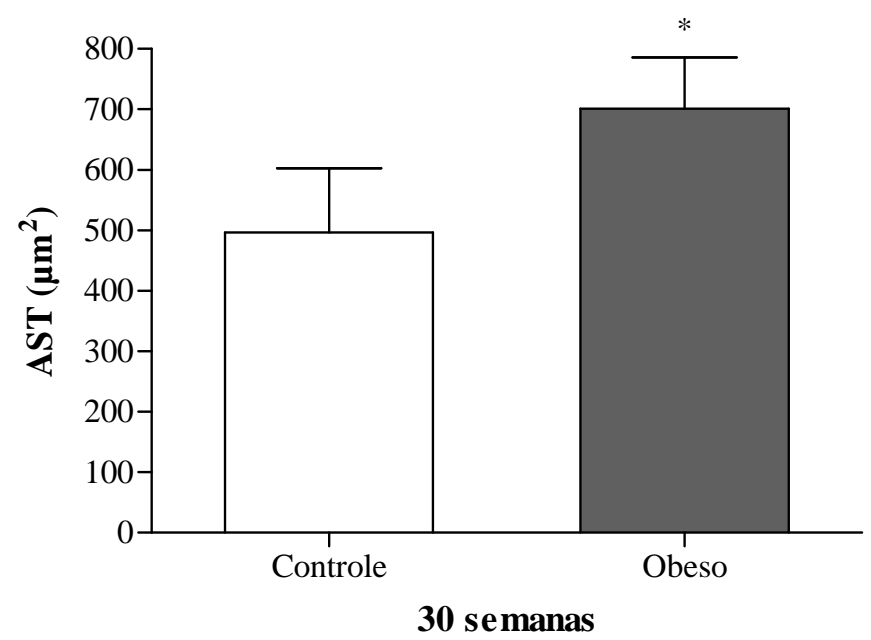

Figura 24. Secções transversas de fragmentos do VE dos grupos controle $\left(\mathrm{C}_{30}, \mathrm{n}=7\right)$ e obeso $\left(\mathrm{Ob}_{30}, \mathrm{n}=5\right)$ submetidos à 30 semanas de tratamento. Técnica de Retículina de gömori 40X. Dados expressos em média \pm desvio padrão. Teste " $t$ " de Student para amostras independentes. $* \mathrm{p}<0,05$ vs $\mathrm{C}_{30}$.
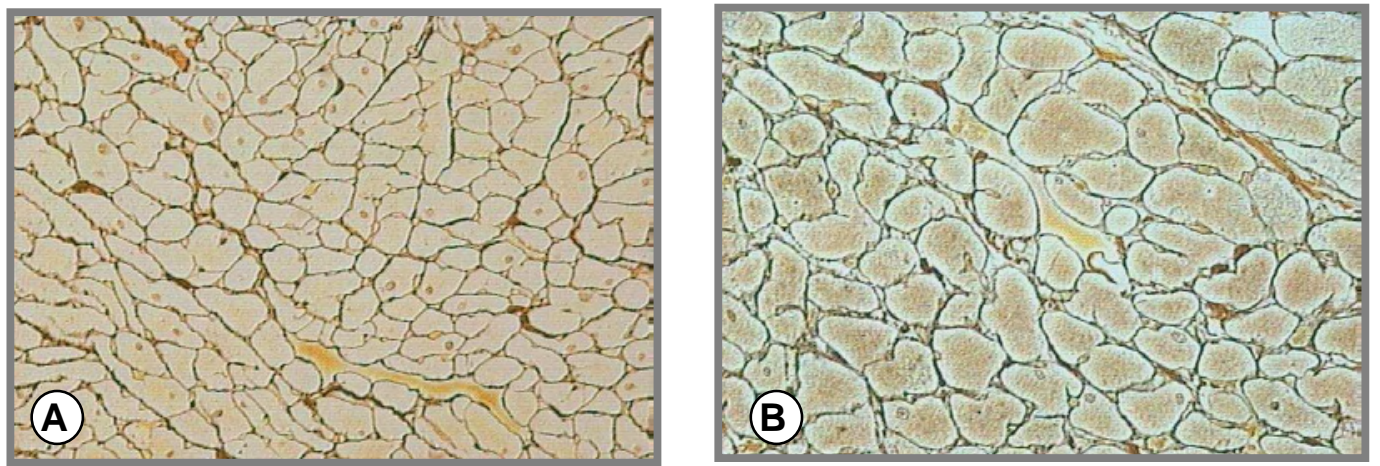

Figura 25. Secções transversas subendocárdicas do ventrículo esquerdo (VE) dos grupos controle e obeso submetidos à 30 semanas de tratamento; A: fragmento do VE do grupo controle; B: fragmento do VE do grupo obeso; Técnica de Reticulina de Gömori 40X. 


\subsection{9- Expressão de RNAm miocárdico}

As Figuras 26 e 27 ilustram a expressão do RNAm das proteínas relacionadas com o trânsito de cálcio miocárdico, CANAL L, RyR, SERCA, PLB, NXC e CSQ nos animais $\mathrm{C}_{30} \mathrm{e}$ $\mathrm{Ob}_{30}$. A expressão gênica do CANAL L, da RyR, da SERCA, da PLB, do NCX e da CSQ foram aumentadas no grupo $\mathrm{Ob}_{30}$ em relação ao $\mathrm{C}_{30}$. Os níveis de $\mathrm{RNAm}$ da $\beta$-actina, dados não mostrados no texto, foram semelhantes entre os grupos.

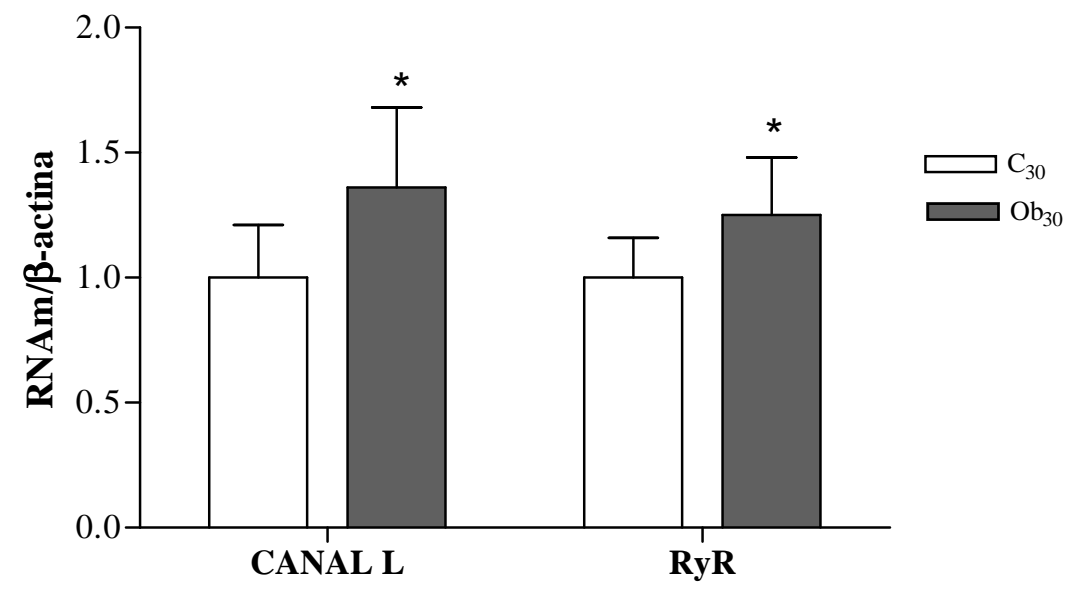

Figura 26. Expressão gênica de CANAL L e RyR no miocárdio dos animais controle $\left(\mathrm{C}_{30}, \mathrm{n}=6\right)$ e obeso $\left(\mathrm{Ob}_{30}\right.$, $\mathrm{n}=6)$ submetidos à 30 semanas de tratamento. Dados expressos em média \pm desvio padrão. Teste " $t$ ” de Student. $*$ p $<0,05$ vs $\mathrm{C}_{30}$.

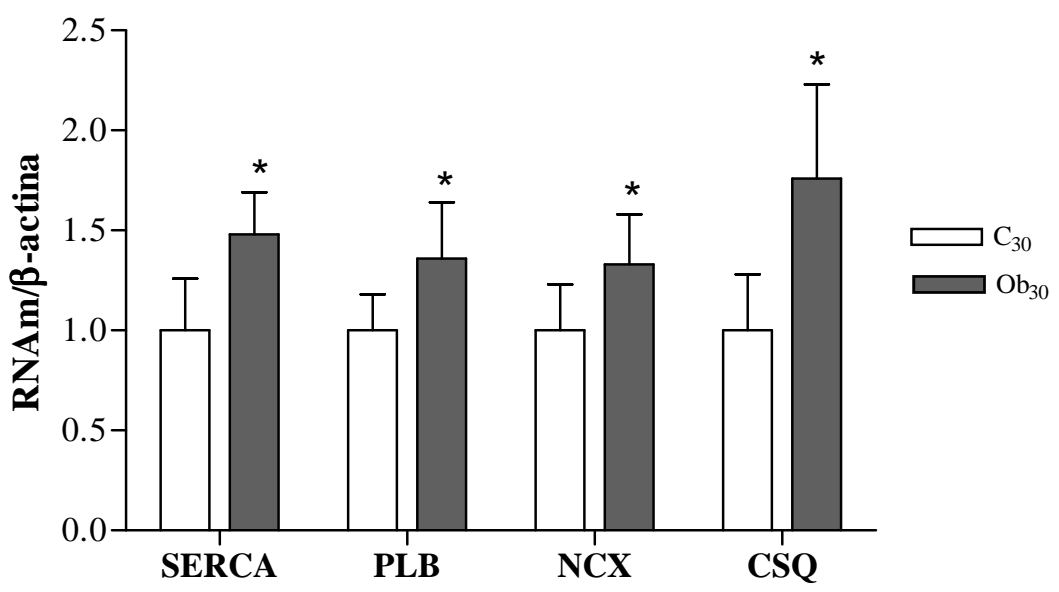

Figura 27. Expressão gênica de SERCA, PLB, NCX e CSQ no miocárdio dos animais controle $\left(\mathrm{C}_{30}, \mathrm{n}=6\right)$ e obeso $\left(\mathrm{Ob}_{30}\right.$, n=6) submetidos à 30 semanas de tratamento. Dados expressos em média \pm desvio padrão. Teste " $t$ " de Student. $* \mathrm{p}<0,05$ vs $\mathrm{C}_{30}$. 


\subsubsection{0- Expressão das proteínas miocárdicas}

As Figuras 28 e 29 ilustram a expressão das proteínas relacionadas com o trânsito de cálcio intracelular miocárdico dos animais $\mathrm{C}_{30}$ e $\mathrm{Ob}_{30}$. A Figura 28 mostra que a obesidade não promoveu alterações nos níveis protéicos do CANAL L, da SERCA, da PLB, da CSQ e na razão SERCA/PLB. Os animais $\mathrm{Ob}_{30}$ apresentam níveis protéicos de pPLB Ser16 e a razão pPLB Ser16/PLB diminuídos em relação ao $\mathrm{C}_{30}$. Não foram observadas alterações de pPLB Thr17 e a razão pPLB Thr 17/PLB entre os grupos (Figura 29).

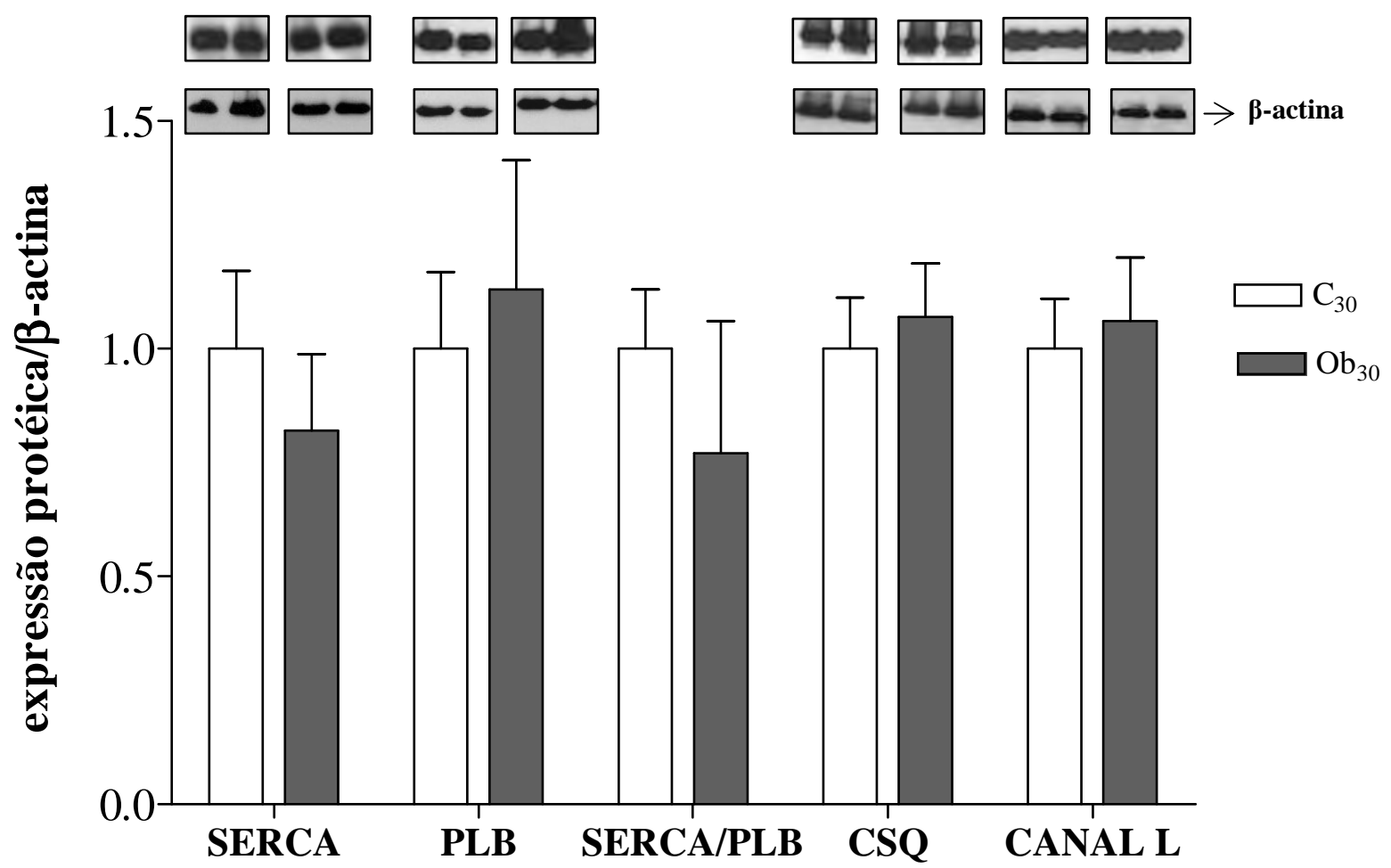

Figura 28. Expressão protéica de SERCA, PLB, CSQ, CANAL L e a razão SERCA/PLB no miocárdio dos animais controle $\left(\mathrm{C}_{30}, \mathrm{n}=6\right)$ e obeso $\left(\mathrm{Ob}_{30}, \mathrm{n}=6\right)$ submetidos à 30 semanas de tratamento. Dados expressos em média \pm desvio padrão. Teste " $t$ " de Student. Não houve diferença estatística entre os grupos. 


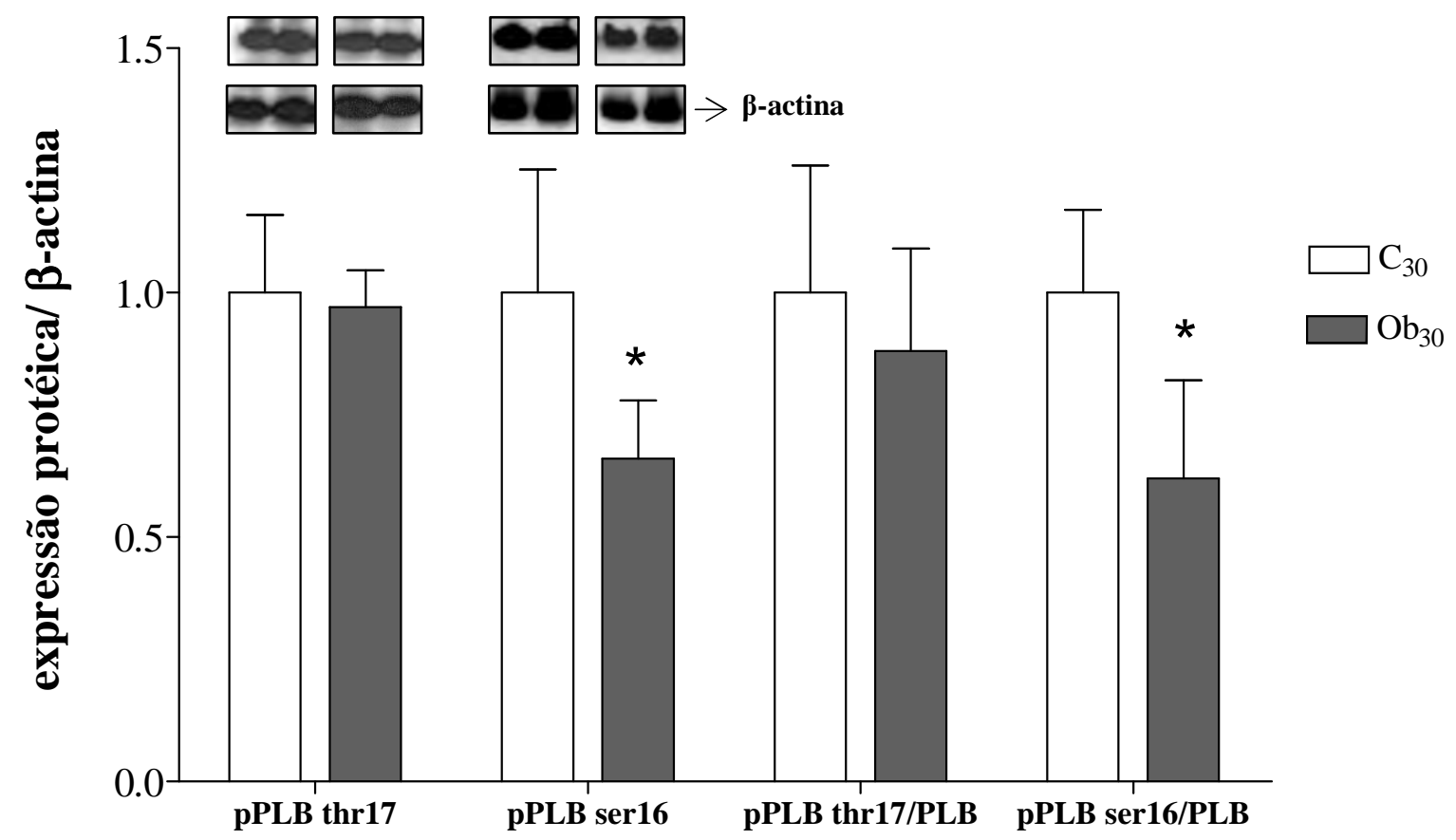

Figura 29. Expressão protéica de pPLB thr 17, pPLB ser16 e as razões pPLB thr17/PLB e pPLB ser16/PLB no miocárdio dos animais controle $\left(\mathrm{C}_{30}, \mathrm{n}=6\right)$ e obeso $\left(\mathrm{Ob}_{30}, \mathrm{n}=6\right)$ submetidos à 30 semanas de tratamento. Dados expressos em média \pm desvio padrão. Teste " $t$ " de Student. * $\mathrm{p}<0,05$ vs $\mathrm{C}_{30}$.

\subsubsection{1- Determinação do teor de água nos tecidos cardíaco, pulmonar e hepático}

A Tabela 7 mostra a porcentagem de umidade dos tecidos cardíaco, pulmonar e hepático dos ratos $\mathrm{C}_{30}$ e $\mathrm{Ob}_{30}$. Não houve diferença significativa na quantidade de água no VE, VD, AT e pulmão. Entretanto, os animais $\mathrm{Ob}_{30}$ apresentaram menor teor de água no fígado que os animais $\mathrm{C}_{30}$. 
Tabela 7. Teor de água nos tecidos cardíaco, pulmonar e hepático após 30 semanas

\begin{tabular}{ccc}
\hline & \multicolumn{2}{c}{ Grupos } \\
\cline { 2 - 3 } Variáveis & $\mathbf{C}_{\mathbf{3 0}}(\mathbf{n}=\mathbf{1 0})$ & $\mathbf{O b}_{\mathbf{3 0}}(\mathbf{n = 1 0})$ \\
\hline VE (\%) & $75,6 \pm 3,4$ & $74,9 \pm 0,7$ \\
\hline VD (\%) & $76,0 \pm 3,4$ & $75,1 \pm 0,9$ \\
\hline AT (\%) & $76,1 \pm 1,8$ & $76,5 \pm 1,9$ \\
\hline Pulmão (\%) & $78,5 \pm 0,9$ & $78,3 \pm 0,5$ \\
\hline Fígado (\%) & $68,1 \pm 0,8$ & $66,2 \pm 1,4^{*}$ \\
\hline
\end{tabular}

Dados expressos em média \pm desvio padrão. $\mathrm{C}_{30}$ : controle; $\mathrm{Ob}_{30}$ : obeso submetidos à 30 semanas de tratamento; VE: ventrículo esquerdo; VD: ventrículo direito; AT: átrio. Teste " $t$ " de Student para amostras independentes. * $\mathrm{p}<0,05$ vs $\mathrm{C}_{30}$. 


\section{4- Obesidade 45 semanas}

\subsection{1- Composição dos grupos controle e obeso}

$\mathrm{Na} 45^{\mathrm{a}}$ semana de tratamento após o início da obesidade foram sorteados 12 animais de cada grupo. Após a aplicação do critério estabelecido para a composição dos grupos de 45 semanas, dez animais do grupo controle $\left(\mathrm{C}_{45} ; \mathrm{n}=10\right)$ e dez animais do grupo obeso $\left(\mathrm{Ob}_{45}\right.$; $\mathrm{n}=10)$ permaneceram no estudo.

\subsection{2- Perfil nutricional}

A Tabela 8 mostra o perfil nutricional dos animais $\mathrm{C}_{45}$ e $\mathrm{Ob}_{45}$. $\mathrm{O}$ peso corporal inicial e final, o ganho de peso, os depósitos de gordura epididimal, retroperitoneal e visceral, a gordura corporal total e o índice de adiposidade foram maiores no $\mathrm{Ob}_{45}$ do que no $\mathrm{C}_{45}$. Não houve diferença significativa entre os grupos nas dosagens séricas de glicose, proteína e lipídeos; contudo, a dosagem de triglicérides apresentou um valor de $\mathrm{p}=0,15$. Durante o período experimental, a ingestão alimentar e calórica, assim como, a eficiência alimentar foram maiores nos animais $\mathrm{Ob}_{45}$ em relação $\mathrm{C}_{45}$. 
Tabela 8. Perfil nutricional após 45 semanas

\begin{tabular}{|c|c|c|}
\hline \multirow[b]{2}{*}{ Variáveis } & \multicolumn{2}{|c|}{ Grupos } \\
\hline & $\mathrm{C}_{45}(\mathrm{n}=10)$ & $\mathrm{Ob}_{45}(\mathrm{n}=10)$ \\
\hline PCI (g) & $282 \pm 16$ & $304 \pm 21^{*}$ \\
\hline PCF $(g)$ & $513 \pm 19$ & $609 \pm 37 *$ \\
\hline Ganho de peso (g) & $231 \pm 21$ & $305 \pm 25^{*}$ \\
\hline Epididimal (g) & $6,27 \pm 1,45$ & $12,5 \pm 2,5^{*}$ \\
\hline Retroperitoneal (g) & $10,7 \pm 1,6$ & $20,7 \pm 6,0^{*}$ \\
\hline Visceral (g) & $6,72 \pm 1,01$ & $14,4 \pm 2,8^{*}$ \\
\hline Gordura total (g) & $23,7 \pm 2,8$ & $47,5 \pm 7,9^{*}$ \\
\hline Índice de Adiposidade (\%) & $4,62 \pm 0,51$ & $7,79 \pm 1,12 *$ \\
\hline Ingestão alimentar (g/dia) & $26,4 \pm 1,5$ & $24,8 \pm 1,6^{*}$ \\
\hline Ingestão calórica (kcal/dia) & $77,9 \pm 4,4$ & $90,7 \pm 5,8^{*}$ \\
\hline Eficiência alimentar (\%) & $0,99 \pm 0,10$ & $1,12 \pm 0,08 *$ \\
\hline Glicose (mg/dL) & $172 \pm 27$ & $168 \pm 29$ \\
\hline Triglicérides (mg/dL) & $77 \pm 15$ & $91 \pm 23$ \\
\hline Colesterol (mg/dL) & $78 \pm 18$ & $79 \pm 10$ \\
\hline HDL (mg/dL) & $28 \pm 3$ & $29 \pm 5$ \\
\hline LDL (mg/dL) & $21 \pm 7$ & $17 \pm 4$ \\
\hline Proteína (g/dL) & $6,6 \pm 0,2$ & $6,7 \pm 0,2$ \\
\hline NEFA (mmol/L) & $0,49 \pm 0,10$ & $0,55 \pm 0,07$ \\
\hline
\end{tabular}

Dados expressos em média \pm desvio padrão. $\mathrm{C}_{45}$ : controle; $\mathrm{Ob}_{45}$ : obeso submetidos à 45 semanas de tratamento; PCI: peso corporal inicial; PCF: peso corporal final; HDL: lipoproteína de alta intensidade; LDL: lipoproteína de baixa intensidade; NEFA: ácidos graxos não-esterificados. Teste " $t$ " de Student para amostras independentes. * p <0,05 vs $\mathrm{C}_{45}$. 


\subsection{3- Pressão arterial sistólica}

A Figura 30 mostra o resultado da pressão arterial sistólica final realizado nos grupos $\mathrm{C}_{45}$ e $\mathrm{Ob}_{45}$. Não houve diferença significativa na pressão arterial sistólica final entre os grupos; portanto, a obesidade durante 45 semanas não acarretou hipertensão arterial.

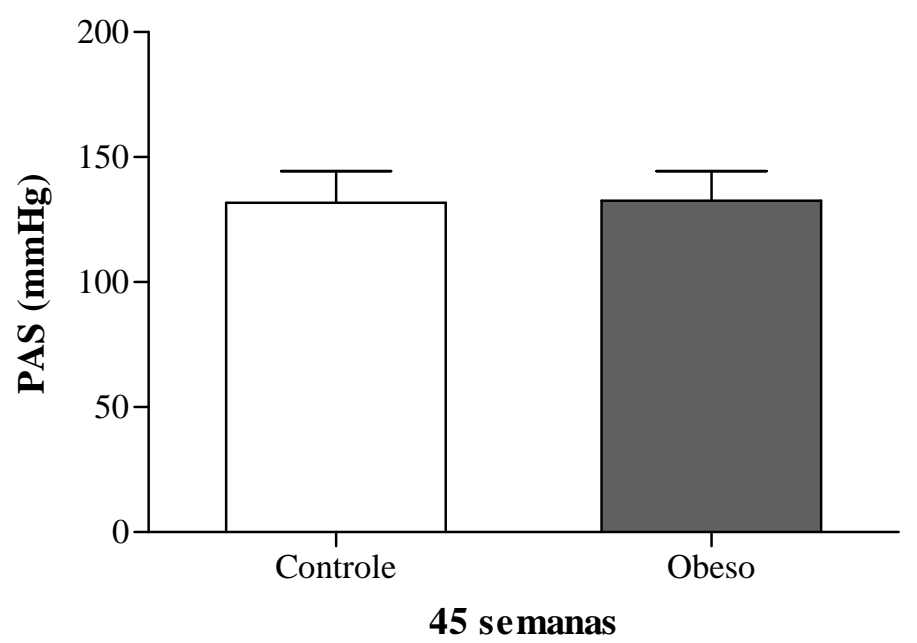

Figura 30. Pressão arterial sistólica final dos animais controle $\left(\mathrm{C}_{45}, \mathrm{n}=10\right)$ e obeso $\left(\mathrm{Ob}_{45}, \mathrm{n}=10\right)$ submetidos à 45 semanas de tratamento. Dados expressos em média \pm desvio padrão. Teste " $t$ " de Student para amostras independentes. Não houve diferença estatística entre os grupos.

\subsection{4- Teste de tolerância à glicose}

As Figuras 31 e 32 ilustram o resultado do teste de tolerância à glicose realizado nos grupos $\mathrm{C}_{45}$ e $\mathrm{Ob}_{45}$. Os níveis glicêmicos basais e os momentos $15(\mathrm{p}=0,07)$ e $60(\mathrm{p}=0,09)$ minutos após a administração de glicose foram semelhantes entre os grupos. Entretanto, a glicemia foi elevada no grupo $\mathrm{Ob}_{45}$ nos momentos 30 , 90 e 120 em relação ao grupo $\mathrm{C}_{45}$ (Figura 31). A área glicêmica foi maior no grupo $\mathrm{Ob}_{45}$ em relação ao $\mathrm{C}_{45}$ (Figura 32). 


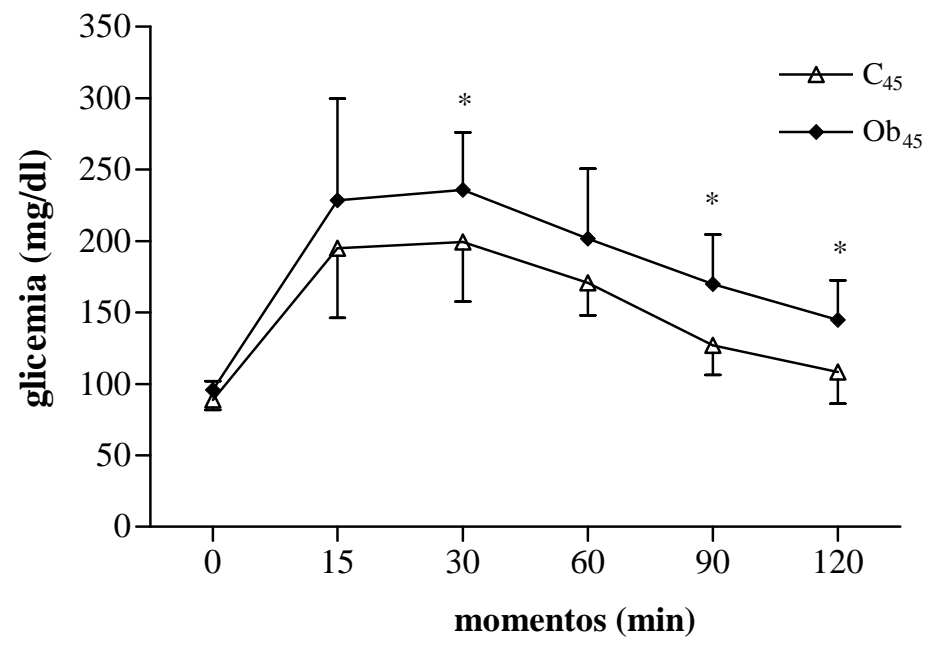

Figura 31. Teste de tolerância à glicose dos animais controle $\left(\mathrm{C}_{45}, \mathrm{n}=9\right)$ e obeso $\left(\mathrm{Ob}_{45}, \mathrm{n}=8\right)$ submetidos à 45 semanas de tratamento. Dados expressos em média \pm desvio padrão. Análise de variância (ANOVA) para o modelo de medidas repetidas em grupos independentes e complementada com o teste post-hoc de Bonferroni. * $\mathrm{p}<0,05$ vs $\mathrm{C}_{45}$.

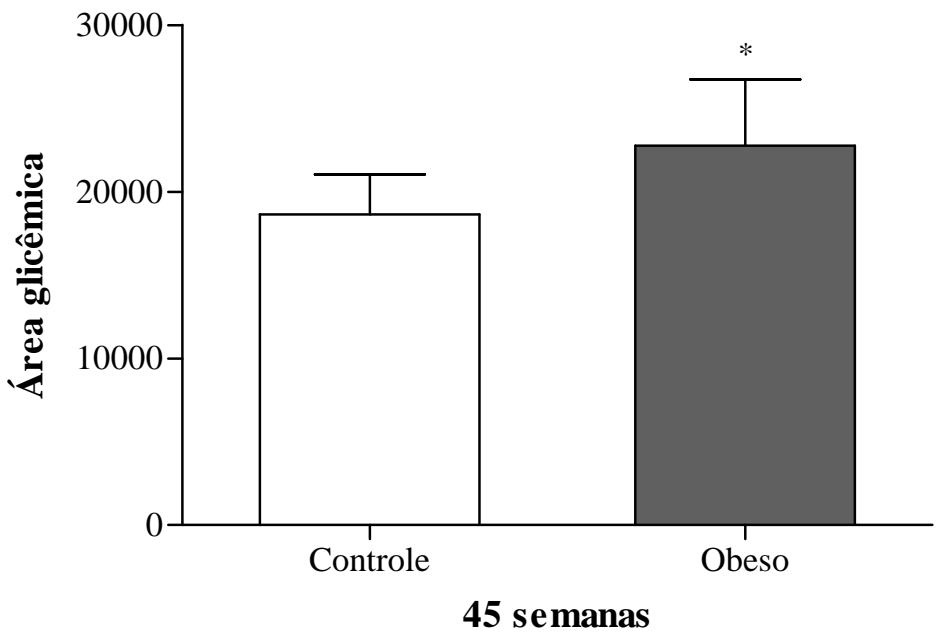

Figura 32. Área glicêmica, obtida no teste de tolerância à glicose, dos animais controle $\left(\mathrm{C}_{45}, \mathrm{n}=9\right)$ e obeso $\left(\mathrm{Ob}_{45}, \mathrm{n}=8\right)$ submetidos à 45 semanas de tratamento. Dados expressos em média \pm desvio padrão. Teste " $t$ " de Student para amostras independentes. ${ }^{*} \mathrm{p}<0,05$ vs $\mathrm{C}_{45}$. 


\subsection{5- Índice de resistência à insulina}

A Figura 33 mostra o resultado do índice HOMA-IR dos grupos $\mathrm{C}_{45}$ e $\mathrm{Ob}_{45}$. Os animais $\mathrm{Ob}_{45}$ apresentaram maior índice HOMA-IR do que o $\mathrm{C}_{45}$.

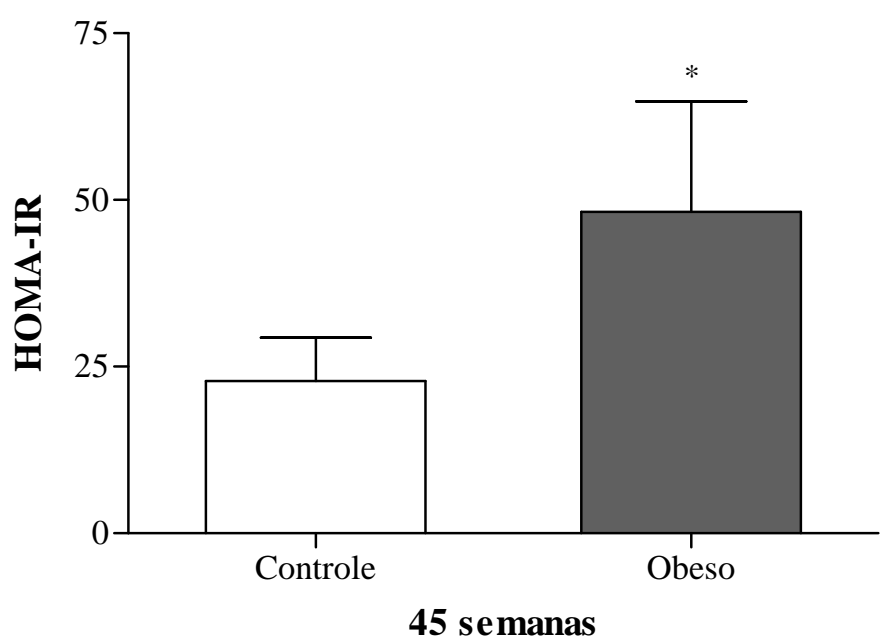

Figura 33. Índice HOMA-IR (resistência à insulina) dos animais controle $\left(\mathrm{C}_{45}, \mathrm{n}=7\right)$ e obeso $\left(\mathrm{Ob}_{45}, \mathrm{n}=8\right)$ submetidos à 45 semanas de tratamento. Dados expressos em média \pm desvio padrão. Teste " $t$ " de Student para amostras independentes. ${ }^{*} \mathrm{p}<0,05$ vs $\mathrm{C}_{45}$.

\subsection{6- Análise sérica dos hormônios insulina e leptina}

A Figura 34 ilustra as dosagens de insulina e leptina dos ratos $\mathrm{C}_{45}$ e $\mathrm{Ob}_{45}$. Após 45 semanas de obesidade os animais $\mathrm{Ob}_{45}$ apresentaram níveis séricos de insulina e leptina maiores que os $\mathrm{C}_{45}$. 


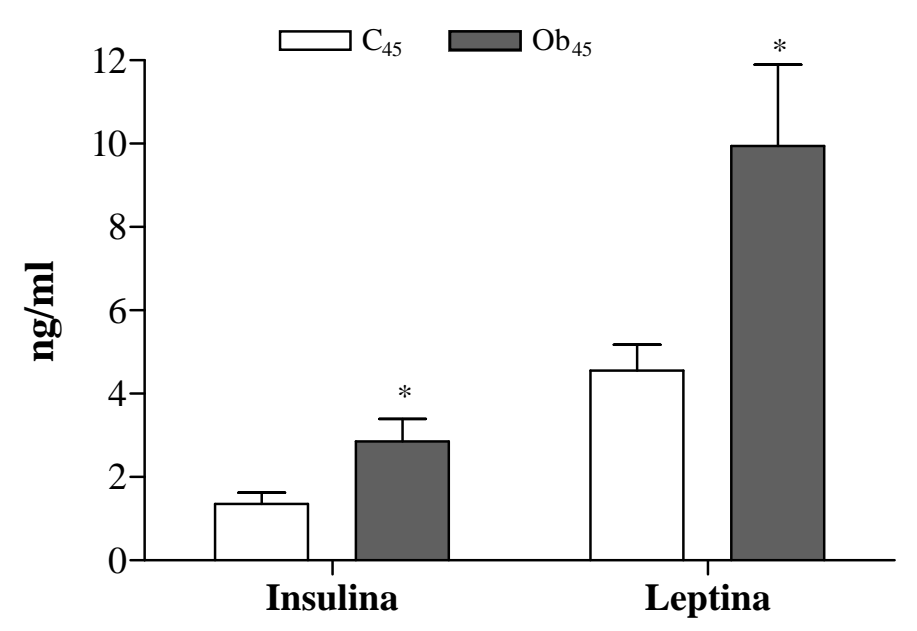

Figura 34. Níveis séricos de insulina e leptina dos animais controle $\left(\mathrm{C}_{45}, \mathrm{n}=7\right)$ e obeso $\left(\mathrm{Ob}_{45}, \mathrm{n}=8\right)$ submetidos à 45 semanas de tratamento. Dados expressos em média \pm desvio padrão. Teste " $t$ " de Student para amostras independentes. * $\mathrm{p}<0,05$ vs $\mathrm{C}_{45}$.

\subsection{7- Análise sérica dos hormônios tireoidianos}

As Figuras 35, 36 e 37 mostram as dosagens séricas dos hormônios tireoidianos TSH, $\mathrm{T} 4$ e $\mathrm{T} 3$ dos ratos $\mathrm{C}_{45}$ e $\mathrm{Ob}_{45}$. Após 45 semanas, a obesidade não promoveu diferença significativa entre os grupos nas dosagens de TSH $(p=0,06)$, T4 e T3 $(p=0,10)$.

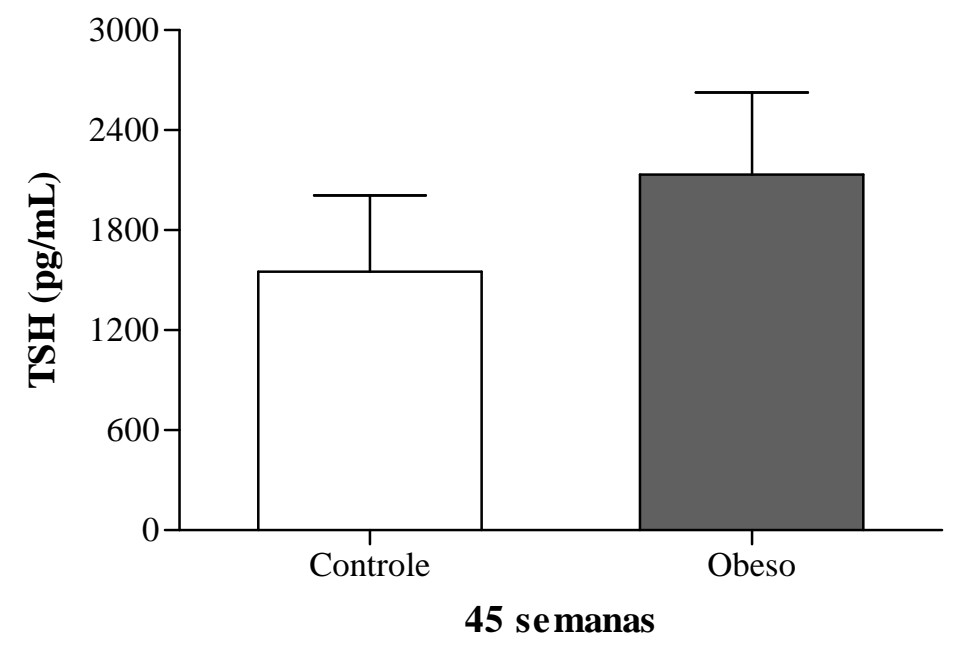

Figura 35. Níveis séricos de TSH dos animais controle $\left(\mathrm{C}_{45}, \mathrm{n}=6\right)$ e obeso $\left(\mathrm{Ob}_{45}, \mathrm{n}=6\right)$ submetidos à 45 semanas de tratamento. Dados expressos em média \pm desvio padrão. Teste " $t$ " de Student para amostras independentes. Não houve diferença significativa entre os grupos. 


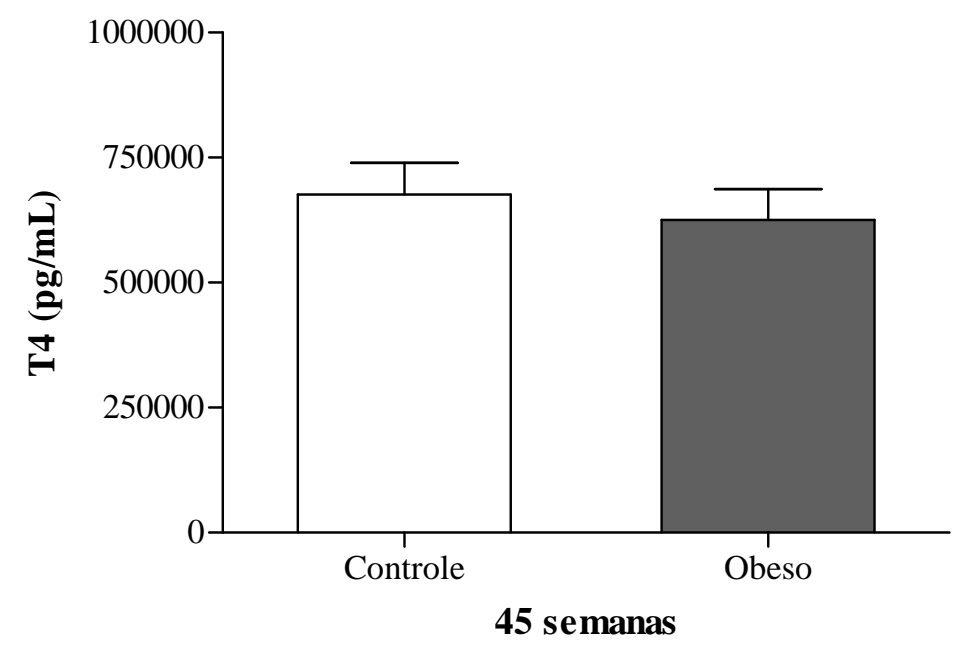

Figura 36. Níveis séricos de $\mathrm{T} 4$ dos animais controle $\left(\mathrm{C}_{45}\right.$, $\mathrm{n}=6)$ e obeso $\left(\mathrm{Ob}_{30}, \mathrm{n}=6\right)$ submetidos à 45 semanas de tratamento. Dados expressos em média \pm desvio padrão. Teste " $t$ " de Student para amostras independentes. Não houve diferença estatística entre os grupos.

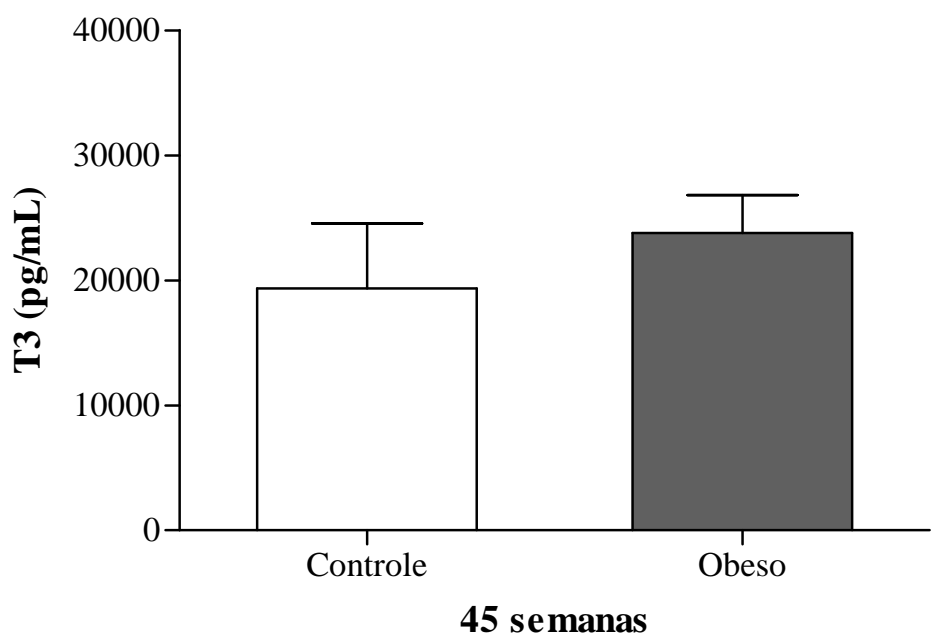

Figura 37. Níveis séricos de T3 dos animais controle $\left(\mathrm{C}_{45}\right.$, $\mathrm{n}=6)$ e obeso $\left(\mathrm{Ob}_{45}, \mathrm{n}=6\right)$ submetidos à 45 semanas de tratamento. Dados expressos em média \pm desvio padrão. Teste " $t$ " de Student para amostras independentes. Não houve diferença estatística entre os grupos. 


\subsection{8- Estrutura do coração post mortem}

\subsubsection{1- Análise macroscópica}

A Tabela 9 mostra a estrutura macroscópica cardíaca post mortem dos ratos $\mathrm{C}_{45} \mathrm{e}$ $\mathrm{Ob}_{45}$. Após 45 semanas de obesidade, os animais $\mathrm{Ob}_{45}$ apresentaram maior peso do coração, do átrio e do comprimento da tíbia do que os animais $\mathrm{C}_{45}$. As relações coração/PCF e VE/PCF foram diminuídas nos animais $\mathrm{Ob}_{45}$; entretanto, a relação AT/tíbia foi maior no grupo $\mathrm{Ob}_{45}$ em relação ao grupo $C_{45}$. Não houve diferença significativa no peso do VD, VE e nas relações VD/PCF, AT/PCF, Coração/tíbia, VE/tíbia e VD/tíbia entre os grupos. 
Tabela 9. Estrutura macroscópica cardíaca post mortem após 45 semanas

\begin{tabular}{|c|c|c|}
\hline \multirow[b]{2}{*}{ Variáveis } & \multicolumn{2}{|c|}{ Grupos } \\
\hline & $C_{45}(n=10)$ & $\mathrm{Ob}_{45}(\mathrm{n}=10)$ \\
\hline PCF (g) & $513 \pm 19$ & $609 \pm 37^{*}$ \\
\hline tíbia (cm) & $4,55 \pm 0,11$ & $4,67 \pm 0,13^{*}$ \\
\hline Coração (g) & $1,19 \pm 0,08$ & $1,27 \pm 0,07 *$ \\
\hline VE (g) & $0,86 \pm 0,05$ & $0,90 \pm 0,05$ \\
\hline VD $(g)$ & $0,25 \pm 0,03$ & $0,27 \pm 0,03$ \\
\hline $\operatorname{AT}(\mathrm{g})$ & $0,08 \pm 0,02$ & $0,10 \pm 0,01 *$ \\
\hline Coração/PCF (mg/g) & $2,32 \pm 0,18$ & $2,09 \pm 0,16^{*}$ \\
\hline VE/PCF (mg/g) & $1,68 \pm 0,12$ & $1,47 \pm 0,13^{*}$ \\
\hline VD/PCF (mg/g) & $0,48 \pm 0,06$ & $0,45 \pm 0,06$ \\
\hline $\mathrm{AT} / \mathrm{PCF}(\mathrm{mg} / \mathrm{g})$ & $0,16 \pm 0,03$ & $0,16 \pm 0,02$ \\
\hline Coração/tíbia (g/cm) & $0,26 \pm 0,02$ & $0,27 \pm 0,02$ \\
\hline VE/tíbia (g/cm) & $0,19 \pm 0,01$ & $0,19 \pm 0,01$ \\
\hline VD/tíbia (g/cm) & $0,05 \pm 0,01$ & $0,06 \pm 0,01$ \\
\hline AT/tíbia (g/cm) & $0,018 \pm 0,003$ & $0,021 \pm 0,003^{*}$ \\
\hline
\end{tabular}

Dados expressos em média \pm desvio padrão. $\mathrm{C}_{45}$ : controle; $\mathrm{Ob}_{45}$ : obeso submetidos à 45 semanas de tratamento; PCF: peso corporal final; VE: peso do ventrículo esquerdo; VD: peso do ventrículo direito; AT: peso do átrio; VE/PCF: relação do peso do ventrículo esquerdo pelo peso corporal final; VD/PCF: relação do peso do ventrículo direito pelo peso corporal final; AT/PCF: relação do peso do átrio pelo peso corporal final. VE/tíbia: relação do peso do ventrículo esquerdo pelo comprimento da tíbia; VD/tíbia: relação do peso do ventrículo direito pelo comprimento da tíbia; AT/tíbia: relação do peso do átrio pelo comprimento da tíbia. Teste " $t$ " de Student para amostras independentes. ${ }^{*} \mathrm{p}<0,05$ vs $\mathrm{C}_{45}$.

\subsubsection{2- Análise microscópica}

As Figuras 38 e 39 mostram a área seccional transversa do miócito realizadas no ventrículo esquerdo dos animais $\mathrm{C}_{45}$ e $\mathrm{Ob}_{45}$. Não houve diferença significativa na área seccional do miócito dos fragmentos do VE entre os dois grupos (Figura 38). 


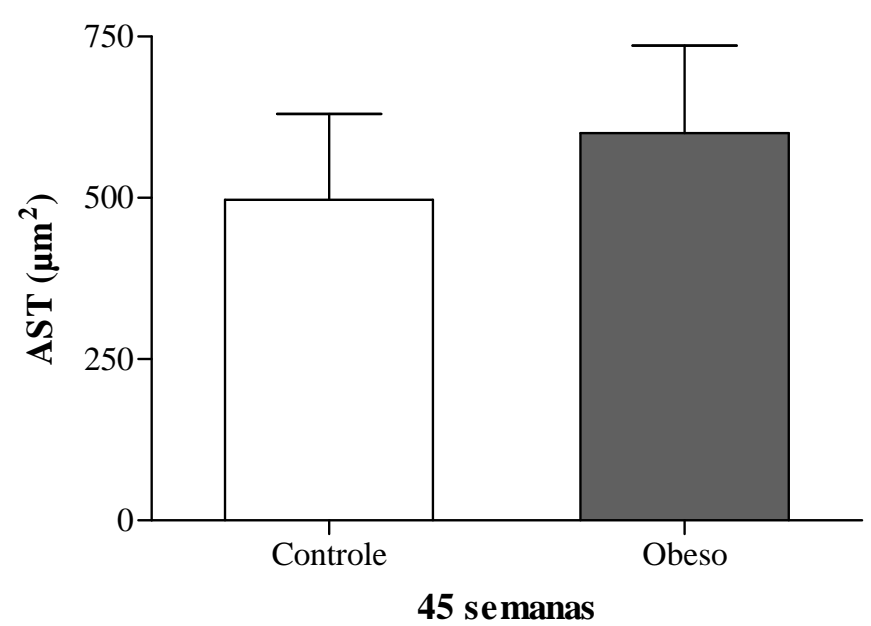

Figura 38. Secções transversas de fragmentos do VE dos grupos controle $\left(\mathrm{C}_{45}, \mathrm{n}=8\right)$ e obeso $\left(\mathrm{Ob}_{45}, \mathrm{n}=6\right)$ submetidos à 45 semanas de tratamento. Técnica de Retículina de gömori 40X. Dados expressos em média \pm desvio padrão. Teste " $t$ " de Student para amostras independentes. Não houve diferença estatística entre os grupos.
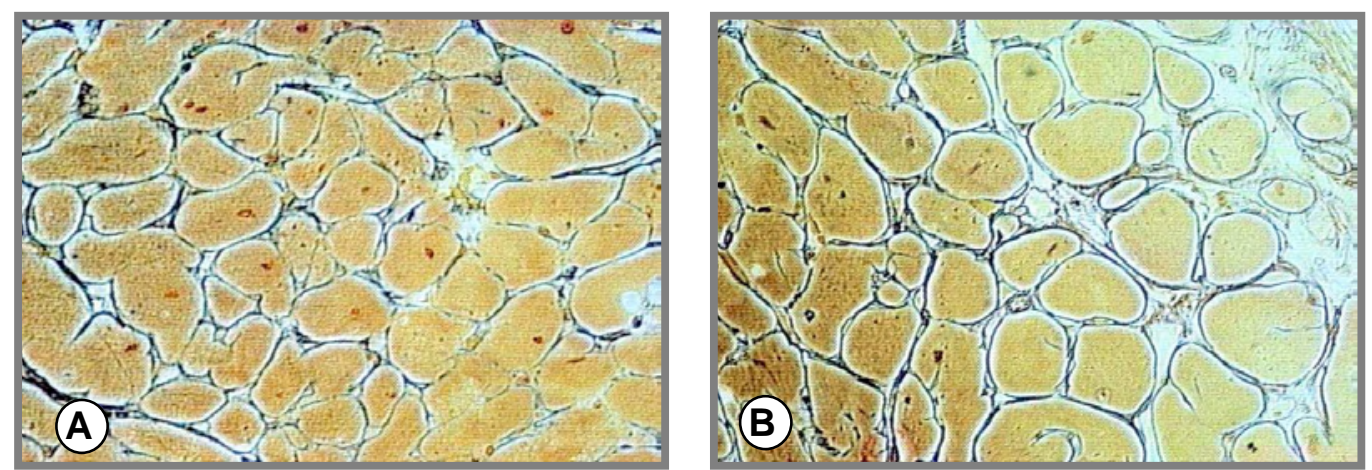

Figura 39. Secções transversas subendocárdicas do ventrículo esquerdo (VE) dos grupos controle e obeso submetidos à 45 semanas de tratamento; A: fragmento do VE do grupo controle; B: fragmento do VE do grupo obeso; Técnica de Reticulina de gömori 40X.

\subsection{9- Expressão de RNAm miocárdico}

As Figuras 40 e 41 ilustram a expressão do RNAm das proteínas relacionadas com o trânsito de cálcio miocárdico, CANAL L, RyR, SERCA, PLB, NXC e CSQ nos animais $\mathrm{C}_{45} \mathrm{e}$ $\mathrm{Ob}_{45}$. Após 45 semanas, a obesidade promoveu diminuição do RNAm da SERCA, da CSQ e do NCX em relação ao $\mathrm{C}_{45}$ (Figuras 40 e 41). A obesidade não promoveu alterações na expressão gênica da PLB, do CANAL L $(p=0,11)$ e da RyR. Os níveis de RNAm da $\beta$-actina, dados não mostrados, foram semelhantes entre os grupos. 


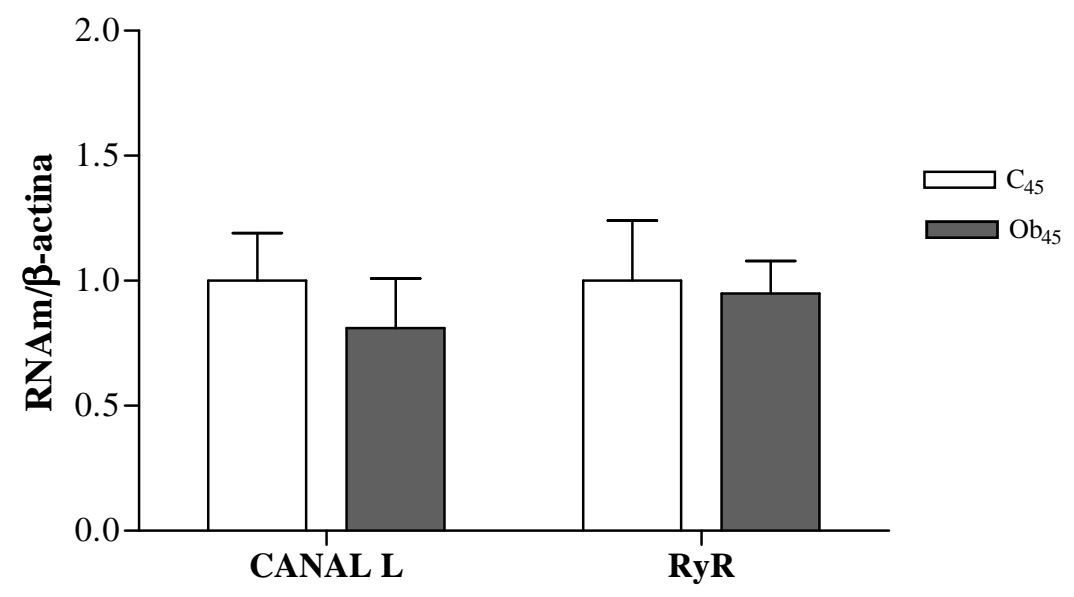

Figura 40. Expressão gênica de CANAL L e RyR no miocárdio dos animais controle $\left(\mathrm{C}_{45}, \mathrm{n}=6\right)$ e obeso $\left(\mathrm{Ob}_{45}\right.$, $\mathrm{n}=6$ ) submetidos à 45 semanas de tratamento. Dados expressos em média \pm desvio padrão. Teste " $t$ " de Student. Não houve diferença estatística entre os grupos.

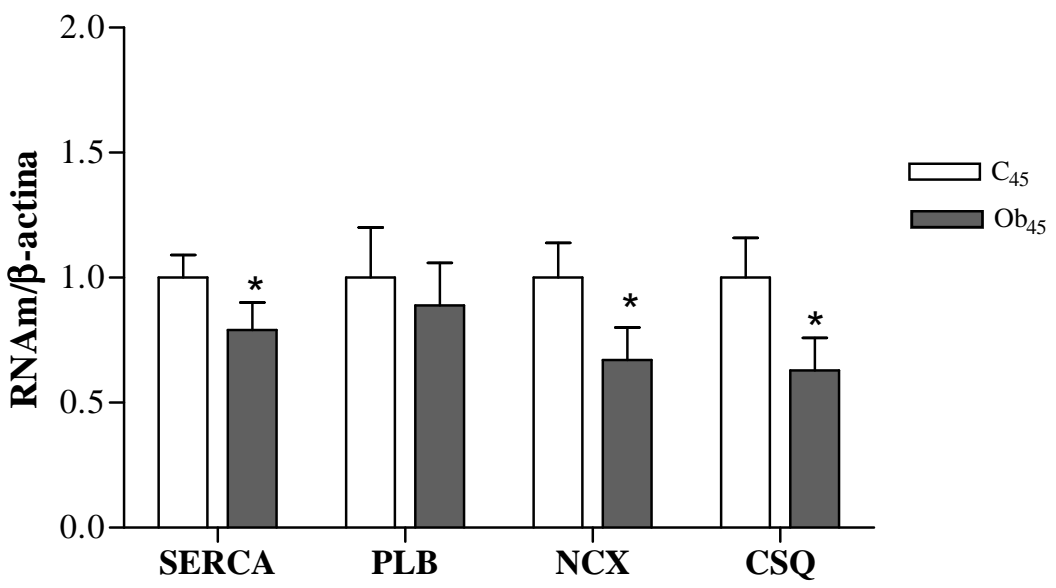

Figura 41. Expressão gênica de SERCA, PLB, NCX e CSQ no miocárdio dos animais controle $\left(\mathrm{C}_{45}, \mathrm{n}=6\right)$ e obeso $\left(\mathrm{Ob}_{45}, \mathrm{n}=6\right)$ submetidos à 45 semanas de tratamento. Dados expressos em média \pm desvio padrão. * $\mathrm{p}<0,05$ vs $\mathrm{C}_{45}$. Teste “ $t$ ” de Student. 


\subsubsection{0- Expressão de proteínas miocárdicas}

As Figuras 42 e 43 ilustram a expressão das proteínas relacionadas com o trânsito de cálcio intracelular miocárdico dos grupos $\mathrm{C}_{45}$ e $\mathrm{Ob}_{45}$. As Figuras 42 e 43 mostram que a obesidade não promoveu alterações nos níveis protéicos do CANAL L, da SERCA, da PLB $(\mathrm{p}=0,10)$, da CSQ, da pPLB Ser16, pPLB Thr17 e as razões SERCA/PLB, pPLB Ser16/PLB e razão pPLB Thr17/PLB em relação ao $\mathrm{C}_{45}$.

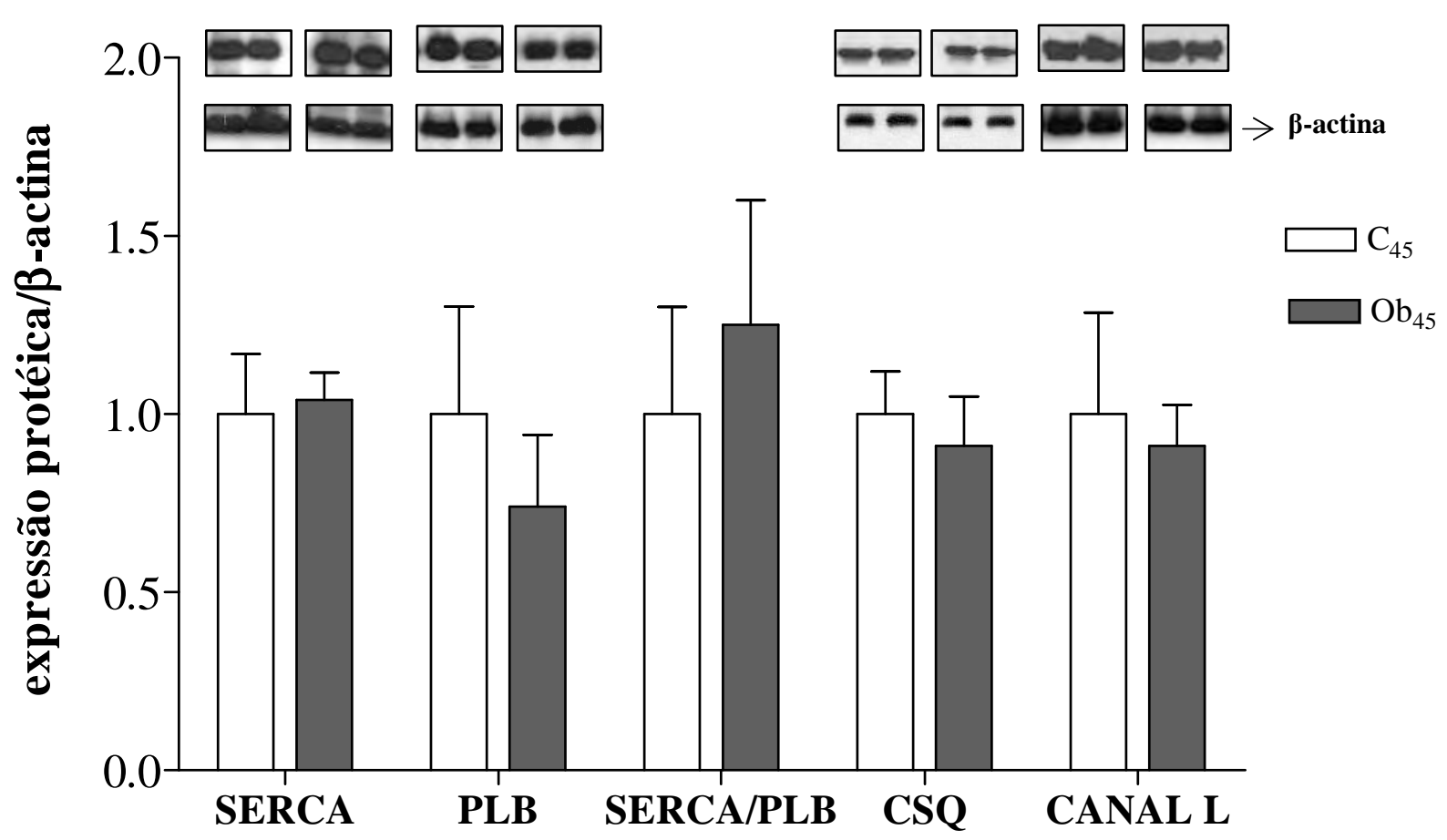

Figura 42. Expressão protéica de SERCA, PLB, CSQ, CANAL L e a razão SERCA/PLB no miocárdio dos animais controle $\left(\mathrm{C}_{45}, \mathrm{n}=6\right)$ e obeso $\left(\mathrm{Ob}_{45}, \mathrm{n}=6\right)$ submetidos à 45 semanas de tratamento. Dados expressos em média \pm desvio padrão. Teste " $t$ " de Student. Não houve diferença estatística entre os grupos. 


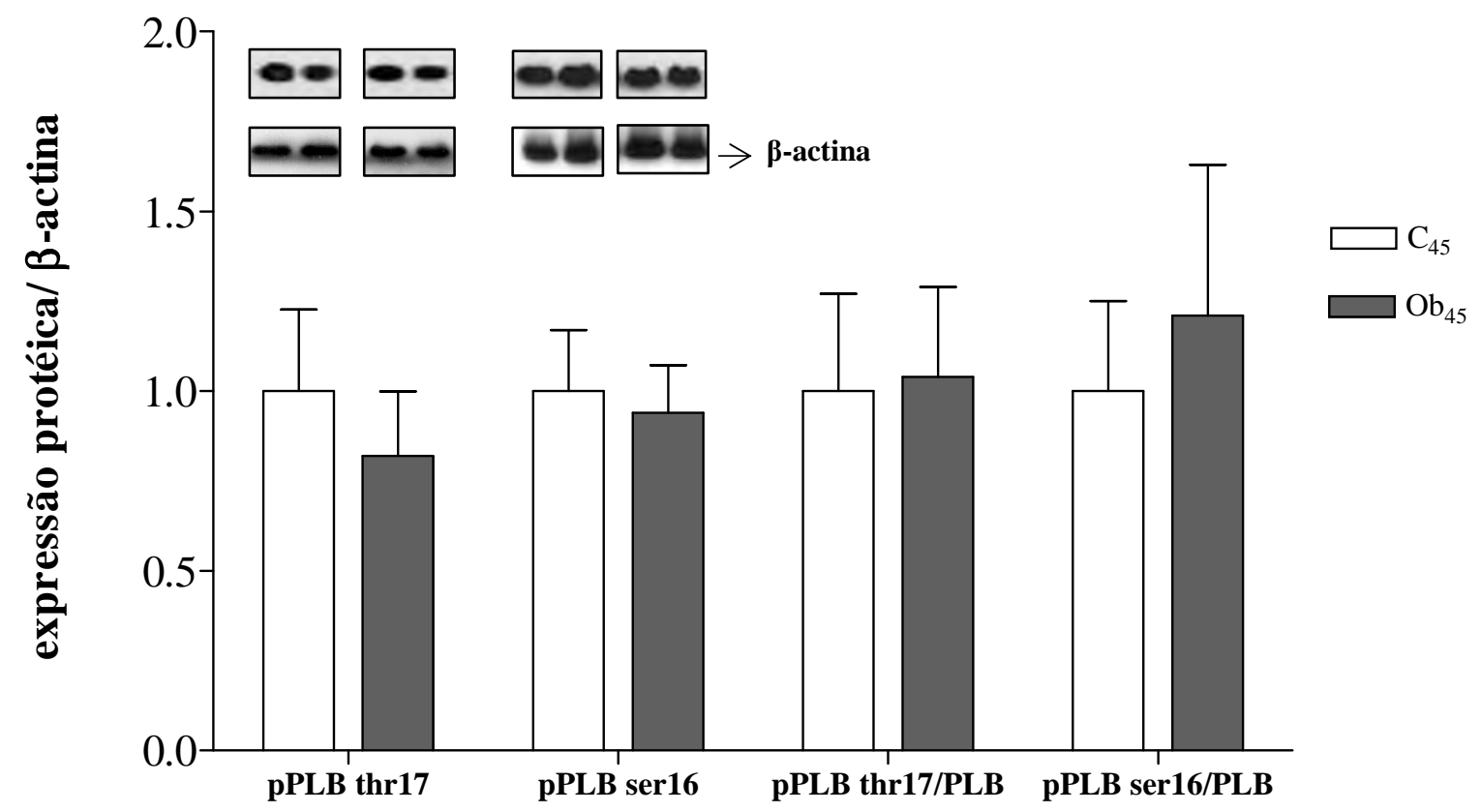

Figura 43. Expressão protéica de pPLB thr 17, pPLB ser16 e as razões pPLB thr17/PLB e pPLB ser16/PLB no miocárdio dos animais animais controle $\left(\mathrm{C}_{45}\right.$, $\mathrm{n}=6)$ e obeso $\left(\mathrm{Ob}_{45}, \mathrm{n}=6\right)$ submetidos à 45 semanas de tratamento. Dados expressos em média \pm desvio padrão. Teste " $t$ " de Student. Não houve diferença estatística entre os grupos.

\subsubsection{1- Determinação do teor de água nos tecidos cardíaco, pulmonar e hepático}

A Tabela 10 mostra a porcentagem de umidade dos tecidos dos ratos $\mathrm{C}_{45}$ e $\mathrm{Ob}_{45}$. Após 45 semanas de tratamento, não houve diferença significativa no teor de água do VE, VD, AT, pulmão e fígado entre os grupos. 
Tabela 10. Teor de água nos tecidos cardíaco, pulmonar e hepático após 45 semanas

\begin{tabular}{ccc}
\hline & \multicolumn{2}{c}{ Grupos } \\
\cline { 2 - 3 } Variáveis & $\mathbf{C}_{\mathbf{4 5}}(\mathbf{n}=\mathbf{1 0})$ & $\mathbf{O b}_{\mathbf{4 5}}(\mathbf{n}=\mathbf{1 0})$ \\
\hline VE (\%) & $72,7 \pm 2,8$ & $75,1 \pm 2,2$ \\
\hline VD (\%) & $73,9 \pm 3,2$ & $74,8 \pm 2,1$ \\
\hline AT (\%) & $74,6 \pm 4,4$ & $76,6 \pm 2,1$ \\
\hline Pulmão (\%) & $77,3 \pm 0,8$ & $77,5 \pm 0,9$ \\
\hline Fígado (\%) & $67,5 \pm 1,5$ & $67,1 \pm 0,7$ \\
\hline
\end{tabular}

Dados expressos em média \pm desvio padrão. $\mathrm{C}_{45}$ : controle; $\mathrm{Ob}_{45}$ : obeso submetidos à 45 semanas de tratamento; VE: ventrículo esquerdo; VD: ventrículo direito; AT: átrio. Teste " $t$ " de Student para amostras independentes. * $\mathrm{p}<0,05$ vs $\mathrm{C}_{45}$. 


\section{5- Comparação entre os grupos controles e obesos após 15, 30 e 45 semanas de tratamento}

\subsection{1- Composição dos grupos controle e obeso}

Os grupos 15, 30 e 45 semanas, após a aplicação do critério, foram constituídos, respectivamente, como referidos anteriormente de $C_{15}, n=9, O b_{15}, n=8, C_{30}, n=10, O_{30}, n=10$, $\mathrm{C}_{45}, \mathrm{n}=10$ e $\mathrm{Ob}_{45}, \mathrm{n}=10$.

\subsection{2- Perfil nutricional}

A Tabela 11 mostra o perfil nutricional dos animais $\mathrm{C}_{15}, \mathrm{C}_{30}, \mathrm{C}_{45}, \mathrm{Ob}_{15}, \mathrm{Ob}_{30}$, e $\mathrm{Ob}_{45}$. A comparação entre os três momentos, fixados os grupos, está descrita a seguir. O PCI, a ingestão alimentar e calórica, os depósitos de gordura epididimal, retroperitoneal, visceral, a gordura corporal total, o índice de adiposidade, os valores séricos de glicose e de NEFA foram semelhantes entre os grupos controles nos três momentos. Entretanto, o PCF, o ganho de peso, a eficiência alimentar, triglicérides, colesterol, HDL, LDL e proteína foram diferentes entres os grupos controles ao longo do tempo. Enquanto a proteína foi maior no $\mathrm{C}_{45}$ e $\mathrm{C}_{30}$ em relação ao $\mathrm{C}_{15}$, a eficiência alimentar diminuiu ao longo do tempo entre os animais controle $\left(\mathrm{C}_{45}<\mathrm{C}_{30}<\mathrm{C}_{15}\right)$. O PCF foi maior no $\mathrm{C}_{45}$ em relação ao $\mathrm{C}_{15}$, enquanto que o ganho de peso e o $\mathrm{LDL}$ foram maiores no $\mathrm{C}_{45}$ em relação ao $\mathrm{C}_{15}$ e o $\mathrm{C}_{30}$. A dosagem sérica de triglicérides foi menor no $\mathrm{C}_{30}$ em relação ao $\mathrm{C}_{45}$; entretanto, o colesterol e o HDL foram elevados no $\mathrm{C}_{45}$ em relação ao $\mathrm{C}_{15}$.

O tempo de exposição à obesidade acarretou aumento no peso corporal final e no ganho de peso dos animais $\mathrm{Ob}_{30}$ e $\mathrm{Ob}_{45}$ em relação ao $\mathrm{Ob}_{15}$. A duração da obesidade não foi capaz de promover alterações nos depósitos de gordura epididimal, retroperitoneal e visceral, na gordura corporal total, no índice de adiposidade, na ingestão alimentar e no consumo calórico. Entretanto, a eficiência alimentar diminuiu ao longo do tempo $\left(\mathrm{Ob}_{15}>\mathrm{Ob}_{30}>\mathrm{Ob}_{45}\right)$. 
O tempo de exposição à obesidade acarretou aumento dos níveis de proteínas no grupo $\mathrm{Ob}_{30}$ em relação aos animais $\mathrm{Ob}_{15}$. Não foram observadas alterações na glicose, no triglicérides, no colesterol, no HDL, no LDL, e NEFA entre os ratos obesos.

A comparação entre os dois grupos, fixados os momentos, mostra que o PCI, o PCF, o ganho de peso, a ingestão calórica, os depósitos de gordura epididimal, retroperitoneal e visceral, a gordura corporal total e o índice de adiposidade foram maiores nos grupos $\mathrm{Ob}$ em relação aos respectivos controles nos três períodos de tratamento. A ingestão alimentar, a glicose, o HDL e o NEFA séricos não apresentaram diferença estatística entre os dois grupos nos três momentos. A eficiência alimentar e os níveis de triglicérides foram maiores no Ob do que no $\mathrm{C}$ nos momentos 15 e 30 semanas. A obesidade durante 15 semanas acarretou aumento nos níveis de colesterol e proteínas séricos, entretanto, os níveis de LDL foram diminuídos nos animais $\mathrm{Ob}_{45}$ em relação ao $\mathrm{C}_{45}$. 
Tabela 11. Perfil nutricional após 15, 30 e 45 semanas

\section{Tratamento}

\begin{tabular}{|c|c|c|c|c|}
\hline Variáveis & Grupos & 15 sem & 30 sem & 45 sem \\
\hline \multirow{2}{*}{ PCI (g) } & $\mathbf{C}$ & $276 \pm 18^{\mathrm{Aa}}$ & $294 \pm 12^{\text {Aa }}$ & $282 \pm 16^{\mathrm{Aa}}$ \\
\hline & Ob & $314 \pm 18^{\mathrm{Ab}}$ & $315 \pm 14^{\mathrm{Ab}}$ & $304 \pm 21^{\mathrm{Ab}}$ \\
\hline \multirow{2}{*}{ PCF (g) } & $\mathbf{C}$ & $459 \pm 18^{\mathrm{Aa}}$ & $490 \pm 33^{\mathrm{ABa}}$ & $513 \pm 19^{\mathrm{Ba}}$ \\
\hline & $\mathbf{O b}$ & $568 \pm 44^{\mathrm{Ab}}$ & $608 \pm 22^{\mathrm{Bb}}$ & $609 \pm 37^{\mathrm{Bb}}$ \\
\hline \multirow{2}{*}{ Ganho de Peso (g) } & $\mathbf{C}$ & $183 \pm 21^{\mathrm{Aa}}$ & $196 \pm 23^{\mathrm{Aa}}$ & $231 \pm 21^{\mathrm{Ba}}$ \\
\hline & Ob & $254 \pm 38^{\mathrm{Ab}}$ & $293 \pm 21^{\mathrm{Bb}}$ & $305 \pm 25^{\mathrm{Bb}}$ \\
\hline \multirow{2}{*}{ Ingestão alimentar (g/dia) } & $\mathbf{C}$ & $25,4 \pm 1,1^{\mathrm{Aa}}$ & $26,1 \pm 1,7^{\mathrm{Aa}}$ & $26,4 \pm 1,5^{\mathrm{Aa}}$ \\
\hline & Ob & $25,9 \pm 2,1^{\mathrm{Aa}}$ & $25,9 \pm 1,2^{\mathrm{Aa}}$ & $24,8 \pm 1,6^{\mathrm{Aa}}$ \\
\hline \multirow{2}{*}{ Ingestão Calórica (Kcal/dia) } & $\mathbf{C}$ & $75,1 \pm 3,1^{\mathrm{Aa}}$ & $77,0 \pm 4,9^{\mathrm{Aa}}$ & $77,9 \pm 4,4^{\mathrm{Aa}}$ \\
\hline & Ob & $94,6 \pm 7,5^{\mathrm{Ab}}$ & $94,7 \pm 4,2^{\mathrm{Ab}}$ & $90,7 \pm 5,8^{\mathrm{Ab}}$ \\
\hline \multirow{2}{*}{ Eficiência alimentar (\%) } & $\mathbf{C}$ & $2,3 \pm 0,2^{\mathrm{Aa}}$ & $1,2 \pm 0,1^{\mathrm{Ba}}$ & $1,0 \pm 0,1^{\mathrm{Ca}}$ \\
\hline & Ob & $2,6 \pm 0,3^{\mathrm{Ab}}$ & $1,5 \pm 0,1^{\mathrm{Bb}}$ & $1,1 \pm 0,1^{\mathrm{Ca}}$ \\
\hline \multirow{2}{*}{ Epididimal (g) } & $\mathbf{C}$ & $7,1 \pm 1,4^{\mathrm{Aa}}$ & $6,1 \pm 2,5^{\mathrm{Aa}}$ & $6,3 \pm 1,5^{\mathrm{Aa}}$ \\
\hline & Ob & $13,7 \pm 4,1^{\mathrm{Ab}}$ & $12,0 \pm 3,0^{\mathrm{Ab}}$ & $12,5 \pm 2,5^{\mathrm{Ab}}$ \\
\hline \multirow{2}{*}{ Retroperitoneal (g) } & $\mathbf{C}$ & $7,5 \pm 1,6^{\mathrm{Aa}}$ & $8,5 \pm 2,5^{\mathrm{Aa}}$ & $11 \pm 2^{\mathrm{Aa}}$ \\
\hline & Ob & $19,3 \pm 8,5^{\mathrm{Ab}}$ & $19,4 \pm 4,3^{\mathrm{Ab}}$ & $21 \pm 6^{\mathrm{Ab}}$ \\
\hline \multirow{2}{*}{ Visceral (g) } & $\mathbf{C}$ & $5,5 \pm 0,9^{\mathrm{Aa}}$ & $4,5 \pm 1,6^{\mathrm{Aa}}$ & $6,7 \pm 1,0^{\mathrm{Aa}}$ \\
\hline & Ob & $12,5 \pm 4,8^{\mathrm{Ab}}$ & $12,0 \pm 3,0^{\mathrm{Ab}}$ & $14,4 \pm 2,8^{\mathrm{Ab}}$ \\
\hline \multirow{2}{*}{ Gordura corporal total (g) } & $\mathbf{C}$ & $20 \pm 3^{\mathrm{Aa}}$ & $19 \pm 5^{\mathrm{Aa}}$ & $24 \pm 3^{\mathrm{Aa}}$ \\
\hline & Ob & $46 \pm 17^{\mathrm{Ab}}$ & $43 \pm 8^{\mathrm{Ab}}$ & $48 \pm 8^{\mathrm{Ab}}$ \\
\hline \multirow{2}{*}{ Índice de Adiposidade (\%) } & $\mathbf{C}$ & $4,4 \pm 0,6^{\mathrm{Aa}}$ & $3,9 \pm 0,9^{\mathrm{Aa}}$ & $4,6 \pm 0,5^{\mathrm{Aa}}$ \\
\hline & Ob & $7,9 \pm 2,4^{\mathrm{Ab}}$ & $7,1 \pm 1,3^{\mathrm{Ab}}$ & $7,8 \pm 1,1^{\mathrm{Ab}}$ \\
\hline
\end{tabular}


Tabela 11. Perfil nutricional após 15,30 e 45 semanas "continua"

\begin{tabular}{|c|c|c|c|c|}
\hline \multirow{2}{*}{ Glicose (mg/dl) } & $\mathbf{C}$ & $163 \pm 22^{\mathrm{Aa}}$ & $157 \pm 15^{\mathrm{Aa}}$ & $172 \pm 27^{\mathrm{Aa}}$ \\
\hline & $\mathbf{O b}$ & $176 \pm 13^{\mathrm{Aa}}$ & $172 \pm 21^{\mathrm{Aa}}$ & $168 \pm 29^{\mathrm{Aa}}$ \\
\hline \multirow{2}{*}{ Triglicérides (mg/dl) } & $\mathbf{C}$ & $61 \pm 11^{\mathrm{ABa}}$ & $54 \pm 9^{\mathrm{Aa}}$ & $77 \pm 15^{\mathrm{Ba}}$ \\
\hline & Ob & $80 \pm 18^{\mathrm{Ab}}$ & $93 \pm 19^{\mathrm{Ab}}$ & $91 \pm 23^{\mathrm{Aa}}$ \\
\hline \multirow{2}{*}{ Colesterol (mg/dl) } & $\mathbf{C}$ & $56 \pm 9^{\mathrm{Aa}}$ & $71 \pm 9^{\mathrm{ABa}}$ & $78 \pm 18^{\mathrm{Ba}}$ \\
\hline & Ob & $74 \pm 11^{\mathrm{Ab}}$ & $73 \pm 16^{\mathrm{Aa}}$ & $79 \pm 10^{\mathrm{Aa}}$ \\
\hline \multirow{2}{*}{ HDL (mg/dl) } & $\mathbf{C}$ & $22 \pm 3^{\mathrm{Aa}}$ & $25 \pm 4^{\mathrm{ABa}}$ & $28 \pm 3^{\mathrm{Ba}}$ \\
\hline & $\mathbf{O b}$ & $26 \pm 5^{\text {Aa }}$ & $26 \pm 4^{\mathrm{Aa}}$ & $29 \pm 5^{\text {Aa }}$ \\
\hline \multirow{2}{*}{ LDL (mg/dl) } & $\mathbf{C}$ & $14 \pm 4^{\mathrm{Aa}}$ & $15 \pm 3^{\mathrm{Aa}}$ & $21 \pm 7^{\mathrm{Ba}}$ \\
\hline & Ob & $15 \pm 4^{\mathrm{Aa}}$ & $14 \pm 2^{\mathrm{Aa}}$ & $17 \pm 4^{\mathrm{Ab}}$ \\
\hline \multirow{2}{*}{ Proteína (g/dL) } & $\mathbf{C}$ & $5,9 \pm 0,3^{\mathrm{Aa}}$ & $6,4 \pm 0,4^{\mathrm{Ba}}$ & $6,6 \pm 0,2^{\mathrm{Ba}}$ \\
\hline & Ob & $6,3 \pm 0,2^{\mathrm{Ab}}$ & $6,7 \pm 0,5^{\mathrm{Ba}}$ & $6,7 \pm 0,2^{\mathrm{ABa}}$ \\
\hline \multirow{2}{*}{ NEFA (mmol/L) } & $\mathbf{C}$ & $0,44 \pm 0,09^{\mathrm{Aa}}$ & $0,42 \pm 0,10^{\mathrm{Aa}}$ & $0,49 \pm 0,10^{\mathrm{Aa}}$ \\
\hline & Ob & $0,48 \pm 0,11^{\mathrm{Aa}}$ & $0,48 \pm 0,11^{\mathrm{Aa}}$ & $0,55 \pm 0,07^{\mathrm{Aa}}$ \\
\hline
\end{tabular}

Dados expressos em média \pm desvio-padrão. C: grupo controle submetido à dieta normocalórica por $15(C ; n=9,30(C$; $\mathrm{n}=10)$ e $45(\mathrm{C} ; \mathrm{n}=10)$ semanas de tratamento; Ob: grupo obeso submetido à dieta hipercalórica por $15(\mathrm{Ob} ; \mathrm{n}=8), 30$ $(\mathrm{Ob} ; \mathrm{n}=10)$ e $45(\mathrm{Ob} ; \mathrm{n}=10)$ semanas de tratamento; PCI: peso corporal inicial; PCF: peso corporal final; HDL: lipoproteína de alta intensidade; LDL: lipoproteína de baixa intensidade; NEFA: ácidos graxos não-esterificados. Letra maiúscula indica comparação entre os momentos fixado o grupo; letra minúscula indica comparação entre os grupos fixado o momento. Letras diferentes indicam diferença significativa $(\mathrm{p}<0,05)$. Análise de variância (ANOVA) two way para grupos independentes, complementada com o teste de comparações múltiplas de Bonferroni.

\subsection{3- Pressão arterial sistólica}

A Figura 44 mostra o resultado da pressão arterial sistólica final realizado nos animais $\mathrm{C}_{15}, \mathrm{C}_{30}, \mathrm{C}_{45}, \mathrm{Ob}_{15}, \mathrm{Ob}_{30}$, e $\mathrm{Ob}_{45}$. Os grupos controles e obesos não apresentaram diferença estatística intra e entre grupos em todos os momentos estudados. 


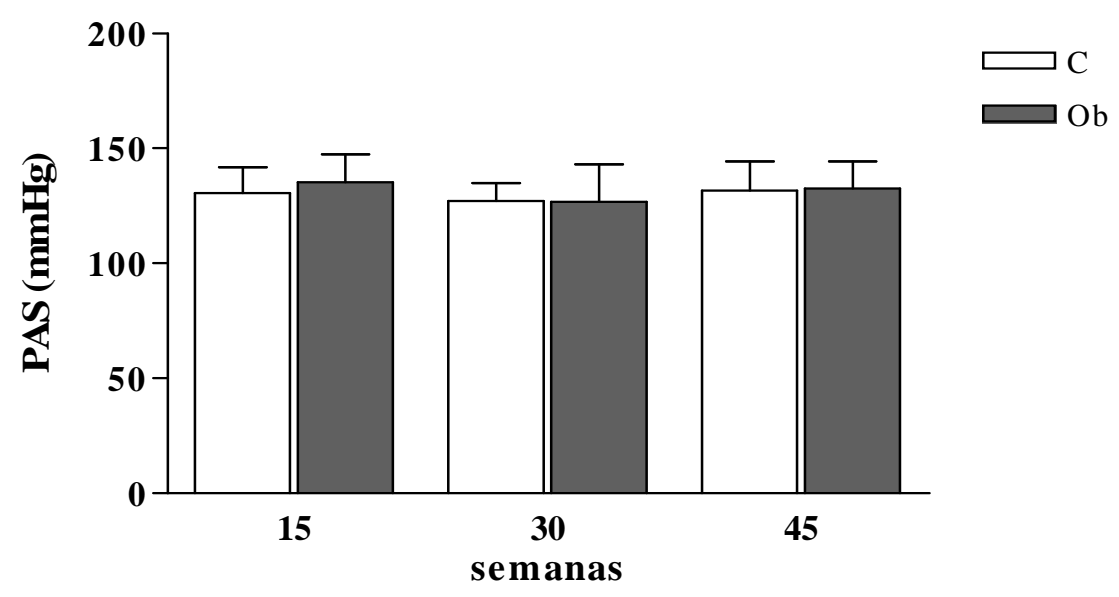

Figura 44. Pressão arterial sistólica final dos animais controle $\left(\mathrm{C}_{15}, \mathrm{n}=9 ; \mathrm{C}_{30}, \mathrm{n}=10 ; \mathrm{C}_{45}, \mathrm{n}=10\right)$ e obeso $\left(\mathrm{Ob}_{15}\right.$, $\left.\mathrm{n}=8 ; \mathrm{Ob}_{30}, \mathrm{n}=10 ; \mathrm{Ob}_{45}, \mathrm{n}=10\right)$ submetidos à 15,30 e 45 semanas de tratamento. Dados expressos em média \pm desvio padrão. Análise de variância (ANOVA) two way para grupos independentes, complementada com o teste post-hoc de Bonferroni. Não houve diferença estatística entre os grupos.

\subsection{4- Teste de tolerância à glicose}

A Figura 45 ilustra o resultado da área glicêmica do teste de tolerância à glicose realizado nos animais $\mathrm{C}_{15}, \mathrm{C}_{30}, \mathrm{C}_{45}, \mathrm{Ob}_{15}, \mathrm{Ob}_{30}$, e $\mathrm{Ob}_{45}$. A área glicêmica foi maior nos grupos $\mathrm{Ob}_{15}, \mathrm{Ob}_{30}$, e $\mathrm{Ob}_{45}$ em relação aos seus respectivos grupos controles. $\mathrm{O}$ tempo de exposição não promoveu alteração na variável nos momentos estudados nos dois grupos. 


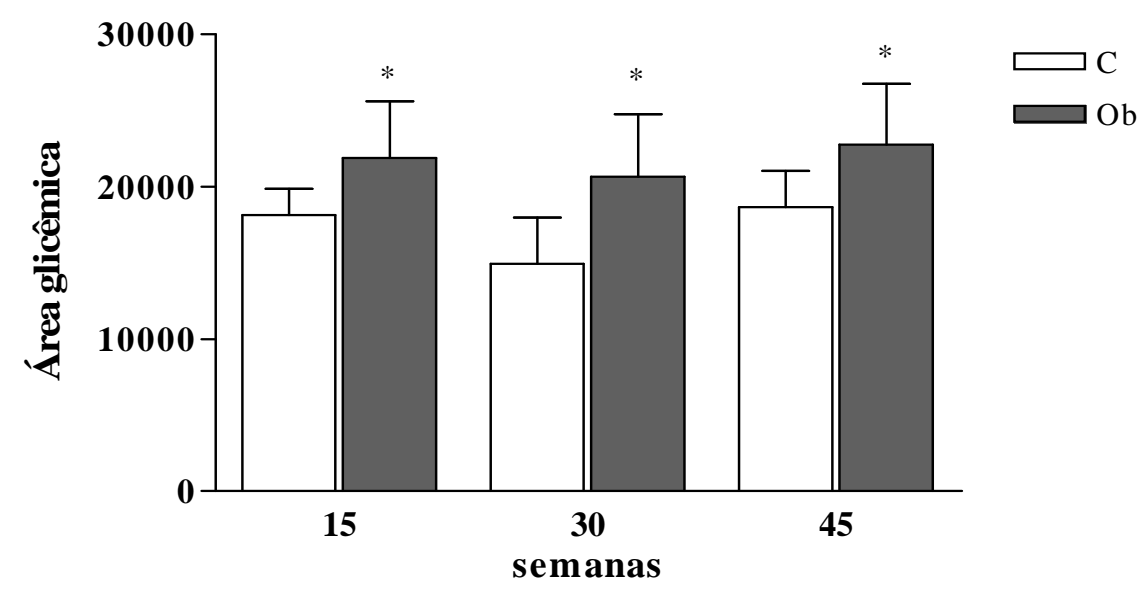

Figura 45. Área glicêmica, obtida no teste de tolerância à glicose, dos animais controle $\left(C_{15}, n=8 ; C_{30}, n=9 ; C_{45}, n=9\right)$ e obeso $\left(\mathrm{Ob}_{15}, \mathrm{n}=8 ; \mathrm{Ob}_{30}, \mathrm{n}=9 ; \mathrm{Ob}_{45}, \mathrm{n}=8\right)$ submetidos à 15,30 e 45 semanas de tratamento. Dados expressos em média \pm desvio padrão. Análise de variância (ANOVA) two way para grupos independentes, complementada com o teste post-hoc de Bonferroni. * $\mathrm{p}<0,05$ vs $\mathrm{C}$.

\subsection{5- Índice de resistência à insulina}

A Figura 46 mostra o resultado do índice HOMA-IR nos grupos $\mathrm{C}_{15}, \mathrm{C}_{30}, \mathrm{C}_{45}, \mathrm{Ob}_{15}$, $\mathrm{Ob}_{30}$, e $\mathrm{Ob}_{45}$. $\mathrm{O}$ índice HOMA-IR foi maior nos grupos $\mathrm{Ob}_{15}$ e $\mathrm{Ob}_{45}$ em relação aos seus respectivos grupos controles; entretanto, não foi possível mostrar diferença nesta variável entre os grupos $\mathrm{Ob}_{30}$ e $\mathrm{C}_{30}(\mathrm{p}=0,054)$. A duração da obesidade acarretou aumento do índice HOMA-IR nos animais $\mathrm{Ob}_{45}$ em relação aos $\mathrm{Ob}_{15}$ e $\mathrm{Ob}_{30}$. Entretanto, não foram observadas alterações deste índice entre os grupos controle ao longo do tempo. 


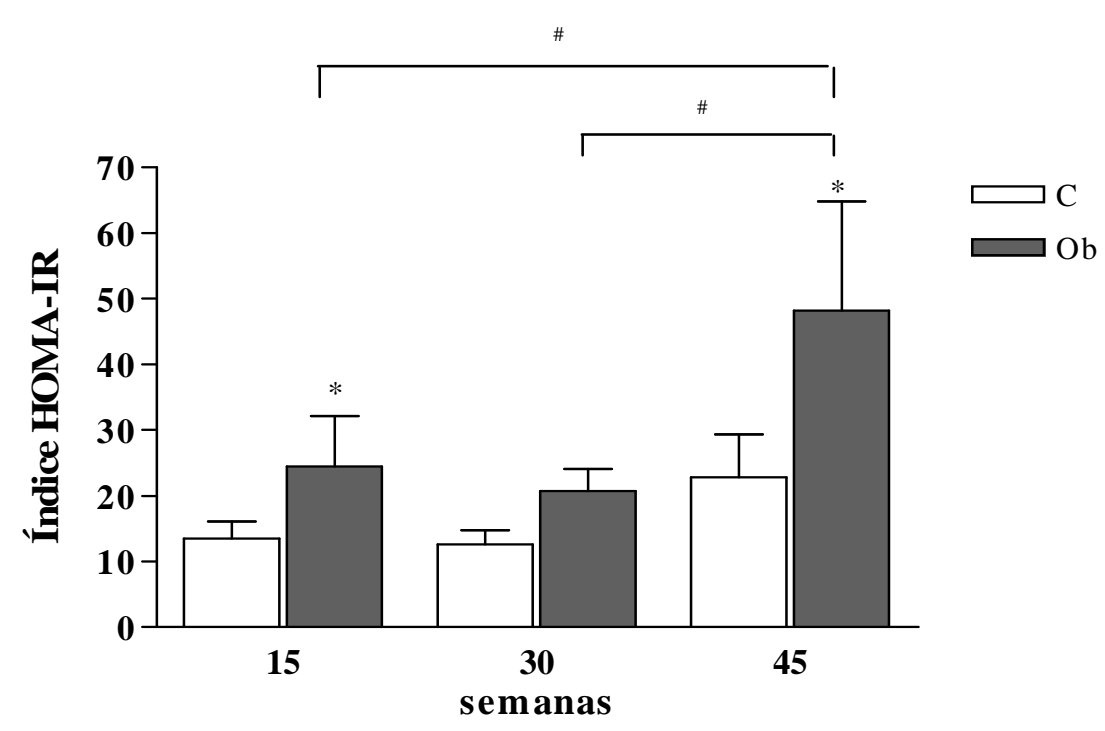

Figura 46. Índice HOMA-IR (resistência à insulina) dos animais controle $\left(C_{15}, n=8 ; C_{30}, n=9 ; C_{45}, n=7\right)$ e obeso $\left(\mathrm{Ob}_{15}, \mathrm{n}=8 ; \mathrm{Ob}_{30}, \mathrm{n}=9 ; \mathrm{Ob}_{45}, \mathrm{n}=8\right)$ submetidos à 15,30 e 45 semanas de tratamento. Dados expressos em média \pm desvio padrão. Análise de variância (ANOVA) two way para grupos independentes, complementada com o teste post-hoc de Bonferroni. * $\mathrm{p}<0,05$ vs C. ${ }^{*} \mathrm{p}<$ 0,05 vs intra-grupo.

\subsection{6- Análise sérica dos hormônios insulina e leptina}

A Figura 47 ilustra o resultado sérico de insulina realizado nos grupos $C_{15}, C_{30}, C_{45}$, $\mathrm{Ob}_{15}, \mathrm{Ob}_{30}$, e $\mathrm{Ob}_{45}$. A Figura 47 mostra que a insulina aumentou nos animais $\mathrm{Ob}_{45}$ em relação ao $\mathrm{Ob}_{15}$ e $\mathrm{Ob}_{30}$. $\mathrm{O}$ mesmo comportamento foi visualizado nos animais controle ao longo do tempo. A comparação entre os grupos, fixados os momentos, mostra que os níveis de insulina sérica foram maiores nos grupos $\mathrm{Ob}_{15}, \mathrm{Ob}_{30}$ e $\mathrm{Ob}_{45}$ em relação aos respectivos controles.

A Figura 48 ilustra o resultado sérico de leptina realizado nos grupos $C_{15}, C_{30}, C_{45}$, $\mathrm{Ob}_{15}, \mathrm{Ob}_{30}$, e $\mathrm{Ob}_{45}$. O tempo de exposição à obesidade promoveu aumento da leptina nos grupos $\mathrm{Ob}_{45}$ em relação ao $\mathrm{Ob}_{15}$; entretanto não foi possível mostrar diferença estatística entre os grupos $\mathrm{Ob}_{15}$ versus $\mathrm{Ob}_{30}(\mathrm{p}=0,055)$ e $\mathrm{Ob}_{30}$ versus $\mathrm{Ob}_{45}(\mathrm{p}=0,09)$. Nos animais controles, o tempo não promoveu alterações nos níveis de leptina. Fixados os momentos, os níveis séricos de leptina foram maiores nos grupos obesos em relação aos respectivos grupos controles. 


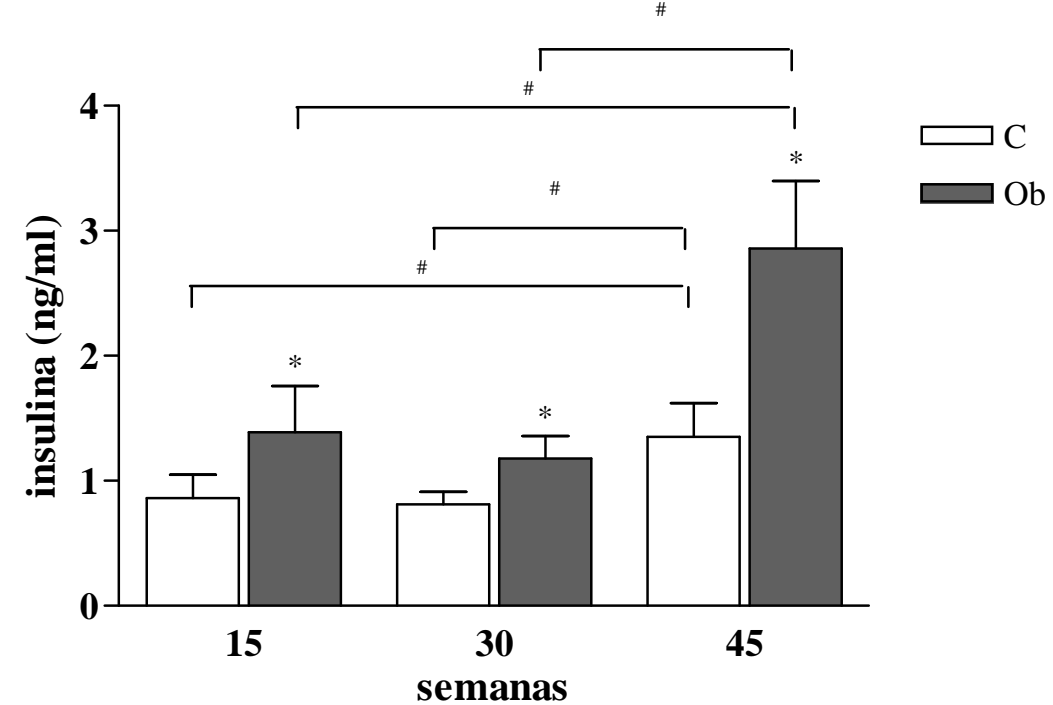

Figura 47. Níveis séricos de insulina dos animais controle $\left(\mathrm{C}_{15}, \mathrm{n}=8 ; \mathrm{C}_{30}, \mathrm{n}=8 ; \mathrm{C}_{45}, \mathrm{n}=7\right)$ e obeso $\left(\mathrm{Ob}_{15}\right.$, $\mathrm{n}=8 ; \mathrm{Ob}_{30}, \mathrm{n}=8 ; \mathrm{Ob}_{45}, \mathrm{n}=8$ ) submetidos à 15,30 e 45 semanas de tratamento. Dados expressos em média \pm desvio padrão. Análise de variância (ANOVA) two way para grupos independentes, complementada com o teste post-hoc de Bonferroni. * $\mathrm{p}<0,05$ vs C. ${ }^{\#} \mathrm{p}<0,05$ vs intra-grupo.

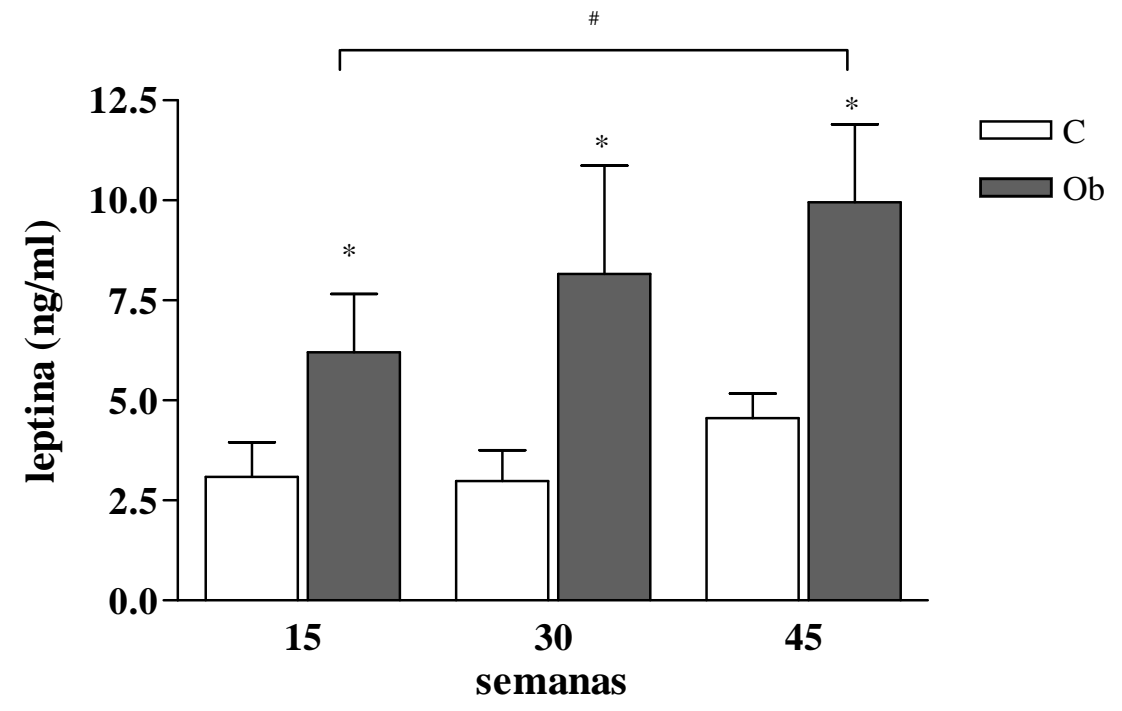

Figura 48. Níveis séricos de leptina dos animais controle $\left(\mathrm{C}_{15}, \mathrm{n}=8 ; \mathrm{C}_{30}, \mathrm{n}=8 ; \mathrm{C}_{45}, \mathrm{n}=7\right)$ e obeso $\left(\mathrm{Ob}_{15}, \mathrm{n}=8 ; \mathrm{Ob}_{30}\right.$, $\mathrm{n}=8 ; \mathrm{Ob}_{45}, \mathrm{n}=8$ ) submetidos à 15,30 e 45 semanas de tratamento. Dados expressos em média \pm desvio padrão. Análise de variância (ANOVA) two way para grupos independentes, complementada com o teste post-hoc de Bonferroni. * $\mathrm{p}<0,05$ vs $\mathrm{C}$. ${ }^{\#} \mathrm{p}<0,05$ vs intra-grupo. 


\subsection{7- Análise sérica dos hormônios tireoidianos}

As Figuras 49, 50 e 51 mostram as dosagens séricas dos hormônios tireoidianos TSH, T4 e T3 realizado nos grupos $\mathrm{C}_{15}, \mathrm{C}_{30}, \mathrm{C}_{45}, \mathrm{Ob}_{15}, \mathrm{Ob}_{30}$, e $\mathrm{Ob}_{45}$. A Figura 49 mostra que duração da obesidade aumentou os níveis de TSH do grupo $\mathrm{Ob}_{45}$ em relação ao $\mathrm{Ob}_{15}$; entretanto, a elevação dos níveis de TSH não ocorreu de modo significante entre os grupos $\mathrm{Ob}_{30}$ e $\mathrm{Ob}_{15}(\mathrm{p}=0,10)$. Não houve diferença estatística nos níveis de TSH entre os grupos controles ao longo do tempo. Fixados os momentos, os níveis de TSH foram diminuídos no grupo $\mathrm{Ob}_{15}$ em relação ao $\mathrm{C}_{15}$; entretanto, houve aumento no TSH no grupo $\mathrm{Ob}_{45}$ em relação $\mathrm{C}_{45}$.

A Figura 50 mostra que os níveis de $\mathrm{T} 4$ foram menores nos animais $\mathrm{Ob}_{45}$ do que os $\mathrm{Ob}_{15}$. Não foi possível mostrar diferença estatística no T4 entre os grupos $\mathrm{Ob}_{15}$ e $\mathrm{Ob}_{30}$ $(\mathrm{p}=0,06)$. Os animais controle apresentaram níveis similares de T4 ao longo dos períodos de tratamento. A comparação entre os grupos controle e obeso, fixado o momento, mostra que não houve alterações nos níveis de $\mathrm{T} 4$ nos grupos $\mathrm{Ob}_{15}$ e $\mathrm{Ob}_{45}$ em relação aos respectivos controles; entretanto, não foi possível mostrar diferença estatística entre os animais $\mathrm{Ob}_{30}$ e $\mathrm{C}_{30}$ $(\mathrm{p}=0,06)$.

A Figura 51 ilustra que os animais $\mathrm{Ob}_{45}$ apresentaram elevação dos níveis de T3 em relação ao grupo $\mathrm{Ob}_{15}$. Além disso, não foi possível mostrar diferença estatística no T3 entre os grupos $\mathrm{Ob}_{45}$ e $\mathrm{Ob}_{30}(\mathrm{p}=0,06)$. Nos grupos controles, houve diminuição do $\mathrm{T} 3$ no $\mathrm{C}_{30} \mathrm{em}$ relação ao $\mathrm{C}_{15}$. Fixados os momentos, embora a análise estatística não tenha mostrado diferença nos valores de $\mathrm{T} 3$ entre os $\mathrm{Ob}_{15}, \mathrm{Ob}_{30}$ e $\mathrm{Ob}_{45}$ e os respectivos controles, o resultado deste teste apresentou os seguintes níveis de significância, $p=0,07, p=0,11$ e p=0,06, respectivamente. 


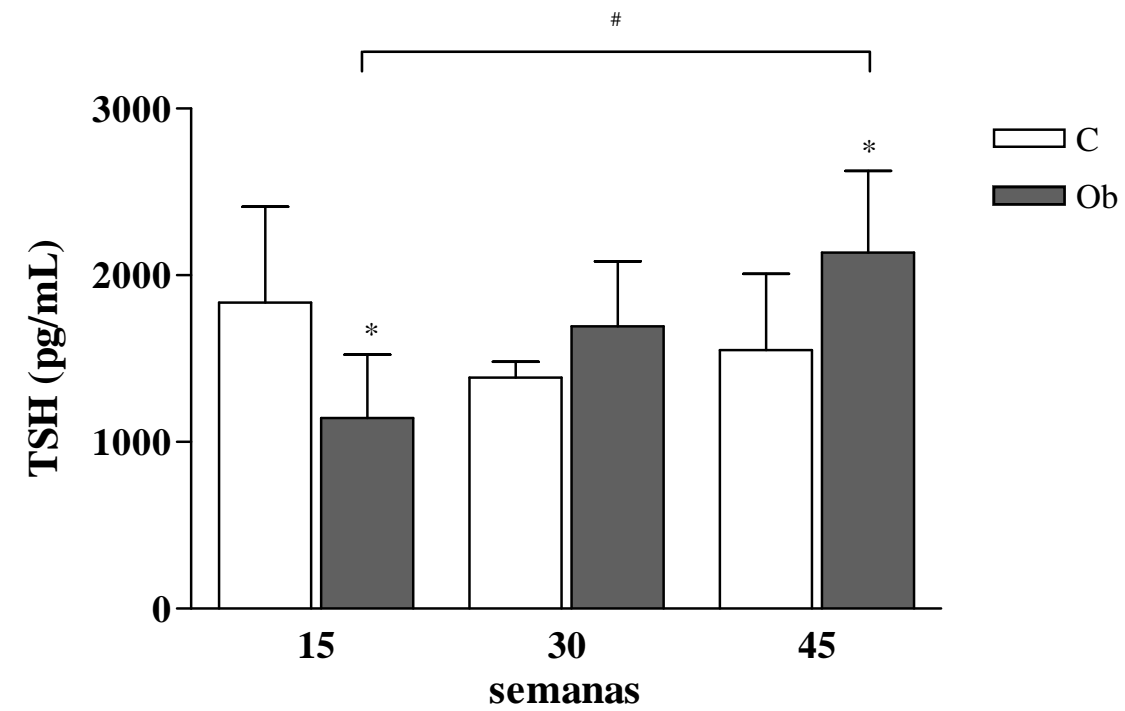

Figura 49. Níveis séricos de TSH dos animais controle $\left(\mathrm{C}_{15}, \mathrm{C}_{30}\right.$ e $\left.\mathrm{C}_{45}\right)$ e obeso $\left(\mathrm{Ob}_{15}, \mathrm{Ob}_{30}\right.$ e $\left.\mathrm{Ob}_{45}\right)$ submetidos à 15,30 e 45 semanas de tratamento. $n=6$ animais por grupo. Dados expressos em média \pm desvio padrão. Análise de variância (ANOVA) two way para grupos independentes, complementada com o teste post-hoc de Bonferroni. * $\mathrm{p}<0,05$ vs $\mathrm{C} .{ }^{\#} \mathrm{p}<0,05$ vs intra-grupo.

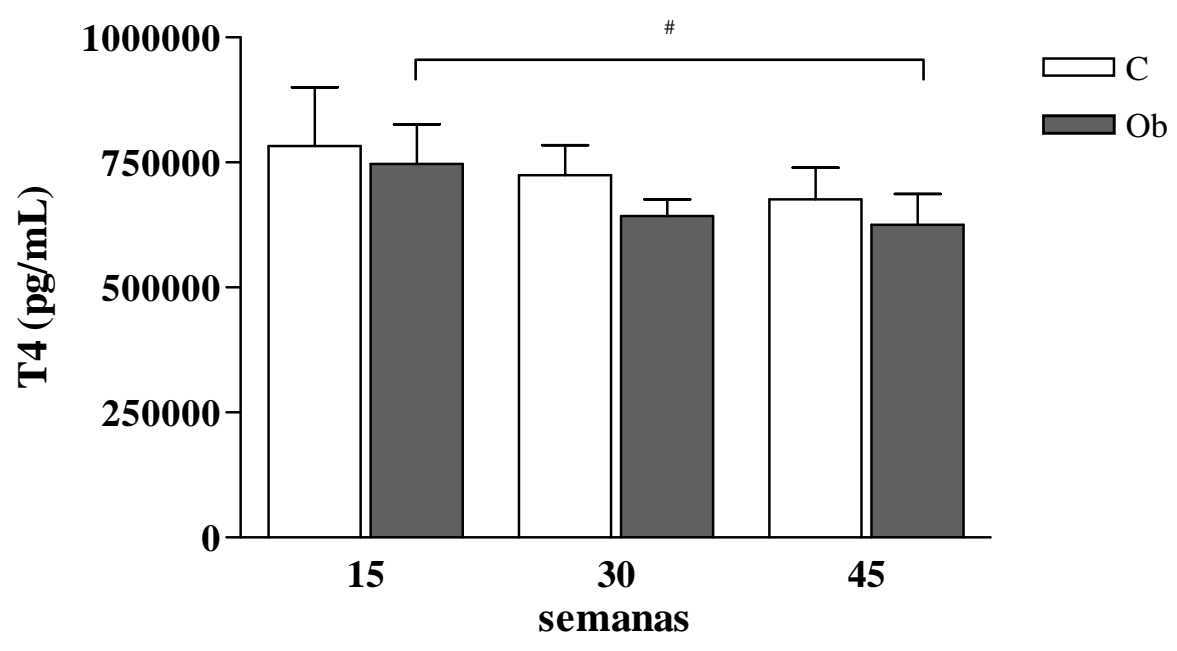

Figura 50. Níveis séricos de $\mathrm{T} 4$ dos animais controle $\left(\mathrm{C}_{15}, \mathrm{C}_{30}\right.$ e $\left.\mathrm{C}_{45}\right)$ e obeso $\left(\mathrm{Ob}_{15}, \mathrm{Ob}_{30}\right.$ e $\left.\mathrm{Ob}_{45}\right)$ submetidos à 15,30 e 45 semanas de tratamento. $n=6$ animais por grupo. Dados expressos em média \pm desvio padrão. Análise de variância (ANOVA) two way para grupos independentes, complementada com o teste post-hoc de Bonferroni. Não houve diferença estatística entre os grupos. ${ }^{\#} \mathrm{p}<0,05$ vs intra-grupo. 


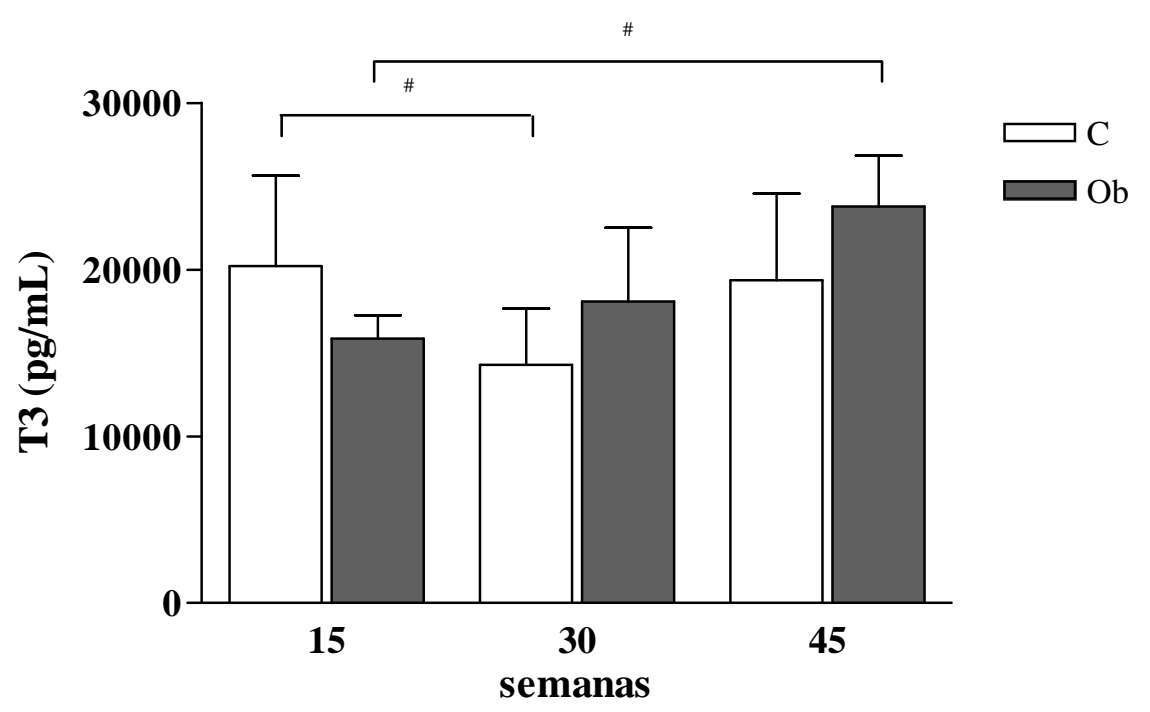

Figura 51. Níveis séricos de $\mathrm{T} 3$ dos animais controle $\left(\left(\mathrm{C}_{15}\right.\right.$, $\mathrm{C}_{30}$ e $\left.\mathrm{C}_{45}\right)$ e obeso $\left(\mathrm{Ob}_{15}, \mathrm{Ob}_{30}\right.$ e $\left.\mathrm{Ob}_{45}\right)$ submetidos à $15,30 \mathrm{e}$ 45 semanas de tratamento. $n=6$ animais por grupo. Dados expressos em média \pm desvio padrão. Análise de variância (ANOVA) two way para grupos independentes, complementada com o teste post-hoc de Bonferroni. Não houve diferença estatística entre os grupos. ${ }^{\#} \mathrm{p}<0,05$ vs intra-grupo.

\subsection{8- Estrutura do coração post mortem}

\subsubsection{1- Análise macroscópica}

A Tabela 12 mostra a estrutura macroscópica cardíaca post mortem dos ratos $\mathrm{C}_{15}, \mathrm{C}_{30}$, $\mathrm{C}_{45}, \mathrm{Ob}_{15}, \mathrm{Ob}_{30}, \mathrm{e} \mathrm{Ob}_{45}$. A comparação entre os três momentos, fixados os grupos, está descrita a seguir. Os pesos do coração, VE, VD, átrio e as relações coração/PCF, VE/PCF, VD/PCF, coração/tíbia, VE/tíbia, VD/tíbia e AT/tíbia foram semelhantes entre os grupos controles nos três momentos. O comprimento da tíbia e a relação AT/PCF apresentaram comportamento diferente entre os grupos controles. Enquanto o comprimento da tíbia foi maior no grupo $\mathrm{C}_{45}$ do que os $\mathrm{C}_{15}$ e $\mathrm{C}_{30}$, a relação AT/PCF foi diminuída nos animais $\mathrm{C}_{30}$ e $\mathrm{C}_{45}$ em relação ao $\mathrm{C}_{15}$.

O tempo de exposição à obesidade mostrou alteração no comprimento da tíbia entre os animais obesos $\left(\mathrm{Ob}_{15}<\mathrm{Ob}_{30}<\mathrm{Ob}_{45}\right)$. A relação coração/PCF foi maior nos animais $\mathrm{Ob}_{15}$ do que os animais $\mathrm{Ob}_{30}$ e $\mathrm{Ob}_{45}$; entretanto, as relações VE/PCF, AT/PCF e AT/tíbia foram 
diminuídas nos animais $\mathrm{Ob}_{30}$ e $\mathrm{Ob}_{45}$ versus o $\mathrm{Ob}_{15}$. Houve diminuição nas relações VD/PCF, coração/tíbia e VE/tíbia entre os grupos $\mathrm{Ob}_{15}$ e $\mathrm{Ob}_{45}\left(\mathrm{Ob}_{45}<\mathrm{Ob}_{15}\right)$. O tempo de exposição à obesidade não promoveu alterações nos pesos do coração, VE, VD, AT e na relação VD/tíbia. A comparação entre os dois grupos, fixados os momentos, mostra que o VD, AT e a relação AT/tíbia foram maiores nos grupos $\mathrm{Ob}$ em relação aos respectivos controles nos três períodos de tratamento. Os pesos do coração, do VE e as relações coração/tíbia e VE/tíbia foram maiores no $\mathrm{Ob}$ do que no $\mathrm{C}$ nos momentos 15 e 30 semanas. Enquanto a obesidade durante 30 e 45 semanas acarretou aumento no comprimento da tíbia, as relações coração/PCF e VE/PCF foram diminuídas nos mesmos períodos entre os grupos. A relação VD/tíbia foi maior nos animais $\mathrm{Ob}_{15}$ do que o $\mathrm{C}_{15}$, entretanto, obesidade durante 30 semanas promoveu diminuição na relação $\mathrm{VD} / \mathrm{PCF}$ em relação $\mathrm{C}_{30}$. Não houve diferença estatística entre os dois grupos nos três momentos na relação AT/PCF. 
Tabela 12. Estrutura macroscópica cardíaca post mortem após 15, 30 e 45 semanas

\section{Tratamento}

\begin{tabular}{|c|c|c|c|c|}
\hline Variáveis & Grupos & 15 sem & 30 sem & 45 sem \\
\hline \multirow{2}{*}{ PCF (g) } & $\mathbf{C}$ & $459 \pm 18^{\mathrm{Aa}}$ & $490 \pm 33^{\mathrm{ABa}}$ & $513 \pm 19^{\mathrm{Ba}}$ \\
\hline & Ob & $568 \pm 44^{\mathrm{Ab}}$ & $608 \pm 22^{\mathrm{Bb}}$ & $609 \pm 37^{\mathrm{Bb}}$ \\
\hline \multirow{2}{*}{ tíbia (cm) } & $\mathbf{C}$ & $4,38 \pm 0,07^{\mathrm{Aa}}$ & $4,42 \pm 0,12^{\mathrm{Aa}}$ & $4,55 \pm 0,11^{\mathrm{Ba}}$ \\
\hline & $\mathbf{O b}$ & $4,42 \pm 0,07^{\mathrm{Aa}}$ & $4,55 \pm 0,11^{\mathrm{Bb}}$ & $4,67 \pm 0,13^{\mathrm{Cb}}$ \\
\hline \multirow{2}{*}{ Coração (g) } & $\mathbf{C}$ & $1,13 \pm 0,11^{\mathrm{Aa}}$ & $1,14 \pm 0,09^{\mathrm{Aa}}$ & $1,19 \pm 0,08^{\mathrm{Aa}}$ \\
\hline & $\mathbf{O b}$ & $1,35 \pm 0,05^{\mathrm{Ab}}$ & $1,28 \pm 0,11^{\mathrm{Ab}}$ & $1,27 \pm 0,07^{\mathrm{Aa}}$ \\
\hline \multirow[b]{2}{*}{ VE (g) } & $\mathbf{C}$ & $0,80 \pm 0,09^{\mathrm{Aa}}$ & $0,81 \pm 0,07^{\mathrm{Aa}}$ & $0,86 \pm 0,05^{\mathrm{Aa}}$ \\
\hline & Ob & $0,95 \pm 0,05^{\mathrm{Ab}}$ & $0,90 \pm 0,09^{\mathrm{Ab}}$ & $0,90 \pm 0,05^{\mathrm{Aa}}$ \\
\hline \multirow{2}{*}{ VD $(g)$} & $\mathbf{C}$ & $0,24 \pm 0,02^{\mathrm{Aa}}$ & $0,25 \pm 0,03^{\mathrm{Aa}}$ & $0,25 \pm 0,03^{\mathrm{Aa}}$ \\
\hline & $\mathbf{O b}$ & $0,29 \pm 0,02^{\mathrm{Ab}}$ & $0,28 \pm 0,03^{\mathrm{Ab}}$ & $0,27 \pm 0,03^{\mathrm{Ab}}$ \\
\hline \multirow{2}{*}{$\mathrm{AT}(\mathrm{g})$} & C & $0,09 \pm 0,01^{\mathrm{Aa}}$ & $0,08 \pm 0,01^{\mathrm{Aa}}$ & $0,08 \pm 0,02^{\mathrm{Aa}}$ \\
\hline & $\mathbf{O b}$ & $0,11 \pm 0,01^{\mathrm{Ab}}$ & $0,10 \pm 0,01^{\mathrm{Ab}}$ & $0,10 \pm 0,01^{\mathrm{Ab}}$ \\
\hline \multirow{2}{*}{ Coração/PCF (mg/g) } & $\mathbf{C}$ & $2,46 \pm 0,19^{\mathrm{Aa}}$ & $2,34 \pm 0,19^{\mathrm{Aa}}$ & $2,32 \pm 0,18^{\mathrm{Aa}}$ \\
\hline & Ob & $2,39 \pm 0,24^{\mathrm{Aa}}$ & $2,11 \pm 0,18^{\mathrm{Bb}}$ & $2,09 \pm 0,16^{\mathrm{Bb}}$ \\
\hline \multirow{2}{*}{ VE/PCF (mg/g) } & $\mathbf{C}$ & $1,74 \pm 0,17^{\mathrm{Aa}}$ & $1,66 \pm 0,18^{\mathrm{Aa}}$ & $1,68 \pm 0,12^{\mathrm{Aa}}$ \\
\hline & $\mathbf{O b}$ & $1,69 \pm 0,18^{\mathrm{Aa}}$ & $1,49 \pm 0,15^{\mathrm{Bb}}$ & $1,47 \pm 0,13^{\mathrm{Bb}}$ \\
\hline \multirow{2}{*}{ VD/PCF (mg/g) } & $\mathbf{C}$ & $0,52 \pm 0,06^{\mathrm{Aa}}$ & $0,52 \pm 0,04^{\mathrm{Aa}}$ & $0,48 \pm 0,06^{\mathrm{Aa}}$ \\
\hline & $\mathbf{O b}$ & $0,51 \pm 0,05^{\mathrm{Aa}}$ & $0,46 \pm 0,04^{\mathrm{ABb}}$ & $0,45 \pm 0,06^{\mathrm{Ba}}$ \\
\hline \multirow{2}{*}{ AT/PCF (mg/g) } & C & $0,20 \pm 0,02^{\mathrm{Aa}}$ & $0,16 \pm 0,02^{\mathrm{Ba}}$ & $0,16 \pm 0,03^{\mathrm{Ba}}$ \\
\hline & Ob & $0,19 \pm 0,02^{\mathrm{Aa}}$ & $0,16 \pm 0,02^{\mathrm{Ba}}$ & $0,16 \pm 0,02^{\mathrm{Ba}}$ \\
\hline \multirow{2}{*}{ Coração/tíbia (g/cm) } & C & $0,26 \pm 0,02^{\mathrm{Aa}}$ & $0,26 \pm 0,02^{\mathrm{Aa}}$ & $0,26 \pm 0,02^{\mathrm{Aa}}$ \\
\hline & Ob & $0,30 \pm 0,02^{\mathrm{Ab}}$ & $0,28 \pm 0,03^{\mathrm{ABb}}$ & $0,27 \pm 0,02^{\mathrm{Ba}}$ \\
\hline
\end{tabular}


Tabela 12. Estrutura macroscópica cardíaca post mortem após 15, 30 e 45 semanas "continua"

\begin{tabular}{ccccc}
\hline VE/tíbia (g/cm) & C & $0,18 \pm 0,02^{\mathrm{Aa}}$ & $0,18 \pm 0,02^{\mathrm{Aa}}$ & $0,19 \pm 0,01^{\mathrm{Aa}}$ \\
& Ob & $0,22 \pm 0,01^{\mathrm{Ab}}$ & $0,20 \pm 0,02^{\mathrm{ABb}}$ & $0,19 \pm 0,01^{\mathrm{Ba}}$ \\
\hline VD/tíbia (g/cm) & $\mathbf{C}$ & $0,06 \pm 0,01^{\mathrm{Aa}}$ & $0,06 \pm 0,01^{\mathrm{Aa}}$ & $0,05 \pm 0,01^{\mathrm{Aa}}$ \\
& Ob & $0,07 \pm 0,01^{\mathrm{Ab}}$ & $0,06 \pm 0,01^{\mathrm{Aa}}$ & $0,06 \pm 0,01^{\mathrm{Aa}}$ \\
\hline AT/tíbia (g/cm) & $\mathbf{C}$ & $0,021 \pm 0,003^{\mathrm{Aa}}$ & $0,018 \pm 0,003^{\mathrm{Aa}}$ & $0,018 \pm 0,003^{\mathrm{Aa}}$ \\
& Ob & $0,025 \pm 0,002^{\mathrm{Ab}}$ & $0,021 \pm 0,003^{\mathrm{Bb}}$ & $0,021 \pm 0,003^{\mathrm{Bb}}$
\end{tabular}

Dados expressos em média \pm desvio-padrão. C: grupo controle submetido à dieta normocalórica por $15(C ; n=9)$, $30(\mathrm{C} ; \mathrm{n}=10)$ e $45(\mathrm{C} ; \mathrm{n}=10)$ semanas de tratamento; Ob: grupo obeso submetido à dieta hipercalórica por $15(\mathrm{Ob}$; $\mathrm{n}=8), 30(\mathrm{Ob} ; \mathrm{n}=10)$ e $45(\mathrm{Ob} ; \mathrm{n}=10)$ semanas de tratamento. PCF: peso corporal final; VE: peso do ventrículo esquerdo; VD: peso do ventrículo direito; AT: peso do átrio; VE/PCF: relação do peso do ventrículo esquerdo pelo peso corporal final; VD/PCF: relação do peso do ventrículo direito pelo peso corporal final; AT/PCF: relação do peso do átrio pelo peso corporal final. VE/tíbia: relação do peso do ventrículo esquerdo pelo comprimento da tíbia; VD/tíbia: relação do peso do ventrículo direito pelo comprimento da tíbia; AT/tíbia: relação do peso do átrio pelo comprimento da tíbia. Letra maiúscula indica comparação entre os momentos fixado o grupo; letra minúscula indica comparação entre os grupos fixado o momento. Letras diferentes indicam diferença significativa $(\mathrm{p}<0,05)$. Análise de variância (ANOVA) two way para grupos independentes, complementada com o teste de comparações múltiplas de Bonferroni.

\subsubsection{2- Análise microscópica}

A Figura 52 mostra os resultados da área seccional transversa do miócito realizadas no ventrículo esquerdo dos ratos $\mathrm{C}_{15}, \mathrm{C}_{30}, \mathrm{C}_{45}, \mathrm{Ob}_{15}, \mathrm{Ob}_{30}$ e $\mathrm{Ob}_{45}$. $\mathrm{O}$ tempo de exposição à obesidade não influenciou a área seccional do miócito dos fragmentos do VE nos animais obesos. O mesmo comportamento foi visualizado nos animais controles. $\mathrm{Na} 30^{\mathrm{a}}$ semana de tratamento, os animais obesos apresentaram elevação na área seccional do miócito dos fragmentos de VE em relação ao controle. Entretanto, os animais $\mathrm{Ob}_{15}$ e $\mathrm{Ob}_{45}$ apresentaram áreas seccionais semelhantes em relação aos respectivos controles. 


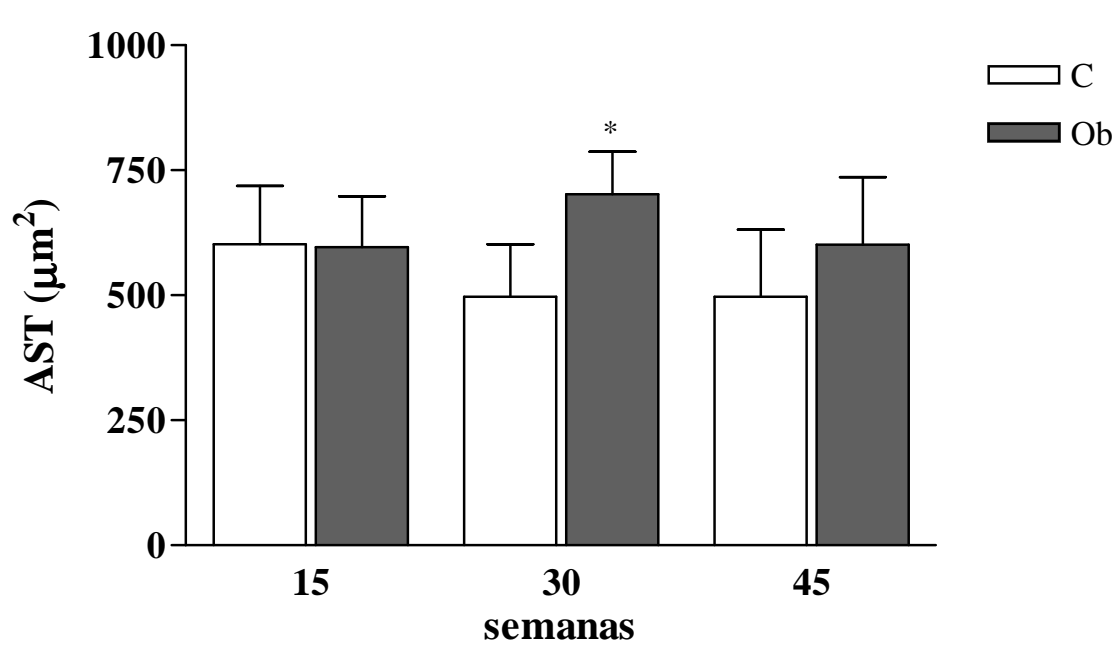

Figura 52. Área seccional transversa dos miócitos (AST) realizada em fragmentos do ventrículo esquerdo de animais controle $\left(\mathrm{C}_{15}=9 ; \mathrm{C}_{30}=7 ; \mathrm{C}_{45}=8\right)$ e obeso $\left(\mathrm{Ob}_{15}=8 ; \mathrm{Ob}_{30}=5\right.$; $\left.\mathrm{Ob}_{45}=6\right)$ submetidos a 15,30 e 45 semanas de tratamento. Dados expressos em média \pm desvio padrão. Análise de variância (ANOVA) two way para grupos independentes e complementada com o teste post-hoc de Bonferroni. * $\mathrm{p}<0,05$ vs C.

\subsection{9- Expressão de RNAm miocárdico}

A Figura 53 ilustra a expressão do RNAm das proteínas relacionadas com o trânsito de cálcio miocárdico, CANAL L, RyR, SERCA, PLB, NXC e CSQ dos ratos $\mathrm{C}_{15}, \mathrm{C}_{30}, \mathrm{C}_{45}, \mathrm{Ob}_{15}$, $\mathrm{Ob}_{30}$ e $\mathrm{Ob}_{45}$. A comparação entre os três momentos, fixados os grupos, está descrita a seguir. O tempo de exposição à obesidade acarretou aumento dos níveis de RNAm do CANAL L, da RyR, da SERCA, da PLB, do NCX e da CSQ no grupo $\mathrm{Ob}_{30}$ em relação ao $\mathrm{Ob}_{15}$ e $\mathrm{Ob}_{45}$. Além disso, os níveis de SERCA e PLB foram maiores no grupo $\mathrm{Ob}_{45}$ em relação ao $\mathrm{Ob}_{15}$.

A comparação entre os dois grupos, fixados os momentos, mostra que os níveis de RNAm da SERCA, do NCX e da CSQ foram diminuídos no grupo $\mathrm{Ob}_{15}$ e $\mathrm{Ob}_{45}$ em relação aos respectivos controles, entretanto na $30^{\text {a }}$ semana de obesidade os níveis de SERCA, do NCX e da CSQ foram elevados em relação ao $C_{30}$. A PLB e o CANAL L apresentaram menores níveis de RNAm na $15^{\mathrm{a}}$ semana de obesidade do que o $\mathrm{C}_{15}$; contudo, $30^{\mathrm{a}}$ semana de obesidade houve aumento das duas variáveis versus $C_{30}$. Não foram observadas diferenças nos níveis de PLB e CANAL L entre os grupos na $45^{\mathrm{a}}$ semana. A obesidade durante 30 
semanas acarretou aumento no RNAm da RyR versus o $\mathrm{C}_{30}$, entretanto, não houve diferença significativa na $15^{\mathrm{a}}$ e $45^{\mathrm{a}}$ semana entre os grupos.
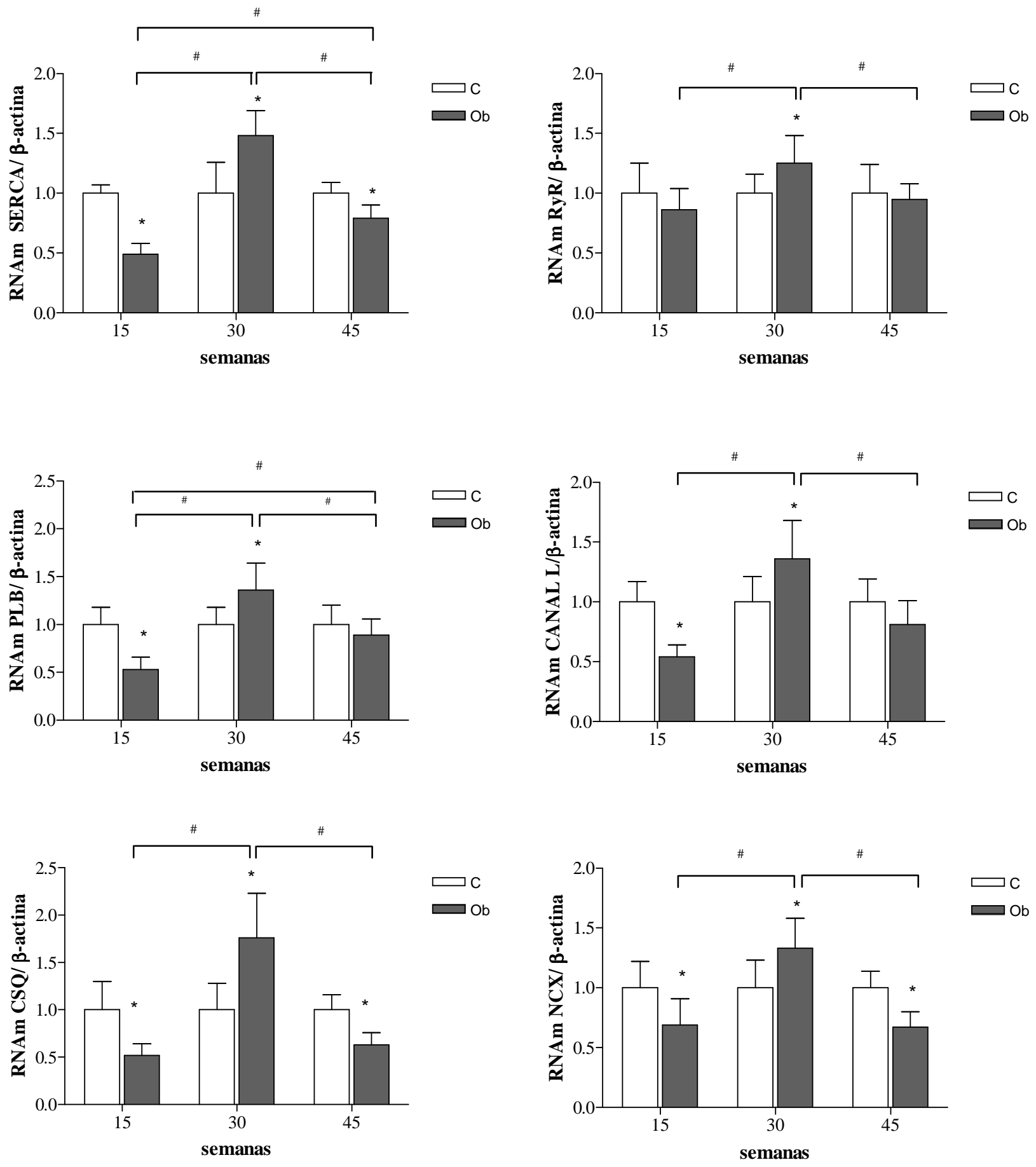

Figura 53. Expressão gênica de SERCA, PLB, RyR, CANAL L, NCX e CSQ normalizados pela $\beta$-actina no miocárdio dos animais controles $\left(\mathrm{C}_{15}, \mathrm{C}_{30}\right.$ e $\left.\mathrm{C}_{45}\right)$ e obeso $\left(\mathrm{Ob}_{15}, \mathrm{Ob}_{30}\right.$ e $\left.\mathrm{Ob}_{45}\right)$ submetidos à 15,30 e 45 semanas de tratamento. $n=6$ animais por grupo. Os dados estão expressos em média \pm desvio padrão relativos aos respectivos grupos controles. Análise de variância (ANOVA) two way para grupos independentes, complementada com o teste post-hoc de Bonferroni. * $\mathrm{p}<0,05$ vs C. ${ }^{\#} \mathrm{p}<0,05$ vs intra-grupo. 
A Tabela 13 mostra os resultados da análise da associação linear de Pearson realizada em todos os animais deste estudo. Não foram observadas correlações significativas entre as concentrações de T3 e os níveis de RNAm de SERCA, PLB, RyR, NCX e CANAL L.

Tabela 13. Medida de associação linear de Pearson entre os níveis de T3 e expressão gênica

\section{T3}

\begin{tabular}{ccc} 
RNAm & Correlação Linear & Valor de $\mathbf{p}$ \\
\hline SERCA & 0,021 & $\mathrm{P}=0,89$ \\
PLB & 0,056 & $\mathrm{P}=0,74$ \\
RyR & 0,040 & $\mathrm{P}=0,81$ \\
NCX & 0,254 & $\mathrm{P}=0,14$ \\
\hline CANAL L & 0,168 & $\mathrm{P}=0,33$ \\
\hline
\end{tabular}

SERCA: ATPase de $\mathrm{Ca}^{+2}$ do retículo sarcoplasmático; PLB: Fosfolambam; RyR: Receptor de Rianodina; NCX: Trocador $\mathrm{Na}^{+} / \mathrm{Ca}^{+2}$.

\subsubsection{0- Expressão de proteínas miocárdicas}

As Figuras 54 e 55 ilustram a expressão das proteínas relacionadas com o trânsito de cálcio intracelular miocárdico dos ratos $\mathrm{C}_{15}, \mathrm{C}_{30}, \mathrm{C}_{45}, \mathrm{Ob}_{15}, \mathrm{Ob}_{30}$ e $\mathrm{Ob}_{45}$. A comparação entre os três momentos, fixados os grupos, está descrita a seguir.

As Figuras 54 e 55 mostram que não foram observadas diferenças significativas na expressão protéica de CANAL L, SERCA, PLB, CSQ, pPLB Thr17 e nas razões SERCA/PLB e pPLB Thr17/PLB entre os grupos obesos. Entretanto, o tempo de exposição à obesidade acarretou aumento nos níveis da pPLB Ser16 no grupo $\mathrm{Ob}_{45}$ em relação ao $\mathrm{Ob}_{15}$ e $\mathrm{Ob}_{30}$. Além disso, houve aumento da razão pPLB Ser16/PLB entre os grupos obesos $\left(\mathrm{Ob}_{45}>\right.$ $\left.\mathrm{Ob}_{30}\right)$.

A comparação entre os dois grupos, fixados os momentos, mostra que a obesidade durante 15 e 30 semanas promoveu diminuição nos níveis de pPLB Ser16 versus os 
respectivos controles; entretanto, não houve diferença estatística da pPLB Ser16 entre os grupos na $45^{a}$ semana. A razão pPLB Ser16/PLB foi diminuída no grupo $\mathrm{Ob}_{30}$ em relação ao respectivo controle, contudo a obesidade durante 15 e 45 semanas, não acarretou diferenças significativas nesta variável entre os grupos. A obesidade, após 15, 30 e 45 semanas, não promoveu alterações na expressão protéica de SERCA, PLB, CSQ, CANAL L, PLB Thr17 e nas razões SERCA/PLB e PLB Thr17/PLB em relação aos respectivos controles. 

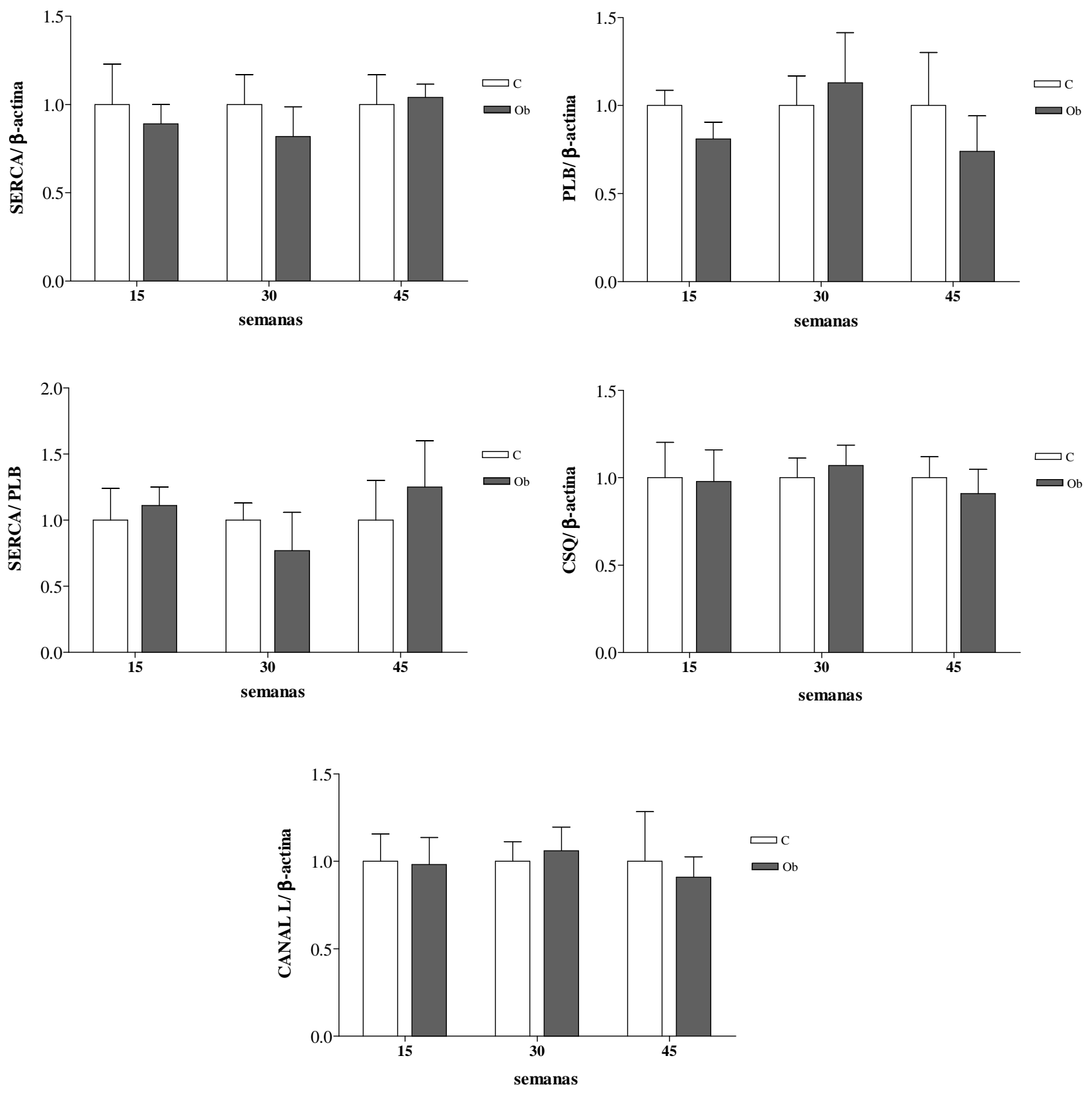

Figura 54. Expressão protéica de SERCA, PLB, CSQ CANAL L e razão SERCA/PLB normalizados pela $\beta$ actina no miocárdio dos animais controles $\left(\mathrm{C}_{15}, \mathrm{C}_{30}\right.$ e $\left.\mathrm{C}_{45}\right)$ e obeso $\left(\mathrm{Ob}_{15}, \mathrm{Ob}_{30}\right.$ e $\left.\mathrm{Ob}_{45}\right)$ submetidos à $15,30 \mathrm{e}$ 45 semanas de tratamento. $n=6$ animais por grupo $n$. Dados expressos em média \pm desvio padrão relativos aos respectivos grupos controles. Análise de variância (ANOVA) two way para grupos independentes, complementada com o teste post-hoc de Bonferroni. * $\mathrm{p}<0,05$ vs C. ${ }^{\#} \mathrm{p}<0,05$ vs intra-grupo. 

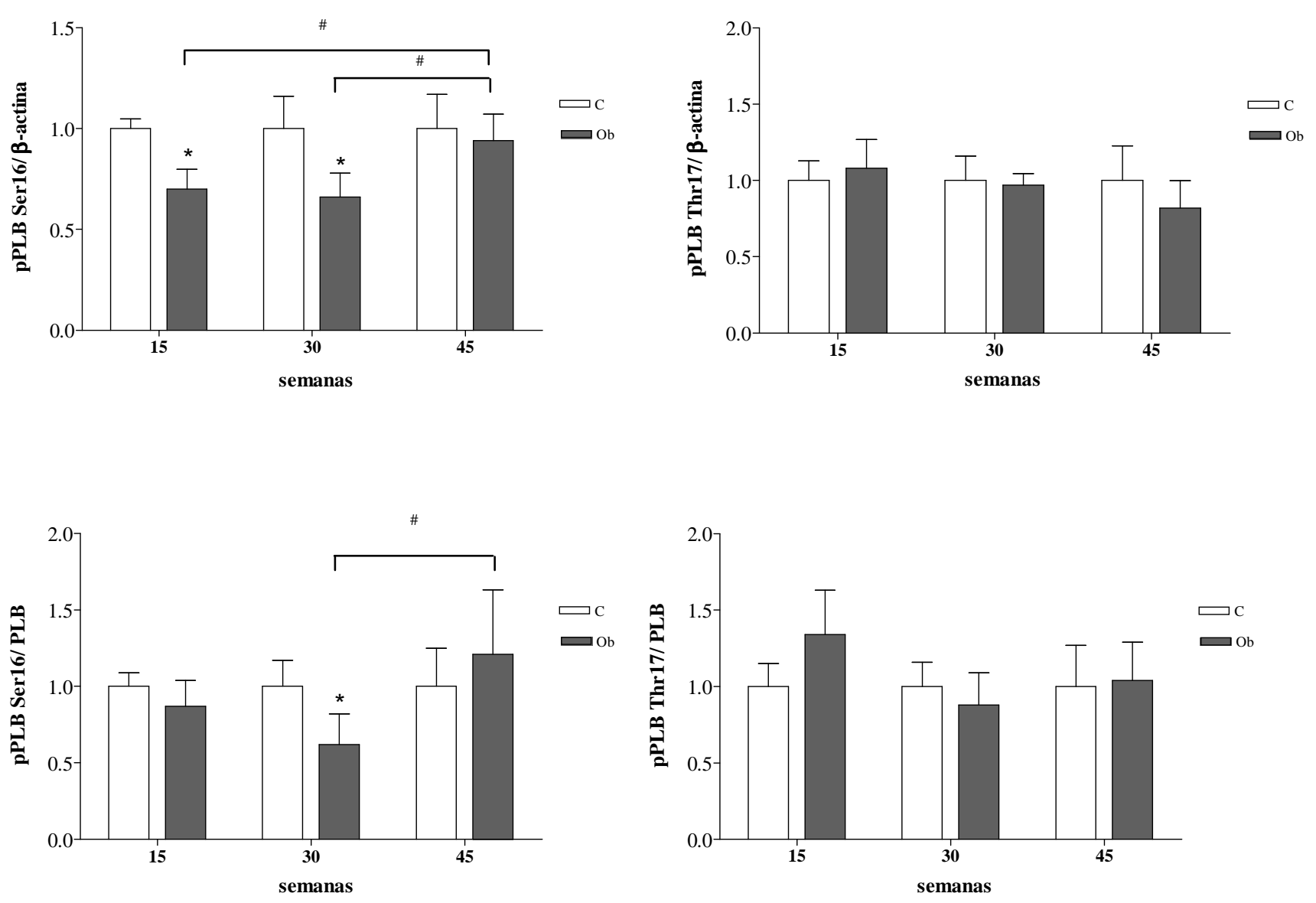

Figura 55. Expressão protéica de pPLB Ser16, pPLB Thr17 e as razões pPLB Ser16/PLB e pPLB Thr17/PLB normalizados pela $\beta$-actina no miocárdio dos animais controles $\left(\mathrm{C}_{15}, \mathrm{C}_{30}\right.$ e $\left.\mathrm{C}_{45}\right)$ e obeso $\left(\mathrm{Ob}_{15}, \mathrm{Ob}_{30}\right.$ e $\left.\mathrm{Ob}_{45}\right)$ submetidos à 15,30 e 45 semanas de tratamento. $n=6$ animais por grupo. Dados expressos em média \pm desvio padrão relativos aos respectivos grupos controles. Análise de variância (ANOVA) two way para grupos independentes, complementada com o teste post-hoc de Bonferroni. * $\mathrm{p}<0,05$ vs C. ${ }^{\#} \mathrm{p}<0,05$ vs intragrupo.

\subsubsection{1- Determinação do teor de água nos tecidos cardíaco, pulmonar e hepático}

A Tabela 14 mostra a porcentagem de umidade dos tecidos dos ratos $\mathrm{C}_{15}, \mathrm{C}_{30}, \mathrm{C}_{45}$, $\mathrm{Ob}_{15}, \mathrm{Ob}_{30}$, e $\mathrm{Ob}_{45}$. A comparação entre os três momentos, fixados os grupos, está descrita a seguir. O teor de água no VE, VD e fígado foram semelhantes entre os grupos controles nos três momentos. Entretanto, a porcentagem de água no átrio foi menor no $\mathrm{C}_{45}$ em relação ao $\mathrm{C}_{15}$. O teor de água no pulmão foi maior no $\mathrm{C}_{30}$ em relação ao $\mathrm{C}_{15}$ e $\mathrm{C}_{45}$. 
O tempo de exposição à obesidade acarretou aumento no teor de água do pulmão entre os grupos obesos $\left(\mathrm{Ob}_{30}>\mathrm{Ob}_{15}\right)$. A duração da obesidade não foi capaz de promover mudanças na quantidade de água dos VE, VD, AT e fígado.

A comparação entre os dois grupos, fixados os momentos, mostra que o teor de água no fígado foi menor nos grupos $\mathrm{Ob}_{15}$ e $\mathrm{Ob}_{30}$ em relação aos respectivos controles. Entretanto, a obesidade durante 45 semanas não foi capaz de promover alterações no teor de água no fígado entre os grupos. As quantidades de água no VE, VD, átrio e pulmão foram similares entre os dois grupos nos três momentos de avaliação.

Tabela 14. Teor de água nos tecidos cardíacos, pulmonar e hepático após 15, 30 e 45 semanas

Tratamento

\begin{tabular}{|c|c|c|c|c|}
\hline Variáveis & Grupos & 15 sem & 30 sem & 45 sem \\
\hline \multirow{2}{*}{ VE $(\%)$} & $\mathbf{C}$ & $75,5 \pm 0,8^{\mathrm{Aa}}$ & $75,6 \pm 3,4^{\mathrm{Aa}}$ & $72,7 \pm 2,8^{\mathrm{Aa}}$ \\
\hline & Ob & $75,2 \pm 0,6^{\mathrm{Aa}}$ & $74,9 \pm 0,7^{\mathrm{Aa}}$ & $75,1 \pm 2,2^{\mathrm{Aa}}$ \\
\hline \multirow{2}{*}{ VD $(\%)$} & $\mathbf{C}$ & $75,6 \pm 1,0^{\mathrm{Aa}}$ & $76,0 \pm 3,4^{\mathrm{Aa}}$ & $73,9 \pm 3,2^{\mathrm{Aa}}$ \\
\hline & $\mathbf{O b}$ & $75,3 \pm 1,0^{\mathrm{Aa}}$ & $75,1 \pm 0,9^{\mathrm{Aa}}$ & $74,8 \pm 2,1^{\mathrm{Aa}}$ \\
\hline \multirow{2}{*}{ AT $(\%)$} & $\mathbf{C}$ & $77,6 \pm 1,1^{\mathrm{Aa}}$ & $76,1 \pm 1,8^{\mathrm{ABa}}$ & $74,6 \pm 4,4^{\mathrm{Ba}}$ \\
\hline & $\mathbf{O b}$ & $77,7 \pm 1,5^{\mathrm{Aa}}$ & $76,5 \pm 1,9^{\mathrm{Aa}}$ & $76,6 \pm 2,1^{\mathrm{Aa}}$ \\
\hline \multirow{2}{*}{ Pulmão (\%) } & $\mathbf{C}$ & $77,4 \pm 0,7^{\mathrm{Aa}}$ & $78,5 \pm 0,9^{\mathrm{Ba}}$ & $77,3 \pm 0,8^{\mathrm{Aa}}$ \\
\hline & $\mathbf{O b}$ & $77,3 \pm 0,6^{\mathrm{Aa}}$ & $78,3 \pm 0,5^{\mathrm{Ba}}$ & $77,5 \pm 0,9^{\mathrm{ABa}}$ \\
\hline \multirow{2}{*}{ Fígado (\%) } & C & $68,0 \pm 1,0^{\mathrm{Aa}}$ & $68,1 \pm 0,8^{\mathrm{Aa}}$ & $67,5 \pm 1,5^{\mathrm{Aa}}$ \\
\hline & $\mathbf{O b}$ & $66,4 \pm 1,0^{\mathrm{Ab}}$ & $66,2 \pm 1,4^{\mathrm{Ab}}$ & $67,1 \pm 0,7^{\mathrm{Aa}}$ \\
\hline
\end{tabular}

Dados expressos em média \pm desvio-padrão. C: grupo controle submetido à dieta normocalórica por $15(\mathrm{C} ; \mathrm{n}=$ 9), $30(C ; n=10)$ e $45(C ; n=10)$ semanas de tratamento; Ob: grupo obeso submetido à dieta hipercalórica por $15(\mathrm{Ob} ; \mathrm{n}=8), 30(\mathrm{Ob} ; \mathrm{n}=10)$ e $45(\mathrm{Ob} ; \mathrm{n}=10)$ semanas de tratamento. Letra maiúscula indica comparação entre os momentos fixado o grupo; letra minúscula indica comparação entre os grupos fixado o momento. Letras diferentes indicam diferença significativa $(p<0,05)$. Análise de variância (ANOVA) two way para grupos independentes, complementada com o teste de comparações múltiplas de Bonferroni. 


\section{4- DISCUSSÃO}

Como referido anteriormente (pág. 46), a discussão foi realizada levando-se em consideração a análise conjunta dos três momentos de obesidade.

\section{1- Momento inicial da obesidade}

Os resultados obtidos mostraram que a dieta hiperlipídica promoveu obesidade a partir da $3^{\text {a }}$ semana de tratamento; o peso e a gordura corporal total e o índice de adiposidade foram maiores nos animais $\mathrm{Ob}_{0}$ em relação ao $\mathrm{C}_{0}$. Os diversos modelos experimentais de obesidade não verificam o momento inicial da obesidade; estes trabalhos apenas mostram o momento em que a dieta acarreta diferença no peso corporal entre os grupos, não identificando se o aumento no peso corporal era acompanhado de elevação na gordura corporal e/ou índice de adiposidade. ${ }^{(99,100)}$ Portanto, a determinação do momento inicial permitiu avaliar com precisão a influência do tempo de exposição à obesidade.

\section{2-Constituição dos grupos controle e obeso}

Um aspecto importante que devemos destacar nesta pesquisa foi a aplicação de um critério de classificação dos grupos, de acordo com o índice de adiposidade, identificando os animais verdadeiramente controle e obeso. Na experimentação biológica, em especial estudos experimentais, mesmo quando mantidas as condições laboratoriais semelhantes, não está assegurada uma homogeneidade de resposta. Animais submetidos à diferentes dietas podem apresentar, em maior ou menor escala, características comuns de resposta, o que poderia não distinguir os grupos. Neste sentido, com a finalidade de diferenciar os grupos foi utilizado o critério de separação descrito na seção "Material e métodos". O descarte dos animais pela ausência de adesão ao critério estabelecido foi, respectivamente, nos grupos controles $\left(\mathrm{C}_{15}=\right.$ $\left.25 \% ; \mathrm{C}_{30}=17 \% ; \mathrm{C}_{45}=17 \%\right)$ e obesos $\left(\mathrm{Ob}_{15}=33 \% ; \mathrm{Ob}_{30}=17 \% ; \mathrm{Ob}_{45}=17 \%\right)$. Nascimento et 
$a l^{(78)}$ utilizando critério semelhante, a partir da mensuração da gordura na carcaça, verificaram resultados diversos dos encontrados neste estudo, desde que, ocorreram descartes inferiores a $20 \%$ nos grupos controle e obeso tratados durante 15 semanas.

\section{3- Perfil nutricional}

Os períodos de dieta hiperlipídica, utilizados nesse estudo, foram eficientes em promover obesidade, desde que o índice de adiposidade utilizado para caracterizar os animais como obesos, foi $79,5 \%, 82 \%$ e $69,5 \%$ maior do que seus respectivos controles, após 15, 30 e 45 semanas. O tempo de exposição à dieta hiperlipídica não promoveu alterações no índice de adiposidade entre os grupos; este resultado indica que, neste trabalho, não houve aumento na intensidade da obesidade ao longo do tempo. O mesmo comportamento foi visualizado nos animais controles. O índice de adiposidade tem sido utilizado frequentemente para classificar a obesidade em roedores. ${ }^{(38,42,82,86,99,100)}$

Neste experimento, a dieta hiperlípidica também acarretou nos ratos obesos elevação no peso e na gordura corporal total. O peso dos animais obesos, após 15, 30 e 45 semanas, aumentou $23,7 \%, 24,1 \%$ e $18,7 \%$ em relação aos controles, respectivamente. O tempo de exposição à obesidade acarretou maior peso corporal final nos animais $\mathrm{Ob}_{30}$ e $\mathrm{Ob}_{45}$ em relação ao $\mathrm{Ob}_{15}$. Neste estudo, a dieta hiperlipídica estabilizou o peso corporal após a $30^{\text {a }}$ semana de obesidade. O comportamento dos animais controles ao longo do tempo mostra que somente $\mathrm{C}_{45}$ apresentou diferença estatística no peso corporal versus o $\mathrm{C}_{15}\left(\mathrm{C}_{45}>\mathrm{C}_{15}\right)$. Os dados deste experimento em relação ao peso corporal corroboram com Ghibaudi et $a l^{(101)}$ que visualizaram, em ratos alimentados com dieta hiperlipídica, durante 28 semanas, elevação de $23,4 \%$ no peso corporal em relação o controle. Entretanto, divergem de outros autores, ${ }^{86}$, 102,103) que utilizando dieta hiperlipídica, por 10, 16 e 17 semanas observaram aumento no peso corporal de $15,6 \%, 15,5 \%$, e $35,6 \%$, respectivamente, entre os grupos controle e obeso. 
Outra pesquisa, ${ }^{(104)}$ realizada com ratos Sprague-Dawley tratado também com dieta hiperlipídica durante 12 meses, mostrou que não houve diferença significante no peso corporal.

Nascimento et $a l^{(78)}$ e Woods et $a l^{(83)}$ relataram que o peso corporal pode não ser um bom indicador de obesidade. Em nosso estudo, a gordura corporal total foi $130 \%, 126 \%$ e $100 \%$ maiores que os respectivos controles após 15, 30 e 45 semanas. Estes dados quando comparados com o peso corporal, indicam que esta variável pode, realmente, subestimar o grau de obesidade. Trabalho realizado com ratos Wistar, ${ }^{(38)}$ alimentados com dieta hiperlipídica, por 12 semanas, mostrou elevação de 96,3\% na quantidade de gordura corporal versus o grupo controle. Outro estudo ${ }^{(101)}$ verificou em ratos, após 28 semanas de dieta hiperlipídica, aumento de 137,5\% na gordura corporal total em relação ao grupo dieta normolipídica.

A epidemia mundial de obesidade humana, geralmente, está associada ao maior consumo de dietas altamente energéticas e uma diminuição do gasto calórico. ${ }^{(105)}$ Estudos mostraram que ratos tornam-se obesos quando são alimentados com uma dieta rica em gordura, e sugerem que a elevação da quantidade de gordura na dieta aumenta o consumo alimentar e energético. ${ }^{(81)}$ Pesquisas recentes mostraram que o consumo de dieta hiperlipídica promove menos saciedade e, consequentemente, maior ingestão alimentar. ${ }^{(38,82)}$ Nosso estudo mostrou que o consumo de dieta hiperlipídica acarretou maior ingestão calórica nos $\mathrm{Ob}_{15}$, $\mathrm{Ob}_{30}$ e $\mathrm{Ob}_{45}$ em relação aos $\mathrm{C}_{15}, \mathrm{C}_{30}$ e $\mathrm{C}_{45}$, respectivamente, apesar dos animais obesos ingerirem a mesma quantidade de ração que os controles. Pesquisadores sugerem que a quantidade de lipídios na dieta é o principal fator pelo acúmulo de gordura nos animais obesos. ${ }^{(106-108)}$ Além disso, a literatura mostra que o maior consumo de gordura pode não ser acompanhado de elevação na sua oxidação, o que favorece maior depósito de tecido adiposo em animais alimentados com dietas hiperlipídicas. ${ }^{(109,110)}$ 
A eficiência alimentar tem sido utilizada para verificar a conversão de ingestão alimentar em ganho de peso corporal. ${ }^{(39)}$ Nossos resultados mostram que a eficiência alimentar foi maior nos $\mathrm{Ob}_{15}$ e $\mathrm{Ob}_{30}$ em relação aos respectivos controles; entretanto, não houve diferença entre os grupos $\mathrm{Ob}_{45}$ e $\mathrm{C}_{45}$. Os dados do presente estudo estão em concordância com diversas pesquisas que verificaram aumento da eficiência alimentar, em ratos submetidos à dieta hiperlipídica por 12 e 15 semanas de tratamento. ${ }^{(37)}$ A ingestão alimentar e o consumo calórico não sofreram influências do tempo de exposição aos tratamentos; contudo, a eficiência alimentar diminuiu ao longo do tempo em ambos os grupos $\left(\mathrm{Ob}_{15}>\mathrm{Ob}_{30}>\mathrm{Ob}_{45}\right) \quad\left(\mathrm{C}_{15}>\mathrm{C}_{30}>\mathrm{C}_{45}\right)$. Este fato pode ser atribuído ao processo de envelhecimento, desde que, há diminuição da necessidade energética com a idade. ${ }^{(111)}$ A causa deste declínio da necessidade energética tem sido atribuída à diminuição da massa magra e redução da taxa metabólica basal. ${ }^{(111)}$

\section{4- Comorbidades}

Neste estudo foram visualizadas algumas comorbidades frequentemente associadas com a obesidade experimental, ${ }^{(38,39,79-84)}$ como intolerância à glicose, resistência à insulina, hiperinsulinemia, hiperleptinemia e dislipidemias. O teste de tolerância à glicose mostrou que embora a glicemia basal fosse semelhante entre os grupos, após sobrecarga de glicose os animais obesos apresentaram áreas glicêmicas maiores nos grupos $\mathrm{Ob}_{15}, \mathrm{Ob}_{30}$, e $\mathrm{Ob}_{45} \mathrm{em}$ relação aos seus respectivos grupos controles, demonstrando que a obesidade promoveu intolerância à glicose. O tempo de exposição à obesidade não modificou a variável entre os momentos estudados. Além disso, a obesidade acarretou hiperinsulinemia, visualizada nos grupos $\mathrm{Ob}_{15}, \mathrm{Ob}_{30}$ e $\mathrm{Ob}_{45}$. O índice HOMA-IR, frequentemente utilizado como indicador de resistência à insulina, ${ }^{(87)}$ mostrou que a obesidade promoveu aumento deste parâmetro nos momentos 15 e 45 semanas e tendência à elevação no grupo $\mathrm{Ob}_{30}(\mathrm{p}=0,054)$. Portanto, os 
dados de hiperinsulinemia e do HOMA-IR, mostram que a obesidade promoveu resistência à insulina, baseando-se no fato de que a euglicemia foi mantida à custa de elevação dos níveis de insulina. A obesidade ao longo do tempo promoveu hiperinsulinemia e, consequentemente, resistência insulínica, visualizada pelo HOMA-IR, de forma mais acentuada nos animais $\mathrm{Ob}_{45}$. Os resultados deste estudo estão de acordo com pesquisas que observaram que uma dieta rica em gordura promove intolerância à glicose, hiperinsulinemia e resistência à insulina em períodos $\operatorname{curtos}^{(81,112,113)}$ e prolongados de obesidade. ${ }^{(84,104,114)}$

A insulina exerce um papel central na regulação da glicose e atua de maneira coordenada em eventos celulares. ${ }^{(115)}$ Além disso, a insulina afeta o metabolismo de lipídeos, aumentando a síntese e atenuando a liberação de ácidos graxos das células adiposas. ${ }^{(16)} \mathrm{A}$ resistência à ação da insulina ocorre quando os níveis circulantes normais deste hormônio são insuficientes para regular estes processos. ${ }^{(116)}$ Nesta condição, as células $\beta$ do pâncreas tendem a secretar maiores quantidades de insulina, hiperinsulinemia, aumentando a captação de glicose, evitando a hiperglicemia. ${ }^{(117)}$ No entanto, esse aumento compensatório nos níveis de insulina podem não perdurar por prolongados períodos, o que acarretaria o desenvolvimento do diabetes mellitus tipo $2 .{ }^{(118)}$ A resistência à insulina pode estar associada às anormalidades no transportador da glicose 4 (GLUT4) ou da via de sinalização insulínica, responsável por desencadear a translocação do GLUT4. Na obesidade tem sido relatado que a resistência à insulina ocorre em nível de transporte de glicose, no músculo esquelético e no tecido adiposo. Concordando com esta afirmação, estudos mostram que a obesidade, associada à resistência insulínica, promoveu redução na expressão de GLUT4 no tecido adiposo. $^{(119)}$ Klip et $a l^{(120)}$ relataram também redução dos níveis de mRNA e protéicos de GLUT4 no tecido adiposo branco em vários modelos animais de obesidade. Dentro deste contexto, podemos inferir que a resistência insulínica na obesidade ocorre em nível de transporte de glicose, indicando que a via de sinalização da insulina estaria preservada. 


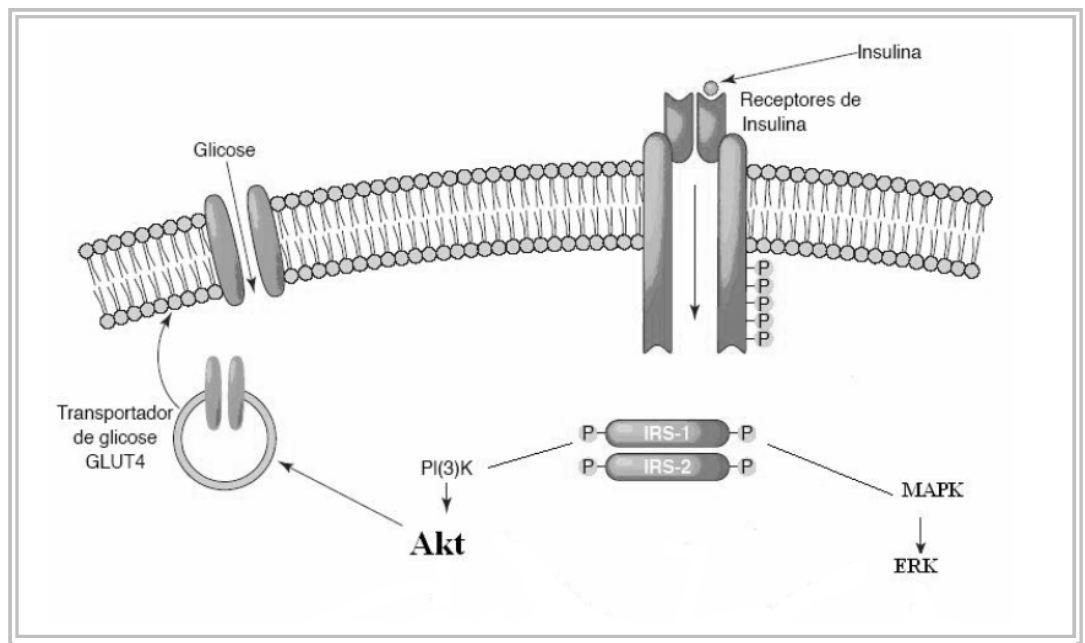

Figura 56. Resumo das vias de sinalização da insulina. Adaptado de Carvalheira JBC 2002. ${ }^{(121)}$

Nesse estudo, os níveis séricos de leptina foram maiores nos grupos obesos em relação aos respectivos grupos controles $\left(\mathrm{Ob}_{15}>\mathrm{C}_{15}, \mathrm{Ob}_{30}>\mathrm{C}_{30}\right.$ e $\left.\mathrm{Ob}_{45}>\mathrm{C}_{45}\right)$. $\mathrm{O}$ tempo de exposição à obesidade promoveu aumento da leptina nos grupos $\mathrm{Ob}_{45}$ em relação ao $\mathrm{Ob}_{15}$; entretanto não foi possível mostrar diferença estatística entre os grupos $\mathrm{Ob}_{15}$ versus $\mathrm{Ob}_{30}(\mathrm{p}=0,055)$ e $\mathrm{Ob}_{30}$ versus $\mathrm{Ob}_{45}(\mathrm{p}=0,09)$. Este hormônio é secretado pelo tecido adiposo e é um membro clássico das adipocinas que participam da sinalização hormonal do tecido adiposo. O efeito fisiológico primário da leptina é comunicar ao sistema nervoso central a quantidade elevada dos estoques energéticos, controlando o consumo alimentar e induzindo o gasto energético. ${ }^{(122)}$ Diversos estudos mostram que os níveis de leptina se correlacionam com a quantidade de gordura corporal. $^{(122,123)}$ Atualmente tem sido relatado que a obesidade, induzida por dietas hiperlipídicas, leva a um estado de resistência à leptina, ${ }^{(122,124)}$ Estudos sugerem que a resistência à leptina é decorrente da incapacidade da leptina atuar no hipotálamo, como resultado do prejuízo no transporte da barreira hemato-encefálica. ${ }^{(125,126)}$ Além disso, tem sido demonstrado que resistência à leptina também pode ser devido à alteração das vias de sinalização molecular da leptina, consequente a hiperleptinemia. A resistência à leptina eleva a ingestão alimentar devido a uma falha no mecanismo da saciedade, acarretando aumento da adiposidade. $^{(18,19,122)}$ Os resultados do presente estudo sugerem que o papel da leptina no 
controle da saciedade, à custa da hiperleptinemia, foi efetivo em todos os grupos, uma vez que, os animais obesos ingeriram a mesma quantidade de alimento que os respectivos grupos controles.

A dislipidemia observada na obesidade é caracterizada pelos níveis elevados de triglicérides (TG), LDL e ácidos graxos não-esterificados (NEFA) e diminuição dos níveis séricos de HDL. ${ }^{(127,128)}$ Entretanto, estas alterações não ocorreram em todos os momentos de avaliação neste trabalho. Os animais obesos apresentaram aumento dos níveis de TG em relação aos controles nos momentos 15 e 30 semanas; entretanto, não foi possível mostrar diferença estatística nos níveis de triglicérides entre os grupos após 45 semanas ( $\mathrm{p}=0,08)$. Os dados de TG corroboram com pesquisas de outros autores, realizadas em curtos períodos, $12 \mathrm{e}$ 16 semanas, que mostraram elevação dos níveis de TG. ${ }^{(88,103)}$ Entretanto, difere de estudos que não identificaram diferença nos níveis de TG durante 12 semanas de obesidade. ${ }^{(38,39,129)}$ Pesquisas mostraram que o aumento nos níveis de TG promovido pela dieta hiperlipídica pode ser consequente à elevada captação dos TG na forma de quilomicróns, e/ou, diminuição da absorção de TG pelos tecidos periféricos. ${ }^{(130)}$ A redução da utilização de TG pelo músculo esquelético tem sido relacionada com a hiperleptinemia. ${ }^{(131,132)}$ Pesquisadores têm relatado que a leptina exerce uma regulação na sinalização da insulina via fosfatidil inositol 3 quinase (PI3-K). A leptina ativa o janus quinase 2 (JAK-2) que induz a fosforilação do substrato do receptor de insulina (IRS), levando à ativação do PI3-K, o qual acarreta aumento de utilização da glicose. ${ }^{(132)}$ Kamohara et $a l^{(133)}$ demonstraram que a leptina administrada à camundongos acarretou aumento da utilização da glicose pelo tecido muscular. Além disso, estudo realizado em ratos com hiperleptinemia mostrou redução no conteúdo de TG no músculo esquelético, fígado e pâncreas, mostrando efeito anti-lipotóxico da leptina nestes tecidos. ${ }^{(134)}$ Desta forma, podemos inferir que a elevação nas concentrações séricas de triglicérides nos grupos obesos, visualizada neste estudo, poderia ter sido ocasionada pela hiperleptinemia destes animais, que 
possivelmente diminuiu a absorção de TG pelo músculo esquelético consequente ao aumento da absorção de glicose. Este fato corrobora com os níveis séricos glicêmicos inalterados nos grupos obesos. O tempo de exposição à obesidade não promoveu alteração nos níveis de TG nos três momentos de avaliação, mostrando que os mecanismos responsáveis pela homeostasia do TG não foi alterado pelo tempo que os animais ficaram expostos à obesidade.

A obesidade acarretou alterações, pontuais, entre o grupo obeso e o respectivo controle no colesterol total, $15^{\mathrm{a}}$ semana, e no LDL, $45^{\mathrm{a}}$ semana. A diferença dos níveis de colesterol e LDL entre os grupos pode ser devido ao baixo nível de colesterol encontrado no grupo $\mathrm{C}_{15} \mathrm{e}$ aumento do LDL no grupo $\mathrm{C}_{45}$, respectivamente. Desde que as concentrações séricas destes lipídeos foram semelhantes nos três momentos de obesidade, as diferenças encontradas entre os grupos foram devidas às alterações nos grupos controles. A composição da dieta hiperlipídica, utilizada neste estudo, é predominantemente de ácidos graxos insaturados. Estudos mostraram que a substituição da gordura saturada, na dieta, por insaturada reduz substancialmente os níveis de colesterol. ${ }^{(135,136)}$ Santos $^{(137)}$ enfatiza que a ingestão de ácidos graxos saturados está fortemente correlacionada com os níveis de colesterol. Os ácidos graxos saturados, na sua maioria, aumentam os níveis séricos das lipoproteínas, principalmente as de baixa densidade (LDL), desde que reduzem a síntese e atividade dos receptores LDL, por meio da diminuição da expressão de RNA mensageiro. ${ }^{(138,139)}$ Estudo realizado em humanos, mostrou que a redução de gordura saturada na dieta está relacionada ao aumento da expressão dos receptores de LDL, que correspondeu similarmente à redução dos níveis circulantes de LDL. ${ }^{(139)}$ Portanto, a característica insaturada das dietas utilizadas em nosso estudo, seria responsável pela não alteração nos níveis séricos de colesterol e LDL.

A obesidade no presente estudo não acarretou diminuição de HDL em relação aos respectivos controles, característica comumente observada em animais obesos. Segundo Mahan et $a l,{ }^{(140)}$ os efeitos dos ácidos graxos monoinsaturados sobre HDL dependem do 
conteúdo total destes ácidos na dieta; o aumento nos níveis acarreta uma discreta elevação do HDL. Assim, a ausência de alteração nos níveis de HDL entre os grupos pode ter ocorrido devido à composição da dieta hiperlipídica, com maior quantidade de ácidos graxos monoinsaturados, levando consequentemente, a uma estabilização ou aumento dos níveis de HDL. O tempo de exposição à obesidade não acarretou alteração nas concentrações séricas de HDL.

Os níveis séricos de NEFA foram semelhantes entre os grupos obesos e controles em todos os momentos avaliados. Além disso, o tempo de exposição aos tratamentos não promoveu alterações no NEFA em ambos os grupos. As concentrações de ácidos graxos nãoesterificados ou ácidos graxos livres (AGL) são usadas para indicar a mobilização de gordura. ${ }^{(141)}$ Neste trabalho, o resultado dos níveis de NEFA sugere que a lipólise não sofreu alterações entre os grupos e ao longo do tempo de tratamento, provavelmente, resultante dos altos níveis de insulina sérica. A liberação de ácidos graxos dos adipócitos depende da taxa de lipólise regulada pela lipase hormônio-sensível. ${ }^{(142)}$ A lipase hormônio sensível promove lipólise dos adipócitos acarretando aumento dos ácidos graxos livres na circulação; entretanto, os altos níveis de insulina, observados nesse estudo, poderia bloquear a atividade da lipase hormônio-sensível nos adipócitos, diminuindo a liberação de ácidos graxos. ${ }^{(121)}$ Apesar dos altos níveis de leptina, visualizada nos animais obesos, a ausência de alteração nas concentrações de NEFA, sugere que a ação da insulina superou os efeitos lipolíticos da leptina. Nossos resultados divergem da literatura que, geralmente, mostra níveis elevados de NEFA em ratos obesos. ${ }^{(88)}$ Wilson et $a l,{ }^{(143)}$ mostraram que dieta rica em gordura, em diferentes períodos, 8, 24 e 48 semanas, promove aumento das concentrações de NEFA; no entanto, este estudo não dosou as concentrações séricas de insulina.

A obesidade, assim como, o tempo de exposição não promoveram alterações no comportamento da pressão arterial sistólica final (PAS). Os mecanismos responsáveis pela 
alteração da pressão arterial, incluem a hiperatividade do sistema nervoso simpático, ${ }^{(17)}$ aumento da atividade do sistema renina-angiotensina-aldosterona (SRAA) ${ }^{(56,72,73)}$ e estresse oxidativo, ${ }^{(17)}$ os quais acarretam vasoconstrição periférica e aumento da reabsorção de sódio renal. A ausência de alteração na pressão arterial, provavelmente, reflete que a obesidade e o tempo de exposição não alteraram os fatores envolvidos no controle da pressão arterial. A literatura não mostra consistência nos resultados de hipertensão arterial na obesidade. Assim, enquanto alguns estudos não observaram alteração da PAS em animais obesos; ${ }^{(38,39)}$ outros pesquisadores relataram que a obesidade promoveu elevação dos níveis da PAS. ${ }^{(102,103)}$

\section{5- Hormônios tireoidianos e obesidade}

Alterações nos níveis hormonais tireoidianos, hormônio estimulante da tireóide (TSH), tiroxina (T4) e triiodotironina (T3) estão frequentemente associados com alteração na gordura corporal. ${ }^{(64,144)}$ Estudos mostram relação positiva entre as concentrações séricas de TSH e os níveis de leptina, ${ }^{(65-67,145)}$ indicando que os hormônios tireoidianos sofrem um processo de adaptação com o aumento da adiposidade corporal. ${ }^{(66)}$ A alteração nas concentrações de TSH na obesidade é resultante do efeito da leptina no eixo hipotálamo-hipófise. ${ }^{(66)}$ No rato, a leptina pode atuar diretamente sobre o hipotálamo através dos receptores de leptina, acarretando liberação de hormônio liberador de tireotrofina (TRH). Este se liga a receptores específicos na hipófise, induzindo a síntese de TSH. Nosso estudo mostrou que a obesidade promoveu aumento nos níveis séricos de TSH ao longo do tempo, provavelmente, ocasionado pelos altos níveis de leptina nos grupos obesos. O fato da ausência de alteração nos níveis de leptina e TSH no grupo controle ao longo do tempo corrobora com esta afirmação. Além disso, análise da associação, dados não apresentados, mostrou que os níveis de leptina dos animais obesos se correlacionam significantemente com os níveis séricos de TSH ( $\mathrm{r}=0,514$; $\mathrm{p}<0,05)$; entretanto, o controle não apresentou o mesmo comportamento $(r=-0,06 ; p=0,81)$. 
Estudos mostraram que a leptina também pode estimular a produção de T3, via conversão de T4 em T3. ${ }^{(67,68,133)}$ Em nosso estudo, a diminuição dos níveis de T4 ao longo do tempo de exposição à obesidade $\left(\begin{array}{llll}\mathrm{Ob}_{15} & \text { vs } & \mathrm{Ob}_{45}\end{array}\right)$ foi acompanhada de elevação das concentrações séricas de $\mathrm{T} 3\left(\mathrm{Ob}_{45}\right.$ vs $\left.\mathrm{Ob}_{15}\right)$, possivelmente, também sob atuação conversora da leptina. Portanto, podemos inferir que a leptina, na obesidade, atua sobre a tireóide a nível central e periférico.

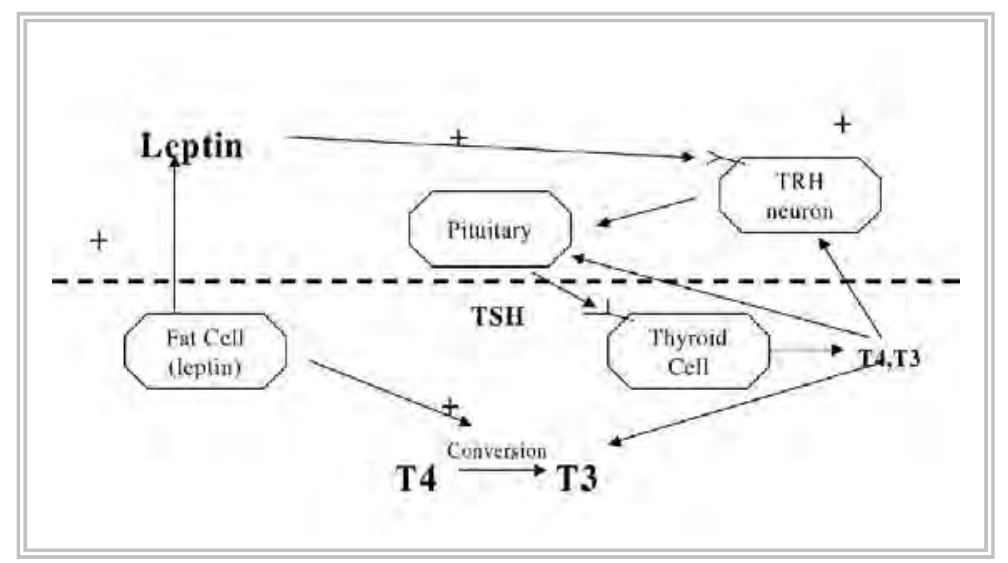

Figura 57. Resumo da via de atuação da leptina. Adaptado de Feldt-Rassmussen U 2007. ${ }^{(146)}$

\section{6- Remodelação cardíaca}

\subsection{1- Estrutura do coração post mortem}

Os resultados do nosso estudo mostraram que os animais obesos em relação aos respectivos controles, quando analisados os pesos isolados das câmaras cardíacas, apresentaram remodelação do coração, VD e do AT nos três momentos, apesar da não significância estatística no peso do coração na $45^{\mathrm{a}}$ semana $(\mathrm{p}=0,052)$; além disso, houve remodelação do VE nos momentos 15 e 30 semanas. A remodelação cardíaca pode também ser avaliada normalizando os pesos do coração e de seus componentes pelo peso corporal; ${ }^{(147)}$ no entanto, o uso deste índice é controverso quando se comparam animais com exacerbada diferença nos pesos corporais. A ocorrência desse comportamento, entre o peso corporal dos 
controles e obesos deste estudo, pode ter influenciado os resultados da normalização. Este fato pode ser constatado comparando-se o comportamento do peso isolado do AT, do VD, do VE e do coração e as respectivas normalizações pelo PCF. Enquanto, por exemplo, o peso do VE e do coração foram maiores nos grupos obesos versus os respectivos controles, na $15^{\mathrm{a}}$ e $30^{\mathrm{a}}$ semana, a obesidade promoveu diminuição das relações coração/PCF e VE/PCF nos mesmos momentos. Desta forma, os pesquisadores têm utilizado como alternativa, a normalização das câmaras cardíacas pelo comprimento da tíbia, uma vez que, a curva de crescimento da tíbia, foi independente da presença lesões patológicas e alterações no peso corporal do rato. ${ }^{(148)} \mathrm{O}$ uso deste índice acarretou respostas opostas em relação à normalização pelo PCF; enquanto, por exemplo, a relação coração/PCF foi diminuída no grupo $\mathrm{Ob}_{15}$, a relação coração/tíbia foi aumentada no mesmo grupo e momento. A presença de remodelação, visualizada pela elevação da normalização do coração, VE e AT pelo comprimento da tíbia foi observada nos grupos obesos na $15^{\mathrm{a}}$ e $30^{\mathrm{a}}$ semana. Estes dados estão em concordância com pesquisas que afirmam que a hipertrofia ventricular é uma característica adaptativa da obesidade. ${ }^{(149)} \mathrm{A}$ análise conjunta dos resultados mostra que os animais na $45^{\mathrm{a}}$ não apresentaram remodelação do VE e coração quando avaliados isoladamente e após normalização pela tíbia.

A análise da área seccional transversa do miócito (AST) também permite verificar a presença de remodelação cardíaca. ${ }^{(89)}$ Este parâmetro mostrou semelhança de resultado em relação ao comportamento do $\mathrm{VE}$, analisado isoladamente ou normalizado pela tíbia, nos momentos 30 e 45 semanas em relação aos respectivos controles. A ausência de alteração na AST após 15 semanas no grupo obeso é conflitante com o aumento do peso do VE isolado e após normalização pela tíbia. Este resultado sugere que possivelmente os animais $\mathrm{Ob}_{15}$ desenvolveram, inicialmente, remodelação do tipo excêntrica. Após 30 semanas de obesidade o aumento do VE, acompanhado da AST poderia indicar a presença de remodelação concêntrica; entretanto, esta afirmação não encontra apoio em fatores que desencadeiam 
hipertrofia concêntrica, como por exemplo, a hipertensão arterial. Apesar da normalização pelo comprimento da tíbia, PCF e AST serem utilizados como indicadores da presença ou ausência de hipertrofia, acreditamos que os métodos mais consistentes e adequados para avaliar o crescimento do coração são as medidas do comprimento e da espessura do miócito isolado e avaliação do volume nuclear. ${ }^{(150)}$

De acordo com os resultados obtidos podemos inferir que as sobrecargas impostas pela obesidade foram mais efetivas no desencadeamento de hipertrofia cardíaca do VE na $15^{\mathrm{a}}$ e $30^{\mathrm{a}}$ semana de tratamento. Este processo mostra que após a 30a semana houve estabilização da hipertrofia cardíaca, indicando que após esse período houve equilíbrio entre as demandas metabólicas corporais e o desempenho do coração.

A hipertrofia cardíaca ocorre como uma resposta adaptativa às variações pressóricas, volumétricas e/ou metabólicas. ${ }^{(151)} \mathrm{Na}$ obesidade geralmente tem sido observado hipertrofia cardíaca do tipo excêntrica, ${ }^{(21,26,152)}$ a qual ocorre em resposta à uma sobrecarga de volume, acarretanto aumento dos sarcômeros em série; ${ }^{(89)}$ entretanto, também pode ocorrer remodelamento concêntrico, promovendo ampliação dos sarcômeros em paralelo, em virtude da sobrecarga pressórica. A literatura mostra que prolongados períodos de obesidade estão associados com hipertrofia excêntrica, e que poucos estudos reportam remodelação concêntrica do coração na ausência da sobrecarga pressórica. ${ }^{(21,153)} \mathrm{O}$ estímulo para a remodelação cardíaca ocorre por agentes mecânicos e bioquímicos, estes, atuando em sinalizadores sarcolemais, ativam fatores citosólicos que promovem a síntese protéica por meio da ativação de fatores transcricionais nucleares. ${ }^{(154,155)} \mathrm{Na}$ obesidade há evidência de diversos preditores da remodelação cardiovascular, como leptina, angiotensina II, endotelina, catecolaminas e marcadores inflamatórios. ${ }^{(13,14)}$ Além destes, pesquisas mostram que a insulina pode exercer influência na hipertrofia cardíaca, estimulando a síntese protéica e inibindo a degradação protéica no coração. ${ }^{(156-158)}$ Nosso estudo mostrou que a obesidade acarretou 
aumento nas concentrações séricas de insulina; este fato nos permite inferir que a hipersinsulinemia pode ter influenciado o processo de remodelação cardíaca, visualizado neste estudo na $15^{\mathrm{a}}$ e $30^{\mathrm{a}}$ semana. A insulina ativa o PI3-K, o qual leva ao recrutamento da proteína quinase AKT, também denominada proteína quinase B. Quando ativada, a AKT fosforila a proteína quinase mTOR, cuja ativação aumenta a síntese protéica, acarretando a hipertrofia cardíaca. ${ }^{(121,159,160)}$ Embora a estabilização da hipertrofia cardíaca, na $45^{\text {a }}$ semana nos animais obesos, possa ser atribuída ao equilíbrio entre as demandas metabólicas corporais e o desempenho do coração, a maior resistência à insulina, visualizada pelo índice de HOMAIR neste animais, também pode estar relacionada ao processo de equilíbrio hipertrófico.

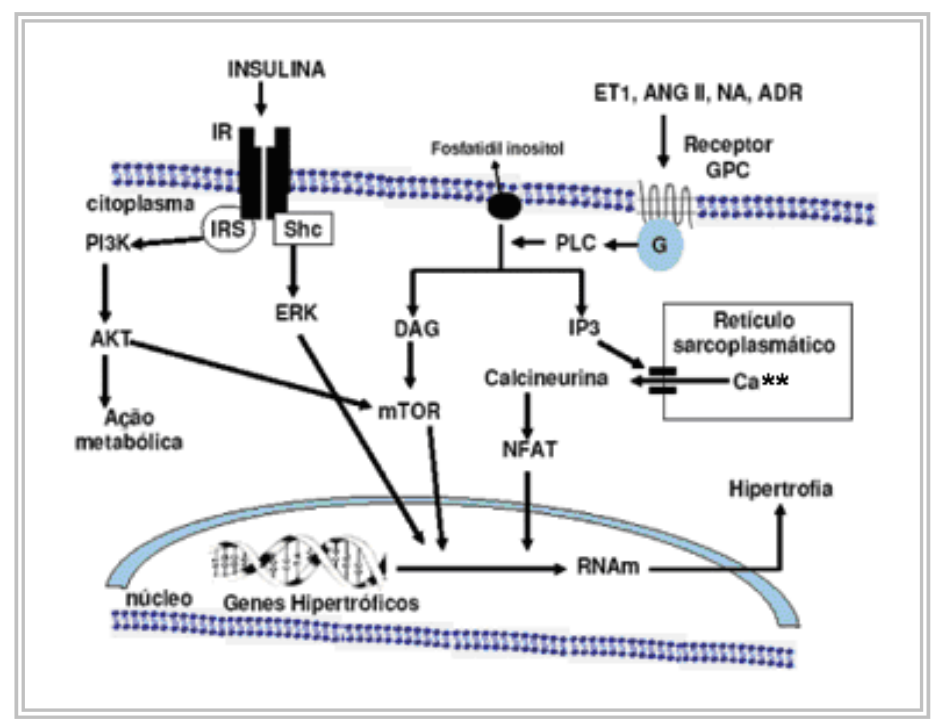

Figura 58. Resumo das vias de sinalização hipertrófica em cardiomiócitos. Adaptado de Garcia JAD 2008. ${ }^{(161)}$

\subsection{2- Expressão de RNAm e proteínas miocárdicas}

O presente estudo teve como objetivo principal avaliar a influência do tempo de exposição à obesidade sobre o RNAm e as respectivas proteínas relacionadas com o trânsito de $\mathrm{Ca}^{+2}$ miocárdico. No cardiomiócito, os íons $\mathrm{Ca}^{+2}$ participam ativamente das diversas funções intracelulares, dentre elas, o acoplamento excitação-contração. Desde que, as proteínas relacionadas com o trânsito de $\mathrm{Ca}^{+2}$ miocárdico participam efetivamente na 
liberação, recaptura e remoção do $\mathrm{Ca}^{+2}$, as mesmas desempenham papel fundamental na regulação da função cardíaca. ${ }^{(43-45)}$ Neste sentido, visualizações de alterações nos níveis de RNAm e, consequentemente, das proteínas poderiam contribuir, em projetos futuros, para o entendimento dos mecanismos envolvidos na disfunção cardíaca promovida pela obesidade.

A liberação dos íons $\mathrm{Ca}^{+2}$ responsáveis pelo início do ciclo contrátil do miocárdio, são mediados pelo CANAL L e RyR. Embora a obesidade tenha alterado os níveis de RNAm do CANAL L, entre os grupos controle e obeso e ao longo do tempo, este comportamento não foi visualizado na expressão protéica, que não se modificou com a obesidade. Semelhante ao CANAL L, a obesidade e o tempo de exposição também influenciaram a expressão gênica de RyR; entretanto, a expressão protéica do RyR em seu estado normal e fosforilado não será discutida, uma vez que, tivemos dificuldades técnicas na medida da sua expressão.

Os processos de recaptura, armazenamento e extrusão dos íons $\mathrm{Ca}^{+2}$, responsáveis pelo relaxamento cardíaco, são principalmente mediados, no retículo sarcoplasmático, pela SERCA, PLB e CSQ, e no sarcolema pelo NCX. Neste estudo, enquanto a obesidade na $15^{\mathrm{a}}$ e 45 a semana, acarretou diminuição dos níveis de RNAm da SERCA, do NCX e da CSQ em relação aos respectivos controles, na $30^{\mathrm{a}}$ semana de obesidade ocorreu aumento dos níveis de SERCA, NCX e da CSQ em relação ao $C_{30}$. Entretanto, esta alteração no RNAm não foi acompanhada de alterações na expressão protéica de SERCA e CSQ em relação aos respectivos controles nos três momentos avaliados. A expressão protéica de NCX não será discutida devido à dificuldade na mensuração.

A atividade da SERCA é regulada pela PLB, que em seu estado desfosforilado, inibe a SERCA e consequentemente diminui a recaptura de íons $\mathrm{Ca}^{+2}$ para o retículo sarcoplasmático. ${ }^{(162)}$ Enquanto os níveis de RNAm de PLB foram diminuídos após 15 semanas de obesidade em relação ao controle, na $30^{\mathrm{a}}$ semana houve aumento do PLB entre os grupos. Em nosso estudo os níveis protéicos de PLB na obesidade não sofreram alterações 
entre os grupos e ao longo do tempo. Entretanto, o fato da obesidade não promover alterações nos níveis protéicos de SERCA e PLB em relação ao grupo controle, não significaria que a recaptura dos íons $\mathrm{Ca}^{+2}$ para o retículo sarcoplasmático estaria normal. Neste sentido, foi necessário analisar a quantidade de PLB em seu estado fosforilado, na serina 16 (pPLB ser16), via adenosina monofosfato cíclico (AMPc), e na treonina 17 (pPLB thr17), via quinase dependente de cálcio, calmodulina quinase. A obesidade não promoveu alterações na expressão protéica de PLB thr17 e na razão PLB thr17/PLB em relação aos respectivos controles e ao longo do tempo. Entretanto, o principal achado deste estudo é que a obesidade, após 15 e 30 semanas, acarretou diminuição nos níveis de pPLB ser16. O tempo de exposição aumentou os níveis da pPLB ser16 no grupo $\mathrm{Ob}_{45}$ em relação ao $\mathrm{Ob}_{15}$ e $\mathrm{Ob}_{30}$. Este resultado corrobora, parcialmente, com Relling et $a l^{(39)}$ que utilizando ratos submetidos à dieta hiperlipídica, por 12 semanas, mostraram que a obesidade promoveu diminuição dos níveis de PLB fosforilado. A fosforilação da PLB na serina 16, via proteína quinase (PKA) dependente de AMPc devido à estimulação $\beta$-adrenérgica, aumenta o relaxamento cardíaco. ${ }^{(163-165)}$ Segundo alguns pesquisadores, a interação das catecolaminas com o receptor adrenérgico, estimula os receptores $\beta$. A ocupação do receptor ativa a proteína $G$, que leva à dissociação de uma de suas subunidades, $\alpha$, a qual interage de modo estimulatório com a enzima adenil ciclase (AC), que por sua vez converte adenosina trifosfato (ATP) em AMPc. Este liga-se à PKA, que acarreta fosforilação de diversas proteínas, promovendo aumento da liberação e recaptura do $\mathrm{Ca}^{+2}$ citosólico. ${ }^{(166,167)}$ De acordo com os resultados deste estudo, diminuição do pPLB ser16, podemos sugerir que, provavelmente, a obesidade acarretou prejuízo na via de sinalização adrenérgica cardíaca. 


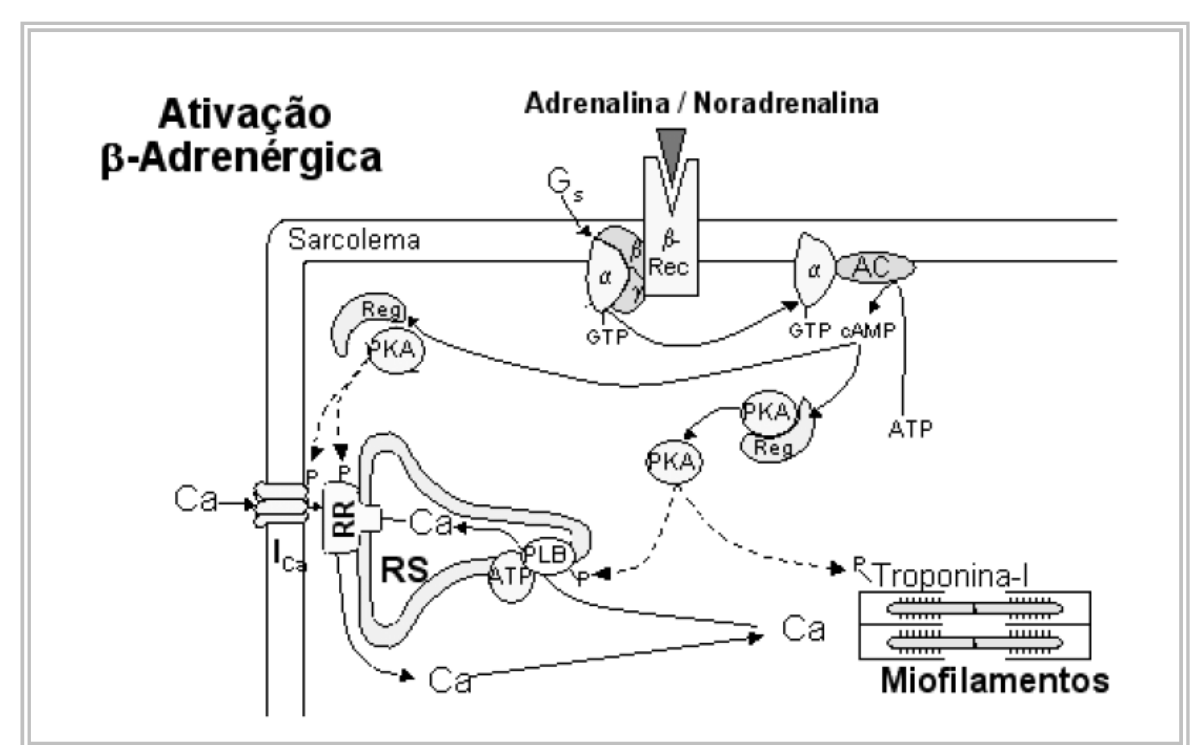

Figura 59. Resumo da cascata de ativação $\beta$-adrenérgica em cardiomiócitos. Adaptado de Bers DM 2001. ${ }^{(168)}$

Corroborando com estes dados, diversos trabalhos têm frequentemente mostrado que o sistema $\beta$-adrenérgico está prejudicado na obesidade. ${ }^{(169,170)}$ Assim, pesquisadores, observaram que a resposta à estimulação $\beta$-adrenérgica e a afinidade aos receptores adrenérgicos estava dimuinuída em coelhos e ratos obesos, alimentados com dieta hiperlipídica por 12 e 30 semanas, respectivamente. ${ }^{(169,170)}$ Além disso, Hohl et al $l^{(171)}$ verificaram que a produção de AMPc estava prejudicada em ratos obesos. Dentro deste contexto, trabalhos futuros são necessários para avaliar a quantidade e atividade das proteínas responsáveis pela cascata de sinalização $\beta$-adrenérgica no miocárdio de ratos obesos. A normalização da pPLB ser16, na $45^{\mathrm{a}}$ semana nos animais obesos, pode ser atribuída ao equilíbrio no processo de hipertrofia cardíaca nestes animais.

Como referido anteriomente na introdução, a literatura mostra escassez de estudos que avaliaram, em modelos experimentais, a relação entre a obesidade por dieta hiperlipídica, o RNAm e as proteínas envolvidas na homeostase intracelular de $\mathrm{Ca}^{+2}$ miocárdico. Os trabalhos encontrados são inconclusivos e realizados em curtos períodos de obesidade. Desta forma, 
não encontramos dados na literatura que permitissem comparar e explicar os mecanismos responsáveis pelas alterações encontradas neste trabalho.

A análise dos dados da expressão de RNAm, referida anteriormente, mostra um aspecto interessante; o tempo de exposição à obesidade promoveu comportamento semelhante nos RNAm das proteínas envolvidas no trânsito de $\mathrm{Ca}^{+2}$ miocárdico. Como no processo de remodelação cardíaca diferentes estímulos externos, primeiro mensageiro, podem ativar diversos fatores transcricionais, ${ }^{(172)}$ podemos inferir que o mesmo agente pode ter ativado diferentes fatores transcricionais, acarretando respostas similares de expressão gênica. A literatura relata que os hormônios tireoidianos podem atuar positivamente na expressão gênica da SERCA, RyR e CANAL L; e, negativamente, no PLB e NCX. ${ }^{(61)}$ Entretanto, a análise de correlação mostrou que não ocorreu associação significativa entre os níveis de T3 e o RNAm das proteínas do trânsito de $\mathrm{Ca}^{+2}$. Desde que a obesidade está associada ao aumento de endotelina, angiotensina II, citocinas, entre outros, ${ }^{(10,13-15)}$ e estes atuam em diferentes fatores transcricionais, é provável que algum destes fatores possa estar envolvido nas alterações na expressão de RNAm das proteínas do trânsito de $\mathrm{Ca}^{+2}$. Este fenômeno pode ser visualizado pela figura abaixo, que mostra uma interação entre os diversos fatores presentes ao longo do tempo de obesidade. 


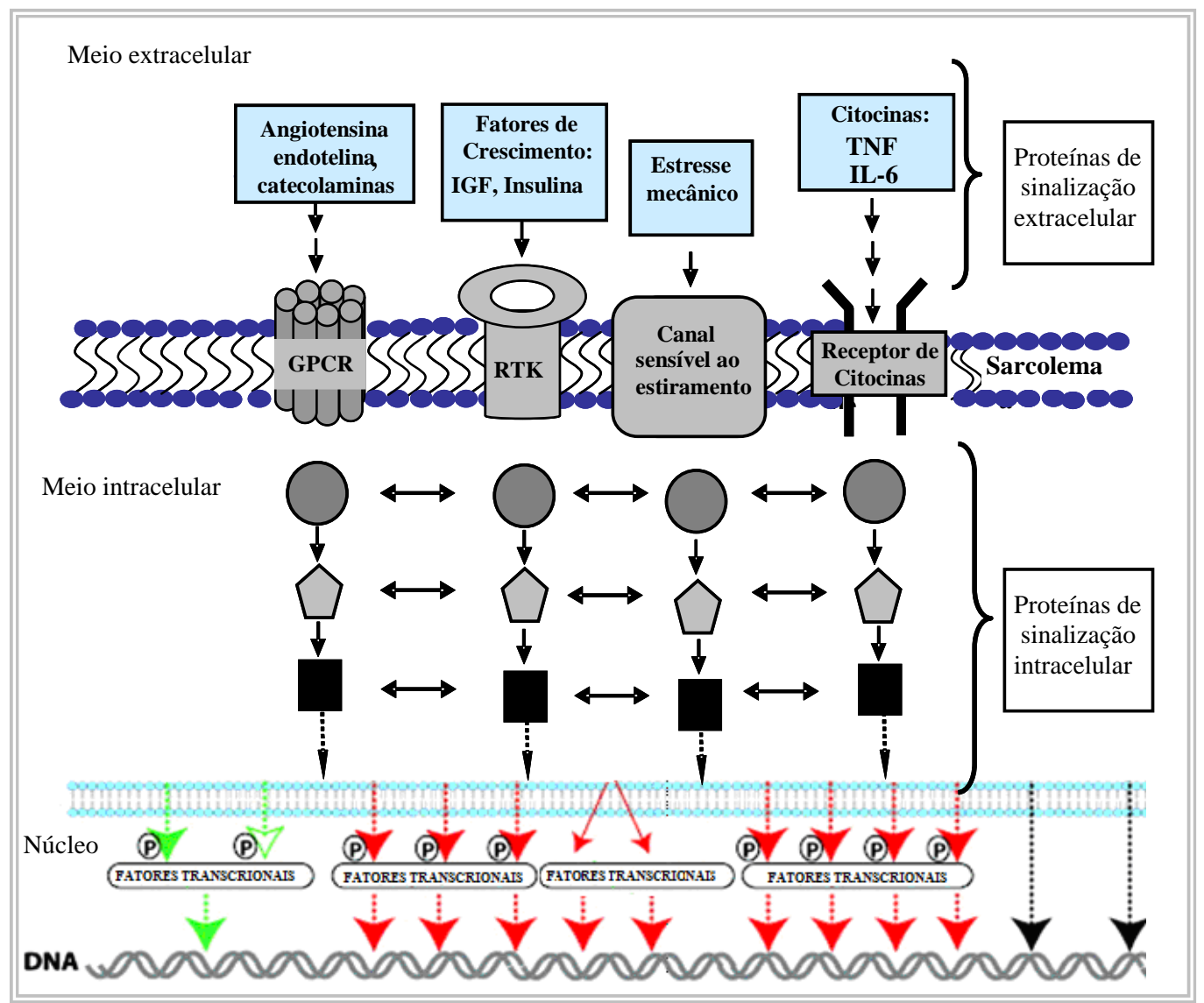

Figura 60. Fatores envolvidos na sinalização transcricional. Adaptado de Katz AM 2001. ${ }^{(172)}$

A análise dos dados de RNAm e das proteínas, referida acima, mostra divergência de comportamento entre os níveis de RNAm e a expressão protéica. Enquanto os RNAm variaram na dependência do tratamento e tempo experimental, as proteínas mostraram comportamento igual entre os grupos e os momentos. Essa divergência, entre o RNAm e a proteína, pode ser atribuída ao processo de tradução celular. As proteínas são sintetizadas nos ribossomas a partir de sinalização molecular específica, o RNAm, transcrito diretamente da cadeia de ácido desoxirribonucléico (DNA). ${ }^{(173)}$ O aumento dos níveis de um determinado RNAm não implica, necessariamente, na elevação da taxa protéica, pois, a eficiência do processo de tradução é regulada pela cauda Poli A do RNAm. ${ }^{(173,174)}$ O comprimento da cauda Poli A favorece o aumento da concentração local de ribossomos, o que facilita a maior 
tradução de proteínas. ${ }^{(174)}$ Portanto, as divergências entre as quantidades de RNAm e proteínas, nesse estudo, poderiam do comprimento da cauda Poli A. Além disso, a não manifestação da elevação protéica na obesidade pode ser atribuída ao discreto aumento no processo de hipertrofia cardíaca, que atingiu $19 \%$ no $\mathrm{Ob}_{15}$ e $12 \%$ no $\mathrm{Ob}_{30}$. Esse modesto remodelamento não implicaria em maior recrutamento dessas proteínas para a manutenção do desempenho cardíaco. 


\section{5- CONCLUSÃO}

Tendo em vista os resultados obtidos neste trabalho, podemos apontar duas conclusões:

1. O tempo de exposição à obesidade promove diferentes respostas na expressão de RNAm e modifica apenas a proteína PLB fosforilada na serina 16. A diminuição na expressão de pPLB ser16 poderia sugerir que a obesidade altera a via de sinalização adrenérgica cardíaca.

2. Os níveis hormonais tireoidianos não influenciam a expressão gênica das proteínas do trânsito de $\mathrm{Ca}^{2+}$ miocárdico.

Trabalhos futuros são necessários para avaliar os mecanismos responsáveis pelas alterações na expressão gênica e na diminuição da fosforilação do PLB na serina 16 decorrentes da obesidade. 


\section{6- REFERÊNCIAS}

1. Katch FI, Mcardle WD. Nutrição, Controle e Peso e Exercício. $3^{\text {rd }}$ ed. Rio de Janeiro: Medsi, 1990.

2. Eckel RH, Barouch WW, Ershow AG. Report of the National Heart, Lung, and Blood Institute-National of Diabetes and Digestive and Kidney Diseases Working Group on the Pathophysiology of Obesity-Associated Cardiovascular Disease. Circulation 2002;105(24):2923-8.

3. O' Brien PE, Dixon JB. The extent of the problem of obesity. Am J Surg 2002;184(6B):4S-8S.

4. Wong CY, O' Moore-Sullivan T, Leano R, Byrne N, Beller E, Marwick TH. Alterations of left ventricular myocardial characteristics associated with obesity. Circulation 2004;110(19):3081-7.

5. World Health Organization. Obesity and Overweight. Geneva:WHO. [access 2009 Aug 20]. Available from: http://www.who.int/en/

6. BRASIL. Ministério do Planejamento, Orçamento e Gestão. Instituto Brasileiro de Geografia e Estatística - IBGE. Pesquisa de Orçamentos Familiares 2002-2003. Antropometria e análise do estado nutricional de crianças e adolescentes no Brasil. Rio de Janeiro: IBGE, 2006.

7. Associação Brasileira para o Estudo da Obesidade e da Síndrome Metabólica. São Paulo: Abeso. [acesso em 2009 Dez 02] Disponível em: http://www.abeso.org.br

8. Stein CJ, Colditz GA. The epidemic of obesity. J Clin Endocrinol Metab. 2004;89(6):2522-5.

9. Raman RP. Obesity and Healthy risks. J Am Coll Nutr. 2002;21(2):134S-9S. 
10. Pausova Z. From big fat cells to high blood pressure: a pathway to obesity-associated hypertension. Curr Opin Nephrol Hypertens. 2006;15(2):173-8.

11. Malnick SDH, Knobler $\mathrm{H}$. The medical complications of obesity. QJM. 2006;99(9):565-79.

12. Poirier P, Giles TD, Bray GA, Hong Y, Stern JS, Pi-Sunyer FX, et al. Obesity and cardiovascular disease: pathophysiology, evaluation, and effect of weight loss. Arterioscler Thromb Vasc Biol. 2006;26(5):968-76.

13. Rondinone CM. Adipocyte-derived hormones, cytokines, and mediators. Endocrine 2006;29(1):81-90.

14. Kershaw EE, Flier JS. Adipose tissue as an endocrine organ. J Clin Endocrinol Metab. 2004;89(6):2548-56.

15. Mohamed-Ali V, Pinckney J, Coppack S. Adipose tissue as an endocrine and paracrine organ. Int J Obes Relat Metab Disord. 1998;22(12):1145-58.

16. Iacobellis G, Ribaudo MC, Zappaterreno A, Iannucci CV, Di Mario U, Leonetti F. Adapted changes in left ventricular structure and function in severe uncomplicated obesity. Obes Res. 2004;12(10):1616-21.

17. Crisostomo LL, Araújo LMB, Câmara E, Carvalho C, Silva FA, Vieira M, et al. Comparison of left ventricular mass and function in obese versus nonobese women $<40$ years of age. Am J Cardiol. 1999;84(9):1127-9.

18. Koch R, Sharma AM. Obesity and cardiovascular hemodynamic function. Curr Hypertens Rep. 1999;(2):127-30.

19. Abel ED, Litwin SE, Sweeney G. Cardiac remodeling in Obesity. Physiol Rev. 2008;88(2):389-419. 
20. Peterson LR, Waggoner AD, Schechtman KB, Meyer T, Gropler RJ, Barzilai B, et al. Alterations in left ventricular structure and functions in young healthy obese women. $\mathbf{J}$ Am Coll Cardiol. 2004;43(8):1399-404.

21. Alpert MA. Obesity cardiomyopathy: pathophysiology and evolution of the clinical syndrome. Am J Med Sci. 2001;321(4):225-36.

22. Morricone L, Malavazos AE, Coman C, Donati C, Hassan T, Caviezel F. Echocardiographic abnormalities in normotensive obese patients: relationship with visceral fat. Obes Res. 2002;10(6):489-98.

23. Berkalp B, Cesur V, Corapcioglu D, Erol C, Baskal N. Obesity and left ventricular diastolic dysfunction. Int J Cardiol. 1995;52(1):23-6.

24. Wong CY, O'Moore-Sullivan T, Leano R, Hukins C, Jenkins C, Marwick TH. Association of subclinical right ventricular dysfunction with obesity. J Am Coll Cardiol. 2006;47(3):611-6.

25. Alaud-din A, Meterissian S, Lisbona R, MacLean LD, Forse RA. Assessment of cardiac function in patients who were morbidly obese. Surgery 1990;108(4):809-18.

26. Pascual M, Pascual DA, Soria F, Vicente T, Hernández AM, Tébar FJ, et al. Effects of isolated obesity on systolic and diastolic left ventricular function. Heart 2003;89(10):1152-56.

27. Iacobellis G, Leonetti F. Epicardial adipose tissue and insulin resistance in obese subjects. J Clin Endocrinol Metab. 2005;90(11):6300-2.

28. Buchanan J, Mazumder PK, Hu P, Chakrabarti G, Roberts MW, Yun UJ, et al. Reduced cardiac efficiency and altered substrate metabolism precedes the onset of hyperglycemia and contractile dysfunction in two mouse models of insulin resistance and obesity. Endocrinology 2005;146(12):5341-9. 
29. Christoffersen C, Bollano E, Lindegaard MLS, Bartels ED, Goetze JP, Andersen CB, et al. Cardiac lipid accumulation associated with diastolic dysfunction in obese mice. Endocrinology 2003;144(8):3483-90.

30. Dong F, Zhang X, Yang X, Esberg LB, Yang H, Zhang Z, et al. Impaired cardiac contractile function in ventricular myocytes from leptin-deficient ob/ob obese mice. $\mathbf{J}$ Endocrinol. 2006;188(1):25-36.

31. Li SY, Yang X, Ceylan-Isik AF, Du M, Sreejayan N, Ren J. Cardiac contractile dysfunction in Lep/Lep obesity is accompained by NADPH oxidase activation, oxidative modification of sarco(endo)plasmic reticulum $\mathrm{Ca}^{2+}-\mathrm{ATPase}$ and myosin heavy chain isozyme switch. Diabetologia 2006;49(6):1434-46.

32. Paradise NF, Pilati CF, Payne WR, Finkelstein JA. Left ventricular function of the isolated, genetically obese rat's heart. Am J Physiol. 1985;248(4 Pt 2):H438-44.

33. Ren J, Walsh MF, Jefferson L, Natavio M, IIg KJ, Sowers JR, et al. Basal and ethanolinduced cardiac contractile response in lean and obese zucker rat hearts. J Biomed Sci. 2000;7(5):390-400.

34. Young ME, Guthrie PH, Razeghi P, Leighton B, Abbasi S, Patil S, et al. Impaired longchain fatty acid oxidation and contractile dysfunction in the obese zucker rats heart. Diabetes 2002;51(8):2587-95.

35. Conti M, Renaud IM, Poirier B, Michel O, Belair M-F, Mandet C, et al. High levels of myocardial antioxidant defense in aging nondiabetic normotensive Zucker obese rats. Am J Physiol Regul Integr Comp Physiol. 2004;286(4):R793-800.

36. Pawloski CM, Kanagy NL, Mortensen LH, Fink GD. Obese Zucker rats are normotensive on normal and increased sodium intake. Hypertension 1992;19(1):I90-5.

37. Lauterio TJ, Bond JP, Ulman EA. Development and characterization of a purified diet to identify obesity-suceptible and resistant rat populations. J Nutr. 1994; 124(11):2172-8. 
38. Carroll JF, Zenebe WJ, Strange TB. Cardiovascular function in a rat model of dietinduced obesity. Hypertension 2006;48(1):65-72.

39. Relling DP, Esberg LB, Frang CX, Johnson WT, Murphy EJ, Carlson EC, et al. High-fat diet-induced juvenile obesity leads to cardiomyocyte dysfunction and upregulation of Foxo3a transcription factor independent of lipotoxicity and apoptosis. J Hypertens. 2006;24(3):549-61.

40. Ren J, Zhu BH, Relling DP, Esberg LB, Ceylan-Isik AF. High-fat diet-induced obesity leads to resistance to leptin-induced cardiomyocyte contractile response. Obesity (Silver Spring) 2008;16(11):2417-23.

41. Leopoldo AS, Sugizaki MM, Lima-Leopoldo AP, Nascimento AF, Martinez PF, Luvizotto RAM, et al. Cardiac remodeling in rat model of diet-induced obesity. Can J Cardiol., in press.

42. Boustany-Kari CM, Gong M, Akers WS, Guo Z, Cassis LA. Enhanced vascular contractility and diminished coronary artery flow in rats made hypertensive from dietinduced obesity. Int J Obes (Lond). 2007;31(11):1652-9.

43. Opie LH. Myocardial contraction and relaxation. In: Opie LH. The Heart. Physiology from cell to circulation. $3^{\text {rd }}$ ed. Philadelphia: Lippincott-Raven; 1998. p.209-31.

44. Bers DM. Cardiac excitation-contraction coupling. Nature 2002;415(6868):198-205.

45. Fabiatto A. Calcium-induced release of calcium from the cardiac sarcoplasmic reticulum. Am J Physiol. 1983;245(1):C1-14.

46. Mattiazzi A, Mundiña-Weilenmann C, Guoxiang C, Vittone L, Kranias E. Role of phospholamban on Thr17 in cardiac physiological and pathological conditions. Cardiovasc Res. 2005;68(3):366:75.

47. Bassani JW, Bassani RA, Bers DM. Relaxation in rabbit and rat cardiac cells: speciesdependent differences in cellular mechanisms. J Physiol. 1994;476(2):279-93. 
48. Kranias EG, Bers DM. Calcium and cardiomyopathies. Subcell Biochem. 2007;45:52337.

49. Kiss E, Ball NA, Kranias EG, Walsh RA. Differential changes in cardiac phospholamban and sarcoplasmic reticular $\mathrm{Ca}^{(2+)}$ ATPase protein levels. Effects on $\mathrm{Ca}^{2+}$ transport and mechanics in compensated pressure-overload hypertrophy and congestive heart failure. Circ Res. 1995;77(4):759-64.

50. Tsutsui H, Ishibashi Y, Imanaka-Yoshida K, Yamamoto S, Yoshida T, Sugimachi M, et al. Alterations in sarcoplasmic reticulum calcium-storing proteins in pressure-overload cardiac hypertrophy. Am J Physiol. 1997;272(1 Pt 2):H168-75.

51. He HB, Yu F, Dai DZ, Dai Y. Down-regulation of FKBP12.6 and SERCA2a contributes to acute heart failure in septic shock and is related to an up-regulated endothelin signalling pathway. J Pharm Pharmacol. 2007;59(7):977-84.

52. Jiang MT, Lokuta AJ, Farrell EF, Wolff MR, Haworth RA, Valdivia HH. Abnormal $\mathrm{Ca}^{2+}$ release, but normal ryanodine receptors, in canine and human heart failure. Circ Res. 2002;91(11):1015-22.

53. Ito K, Yan X, Feng X, Manning WJ, Dillmann WH, Lorell BH. Transgenic expression of sarcoplasmic reticulum $\mathrm{Ca}^{(2+)}$ atpase modifies the transition from hypertrophy to early heart failure. Circ Res. 2001;89(5):422-9.

54. Ito K, Yan X, Tajima M, Su Z, Barry WH, Lorell BH. Contractile reserve and intracellular calcium regulation in mouse myocytes from normal and hypertrophied failing hearts. Circ Res. 2000;87(7):588-95.

55. Kuo TH, Tsang W, Wang KK, Carlock L. Simultaneous reduction of the sarcolemmal and SR calcium ATPase activities and gene expression in cardiomyopathic hamster. Biochim Biophys Acta. 1992;1138(4):343-9. 
56. Dincer UD, Araiza A, Knudson JD, Shao CH, Bidasee KR, Tune JD. Dysfunction of cariac ryanodine receptors in the metabolic syndrome. J Moll Cell Cardiol. 2006;41(1):108-14.

57. Philip-Couderc P, Smih F, Hall JE, Pathak A, Roncalli J, Harmancey R, et al. Kinetic analysis of cardiac transcriptome regulation during chronic high-fat diet in dogs. Physiol Genomics. 2004;19(1):32-40.

58. Lima-Leopoldo AP, Sugizaki MM, Leopoldo AS, Carvalho RF, Nogueira CR, Nascimento AF, et al. Obesity induces upregulation of genes involved in myocardial $\mathrm{Ca}^{2+}$ handling. Braz J Med Biol Res. 2008;41(7):615-20.

59. Dillmann WH. Cellular action of thyroid hormone on the heart. Thyroid 2002;12(6):44752.

60. Dillmann WH, Gloss BR. The role of thyroid hormone receptors in the heart. Methods Mol Biol. 2002;202:55-70.

61. Carr AN, Kranias EG. Thyroid hormone regulation of calcium cycling proteins. Thyroid 2002;12(6):453-7.

62. Nunes MT. Hormônios tireoidianos: Mecanismo de ação e importância biológica. Arq Bras Endocrinol Metab. 2003;47(6):639-43.

63. Kahaly GJ, Dillmann WH. Thyroid hormone action in the heart. Endocr Rev. 2005;26(5):704-28.

64. Reinehr T, de Sousa G, Andler W. Hyperthyrotropinemia in obese children is reversible after weight loss and is not related to lipids. J Clin Endocrinol Metab. 2006;91(8):308891.

65. Tagliaferri M, Berselli ME, Calo G, Minocci A, Savia G, Petroni ML, et al. Subclinical hypothyroidism in obese patients: relation to resting energy expenditure, serum leptin, body composition, and lipid profile. Obes Res. 2001;9(3):196-201. 
66. Chomard P, Vernhes G, Autissier N, Debry G. Serum concentrations of total T4, T3, reverse T3 and free T4, T3 in moderately obese patients. Hum Nutr Clin Nutr. $1985 ; 39(5): 371-8$.

67. Matzen LE, Kvetny J, Pedersen KK. TSH, thyroid hormones and nuclearbinding of T3 in mononuclear blood cells from obese and non-obese women. Scand J Clin Lab Invest. 1989;49(3):249-53.

68. Duntas L, Hauner H, Rosenthal J, Pfeiffer EF. Thyrotropin releasing hormone (TRH) immunoreactivity and thyroid function in obesity. Int J Obes. 1991;15(1):83-7.

69. Naslund E, Andersson I, Degerblad M, Kogner P, Kral JG, Rossner S, et al. Associations of leptin, insulin resistance and thyroid function with long-term weight loss in dieting obese men. J Intern Med. 2000;248(4):299-308.

70. Iacobellis G, Ribaudo MC, Zappaterreno A, Iannucci CV, Leonetti F. Relationship of thyroid function with body mass index, leptin, insulin sensitivity and adiponectin in euthyroid obese women. Clin Endocrinol. 2005;62(4):487-91.

71. Must A, Jacques PF, Dallal GE, Bajema CJ, Dietz WH. Long-term morbity and mortality of overweight adolescents: a follow-up of the Harvard Growth Study 1922 to 1935. N Engl J Med. 1992;327(19):1350-5.

72. Srinivasan SR, Bao W, Wattigney WA, Berenson GS. Adolescent overweights associated with adult overweight and related multiple cardiovascular risk factors: The Bogalusa Study. Metabolism 1996;45(2):235-40.

73. Scaglione R, Dichiara MA, Indovina A, Lipari R, Ganguzza A, Parrinello G, et al. Left ventricular diastolic and systolic function in normotensive obese subjects: influence of degree and duration of obesity. Eur Heart J. 1992;13(6):738-42.

74. Committee on Care and Use of Laboratory Animals. Guide for the care and use of laboratory animals. Bethesda: National Institute of Health; 1985. 
75. Nascimento AF, Sugizaki MM, Leopoldo AS, Lima-Leopoldo AP, Luvizotto RA, Nogueira CR, et al. A hypercaloric pellet-diet cycle induces obesity and co-morbidities in Wistar rats. Arq Bras Endocrinol Metabol. 2008;52(6):968-74.

76. Taylor BA, Phillips SJ. Detection of obesity QTLs on mouse chromosomes 1 and 7 by selective DNA pooling. Genomics 1996;34(3):389-98.

77. Johnson MM, Peters JP. Technical note: an improved method to quantify nonesterified fatty acids in bovine plasma. J Anim Sci. 1993;71(3):753-6.

78. Nascimento AF, Sugizaki MM, Leopoldo AS, Lima-Leopoldo AP, Nogueira CR, Novelli EL, et al. Misclassification probability as obese or lean in hypercaloric and normocaloric diet. Biol Res. 2008;41(3):253-9.

79. Levin BE, Richard D, Michel C, Servatius R. Differential stress responsivity in dietinduced obese and resistant rats. Am J Physiol Regul Integr Comp Physiol. 2000;279(4):R1357-64.

80. Dobrian AD, Davies MJ, Prewitt RL, Lauterio TJ. Development of hypertension in a rat model of diet-induced obesity. Hypertension. 2000;35(4):1009-15.

81. Akiyama T, Tachibana I, Shirohara H, Watanabe N, Otsuki M. High-fat hypercaloric diet induces obesity, glucose intolerance and hyperlipidemia in normal adult male Wistar rat. Diabetes Res Clin Pract. 1996;31(1-3):27-35.

82. Dourmashkin JT, Chang GQ, Gayles EC, Hill JO, Fried SK, Julien C, et al. Different forms of obesity as a function of diet composition. Int J Obes. 2005;29(11):1368-78.

83. Woods SC, Seeley RJ, Rushing PA, D'Alessio DA, Tso P. A controlled high-fat diet induces an obese syndrome in rats. J Nutr. 2003;133(4):1081-7.

84. Nivoit P, Morens C, Van Assche FA, Jansen E, Poston L, Remacle C, et al. Established diet-induced obesity in female rats leads to offspring hyperphagia, adiposity and insulin resistance. Diabetologia. 2009;52(6):1133-42. 
85. Boustany CM, Bharadwaj K, Daugherty A, Brown DR, Randall DC, Cassis LA. Activation of the systemic and adipose renin-angiotensin system in rats with dietinduced obesity and hypertension. Am J Physiol Regul Integr Comp Physiol. 2004;287(4):R943-9.

86. Smith AD, Brands MW, Wang MH, Dorrance AM. Obesity-induced hypertension develops in young rats independently of the renin-angiotensin-aldosterone system. Exp Biol Med. 2006;231(3):282-7.

87. Matthews DR, Hosker JP, Rudenski AS, Naylor BA, Treacher DF, Turner RC. Homeostasis model assessment: insulin resistance and beta-cell function from fasting plasma glucose and insulin concentrations in man. Diabetologia 1985;28(7):412-9.

88. Naderali EK, Brown MJ, Pickavance LC, Wilding JP, Doyle PJ, Williams G. Dietary obesity in the rat induces endothelial dysfunction without causing insulin resistance: a possible role for triacylglycerols. Clin Sci. 2001;101(5):499-506.

89. Matsubara LS, Matsubara BB, Okoshi MP, Cicogna AC, Janicki JS. Alterations in myocardial collagen content affect rat papillary muscle function. Am J Physiol Heart Circ Physiol. 2000;279(4):H1534-9.

90. Schwint OA, Labraga M, Cervino CO, Haffar M, Sequeiros PH, Marcos HJ. A modification of the staining technique of reticular fibres for image analysis of the cardiac collagen network. Cardiovasc Pathol. 2004;13(4):213-20.

91. Wilhelm J, Pingoud A. Real-time polymerase chain reaction. Chembiochem. 2003;4(11):1120-8.

92. Valasek MA, Repa JJ. The power of real-time PCR. Adv Physiol Educ. 2005;29(3):1519.

93. Chomczynski P, Sacchi N. Single-step method of RNA isolation by acid guanidinium thiocyanate-phenol-chloroform extraction. Anal Biochem. 1987;162(1):156-9. 
94. Rolim NP, Medeiros A, Rosa KT, Mattos KC, Irigoyen MC, Krieger EM, Krieger JE, Negrão CE, Brum PC. Exercise training improves the net balance of cardiac $\mathrm{Ca}^{2+}$ handling protein expression in heart failure. Physiol Genomics. 2007;29(3):246-52.

95. De Tomasi LC, Bruno A, Sugizaki MM, Lima-Leopoldo AP, Nascimento AF, Júnior $\mathrm{SA}$, et al. Food restriction promotes downregulation of myocardial L-type $\mathrm{Ca}^{2+}$ channels. Can J Physiol Pharmacol. 2009;87(6):426-31.

96. Bradford MM. A rapid and sensitive method for the quantitation of microgram quantities of protein utilizing the principle of protein-dye binding. Anal Biochem. 1976;72:248-54.

97. Halpern A, Mancini MC. O tratamento da obesidade no paciente portador de hipertensão arterial. Rev Bras Hipertens. 2000;2:166-71.

98. Bayley BJR. Tables of the Bonferroni "t" statistic. J Am Stat Assoc. 1977; 72:469-78.

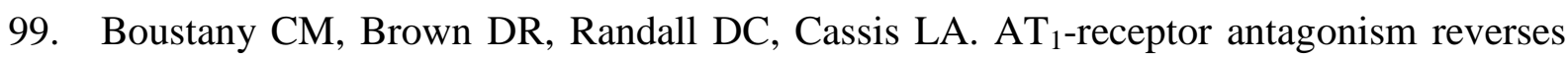
the blood pressure elevation associated with diet-induced obesity. Am J Physiol Regul Integr Comp Physiol. 2005;289(1):R181-6.

100. Levin BE, Triscari J, Sullivan AC. Altered sympathetic activity during development of diet-induced obesity in rat. Am J Physiol. 1983;244(3):R347-55.

101. Ghibaudi L, Cook J, Farley C, van Heek M, Hwa JJ. Fat intake affects adiposity, comorbidity factors, and energy metabolism of Sprague-Dawley rats. Obes Res. 2002; 10(9):956-63.

102. Fitzgerald SM, Henegar JR, Brands MW, Henegar LK, Hall JE. Cardiovascular and renal responses to a high-fat diet in Osborne-Mendel rats. Am J Physiol Regul Integr Comp Physiol. 2001;281(2):R547-52. 
103. du Toit EF, Nabben M, Lochner A. A potential role for angiotensin II in obesity induced cardiac hypertrophy and ischaemic/reperfusion injury. Basic Res Cardiol. 2005;100(4):346-54.

104. da Silva AA, Kuo JJ, Tallam LS, Hall JE. Role of endothelin-1 in blood pressure regulation in a rat model of visceral obesity and hypertension. Hypertension 2004;43(2):383-7.

105. Astrup A, Buemann B, Western P, Toubro S, Raben A, Christensen NJ. Obesity as an adaptation to a high-fat diet: evidence from a cross-sectional study. Am J Clin Nutr. 1994;59(2):350-5.

106. Borst SE, Conover CF. High-fat induces increased tissue expression of TNF-alpha. Life Sci. 2005; 77(17):2156-65.

107. Flatt JP. Dietary fat, carbohydrat balance, and weight maintenance: effects of exercise. Am J Clin Nutr. 1987;45(1):296-306.

108. Flatt JP. Use and storage of carbohydrate and fat. Am J Clin Nutr. 1995;61(4):952S-9S.

109. Tentolouris N, Pavlatos S, Kokkinos A, Perrea D, Pagoni S, Katsilambros N. Dietinduced thermogenesis and substrate oxidation are not different between lean and obese women after two different isocaloric meals, one rich in protein and one rich in fat. Metabolism. 2008;57(3):313-20.

110. Schrauwen P, Westerterp KR. The role of high-fat diets and physical activity in the regulation of body weight. Br J Nutr. 2000;84(4):417-27.

111. Passadore MD, Griggio MA, Nunes MT, Luz J. Effects of ageing on the energy balance of food-restricted rats. Acta Physiol Scand. 2004;181(2):193-8. 
112. Huang BW, Chiang MT, Yao HT, Chiang W. The effect of high-fat and high-fructose diets on glucose tolerance and plasma lipid and leptin levels in rats. Diabetes Obes Metab. 2004; 6:120-126.

113. Li L, Yang G, Li Q, Tang Y, Li K. High-fat- and Lipid-induced insulin resistance in rats: the comparison of glucose metabolism, plasm resistin and adiponectin levels. Ann Nutr Metab 2006; 50:499-505.

114. Winzell MS, Ahrén B. The high-fat diet-fed mouse: a model for studying mechanisms and treatment of impaired glucose tolerance and type 2 diabetes. Diabetes. 2004; 53: S215-S219.

115. Haber EP, Curi R, Carvalho CRO, Carpinelli AR. Secreção de insulina: efeito autócrino da insulina e modulação por ácidos graxos. Arq Bras Endocrinol Metab. 2001;45(3):219-27.

116. Pessin JE, Saltiel AR. Signaling pathways in insulin action: molecular targets of insulin resistance. J Clin Invest. 2000;106(2):165-9.

117. Jellinger PS. Metabolic consequences of hyperglycemia and insulin resistance. Clin Cornerstone. 2007;8(7):S30-42.

118. DeFronzo RA, Ferrannini E. Insulin resistance. A multifaceted syndrome responsible for NIDDM, obesity, hypertension, dyslipidemia, and atherosclerotic cardiovascular disease. Diabetes Care 1991;14(3):173-94.

119. Shepherd PR, Kahn BB. Glucose transporters and insulin action--implications for insulin resistance and diabetes mellitus. N Engl J Med. 1999;341(4):248-57.

120. Klip A, Tsakiridis T, Marette A, Ortiz PA. Regulation of expression of glucose transporters by glucose: a review of studies in vivo and in cell cultures. FASEB J. 1994;8(1):43-53. 
121. Carvalheira JBC, Zecchin HG, Saad MJA. Vias de sinalização da insulina. Arq Bras Endocrinol Metab. 2002;46(4):419-25.

122. Yang R, Barouch LA. Leptin signaling and obesity: cardiovascular consequences. Circ Res. 2007;101(6):545-59.

123. Maffei M, Halaas J, Ravussin E, Pratley RE, Lee GH, Zhang Y, et al. Leptin levels in human and rodent: measurement of plasma leptin and ob RNA in obese and weightreduced subjects. Nat Med. 1995;1(11):1155-61.

124. Sahu A. Minireview: A hypothalamic role in energy balance with special emphasis on leptin. Endocrinology 2004;145(6):2613-20.

125. Schwartz MW, Seeley RJ, Campfield LA, Burn P, Baskin DG. Identification of targets of leptin action in rat hypothalamus. J Clin Invest. 1996;98(5):1101-6.

126. Burguera B, Couce ME, Long J, Lamsam J, Laakso K, Jensen MD, Parisi JE, Lloyd RV. The long form of the leptin receptor $(\mathrm{OB}-\mathrm{Rb})$ is widely expressed in the human brain. Neuroendocrinology 2000;71(3):187-95.

127. Reilly MP, Rader DJ. The metabolic syndrome: more than the sum of its parts? Circulation. 2003;108(13):1546-51.

128. Moller DE, Kaufman KD. Metabolic syndrome: a clinical and molecular perspective. Annu Rev Med. 2005;56:45-62.

129. Stark AH, Timar B, Madar Z. Adaptation of Sprague Dawley rats to long-term feeding of high fat or high fructose diets. Eur J Nutr. 2000;39(5):229-34.

130. Schaalan M, El-Abhar HS, Barakat M, El-Denshary ES. Westernized-like-diet-fed rats: effect on glucose homeostasis, lipid profile, and adipocyte hormones and their modulation by rosiglitazone and glimepiride. J Diabetes Complications 2009;23(3):199208. 
131. Ceddia RB. Direct metabolic regulation in skeletal muscle and fat tissue by leptin: implications for glucose and fatty acids homeostasis. Int J Obes. 2005;29(10):1175-83.

132. Ceddia RB, William WN Jr, Curi R.The response of skeletal muscle to leptin. Front Biosci. 2001;6:D90-7.

133. Kamohara S, Burcelin R, Halaas JL, Friedman JM, Charron MJ. Acute stimulation of glucose metabolism in mice by leptin treatment. Nature 1997;389(6649):374-7.

134. Shimabukuro M, Koyama K, Chen G, Wang MY, Trieu F, Lee Y, et al. Direct antidiabetic effect of leptin through triglyceride depletion of tissues. Proc Natl Acad Sci U S A. 1997;94(9):4637-41.

135. Djoussé L, Pankow JS, Eckfeldt JH, Folsom AR, Hopkins PN, Province MA, et al. Relation between dietary linolenic acid and coronary artery disease in the National Heart, Lung, and Blood Institute Family Heart Study. Am J Clin Nutr. 2001;74(5):6129.

136. Dewailly EE, Blanchet C, Gingras S, Lemieux S, Sauvé L, Bergeron J, et al. Relations between n-3 fatty acid status and cardiovascular disease risk factors among Quebecers. Am J Clin Nutr. 2001;74(5):603-11.

137. Santos TM. Lipídios. In: Dutra-de Oliveira JE, Marchini JS. Ciências nutricionais. São Paulo: Sarvier; 1998. p. 87-97.

138. Schaefer EJ. Lipoproteins, nutrition, and heart disease. Am J Clin Nutr. 2002;75(2):191212.

139. Mustad VA, Etherton TD, Cooper AD, Mastro AM, Pearson TA, Jonnalagadda SS, et al. Reducing saturated fat intake is associated with increased levels of LDL receptors on mononuclear cells in healthy men and women. J Lipid Res. 1997;38(3):459-68.

140. Mahan LK, Escott-Stump S. Alimentos, nutrição e dietoterapia. 9a ed. São Paulo: Roca; 1998. 
141. Holmes JH, Lambourne LJ. The relation between plasma free fatty acid concentration and the digestible energy intake of cattle. Res Vet Sci. 1970;11(1):27-36.

142. Birnbaum MJ. Lipolysis: more than just a lipase. J Cell Biol. 2003;161(6):1011-2.

143. Wilson CR, Tran MK, Salazar KL, Young ME, Taegtmeyer H. Western diet, but not high fat diet, causes derangements of fatty acid metabolism and contractile dysfunction in the heart of Wistar rats. Biochem J. 2007;406(3):457-67.

144. Reinehr T. Obesity and thyroid function. Mol Cell Endocrinol. 2009. in press

145. Ruscica M, Dozio E, Gandini S, Gnocchi P, Devalle GG, Motta M, et al. Total, free and bound leptin and thyroid function in elderly women with different body weights. Clin Endocrinol. 2008;68(6):1002-8.

146. Feldt-Rasmussen U. Thyroid and leptin. Thyroid 2007;17(5):413-9.

147. Lu MC, Tzang BS, Kuo WW, Wu FL, Chen YS, Tsai CH, et al. More activated cardiac mitochondrial-dependent apoptotic pathway in obese Zucker rats. Obesity 2007;15(11):2634-42.

148. Yin FC, Spurgeon HA, Rakusan K, Weisfeldt ML, Lakatta EG. Use of tibial length to quantify cardiac hypertrophy: application in the aging rat. Am $\mathrm{J}$ Physiol. 1982;243(6):H941-7.

149. Rider OJ, Francis JM, Ali MK, Byrne J, Clarke K, Neubauer S, et al. Determinants of left ventricular mass in obesity; a cardiovascular magnetic resonance study. J Cardiovasc Magn Reson. 2009;11(1):9.

150. Murad N, Franco MF, Tucci PJF. Caracterização funcional da hipertrofia miocárdica induzida pelo isoproterenol e de sua regressão. Arq Bras Cardiol. 2001;77(1):51-8. 
151. Skurk C, Izumiya Y, Maatz H, Razeghi P, Shiojima I, Sandri M, et al. The FOXO3a transcription factor regulates cardiac myocyte size downstream of AKT signaling. J Biol Chem. 2005;280(21):20814-23.

152. Iacobellis G, Ribaudo MC, Leto G, Zappaterreno A, Vecci E, Di Mario U, et al. Influence of excess fat on cardiac morphology and function: study in uncomplicated obesity. Obes Res. 2002;10(8):767-73.

153. Alpert MA, Lambert CR, Panayiotou H, Terry BE, Cohen MV, Massey CV, et al. Relation of duration of morbid obesity to left ventricular mass, systolic function, and diastolic filling, and effect of weight loss. Am J Cardiol. 1995;76(16):1194-7.

154. Okoshi K, Ribeiro HB, Okoshi MP, Matsubara BB, Gonçalves G, Barros R, et al. Improved systolic ventricular function with normal myocardial mechanics in compensated cardiac hypertrophy. Jpn Heart J. 2004;45(4):647-56.

155. Cicogna AC, Okoshi MP, Okoshi K. História natural da remodelação miocárdica: da agressão aos sintomas. Rev Soc Cardiol. Estado de São Paulo 2000;10:8-16.

156. Brownsey RW, Boone AN, Allard MF. Actions of insulin on the mammalian heart: metabolism, pathology and biochemical mechanisms. Cardiovasc Res. 1997;34(1):3-24.

157. McNulty PH, Jacob R, Deckelbaum LI, Young LH. Effect of hyperinsulinemia on myocardial aminoacid uptake in patients with coronary artery disease. Metabolism. 2000;49(10):1365-9.

158. Young LH, Dahl DM, Rauner D, Barrett EJ. Physiological hyperinsulinemia inhibits myocardial protein degradation in vivo in the canine heart. Circ Res. 1992;71(2):393400.

159. Proud CG. Ras, PI3-kinase and mTOR signaling in cardiac hypertrophy. Cardiovasc Res. 2004;63(3):403-13. 
160. Kemi OJ, Ceci M, Wisloff U, Grimaldi S, Gallo P, Smith GL, et al. Activation or inactivation of cardiac Akt/mTOR signaling diverges physiological from pathological hypertrophy. J Cell Physiol. 2008;214(2):316-21.

161. Garcia JAD, Incerpi EK. Fatores e mecanismos envolvidos na hipertrofia ventricular esquerda e o papel anti-hipertrófico do óxido nítrico. Arq Bras Cardiol. 2008;90(6):44350 .

162. Watanabe A, Arai M, Yamazaki M, Koitabashi N, Wuytack F, Kurabayashi M. Phospholamban ablation by RNA interference increases $\mathrm{Ca}^{2+}$ uptake into rat cardiac myocyte sarcoplasmic reticulum. Mol Cell Cardiol. 2004;37(3):691-8.

163. Lindemann JP, Jones LR, Hathaway DR, Henry BG, Watanabe AM. ßeta-adrenergic stimulation of phospholamban phosphorylation and $\mathrm{Ca}^{2+}$ ATPase activity in guinea pig ventricles. J Biol Chem. 1983;258(1):464-71.

164. Lindemann JP, Watanabe AM. Phosphorylation of phospholamban in intact myocardium. Role of $\mathrm{Ca}^{2+}$ calmodulin-dependent mechanisms. J Biol Chem. 1985;260(7):4516-25.

165. Vittone L, Mundiña C, Chiappe de Cingolani G, Mattiazzi A. cAMP and calciumdependent mechanisms of phospholamban phosphorylation in intact hearts. Am J Physiol. 1990;258(2):H318-25.

166. Zornoff LAM, Paiva SAR, Duarte DR, Spadaro J. Remodelação ventricular pós-infarto do miocárdio: conceitos e implicações clínicas. Arq Bras Cardiol. 2009;92(2):157-64.

167. Brodde OE, Michel MC. Adrenergic and muscarinic receptors in the human heart. Pharmacol Rev. 1999;51(4):651-90.

168. Bers DM. Excitation-contraction coupling and cardiac contractile force. $2^{\text {nd }}$ ed. Dordrecht: Kluwer Academic Publishers; 2001. 
169. Cabrol P, Galinier M, Fourcade J, Verwaerde P, Massabuau P, Tran MA, et al. Functional decoupling of left ventricular beta-adrenoceptor in a canine model of obesity-hypertension. Arch Mal Coeur Vaiss. 1998;91(8):1021-4.

170. Carroll JF, Jones AE, Hester RL, Reinhart GA, Cockrell K, Mizelle HL. Reduced cardiac contractile responsiveness to isoproterenol in obese rabbits. Hypertension 1997;30(6):1376-81.

171. Hohl CM, Hu B, Fertel RH, Russell JC, McCune SA, Altschuld RA. Effects of obesity and hypertension on ventricular myocytes: comparison of cells from adult SHHF/Mcc$c p$ and JCR:LA- $c p$ rats. Cardiovasc Res. 1993;27(2):238-42.

172. Katz AM. Heart Failure. In: Katz AM. Physiology of the heart. $4^{\text {th }}$ ed. Philadelphia: Lippincott Willians \& Wilkins; 2001. p.546-581.

173. Alberts B, Johnson A, Lewis J, Raff M, Roberts K, Walter P. How cells read the genome: from DNA to protein. In: Alberts B. Molecular biology of the cell. $4^{\text {th }}$ ed. New York:Garland;2002.p.299-374.

174. Seraphim PM, Nunes MT, Giannocco G, Machado UF. Age related obesity-induced shortening of GLUT4 mRNA poly(A) tail length in rat gastrocnemius skeletal muscle. Mol Cell Endocrinol. 2007;276(1-2):80-7. 


\section{ANEXOS}

\section{1- Perfil das rações}

Os perfis de aminoácidos, carboidratos e ácidos graxos, avaliados no Laboratório de Bioquímica de Microrganismos e Plantas do Departamento de Tecnologia - Faculdade de Ciências Agrárias e Veterinárias, UNESP, Jaboticabal, SP, Brasil, estão apresentado nos Quadros 3, 4 e 5, respectivamente. 
Quadro 3- Perfil de aminoácidos das rações (\%)

\begin{tabular}{|c|c|c|}
\hline \multirow[b]{2}{*}{ Aminoácidos } & \multicolumn{2}{|c|}{ Rações } \\
\hline & Padrão & Hiperlipídica \\
\hline Ácido Aspártico & 10,81 & 9,92 \\
\hline Ácido Glutâmico & 20,12 & 18,99 \\
\hline Serina & 5,23 & 5,06 \\
\hline Glicina & 4,48 & 4,32 \\
\hline Histidina & 2,50 & 2,43 \\
\hline Arginina & 7,47 & 7,07 \\
\hline Treonina & 3,38 & 4,01 \\
\hline Alanina & 4,53 & 4,69 \\
\hline Prolina & 5,93 & 5,80 \\
\hline Tirosina & 3,34 & 3,48 \\
\hline Valina & 5,05 & 5,33 \\
\hline Metionina & 1,89 & 2,43 \\
\hline Cistina & 1,63 & 1,85 \\
\hline Isoleucina & 4,22 & 4,38 \\
\hline Leucina & 7,78 & 7,96 \\
\hline Fenilalanina & 5,01 & 5,01 \\
\hline Lisina & 5,62 & 6,59 \\
\hline Triptofano & 1,01 & 0,68 \\
\hline
\end{tabular}


Quadro 4- Perfil de carboidratos das rações (\%)

\begin{tabular}{|c|c|c|}
\hline \multirow[b]{2}{*}{ Carboidratos } & \multicolumn{2}{|c|}{ Rações } \\
\hline & Padrão & Hiperlipídica \\
\hline Raffinose & 1,74 & 0,81 \\
\hline Maltose & 1,07 & 1,60 \\
\hline Glicose Livre & 0,82 & 1,63 \\
\hline Glicose & 46,58 & 42,37 \\
\hline Frutose Livre & 0,62 & 0,96 \\
\hline Frutose & 20,93 & 16,46 \\
\hline Sacarose & 8,83 & 11,57 \\
\hline Lactose & 0,65 & 4,48 \\
\hline Fucose & 0,17 & 0,15 \\
\hline Arabinose & 5,55 & 6,78 \\
\hline Galactose & 4,55 & 6,08 \\
\hline Xilose & 5,47 & 4,27 \\
\hline Rhamnose & 0,22 & 0,26 \\
\hline Manose & 2,80 & 2,58 \\
\hline
\end{tabular}


Quadro 5- Perfil de ácidos graxos saturados e insaturados das rações (\%)

\begin{tabular}{|c|c|c|}
\hline \multirow[b]{2}{*}{ Ácidos graxos } & \multicolumn{2}{|c|}{ Rações } \\
\hline & Padrão & Hiperlipídica \\
\hline Capróico (c6:0) & 0,00 & 0,02 \\
\hline Caprílico (c8:0) & 0,03 & 0,03 \\
\hline Cáprico (c10:0) & 0,02 & 0,05 \\
\hline Láurico (c12:0) & 0,33 & 0,25 \\
\hline Mirístico (c14:0) & 0,30 & 0,33 \\
\hline Palmítico (c16:0) & 16,56 & 15,09 \\
\hline Heptadecanóico (c17:0) & 0,02 & 0,08 \\
\hline Esteárico (c18:0) & 3,90 & 4,36 \\
\hline Palmitoléico (c16:1) & 0,06 & 0,15 \\
\hline Oléico (c18:1n9c) & 27,96 & 37,94 \\
\hline Linoléico (c18:2n6c) & 47,10 & 40,83 \\
\hline$\alpha$-Linolênico (c18:3n3c) & 3,72 & 0,87 \\
\hline Ácidos Graxos Saturados (\%) & 21,16 & 20,21 \\
\hline Ácidos Graxos Insaturados (\%) & 78,84 & 79,79 \\
\hline
\end{tabular}




\section{2- Curvas das dosagens dos hormônios tireoidianos}

Dosagens realizadas pela empresa Genese Produtos Diagnósticos (São Paulo, SP, Brasil) com a tecnologia Luminex Corporation's xMAPTM, por reação de imunoensaio multiplex, Lincoplex kits (Linco Research Inc, St. Louis, MO, USA).

\subsection{1- Curva da dosagem de $T 3$}

Test Name: T3

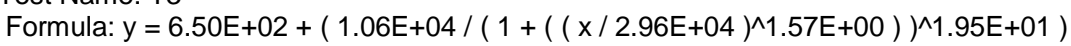

T3

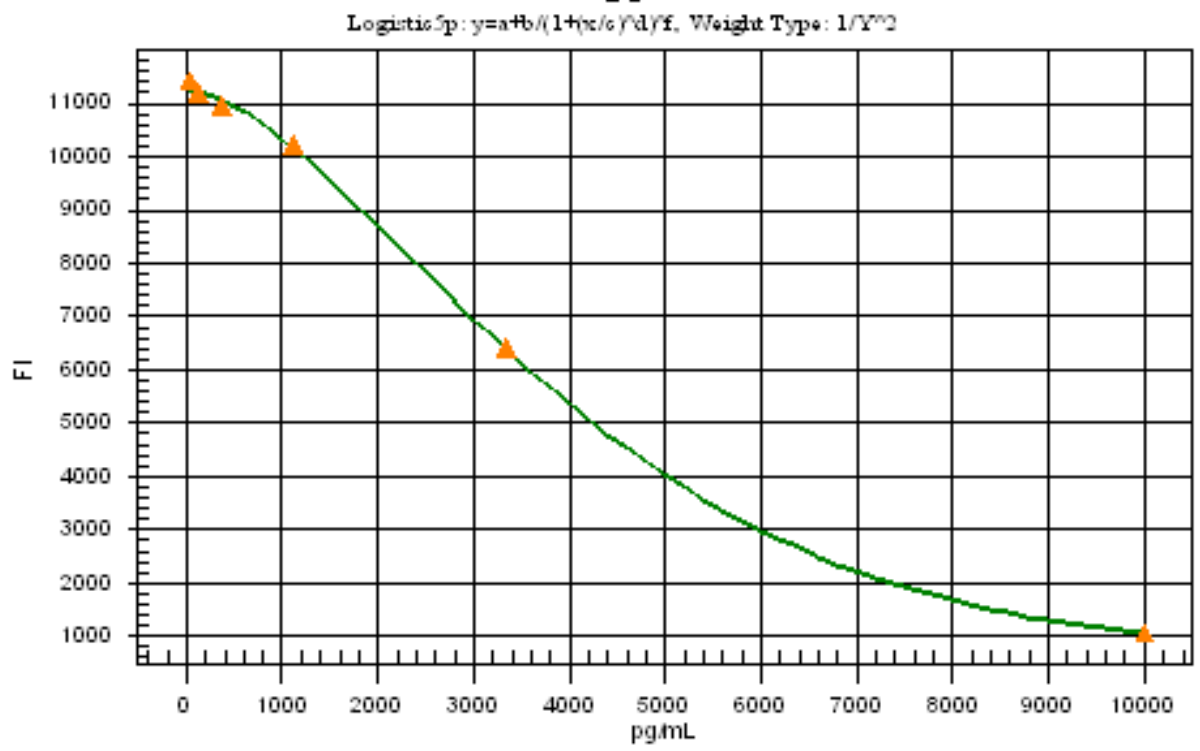

Curve Data:

Coeff $1=650.257425549637$

Coeff2 $=10638.3697076286$

Coeff $3=29594.4228984533$

Coeff $4=1.57496590134791$

Coeff5 $=19.4630782293911$ 


\subsection{2- Curva da dosagem de $\mathbf{T} 4$}

Test Name: T4

Formula: $\mathrm{y}=2.22 \mathrm{E}+02+\left(1.34 \mathrm{E}+04 /\left(1+\left((x / 2.77 \mathrm{E}+05)^{\wedge} 1.40 \mathrm{E}+00\right)\right)^{\wedge} 1.11 \mathrm{E}+01\right)$ T4

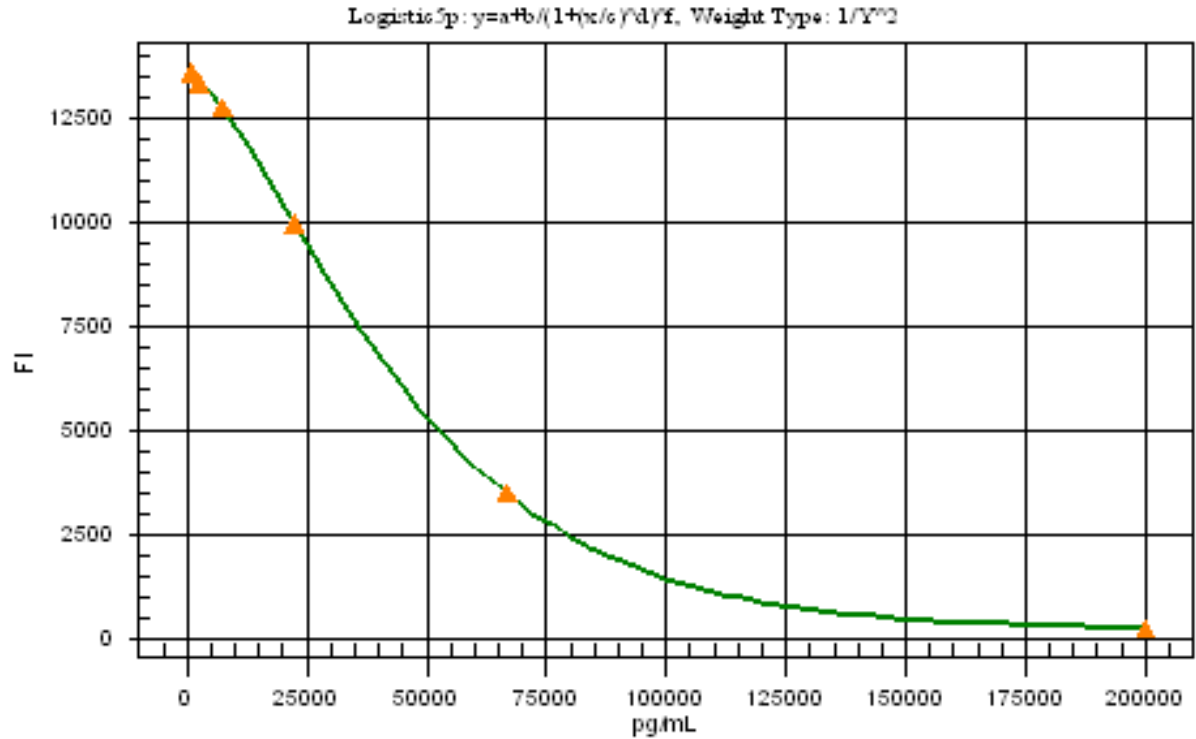

Curve Data:

Coeff1 $=222.377743984198$

Coeff2 $=13421.425375908$

Coeff3 $=277225.80836656$

Coeff $4=1.40385159717857$

Coeff5 $=11.0715412720862$

\subsection{3- Curva da dosagem de TSH}

Test Name: TSH

Formula: $y=-3.50 \mathrm{E}+01+\left(1.62 \mathrm{E}+04 /\left(1+\left((\mathrm{x} / 1.32 \mathrm{E}+04)^{\wedge}-1.10 \mathrm{E}+00\right)\right)^{\wedge} 8.33 \mathrm{E}-01\right)$ TSH

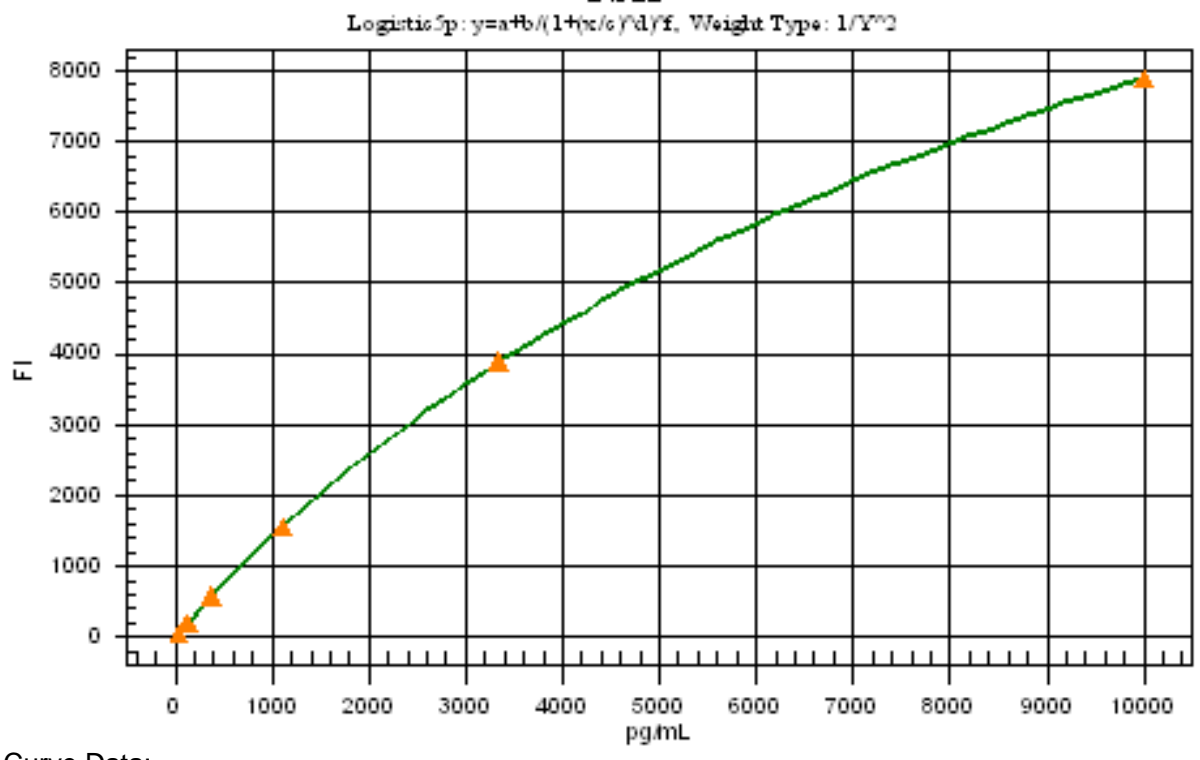

Curve Data:

Coeff $1=-34.9653387285764$

Coeff2 $=16172.9285583561$

Coeff3 $=13180.4706361975$

Coeff $4=-1.09549804233683$

Coeff $5=0.832610887363898$ 


\section{3- Amplificação de PCR em tempo real}

7.3.1- Curvas de amplificação dos grupos controle e obeso 15 semanas

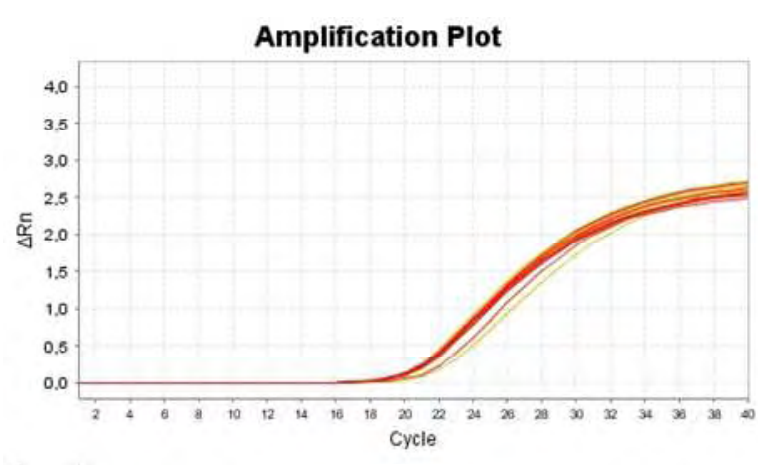

SERCA

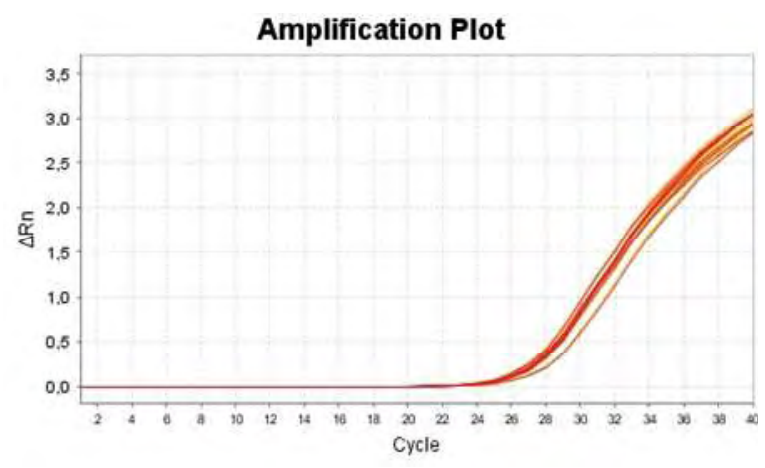

Canal L

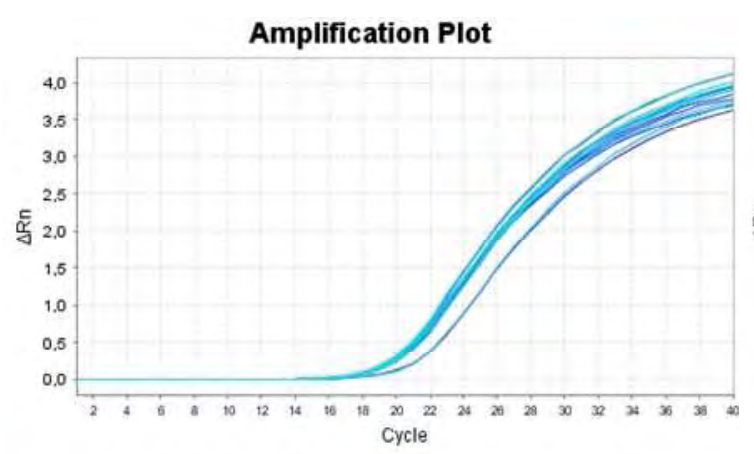

PLB

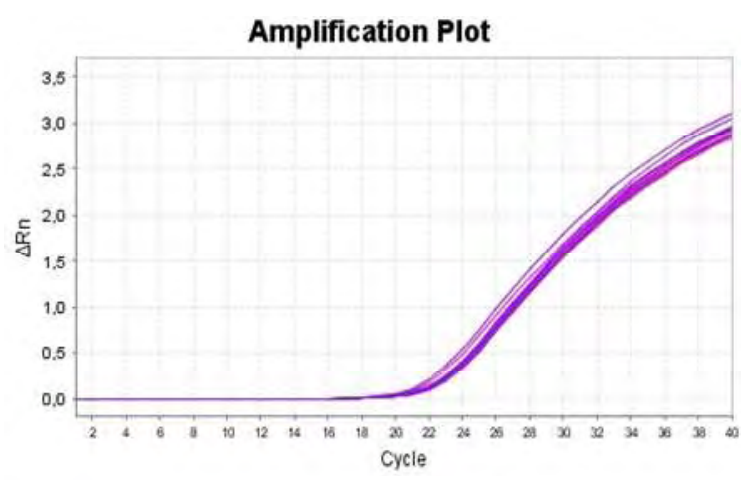

Amplification Plot

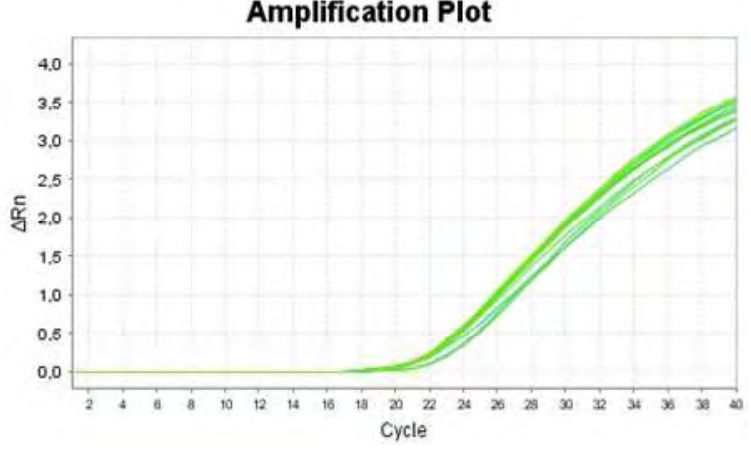

RyR

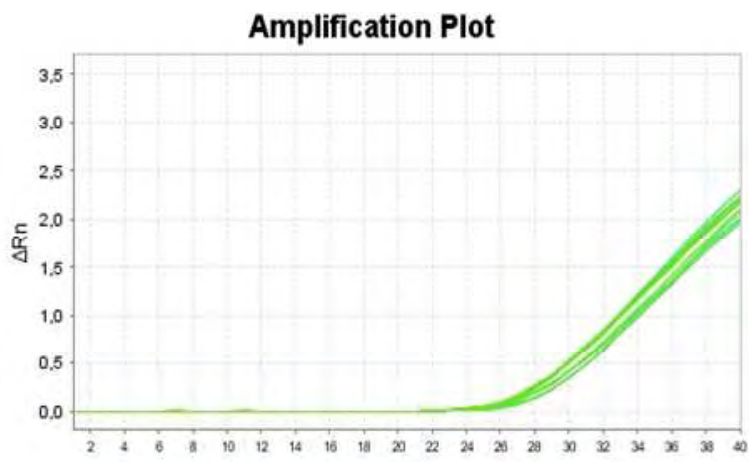

NCX

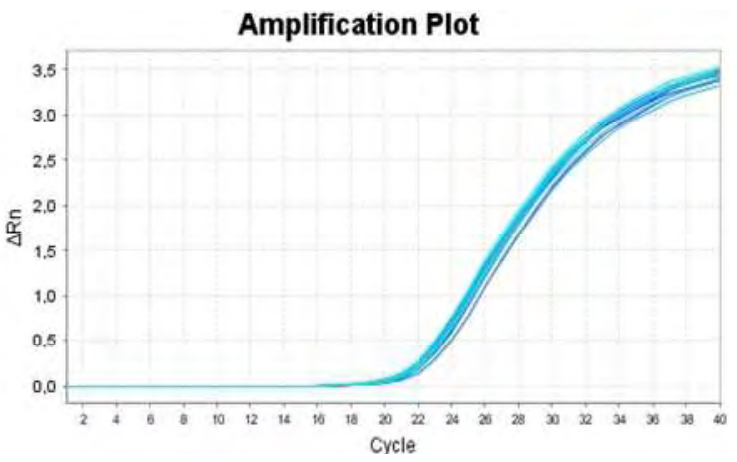

CSQ

$\beta$-actina 
7.3.2- Curvas de amplificação dos grupos controle e obeso 30 semanas

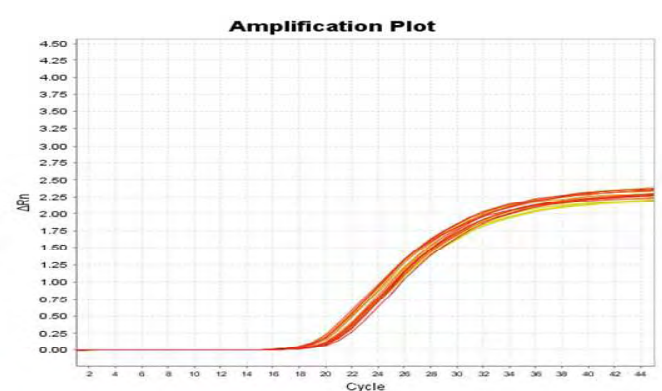

SERCA

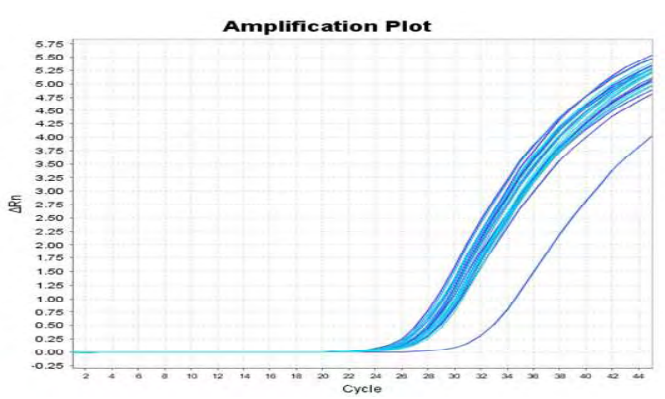

Canal L

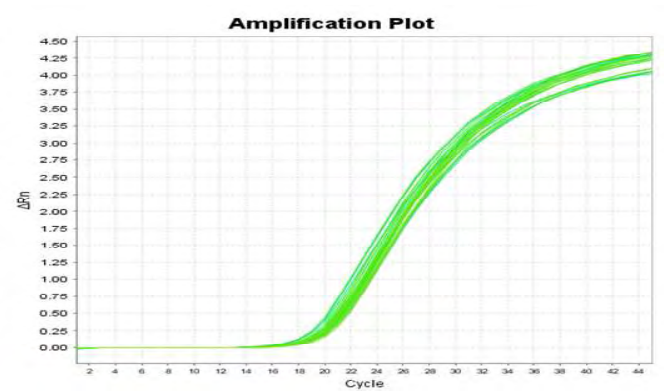

PLB

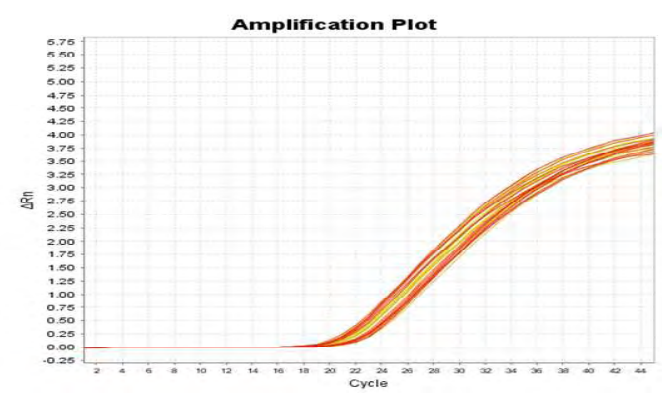

RyR

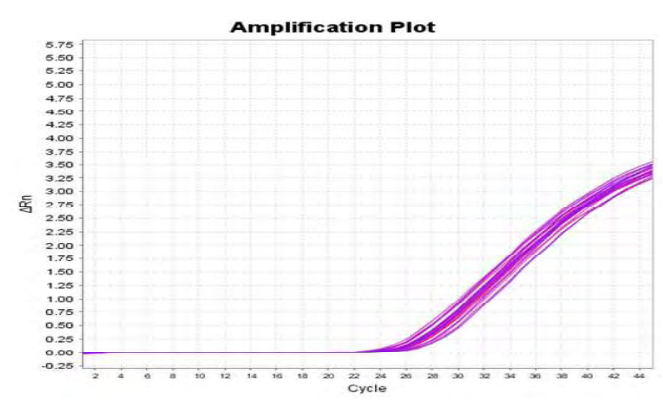

NCX

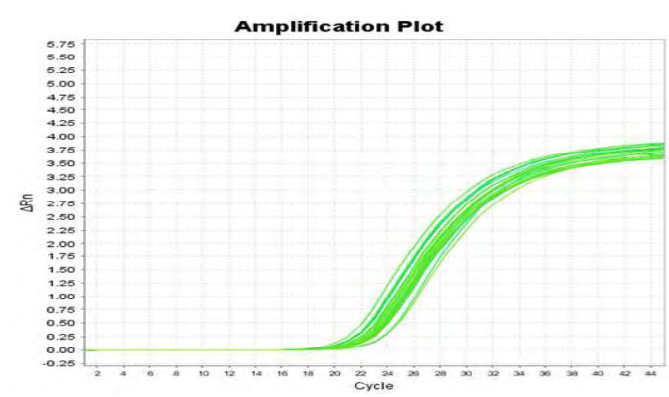

CSQ

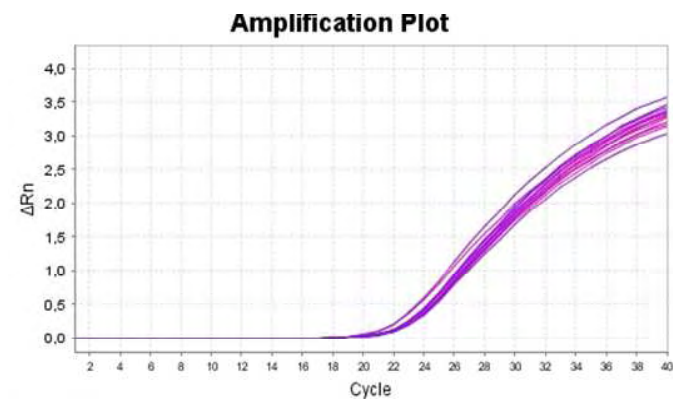

$\beta$-actina 
7.3.3- Curvas de amplificação dos grupos controle e obeso 45 semanas

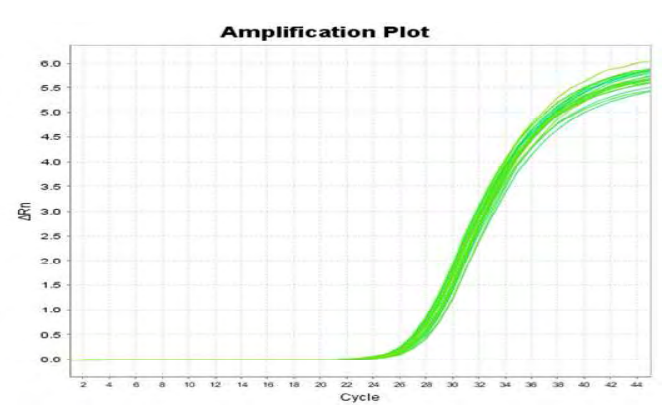

SERCA

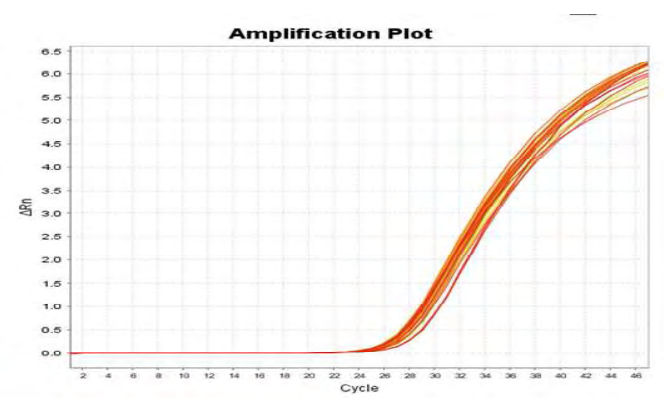

Canal L

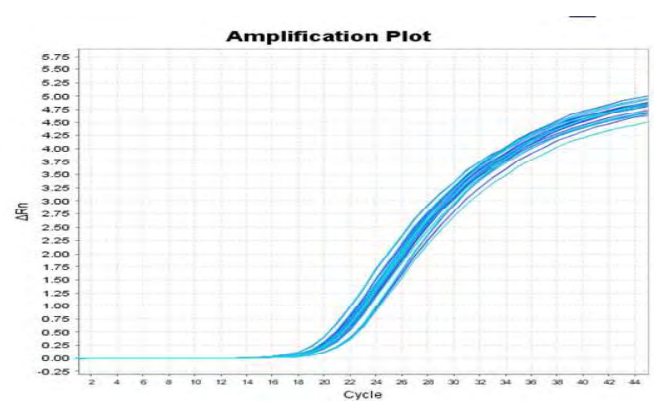

PLB

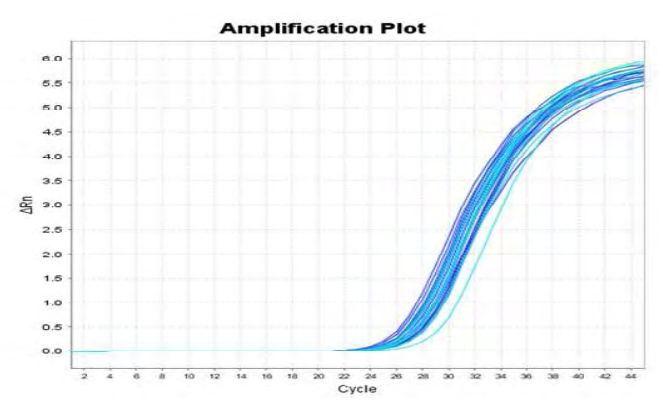

RyR

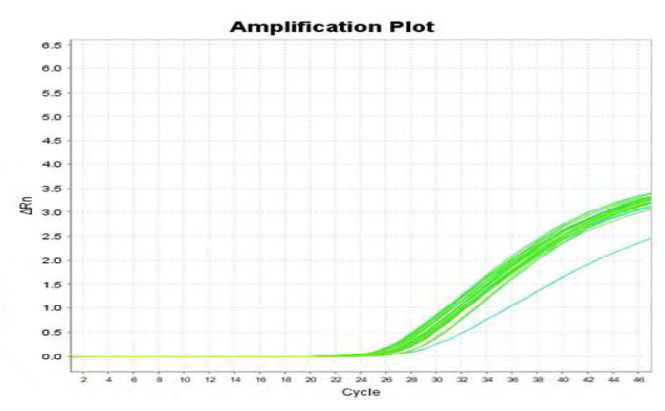

NCX

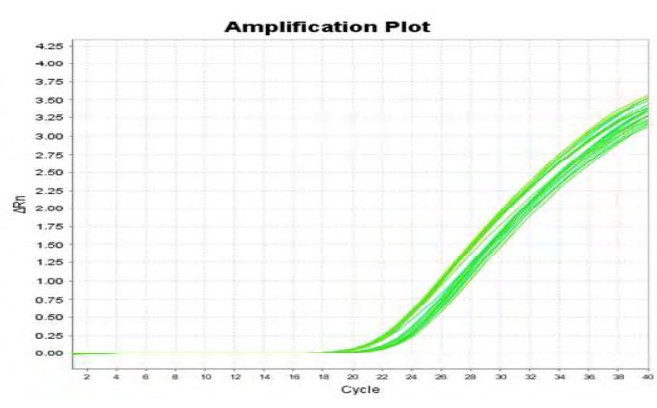

CSQ

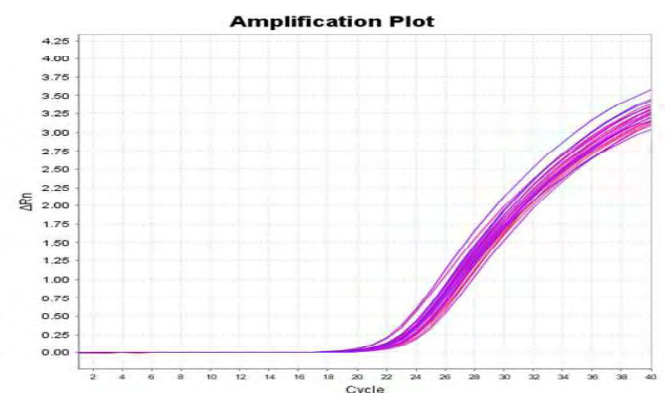

$\beta$-actina 


\section{4- Dificuldades na técnica de Western Blot}

\subsection{1- RyR e pRyR}

Apesar de todas as tentativas de padronização, verificamos que a qualidade dos blots não foram satisfatórios, o que impediu a quantificação das proteínas RyR e pRyR. Com a finalidade de identificar o(s) fator(es) responsável(eis) pela falta de qualidade dos blots foram realizados diversos experimentos, alterando-se a extração e concentração protéica, concentração do gel, diluição dos anticorpos e os tempos de corrida e transferência. As figuras abaixo ilustram as tentativas para a quantificação dessas proteínas. Apesar das diversas mudanças metodológicas, os blots não apresentaram a qualidade esperada.

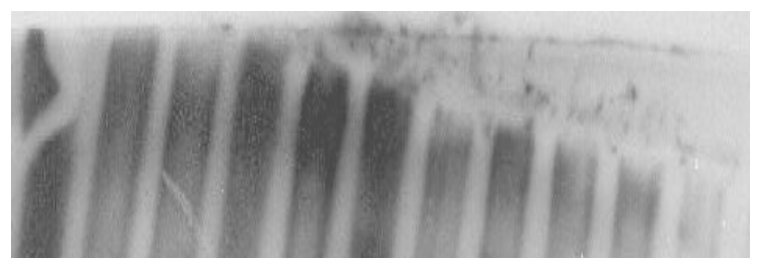

RyR

Gel de poliacrilamida: $6,5 \%$

Corrida: $4 \mathrm{~h}$

Transferência: úmida - 6h (troca do tampão após 3h)

Bloqueio: ON

Diluição anticorpo: 1:4000 (1\% leite)

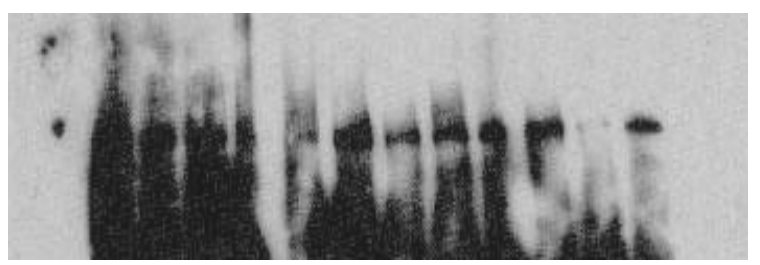

\section{RyR}

Gel de poliacrilamida: $6 \%$ com glicerol

Corrida: $9 \mathrm{~h}$

Transferência: úmida $-8 \mathrm{~h}$ (troca do tampão após $4 \mathrm{~h}$ )

Bloqueio: ON

Diluição anticorpo: 1:4000 (1\% leite) 


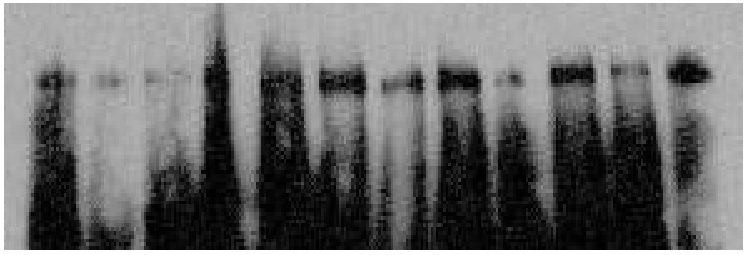

RyR

Gel de poliacrilamida: $6 \%$ com glicerol

Corrida: $9 \mathrm{~h}$

Transferência: úmida - 8h (troca do tampão após 4h)

Bloqueio: ON

Diluição anticorpo: 1:1000 (3\% leite)

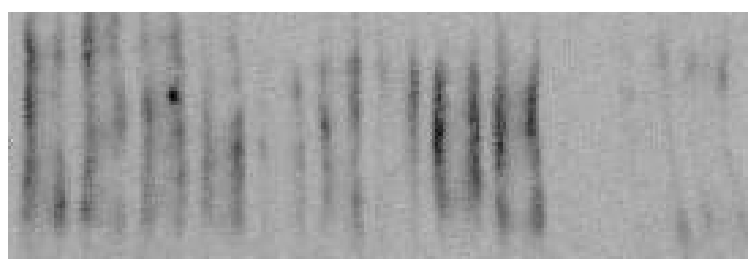

pRyR

Gel de poliacrilamida: 6,5\%

Corrida: $4 \mathrm{~h}$

Transferência: úmida - 8h (troca do tampão após 4h)

Bloqueio: ON

Diluição anticorpo: 1:4000 (3\% leite)

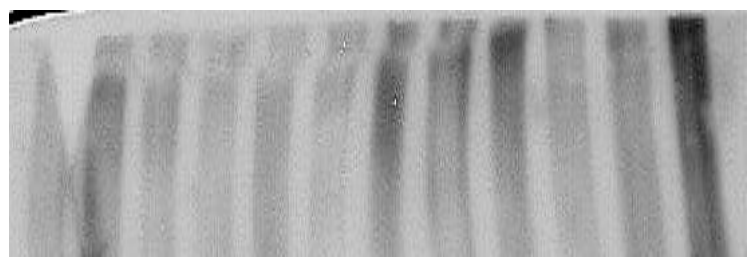

pRyR

Gel de poliacrilamida: $6 \%$

Corrida: $6 \mathrm{~h}$

Transferência: úmida - 8h (troca do tampão após 4h)

Bloqueio: ON

Diluição anticorpo: 1:4000 (3\% leite)

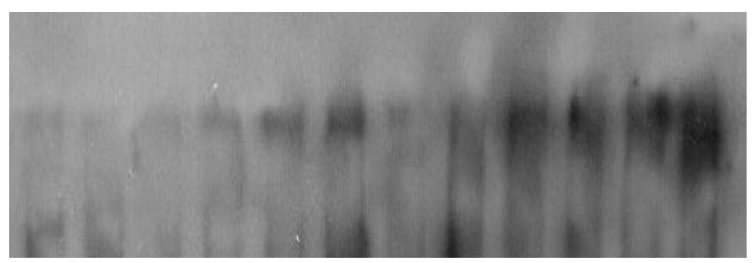

pRyR

Gel de poliacrilamida: $6 \%$ com glicerol

Corrida: $6 \mathrm{~h}$

Transferência: úmida - 8h (troca do tampão após 4h)

Bloqueio: ON

Diluição anticorpo: 1:5000 (1\% leite) 


\subsection{2- NCX}

A expressão de NCX também não apresentou a qualidade esperada, apesar de todas as alterações metodológicas. A literatura mostra que a quantificação protéica de NCX, geralmente, é realizada em 120kDa; além disso, algumas pesquisas mostram que a expressão de NCX apresenta duas isoformas, 120kDa e 70kDa. Os blots de NCX, visualizados neste estudo, apresentaram qualidade suficiente para quantificação; entretanto, esses blots sempre encontravam-se na altura de 70kDa. Uma vez que, os blots visualizados em $120 \mathrm{kDa}$ nunca apresentaram boa qualidade, optamos pela não quantificação de NCX. As figuras abaixo ilustram os blots de NCX.
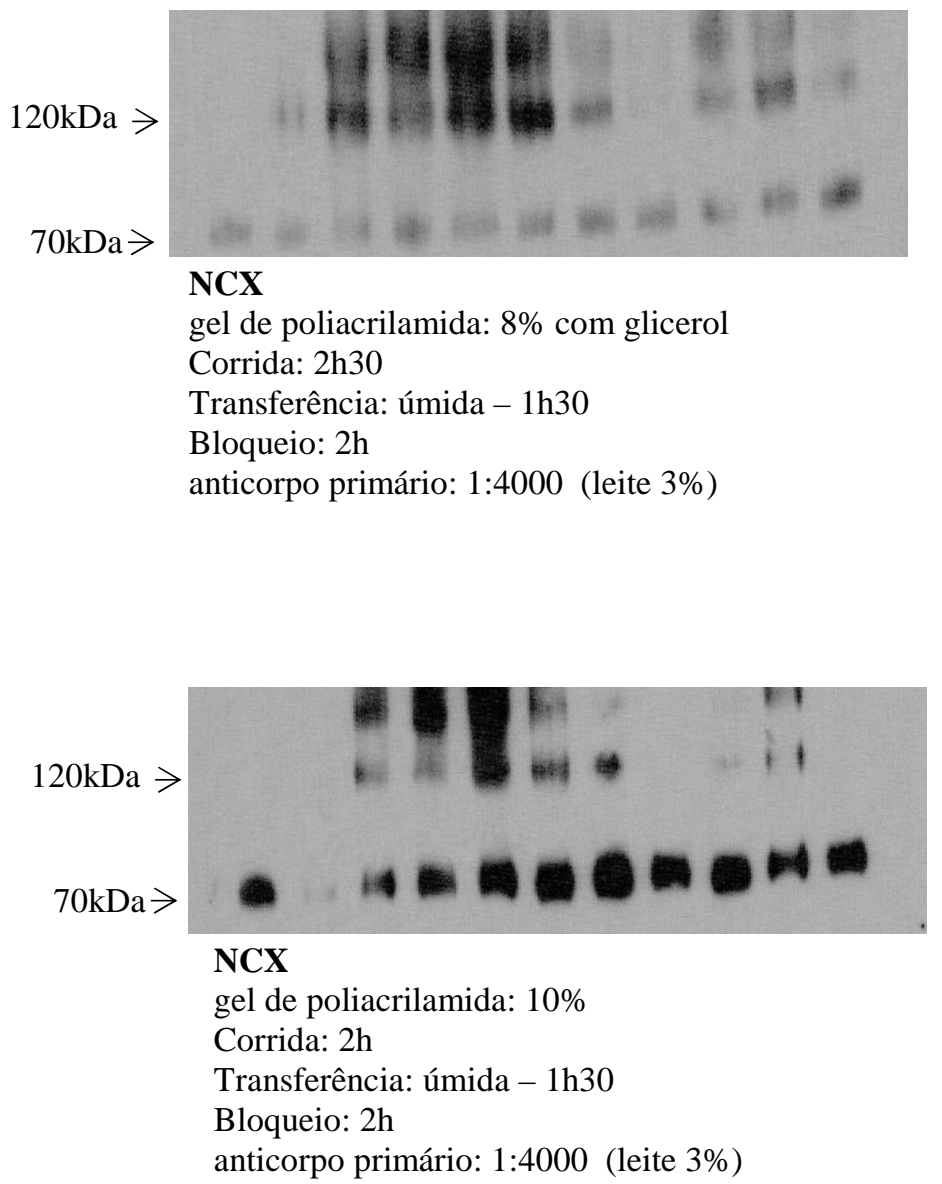


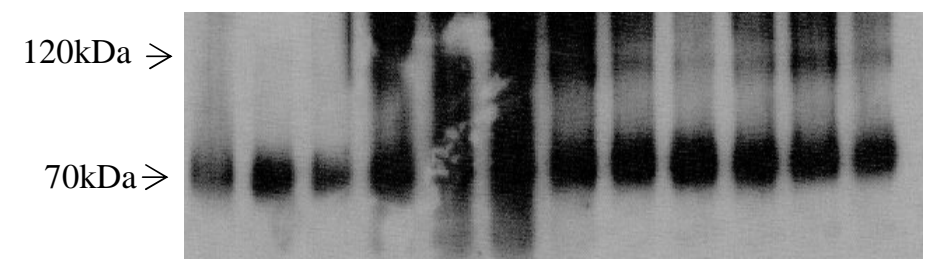

NCX

gel de poliacrilamida: $10 \%$ com glicerol

Corrida: $2 \mathrm{~h}$

Transferência: úmida - 1h30

Bloqueio: $2 \mathrm{~h}$

anticorpo primário: 1:2000 (leite 3\%) 